Cristiano Bigonha Tibiriçá

\title{
ESTUDO TEÓRICO- EXPERIMENTAL DA TRANSFE- RÊNCIA DE CALOR E DO FLUXO CRÍTICO DURANTE A EBULIÇÃO CONVECTIVA NO INTERIOR DE MICROCANAIS
}

Tese apresentada à Escola de Engenharia de São Carlos da Universidade de São Paulo para obtenção do título de Doutor em Engenharia Mecânica.

Área de concentração: Térmica e Fluidos

Orientador: Prof. Dr. Gherhardt Ribatski

São Carlos 2011 
AUTORIZO A REPRODUÇÃO E DIVULGAÇÃO TOTAL OU PARCIAL DESTE TRABALHO, POR QUALQUER MEIO CONVENCIONAL OU ELETRÔNICO, PARA FINS DE ESTUDO E PESQUISA, DESDE QUE CITADA A FONTE.

Ficha catalográfica preparada pela Seção de Tratamento da Informação do Serviço de Biblioteca - EESC/USP

Tibiriçá, Cristiano Bigonha.
Estudo teórico-experimental da transferência de calor
e do fluxo crítico durante a ebulição convectiva no
interior de microcanais / Cristiano Bigonha Tibiriçá ;
orientador Gherhardt Ribatski. São Carlos, 2011.
Tese (Doutorado - Programa de Pós-Graduação em
Engenharia Mecânica e Área de Concentração em Térmica e
Eluidos) -- Escola de Engenharia de São Carlos da
Universidade de são Paulo, 2011.
1. Transferência de calor. 2. Ebulição convectiva. 3.
Microcanais. 4. Coeficiente de transferência de calor. 5.
Fluxo crítico de calor. 6. Padrão de escoamento. I.
Título.


FOLHA DE JULGAMENTO

Candidato: Engenheiro CRISTIANO BIGONHA TIBIRIÇÁ

Título da tese: Estudo teórico-experimental da transferência de calor e fluxo crítico durante a ebulição convectiva no interior de microcanais.

Data da defesa: 13/07/2011:

Comissão Julgadora:

Resultado:

Prof. Dr. Gherhardt Ribatski (Orientador)

(Escola de Engenharia de São Carlos/EESC)

Prof. Titular Paulo Seleghim Junior

(Escola de Engenharia de São Carlos/EESC)

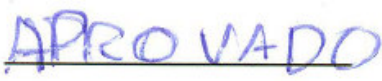

Prof. Dr. Jader Riso Barbosa Junior

(Universidade Federal de Santa Catarina/UFSC)

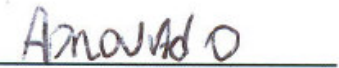

Prof. Titular Jurandir Itizo Yanagihara

(Escola Politécnica/USP)

Prof. Associado Jorge Luis Baliño

(Escola Politécnica/USP)

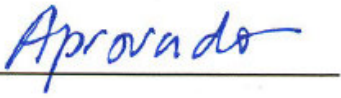

APROVADO

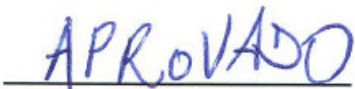

Coordenador do Programa de Pós-Graduação em Engenharia Mecânica:

Prof. Associado Marcelo Areias Trindade

Presidente da Comissão de Pós-Graduação:

Prof. Associado Paulo Cesar Lima Segantine 


\section{DedicatóRIA}

Dedico este trabalho a minha família, pelo eterno apoio e confiança, à qual serei sempre grato. 


\section{AGRADECIMENTOS}

Ao professor Gherhardt Ribatski, pela excelente orientação durante este trabaIho, pela amizade e oportunidades abertas. Gostaria reconhecer e valorizar sua dedicação à pesquisa e também ao ensino dentro da comunidade acadêmica brasileira e internacional.

Ao professor John Richard Thome, pela oportunidade de realização de experimentos em seu laboratório e pelo apoio e orientação durante minha estadia na Suíça. Também não poderia de valorizar seu bom humor nos intervalos de trabaIho, nas aulas e nos congressos que nos encontramos.

A José Roberto Bogni, pela amizade, ensinamentos e imprescindível ajuda na construção e manutenção do aparato experimental.

Ao amigo Anderson Ubices de Moraes, pela indicação deste doutorado, sem a qual, o presente trabalho não teria ocorrido.

Aos membros da banca de defesa, professores Jader Barbosa, Jorge Baliño, Jurandir Yanagihara e Paulo Seleghim pelas importantes contribuições e críticas as quais contribuíram para o aperfeiçoamento deste trabalho.

Aos amigos do Núcleo de Engenharia Térmica (NETeF), pela construção de um ambiente saudável de estudo, pela motivação no dia a dia e também pelas importantes discussões e sugestões ao longo destes anos: Alan Carvalho Oliveira, Alexandre Arcanjo, Analice Brandi, André Vosnika, Bruno Trevisan, Daniel Sempertéghi, Daniela Araújo, Daniela Mortari, Ernest Becker Junior, Evelise Corbalan, Fábio Toshio Kanizawa, Fernando Guimarães, Fernando Mendez, Franciane Motta, Francisco Nascimento, Francismara Cabral, Gustavo de Souza, Henrique Felcar, Hugo Leão, lara Rodriguez, Israel Saba,Jaqueline Diniz da Silva, Jéssica Alves, Jonas Ansoni, Juliano Freitas, Luiz Enrique Vidal, Luiz Fernando, Marcelo Souza de Castro, Marcio Ota, Mogaji Taye, Renan Sasahara, Sávider Conti, Sérgio Lucas Ferreira e Vanessa Santos.

Aos amigos do Laboratoire de Transfert de Chaleur et de Masse (LTCM-EPFL), os quais me proporcionaram grandes aprendizados: Andrea Cioncolini, Bogdan Nichita, Cecile Taverney, Christophe Zurmühle, Duan Wu, Etienne Costa-Patry, 
Eugene van Rooyen, Farzad Vakili Farahani, Gustavo Rabello dos Anjos, J. Ong, J.E. Park, Jackson Marcinichen, Jean-Pierre Rougnon, Jonattan. Olivier, Laurent Chevalley, Marcel Christians-Lupi, Marco Milan, Marc Salle, Maurice Muller, Nathalie Matthey-de-L'Endroit, Navid Borran, Nicolas Jaunin, Ricardo da Silva Lima, Sepideh Khodaparast, Stefano Nebuloni, Sylwia Szczukiewicz e Yassir Madhour.

À Danira, pelo apoio, ensinamentos de vida e paciência nos momentos de distância.

Aos grandes amigos, Marcelo Leite Ribeiro, André Gonçalves e Dante Bittencourt pelos incontáveis e inesquecíveis pedais, expedições e escaladas em montanha, desde a Mantiqueira aos imponentes Andes e Alpes, as quais foram e continuam sendo essenciais para equilíbrio físico e mental na busca de uma vida plena e saudável.

Aos funcionários da secretaria da Engenharia Mecânica, pela amizade e atenção dada.

Aos funcionários da secretaria da pós-graduação da Engenharia Mecânica, pela ajuda e esclarecimentos nos temas relacionados à pós-graduação.

Aos demais professores e funcionários do Departamento de Engenharia Mecânica, os quais sempre contribuíram com discussões e idéias no dia a dia deste trabalho.

À FAPESP, pela bolsa de doutorado concedida (processo $n^{\circ}$ 07/53950-5).

À CAPES, pela bolsa de estágio doutoral concedida.

À Universidade de São Paulo, à Escola de Engenharia de São Carlos e à École Polytechnique Fédérale de Lausanne, pela infraestrutura de trabalho. 


\section{RESUMO}

TIBIRIÇÁ, C. B. (2011). ESTUDO TEÓRICO-EXPERIMENTAL DA TRANSFERÊNCIA DE CALOR E DO FLUXO CRÍTICO DURANTE A EBULIÇÃO CONVECTIVA NO INTERIOR DE MICROCANAIS. 224p. Tese (Doutorado) Escola de Engenharia de São Carlos, Universidade de São Paulo, São Carlos.

A pesquisa realizada tratou do estudo da transferência de calor e do fluxo crítico durante a ebulição convectiva no interior de canais de diâmetro reduzidos a partir de dados levantados em bancadas experimentais construídas para esta finalidade. Extensa pesquisa bibliográfica foi efetuada e os principais métodos disponíveis para previsão de coeficiente de transferência de calor, fluxo crítico e mapas de escoamento foram levantados. Os resultados obtidos foram parametricamente analisados e comparados com os métodos da literatura. Pela primeira vez para microcanais, resultados experimentais foram levantados por um mesmo autor em laboratórios distintos buscando verificar a tendência e comportamentos. Tal comparação tem sua importância destacada em face das elevadas discrepâncias observadas na literatura quando resultados de autores distintos, obtidos em condições similares, são comparados. Os resultados levantados foram utilizados na elaboração de modelos que consideram os padrões de escoamento observados em microcanais. A incorporação dos padrões permitiu o desenvolvimento de modelos mecanísticos para coeficiente de transferência de calor, fluxo crítico e critérios para a caracterização da transição entre macro e microcanais baseados na formação do padrão de escoamento estratificado e na simetria do filme líquido no escoamento anular.

Palavras-chave: ebulição convectiva, microcanais, coeficiente de transferência de calor, fluxo crítico de calor, padrão de escoamento. 


\section{ABSTRACT}

TIBIRIÇÁ, C. B. (2011). A THEORETICAL AND EXPERIMENTAL STUDY ON FLOW BOILING HEAT TRANSFER AND CRITICAL HEAT FLUX IN MICROCHANNELS. 224p. Tese doutorado - Escola de Engenharia de São Carlos, Universidade de São Paulo, São Carlos.

This research comprises an experimental and theoretical study on flow boiling heat transfer and critical heat flux inside small diameter tubes based on data obtained in experimental facilities specially designed for this purpose. A broad literature review was carried out and the main methods to predict the heat transfer coefficient, critical heat flux and flow patterns were pointed out. The experimental results were parametrically analyzed and compared against the predictive methods from literature. For the first time, microchannels experimental results obtained by an unique researcher in distinct laboratories were compared and a reasonable agreement was observed. The importance of such a comparison is highlighted for flow boiling inside microchannels due to the high discrepancies observed when results from independent laboratories obtained under similar experimental conditions are compared. Moreover, the experimental results obtained in the present study were used to develop correlations and models for the heat transfer coefficient and heat flux that takes into account the flow patterns observed in microchannels. The heat transfer coefficient and critical heat flux models were developed based on mechanistic approach. In addition, criteria to characterize macro to microchannel transition were proposed based in the occurrence of the stratified flow pattern and the liquid film symmetry under annular flow conditions.

Key-words: flow boiling, microchannel, heat transfer coefficient, critical heat flux, flow pattern. 


\section{LISTA DE FIGURAS}

FIGURA 2.1 - REGIMES DE TRANSFERÊNCIA DE CALOR DURANTE A EBULIÇÃO CONVECTIVA: (A) ESCOAMENTO VERTICAL; (B) ESCOAMENTO HORIZONTAL (COLLIER; THOME, 1999).

FIGURA 2.2 - SUPERAQUECIMENTO DA PAREDE NECESSÁRIO PARA INÍCIO DA EBULIÇÃO COM R134A (KANDLIKAR ET AL., 2005)

FigURA 2.3 - DiÂMETROS DE TRANSIÇÃO ENTRE MACRO E MICROCANAIS PARA: (A) R134A; (B) R245FA............. 10

FIGURA 2.4 - GRANDEZA DAS FORÇAS ASSOCIADAS A ESCOAMENTOS BIFÁSICOS (KANDLIKAR, 2010). 11

FIGURA 2.5 - PADRÕES DE ESCOAMENTOS ADIABÁTICOS: (A) VERTICAL; (B) HORIZONTAL (CHENG; RIBATSKI; THOME, 2007).

FigURA 2.6 - PADRÕES DE ESCOAMENTO EM MICROCANAIS HORIZONTAIS. $D=0,5 \mathrm{MM}, G=500 \mathrm{KG} / \mathrm{M}^{2} \mathrm{~S}, T_{S A T}=30^{\circ} \mathrm{C}$ (REVELLIN; THOME, 2007A): (A) BOLHAS; (B) BOLHAS; (C) PISTONADO; (D) AGITANTE; (E) AGITANTE; (F) ANULAR; (G) ANULAR.

FIGURA 2.7 - PADRÕES DE ESCOAMENTO EM MICROCANAIS HORIZONTAIS. R134A, $D=2$, 1 MM (ARCANJO; TIBIRIÇÁ; RIBATSKI, 2010).

Figura 2.8 - MAPA DE ESCOAMENTO HORIZONTAL DE TAITEl E DUKLER (1976). FR, K X T, PARÂMETROS ADIMENSIONAIS DO MODELO.

FigurA 2.9 - MAPA DE ESCOAMENTOS DE WOJTAN, URSENBACHER E ThOME (2005). 16

Figura 2.10 - MAPA DE ESCOAMENTO DE ONG E THOME (2011A). 17

FIGURA 2.11 - COMPARAÇÃO ENTRE O MÉTODO DE FELCAR, RIBATSKI E JABARDO (2007) E DADOS EXPERIMENTAIS AR-ÁGUA.

FIGURA 2.12 - COMPARAÇÃO ENTRE O MÉTODO DE FELCAR, RIBATSKI E JABARDO (2007) E RESULTADOS DE ARCANJO, TibIRIÇÁ E RIBATSKI, (2010) PARA o ESCOAMENTO DiABÁTICO COM R134A, D=2,32MM. .......... 18

Figura 2.13 - RESUltados de CONSOLINi (2008), PARA EBULIÇÃO CONVECTIVA EM MiCROCANAIS, COM R134A, $D=0,5 \mathrm{MM}$.

FIGURA 2.14 - CAMPO DE TEMPERATURA A PARTIR DE IMAGENS EM INFRAVERMELHO E AS RESPECTIVAS IMAGENS OBTIDAS DO ESCOAMENTO COM CÂMERA DE ALTA VELOCIDADE.

FiguRA 2.15 - ILUSTRAÇÃO ESQUEMÁTICA DO MODELO DE 3 ZONAS, PROPOSTO POR THOME, DUPONT E JACOBI (2004).

Figura 2.16 - MECANiSMo dE FCC EM ESCOAMENTO (A) SATURAdo E (B) SUB-RESFRIADO, SEGUNDO LEE E MUDAWAR (2009). 28

FIGURA 2.17 - SECAGEM DE PAREDE COM E SEM ONDAS INTERFACIAIS (REVELLIN; THOME, 2007B) .28

Figura 3.1 - COMPARAÇÃO DA CORRELAÇÃO DE SAITOH, DAIGUJi E HiHARA (2007) COM O BANCO DE DADOS EXPERIMENTAIS LEVANTADOS PARA ESTE ESTUDO. 
FigURA 3.2 - COMPARAÇÃO ENTRE O MODELO DE REVELLIN E THOME (2007B) PARA ESCOAMENTO ANULAR E OS DAdOS DE CONSOLLINI (2008). (R134A, $\left.D=0,5 \mathrm{MM} ; Q=108 \mathrm{KW} / \mathrm{M}^{2} ; G=1435 \mathrm{KG} / \mathrm{M}^{2} \mathrm{~S} ; L=75 \mathrm{MM}\right)$. PADRÃO DE ESCOAMENTO DETERMINADO SEGUNDO REVELLIN E THOME (2007A).

FiguRA 4.1 - DiAGRAMA ESQUEMÁTICO DA SEÇÃO DE TESTES E CIRCUITO AUXILIAR.......................................48

FIGURA 4.2 - VISTA DA BANCADA EXPERIMENTAL UTILIZADA. .................................................................49

FIGURA 4.3 - DIAGRAMA P-V DO CIRCUITO DE TESTES PARA R134A.................................................................50

FigURA 4.4 - DETALHES DA SEÇÃO DE TESTES E DO POSICIONAMENTO DOS TERMOPARES....................................51

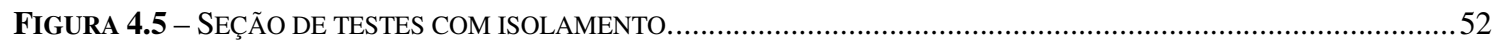

FIGURA 4.6 - RESISTÊNCIA TOTAL POR UNIDADE DE COMPRIMENTO EM FUNÇÃO DA ESPESSURA DE ISOLAMENTO DO TUBO.

FiguRA 4.7 - MODELO PARA AVALIAÇÃO DO EFEITO DO ELETRODO NO CAMPO DE TEMPERATURAS DA SUPERFÍCIE DE TESTES.

FIGURA 4.8 - (A) SIMULAÇÃO EM ELEMENTOS FINITOS (ANSYS) DA DISTRIBUIÇÃO DE TEMPERATURA AO LONGO DA SEÇÃO DE TESTES JUNTO AO ELETRODO; (B) AMPLIAÇÃO DA ÁREA CIRCULADA (1MM POR DIVISÃO HORIZONTAL).

FiguRA 4.9 - COMPRIMENTO DE DESENVOLVIMENTO TÉRMICO PARA O TUBO DE 2,32MM EM FUNÇÃO DO NÚMERO

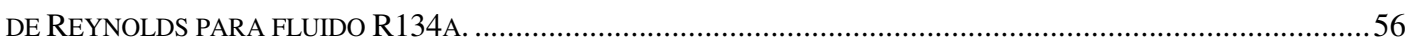

FIGURA 4.10 - DETALHES DA SEÇÃO DE TESTES E O POSICIONAMENTO DOS TERMOPARES...................................58

FIGURA 4.11 - SEÇÃO DE TESTES, PRÉ-AQUECIMENTO E VISUALIZAÇÃO DE 1,10MM APÓS O ISOLAMENTO. ...........59

FIGURA 4.12 - RESISTÊNCIA TOTAL POR UNIDADE DE COMPRIMENTO EM FUNÇÃO DA ESPESSURA DE ISOLAMENTO PARA O TUBO 1,10MM.

FIGURA 4.13 - COMPRIMENTO DE DESENVOLVIMENTO TÉRMICO PARA O TUBO DE 1,10MM EM FUNÇÃO DO NÚMERO DE REYNOLDS PARA FLUIDO R134A. 60

FIGURA 4.14 - IMAGEM DA SEÇÃO DE VISUALIZAÇÃO PARA SEÇÃO DE TESTES DE $D_{l}=2,32 \mathrm{MM}$. 61

FIGURA 4.15 - POSICIONAMENTO DA CÂMERA DE ALTA VELOCIDADE JUNTO À SEÇÃO DE VISUALIZAÇÃO. 62

FIGURA 4.16 - PADRÕES DE ESCOAMENTO FILMADOS NA BANCADA EXPERIMENTAL (DE CIMA PARA BAIXO: BOLHAS, BOLHAS ALONGADAS, AGITANTE, ANULAR), $D=2,10 \mathrm{MM}$. VELOCIDADE DE CAPTURA DE 3000 IMAGENS POR SEGUNDO E RESOLUÇÃO DE 1280 X 50 PIXELS. .63

FigURA 4.17 - SEÇÃo TRANSPARENTE DE VISUALIZAÇÃo TUBO DE 1,00MM...................................................64

FIGURA 4.18 - SENSORES E ATUADORES LIGADOS AO SISTEMA DE AQUISIÇÃO. ................................................65

FIGURA 4.19 - INTERFACE DO PROGRAMA DE AQUISIÇÃO E CONTROLE DA BANCADA EXPERIMENTAL....................66

FIGURA 4.20 - PERFIS DOS CANAIS AVALIADOS NA BANCADA EXPERIMENTAL II (LTCM-EPFL). ........................70

FIGURA 4.21 - DIAGRAMA ESQUEMÁTICO DA BANCADA EXPERIMENTAL II (LTCM-EPFL). .............................71

FIGURA 4.22 - FOTOGRAFIA DA BANCADA EXPERIMENTAL II (LTCM-EPFL) ................................................. 71

FigURA 4.23 - DETALHES DA SEÇÃO DE TESTES E O POSICIONAMENTO DOS TERMOPARES NO CANAL DE 2,20MM. 72 FigURA 4.24 - DETALHES DA SEÇÃO DE TESTES E POSICIONAMENTO DOS TERMOPARES NO CANAL DE 1,00MM.....73

FigURA 4.25 - ViSTA EXPLODIDA DA MONTAGEM DO TUBO ACHATADO COM (H/W)=1/4. OBS.: NESTA ILUSTRAÇÃO, O COMPRIMENTO DO TUBO NÃO ESTÁ EM ESCALA. 
FigURA 4.26 - RESUlTADO, EM ELEMENTOS FINITOS, NO TUBO DE 2,32MM, MOSTRANDO A DISTRIBUIÇÃO DE TEMPERATURA NA PAREDE DO TUBO NA PRESENÇA DE CONVECÇÃO ASSIMÉTRICA EM RELAÇÃO AO EIXO- $X$ NO INTERIOR DO TUBO.

FIGURA 4.27 - VALORES DO FLUXO DE CALOR NA DIREÇÃO Y, CORRESPONDENTE ÀS CONDIÇÕES SIMULADAS NA FIGURA 4.26.

FigURA 4.28 - SUPERAQUECIMENTO DA PAREDE PARA R134A PARA G=200 KG/M ${ }^{2} \mathrm{~S}, T_{S A T}=31^{\circ} \mathrm{C}, L_{A Q U E}=361 \mathrm{MM}$, $T_{S U B}=4 \mathrm{~K}$

FIGURA 4.29 - AVALIAÇÃO DO BALANÇO DE ENERGIA MONOFÁSICO PARA TEMPERATURAS DE SUBRESFRIAMENTO NA SAÍDA DA SEÇÃO DE TESTES, $T_{S U B, S A}$, DE 2 E $10^{\circ} \mathrm{C}$. $\left(\mathrm{R} 134 \mathrm{~A}, D=2,32 \mathrm{MM}, T_{E N T}=16^{\circ} \mathrm{C}, P=10^{6} \mathrm{PA}, Q_{S T}=Q_{P A}\right) \ldots 88$

Figura 4.30 - AVALIAÇÃo do BALANÇO DE ENERGia MONOFÁSICO (R134A, $D=2,3 \mathrm{MM}, T_{E N T}=13^{\circ} \mathrm{C}$ ): (A) FUNÇÃO DA VELOCIDADE MÁSSICA E TEMPERATURA DE SAÍDA; (B) FUNÇÃO DA POTÊNCIA APLICADA E VELOCIDADE MÁSSICA.

FIGURA 4.31 - (A) COMPARAÇÃO ENTRE CTC EXPERIMENTAL MONOFÁSICO E O PREVISTO PELA CORRELAÇÃO DE GNIELINSKI (1976) (R134A, $\left.D=2,32 \mathrm{MM}, \mathrm{T}_{\mathrm{SAI}}=40^{\circ} \mathrm{C}\right)$; (B) COMPARAÇÃO ENTRE A PERDA DE PRESSÃO EXPERIMENTAL MONOFÁSICA E A PREVISTA TEORICAMENTE (R134A, $\left.D=2,32 \mathrm{MM}, \mathrm{T}_{\mathrm{SAI}}=40^{\circ} \mathrm{C}\right)$.

FIGURA 4.32 - (A) COMPARAÇÃO ENTRE CTC EXPERIMENTAL MONOFÁSICO E O PREDITO PELA CORRELAÇÃO DE GNIELINSKI (1976) (R24FA, $\left.D=2,32 \mathrm{MM}, \mathrm{T}_{\mathrm{SAI}}=31^{\circ} \mathrm{C}\right)$; (B) COMPARAÇÃO ENTRE A PERDA DE PRESSÃO EXPERIMENTAL MONOFÁSICA E A PREVISTA TEORICAMENTE (R245FA, $D=2,32 \mathrm{MM}, \mathrm{T}_{\mathrm{SAI}}=31^{\circ} \mathrm{C}$ ).

FIGURA 4.33 - (A) COMPARAÇÃO ENTRE CTC EXPERIMENTAL MONOFÁSICO E O PREVISTO PELA CORRELAÇÃO DE GNIELINSKI (1976) (R245FA, $\left.D=1,10 \mathrm{MM}, \mathrm{T}_{\mathrm{SAl}}=31^{\circ} \mathrm{C}\right)$; (B) COMPARAÇÃO ENTRE A PERDA DE PRESSÃO EXPERIMENTAL MONOFÁSICA E A PREVISTA TEORICAMENTE (R245FA, $\left.D=1,10 \mathrm{MM}, \mathrm{T}_{\mathrm{SAI}}=31^{\circ} \mathrm{C}\right)$.

FIGURA 4.34 - COMPARAÇÃO ENTRE DADOS DA LITERATURA (YAN; LIN, 1998) E OS OBTIDOS NO PRESENTE $\operatorname{ESTUDO}\left(\mathrm{G}=200 \mathrm{KG} / \mathrm{M}^{2} \mathrm{~S}, Q=5 \mathrm{KW} / \mathrm{M}^{2}, T_{S A T}=31^{\circ} \mathrm{C}\right)$.

FIGURA 4.35 - COMPARAÇÃO ENTRE $\bar{h}$ MEDIDOS EM POSIÇÕES AXIAIS DISTINTAS DO TUBO (G=300KG/M² S, $\left.Q=15 \mathrm{KW} / \mathrm{M}^{2}, T_{S A T}=41^{\circ} \mathrm{C}\right)$......

FIGURA 4.36 - REPETITIVIDADE DOS ENSAIOS EXPERIMENTAIS BIFÁSICOS $\left(\mathrm{G}=400 \mathrm{KG} / \mathrm{M}^{2} \mathrm{~S}, \mathrm{~T}_{\mathrm{SAT}}=22^{\circ} \mathrm{C}, Q=35 \mathrm{KW} / \mathrm{M}^{2}\right)$

FIGURA 4.37 - COMPARAÇÃO ENTRE A HIPÓTESE DE QUEDA DE PRESSÃO LINEAR UTILIZADA PARA O CÁLCULO DA TEMPERATURA DE SATURAÇÃO AO LONGO DA SEÇÃO DE TESTES E AS MEDIDAS DE PRESSÃO DERIVADAS DAS TEMPERATURAS DA SUPERFÍCIE DO TUBO NO ESCOAMENTO EM EBULIÇÃO CONVECTIVA ADIABÁTICA. R245FA NO TUBO DE 2,32MM, EM TIBIRIÇÁ E RIBATSKI (2011)

FigURA 5.1 - PADRÕES DE ESCOAMENTO PARA R1234ZE(E) EM CANAIS DE 1,00MM E 2,20MM, $T_{\text {SAT }}=31^{\circ} \mathrm{C} \ldots \ldots \ldots . . . .96$

FigURA 5.2 - MAPAS DE PADRÃO DE ESCOAMENTO PARA R1234ZE, R134 E R245FA. $\left(T_{S A T}=31^{\circ} \mathrm{C}, D_{I}=1,00 \mathrm{MM}\right) \ldots 97$

FIGURA 5.3 - CURVAS DE TRANSIÇÃO, COMPARANDO EFEITO DA TEMPERATURA DE SATURAÇÃO PARA R134A E R245FA.

FIGURA 5.4 - COMPARAÇÃO ENTRE O MÉTODO DE BARNEA, LUNINSKI E TAYTEL (1983) E DADOS EXPERIMENTAIS PARA R245FA, $D=2,32 \mathrm{MM}$. 
FigURA 5.5 - COMPARAÇÃO ENTRE OS MÉTODOS PREDITIVOS (LINHAS) DE REVELLIN E THOME (2007A) E ONG E THOME (2011A) E OS DADOS EXPERIMENTAIS (SÍMBOLOS), PARA R245FA E D=2,32MM.

FigURA 5.6 - COMPARAÇÃO ENTRE O MÉTODO DE FELCAR, RIBATSKI E JABARDO (2007) E DADOS EXPERIMENTAIS, R134A E $D=2,32 \mathrm{MM}$. 102

Figura 5.7 - COMPARAÇÃo ENTRE O MÉTOdO DE ONG E THOME (2011A) E DADOS EXPERIMENTAIS DE TiBIRIÇÁ, RIBATSKI E THOME, (2011) PARA R134A, R1234ZE E R245FA.

FiguRA 5.8 - DisTRIBUIÇÃO dO CTC AO LONGO DO PERÍMETRO DO TUBO E IMAGENS DO ESCOAMENTO BIFÁSICO CORRESPONDENTES (R134A, D=2,32 MM, G=100KG/M ${ }^{2} \mathrm{~S}, Q=5 \mathrm{KW} / \mathrm{M}^{2}, \mathrm{~T}_{\mathrm{SAT}}=22^{\circ} \mathrm{C}$ ). 105

FIGURA 5.9 - CTC AO LONGO DO PERÍMETRO DO TUBO E IMAGEM DO ESCOAMENTO BIFÁSICO CORRESPONDENTE PARA R245FA A $G=200 \mathrm{KG} / \mathrm{M}^{2} \mathrm{~S}, Q=10 \mathrm{KW} / \mathrm{M}^{2}, X=35 \%, T_{S A T}=31^{\circ} \mathrm{C}$.

FigURA 5.10 - EFEITO DA CONDIÇÃO DE ENTRADA DO FLUIDO NA SEÇÃO DE TESTES NO CTC. (R134A, D=1,00MM, $\left.G=200 \mathrm{KG} / \mathrm{M}^{2} \mathrm{~S}, Q=15 \mathrm{KW} / \mathrm{M}^{2}\right)$.

FIGURA 5.11 - COMPARAÇÕES DE DADOS EXPERIMENTAIS LEVANTADOS NA EESC-USP E NO LTCM-EPFL. .... 107

FIGURA 5.12 - EFEITO DO DIÂMETRO NO CTC PARA R134A 108

FIGURA 5.13 - EFEITO DO DIÂMETRO NO CTC PARA R245FA. 109

Figura 5.14 - IluSTRAÇÃO DO EFEITO DA VELOCIDADE MÁSSICA NO CTC ( $\mathrm{D}=2,32 \mathrm{MM}, \mathrm{R} 134 \mathrm{~A}, T_{S A T}=31^{\circ} \mathrm{C}$, $\left.Q=15 \mathrm{KW} / \mathrm{M}^{2}\right)$.

Figura 5.15 - IlUSTRAÇÃo dO EFEITO DA VElOCIDADE MÁSSICA NO CTC (D=2,32MM, R245FA, $T_{S A T}=31^{\circ} \mathrm{C}$, $\left.Q=15 \mathrm{KW} / \mathrm{M}^{2}\right)$.

Figura 5.16 - ILUSTRAÇÃO DO EFEITO DA VELOCIDADE MÁSSICA NO CTC $\left(D=1,00 \mathrm{MM}, \mathrm{R} 1234 \mathrm{ZE}(\mathrm{E}), T_{S A T}=31^{\circ} \mathrm{C}\right.$, $\left.Q=35 \mathrm{KW} / \mathrm{M}^{2}\right)$. 110

FIGURA 5.17 - COMPARAÇÃO DO EFEITO DO FLUIDO NO CTC PARA R134A, R245FA E R1234ZE(E). 112

FIGURA 5.18 - COMPARAÇÃO DO EFEITO DO FLUIDO NO CTC PARA R134A E R1234ZE(E) (TIBIRIÇÁ; RIBATSKI; THOME, 2011).

FigurA 5.19 - ILUSTRAÇÃO DO EFEITO DA TEMPERATURA DE SATURAÇÃO NO CTC. (R245FA, Q=25KW/M², $\left.\mathrm{G}=300 \mathrm{KG} / \mathrm{M}^{2} \mathrm{~S}, D_{I}=2,32 \mathrm{MM}\right)$.

FIGURA 5.20 - ILUSTRAÇÃO DO EFEITO DA TEMPERATURA DE SATURAÇÃO NO CTC PARA R134A, $D_{l}=1,00 \mathrm{MM}$, $G=600 \mathrm{KG} / \mathrm{M}^{2} \mathrm{~S}, Q=55 \mathrm{KW} / \mathrm{M}^{2}$.

FIGURA 5.21 - ILUSTRAÇÃO DO EFEITO DO FLUXO DE CALOR NO CTC PARA (R134A, $\left.D_{I}=2,32 \mathrm{MM}, T_{S A T}=22^{\circ} \mathrm{C}\right)$. (A) $G=200 \mathrm{KG} / \mathrm{M}^{2} \mathrm{~S}$; (B) $G=400 \mathrm{KG} / \mathrm{M}^{2} \mathrm{~S}$; (C) $G=600 \mathrm{KG} / \mathrm{M}^{2} \mathrm{~S}$

FIGURA 5.22 - EFEITO DO FLUXO DE CALOR NO CTC PARA R134A. 116

FIGURA 5.23 - EFEITO DO FLUXO DE CALOR NO CTC PARA R245FA. 116

FIGURA 5.24 - EFEITO DA ORIENTAÇÃO DA SEÇÃO TRANSVERSAL DO TUBO ACHATADO NO CTC $\left(D_{E Q}=2,20 \mathrm{MM}\right) 118$

FigURA 5.25 - COMPARAÇÃO ENTRE CTC PARA TUBOS ACHATADOS E CIRCULAR, PARA $D_{E Q}=2,20 \mathrm{MM}$ 118

FIGURA 5.26 - COMPARAÇÃO DA EVOLUÇÃO DO CTC COM O TÍTULO DE VAPOR PARA OS DADOS EXPERIMENTAIS E MÉTODOS DE PREVISÃO. (A) $\mathrm{G}=50 \mathrm{KG} / \mathrm{M}^{2} \mathrm{~S} ; Q=7,5 \mathrm{KW} / \mathrm{M}^{2} ; \mathrm{T}_{\mathrm{SAT}}=31^{\circ} \mathrm{C} ;$ (B) $\mathrm{G}=200 \mathrm{KG} / \mathrm{M}^{2} \mathrm{~S}$; $Q=15 \mathrm{KW} / \mathrm{M}^{2} ; \mathrm{T}_{\mathrm{SAT}}=31^{\circ} \mathrm{C} ;(\mathbf{C}) \mathrm{G}=400 \mathrm{KG} / \mathrm{M}^{2} \mathrm{~S} ; Q=35 \mathrm{KW} / \mathrm{M}^{2} ; \mathrm{T}_{\mathrm{SAT}}=22^{\circ} \mathrm{C} ;(\mathbf{D}) \mathrm{G}=600 \mathrm{KG} / \mathrm{M}^{2} \mathrm{~S} ; \mathrm{Q}=45 \mathrm{KW} / \mathrm{M}^{2} ;$ $\mathrm{T}_{\mathrm{SAT}}=41^{\circ} \mathrm{C}$.

FIGURA 5.27 - EFEITO DO DIÂMETRO PARA FCC COM R134A COM TUBOS DE 1,00MM E 2,20MM. 
FigURA 5.28 - COMPARAÇÃO ENTRE O FCC DO R134A E R245FA PARA TUBO DE 2,20MM. 124

FiguRA 5.29 - COMPARAÇÃO ENTRE O FCC DO R134A E R1234ZE(E) PARA TUBO DE 1,00MM. ........................125

FigURA 5.30 - EFEITO DA TEMPERATURA DE SATURAÇÃO NO FCC PARA R134A E $D_{l}=2,20 \mathrm{MM} . \ldots \ldots \ldots \ldots \ldots \ldots \ldots . . . . . . . . . . . .125$

FIGURA 5.31 - EFEITO DO SUBRESFRIAMENTO NO FCC PARA O FLUIDO R245FA EM TUBO DE 2,20MM...............126

FigURA 5.32 - EFEITO DO SUBRESFRIAMENTO NO FCC PARA O FLUIDO R1234ZE EM TUBO DE 1,00MM............. 126

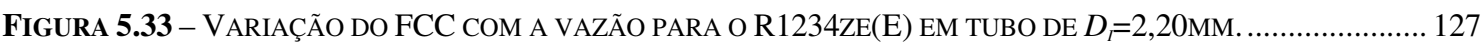

FigURA 5.34 - EFEITO DO COMPRIMENTO AQUECIDO NO FCC PARA R134A EM TUBO DE $D_{l}=2,20 \mathrm{MM} \ldots \ldots \ldots \ldots \ldots .128$

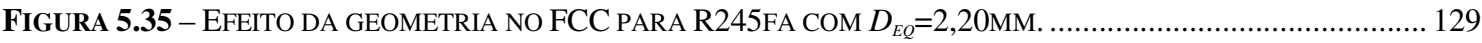

FIGURA 5.36 - COMPARAÇÃO ENTRE CORRELAÇÕES E DADOS EXPERIMENTAIS PARA FCC. ................................. 130

FIGURA 6.1 - FORÇAS DE PRESSÃO E DE TENSÃO SUPERFICIAL PARA MODELAGEM DA CONDIÇÃO DE ESTRATIFICAÇÃO.

FIGURA 6.2 - EXPERIMENTO ELABORADO PARA VERIFICAR O DIÂMETRO EM QUE OCORRE ESTRATIFICAÇÃO DE ÁGUA E AR (DIÂMETROS EM MILÍMETROS).

Figura 6.3 - PADRÕES DE ESCOAMENTO ANULAR OBTIDOS POR REVELlin (2005) PARA R134A, D=0,509MM, $G=500 \mathrm{KG} / \mathrm{M}^{2} \mathrm{~S}, T_{S A T}=30^{\circ} \mathrm{C}$. (A) X=40\%, (B) X=82\%; 144

FIGURA 6.4 - EVOLUÇÃO DAS ONDULAÇÕES NA SUPERFÍCIE DO FILME LÍQUIDO DURANTE O ESCOAMENTO ANULAR DO R134A, $\mathrm{D}=2,32 \mathrm{MM}, \mathrm{G}=50 \mathrm{KG} / \mathrm{M}^{2} \mathrm{~S}, \mathrm{~T}_{\mathrm{SAT}}=31^{\circ} \mathrm{C}, \mathrm{X}=80 \%$. INTERVALO ENTRE IMAGENS: $2 \mathrm{MS}$. 144

FIGURA 6.5 - FRENTE DE ONDA DURANTE A EBULIÇÃO CONVECTIVA DO R134A PARA $G=200 \mathrm{KG} / \mathrm{M}^{2} \mathrm{~S} ; Q=15 \mathrm{KW} / \mathrm{M}^{2}$, $\mathrm{T}_{\mathrm{SAT}}=31^{\circ} \mathrm{C}, \mathrm{X}=75 \%$ 144

FIGURA 6.6 - ILUSTRAÇÃO DO MODELO PARA AVALIAÇÃO DO EFEITO DA ASSIMETRIA DO NÚCLEO DE VAPOR NO CTC MÉDIO. 146

FigURA 6.7 - ILUSTRAÇÃO ESQUEMÁTICA DAS ONDULAÇÕES NA INTERFACE EM TORNO DA ESPESSURA MÉDIA, $\bar{\delta}$.

FIGURA 6.8 - COMPARAÇÃO DOS NOVOS MODELOS DE CTC COM DADOS EXPERIMENTAIS 152

FIGURA 6.9 - COMPARAÇÃO DE CORRELAÇÕES DA LITERATURA PARA CTC COM DADOS EXPERIMENTAIS........... 153

FIGURA 6.10 - MODELO DE PÓS-SECAGEM DA PAREDE, PELA EQUAÇÃo (6-25). 153

FIGURA 6.11 - COMPARAÇÃO ENTRE VALORES DE FCC E CORRELAÇÕES ORIGINAIS DA LITERATURA SELECIONADAS PARA OTIMIZAÇÃO COM O BANCO DE DADOS 156

FIGURA 6.12 - COMPARAÇÃO ENTRE VALORES DE FCC E AS CORRELAÇÕES PROPOSTAS, COM BASE NO BANCO DE DADOS LEVANTADO. 156

FIGURA 6.13 - COMPARAÇÕES ENTRE AS CORRELAÇÕES MODIFICADAS E O BANCO DE DADOS EXPERIMENTAL. (A) ModificAÇÃo de KatTo E OHNO (1984); (B) ModifiCAÇÃo DE Zhang ET AL. (2006); (C) MOdIFICAÇÃO DE ONG E THOME (2011B).

FIGURA 6.14 - COMPARAÇÃO DOS DADOS EXPERIMENTAIS PARA CANAIS NÃO CIRCULARES E CORRELAÇÕES DE FCC. (A) MODELOS ORIGINAIS; (B) MODELOS REAJUSTADOS 159

FIGURA 6.15 - COMPARAÇÃO DOS DADOS EXPERIMENTAIS DE FCC PARA CANAIS NÃO CIRCULARES VERSUS CORRELAÇÕES MODIFICADAS.

FIGURA A.0.1 - BANHO TERMOSTÁTICO UTILIZADO PARA CALIBRAR OS CANAIS DE TERMOPARES 177 


\section{LISTA DE QUADROS}

QUADRO 2.1 - MÉTODOS AVALIADOS PARA O CÁLCULO DO FLUXO CRÍTICO DE CALOR. ......................................30

QUADRO 3.1 - DESCRIÇÃO DE ESTUDOS ENVOLVENDO MEDIÇÃO DO COEFICIENTE DE TRANSFERÊNCIA DE CALOR

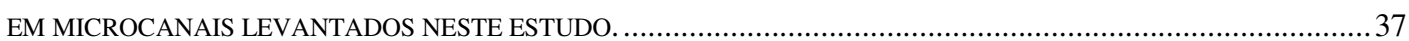

QUADRO 3.2 - BANCO DE DADOS PARA FCC EM MICROCANAIS.....................................................................43

QUADRO 4.1 - SENSORES E ATUADORES UTILIZADOS NA BANCADA EXPERIMENTAL............................................65 


\section{LISTA DE TABELAS}

TABELA 2.1 - VALORES DE COEFICIENTES DE TRANSFERÊNCIA DE CALOR ATRAVÉS DE MECANISMOS DE CONVECÇÃO.

TABELA 2.2 - MÉTODOS PARA O CÁlCULO DO COEFICIENTE DE TRANSFERÊNCIA DE CALOR EM EBULIÇÃO CONVECTIVA.

TABELA 3.1 - RESULTADOS DA COMPARAÇÃO ENTRE O BANCO DE DADOS DESCRITO NO QUADRO 3.1 E OS MÉTODOS PARA PREVISÃO DO CTC.

TABELA 3.2 - COMPARAÇÃO ENTRE OS MÉTODOS DE PREVISÃO E O BANCO DE DADOS, COM CLASSIFICAÇÃO SEGUNDO PADRÕES DE ESCOAMENTO UTILIZANDO REVELLIN E THOME (2007A).

TABELA 3.3 - COMPARAÇÃO dOS MÉTODOS DE PREVISÃO DE FCC COM OS DADOS EXPERIMENTAIS DESCRITOS NO QUADRO 3.2.

TABELA 4.1 - RELAÇÃO ENTRE AS RESOLUÇÕES VERTICAIS E HORIZONTAIS, EM FUNÇÃO DA FREQUÊNCIA DE

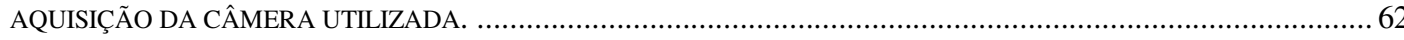

TABELA 4.2 - FAIXAS DOS PARÂMETROS EXPERIMENTAIS ENSAIADOS COM ESCOAMENTO MONOFÁSICO..............69

TABELA 4.3 - FAIXAS DOS PARÂMETROS EXPERIMENTAIS ENSAIADOS COM ESCOAMENTO BIFÁSICO.....................69

TABELA 4.4 - FAIXAS DOS PARÂMETROS EXPERIMENTAIS ENSAIADOS COM ESCOAMENTO MONOFÁSICO.............. 75

TABELA 4.5 - FAIXAS DOS PARÂMETROS EXPERIMENTAIS ENSAIADOS COM ESCOAMENTO BIFÁSICO.....................76

TABELA 4.6 - INCERTEZA DOS PARÂMETROS EXPERIMENTAIS BANCADA EXPERIMENTAL I. ..................................86

TABELA 4.7- INCERTEZA DOS PARÂMETROS EXPERIMENTAIS BANCADA EXPERIMENTAL II. ..................................86

TABELA 4.8 - INCERTEZA DOS PARÂMETROS EXPERIMENTAIS $G, Q, X$ E $H$, NA BANCADA I..................................8 86

TABELA 4.9 - INCERTEZA DOS PARÂMETROS EXPERIMENTAIS $G, Q, X$ E $H$, NA BANCADA II. ...............................8 87

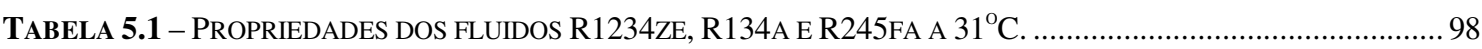

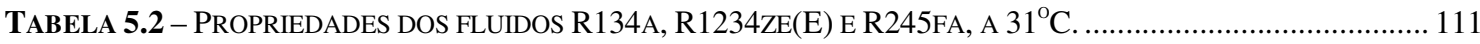

TABELA 5.3 - RESUltAdOS ESTATÍSTICOS DAS COMPARAÇÕES ENTRE OS VALORES FORNECIDOS PELOS MÉTODOS DE PREVISÃO DO CTC E OS RESULTADOS EXPERIMENTAIS DE TIBIRIÇÁ E RIBATSKI (2010)

TABELA 5.4 - ESTATÍSTICAS DE COMPARAÇÃO DO CTC ENTRE CORRELAÇÕES E DADOS EXPERIMENTAIS PARA R1234ZE(Y) PARA TUBOS CIRCULARES COM D=1,00MM E D=2,20MM (TIBIRIÇÁ; RIBATSKI; THOME, 2011)

TABELA 5.5 - RESUlTAdOS DAS COMPARAÇÕES PARA FCC ENTRE MÉTODOS DE PREVISÃO E RESULTADOS EXPERIMENTAIS PARA $D_{l}=2,20 \mathrm{MM}$, PARA R134A E R245FA. 130

TABELA 5.6 - ESTATÍSTICAS DE COMPARAÇÃO PARA FCC ENTRE CORRELAÇÕES E BANCO DE DADOS DE 1,00MM E 2,20MM PARA R1234ZE(E).

TABELA 6.1 - DIÂMETROS DE TRANSIÇÃO PARA CRITÉRIOS DA LITERATURA E PARA OS NOVOS CRITÉRIOS DE TRANSIÇÃO, BASEADOS EM ESTRATIFICAÇÃO (DIÂMETROS EM MILÍMETROS) 
xviii

TABELA 6.2 - PARÂMETROS DE KANDLIKAR (2010) PARA AVALIAR A GRANDEZA DAS FORÇAS EM ESCOAMENTOS BIFÁSICOS.

TABELA 6.3 - DIÂMETROS PARA SIMETRIA DO FILME LÍQUIDO DADO PELA EQUAÇÃo (6-5), COMPARADO COM DIÂMETRO PARA SIMETRIA DADO PELO MODELO DE HULBURT E NEWELL (2000).

TABELA 6.4 - COMPARAÇÃO ENTRE AS CORRELAÇÕES ORIGINAIS, MODIFICADAS, E O NOVO MODELO PARA ESCOAMENTO ANULAR VERSUS DADOS EXPERIMENTAIS DESTE ESTUDO.

TABELA 6.5 - COMPARAÇÃO DO BANCO DE DADOS DE FCC COM OS MÉTODOS DE PREVISÃO ORIGINAIS E SUAS MODIFICAÇÕES.

TABELA 6.6 - COMPARAÇÃO DO BANCO DE DADOS DE FCC DE TUBOS ACHATADOS, CONTRA AS NOVAS CORRELAÇÕES E AS CORRELAÇÕES DA LITERATURA. BANCO DE DADOS COM 74 PONTOS EXPERIMENTAIS.. 159

TABELA A.0.1 - VALORES INDICADOS PELOS CANAIS DE TEMPERATURA PARA OBTENÇÃO DA PRIMEIRA CURVA DE CALIBRAÇÃO. 178

TABELA A.0.2 - VALORES DOS COEFICIENTES DA EQUAÇÃO DE AJUSTE, M E B, PARA CADA CANAL E OS VALORES

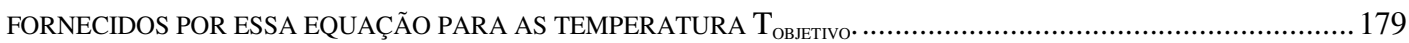

TABELA A.0.3 - ÍNDICE DE PRECISÃO, $S_{I}$, DE CADA CANAL PARA CADA T ToBJetivo ….......................................... 180

TABELA A.0.4 - ÍNDICE DE PRECISÃO DE CALIBRAÇÃO,S , GRAUS DE LIBERDADE, DF, ERRO SISTEMÁTICO, B, PERCENTIL T-STUDENT, T95 E INCERTEZA EXPERIMENTAL DE CADA CANAL, U. 180

TABELA A.0.5 - VALORES DE CORREÇÃO DOS CANAIS DE TEMPERATURA. ........................................................ 181

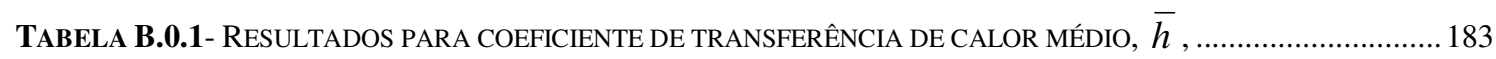

TABELA B.0.2 - RESUlTAdOS PARA FLUXO CRÍTICO DE CALOR PARA CANAIS CIRCULARES................................218 


\section{LISTA DE ABREVIATURAS E SIGLAS}

$\begin{array}{ll}\text { CTC } & \text { Coeficiente de transferência de calor } \\ \text { CHF } & \text { Fluxo crítico de calor (Critical heat flux) } \\ \text { DNB } & \text { Crise da ebulição (Departure from nucleated boiling) } \\ \text { FCC } & \text { Fluxo crítico de calor } \\ \text { GWP } & \text { Potencial de aquecimento global (Global warming potential) } \\ \text { LED } & \text { Diodo emissor de luz (Light emitting diode) } \\ \text { ODP } & \text { Potencial de destruição de ozônio (Ozone depletion potential). } \\ \text { ONB } & \text { Início da ebulição (Onset of nucleated boiling) } \\ \text { PI } & \text { Proporcional integral }\end{array}$




\section{LISTA DE SÍMBOLOS}

Latim

A área $\left[\mathrm{m}^{2}\right]$

Bo número de ebulição [-], $B o=\frac{q}{G \cdot i_{l v}}$

Bond número de Bond [-], Bond $=\frac{\left(\rho_{l}-\rho_{v}\right) \cdot g \cdot(D / 2)^{2}}{\sigma}$

c calor específico $[\mathrm{J} / \mathrm{kg} \mathrm{K}]$

Co número de confinamento [-], Co $=\frac{1}{D_{h}} \cdot \sqrt{\frac{4 \cdot \sigma}{g \cdot\left(\rho_{l}-\rho_{v}\right)}}$

$D$ diâmetro [m]

E potência [W]

Eo número de Eotvos [-], Eo $=\frac{(2 \cdot \pi)^{2} \cdot \sigma}{\left(\rho_{l}-\rho_{v}\right) \cdot D_{h}^{2} \cdot g}$

$f \quad$ fator de atrito [-], freqüência [ciclos/s]

$F \quad$ fator de intensificação de efeitos convectivos [-], força [N]

Fr número de Froude, $\mathrm{Fr}=\frac{G^{2}}{\rho_{l}^{2} g D}[-]$

$g$ aceleração da gravidade $\left[\mathrm{m} / \mathrm{s}^{2}\right]$

$G \quad$ velocidade mássica $\left[\mathrm{kg} / \mathrm{m}^{2} \mathrm{~s}\right]$

$g$ aceleração gravitacional $\left[\mathrm{m} / \mathrm{s}^{2}\right]$

$h \quad$ coeficiente de transferência de calor $\left[\mathrm{W} / \mathrm{m}^{2} \mathrm{~K}\right]$

$\bar{h} \quad$ coeficiente de transferência de calor médio na seção [W/m² $\mathrm{K}$ ]

$H \quad$ altura (Height) [m]

$i \quad$ entalpia específica [J/kg]

j velocidade superficial $[\mathrm{m} / \mathrm{s}]$

$k \quad$ condutividade térmica $[\mathrm{W} / \mathrm{m} \mathrm{K}]$

$L$ comprimento [m]

$m$ vazão mássica $[\mathrm{kg} / \mathrm{s}]$

$N \quad$ número de pontos experimentais [-] 


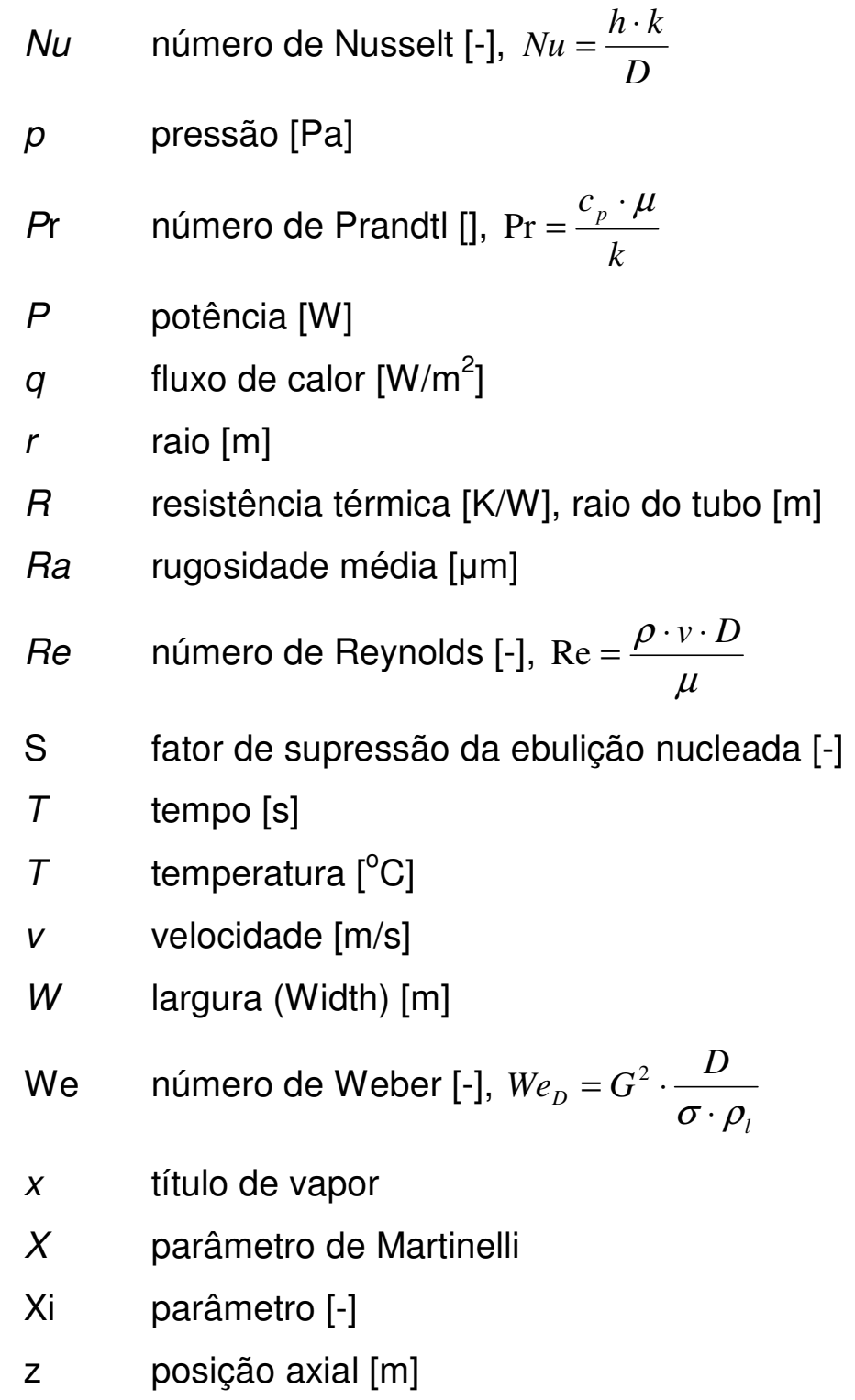

Grego

$\theta \quad$ ângulo de contato [rad], ângulo [rad]

$\tau$ tensão de cisalhamento $\left[\mathrm{N} / \mathrm{m}^{2}\right]$

$\varepsilon \quad$ fração de vazio [-]

$\mu \quad$ viscosidade dinâmica [Pa.s]

$v \quad$ volume específico $\left[\mathrm{m}^{3} / \mathrm{kg}\right]$

$\sigma \quad$ tensão superficial $[\mathrm{N} / \mathrm{m}]$ 
$\Delta \mathrm{E} \quad$ diferença de potência [W]

$\Delta \mathrm{p} \quad$ queda de pressão [Pa]

$\delta \mathrm{R} \quad$ erro relativo [-]

$\Delta \mathrm{T} \quad$ diferença de temperatura $\left[{ }^{\circ} \mathrm{C}\right]$

$\rho \quad$ densidade $\left[\mathrm{kg} / \mathrm{m}^{3}\right]$

$\delta \quad$ espessura do filme líquido [m]

$\varepsilon \quad$ erro médio absoluto [\%], $\varepsilon=\frac{1}{N} \sum_{1}^{N}\left|\frac{\text { valor previsto - valor experimental }}{\text { valor experimental }}\right|$

$\lambda$ fração dos resultados com erro inferior a certa porcentagem [\%]

$\Psi \quad$ amplitude da onda [m]

Subscritos

1 comprimento na posição 1 da seção de pré-aquecimento

2 comprimento na posição 2 da seção de testes

aque aquecido

ar ar atmosférico

b bolhas

base base do tubo

calc calculado

crit crítico

e diâmetro externo

elet potência elétrica

eq equivalente

ent entrada

ent,st entrada da seção de testes

exp experimental

g geração interna

grav gravidade

h hidráulico

i interno; diâmetro interno; i-ésimo elemento; inércia

iso isolamento

I líquido 


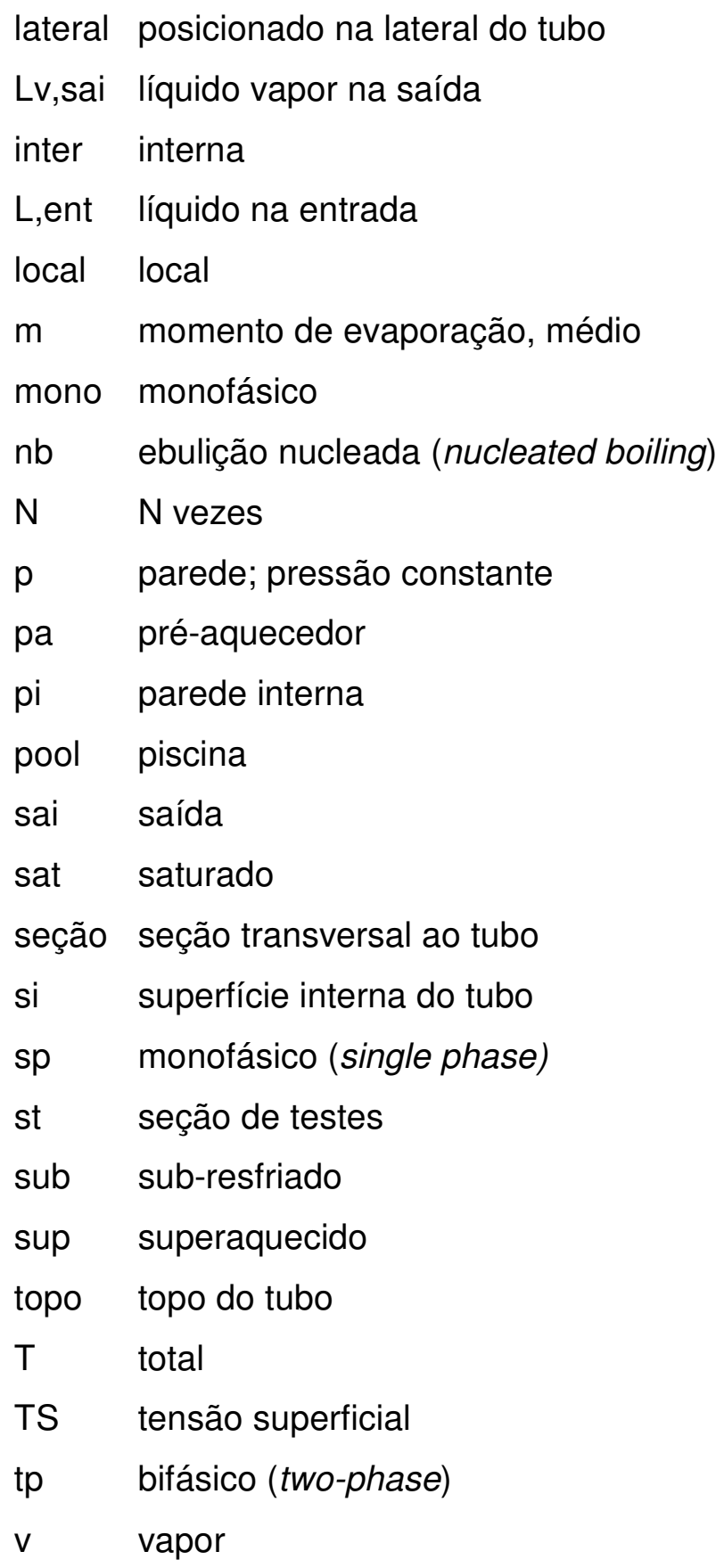


xxiv 


\section{SUMÁRIO}

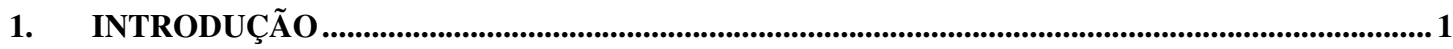

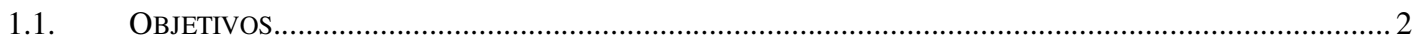

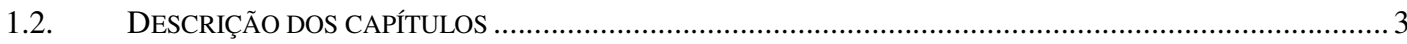

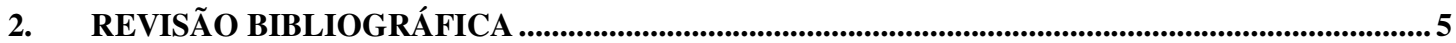

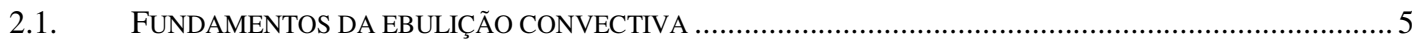

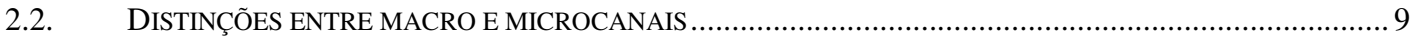

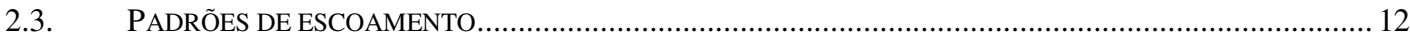

2.3.1. Métodos para previsão de padrão de escoamento ..................................................................... 14

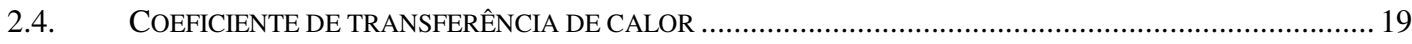

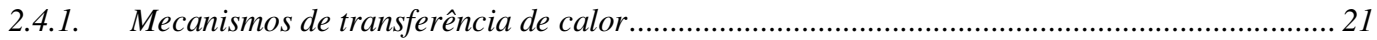

2.4.2. Correlaçães e modelos para previsão do coeficiente de transferência de calor ......................... 23

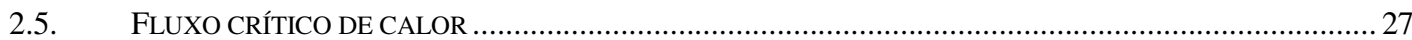

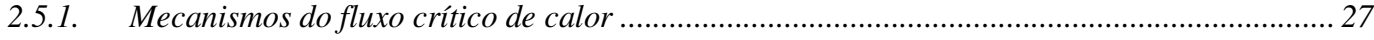

2.5.2. Correlações e modelos para previsão do fluxo crítico de calor ................................................... 29

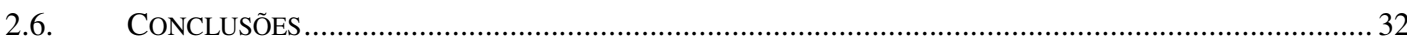

\section{COMPARAÇÃO ENTRE DADOS EXPERIMENTAIS DA LITERATURA E MÉTODOS DE}

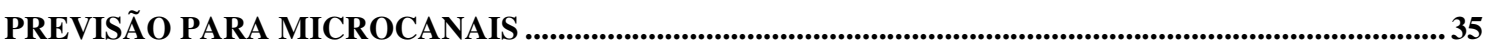

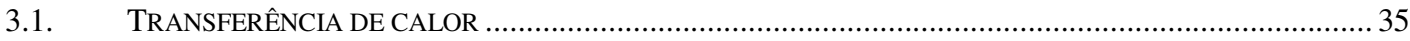

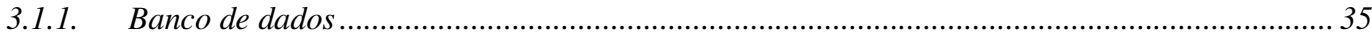

3.1.2. Comparação entre métodos de previsão do CTC com resultados experimentais da literatura. 38

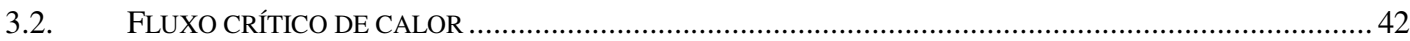

3.2.1. Banco de dados ......................................................................................................... 43

3.2.2. Comparação entre métodos de previsão do fcc com resultados experimentais da literatura.... 44

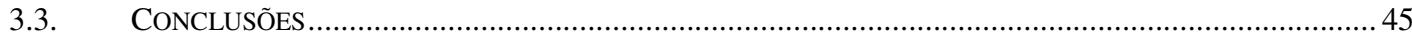

4. EQUIPAMENTO E PROCEDIMENTO EXPERIMENTAL .............................................................47

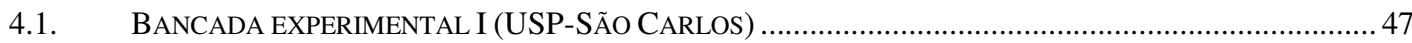

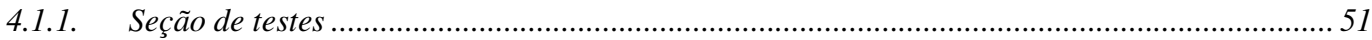

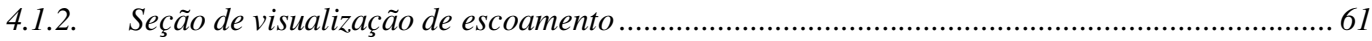

4.1.3. Sensores, controladores e sistema de aquisição de dados................................................................. 64

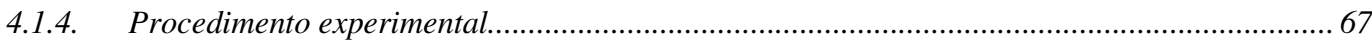

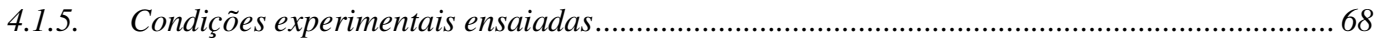

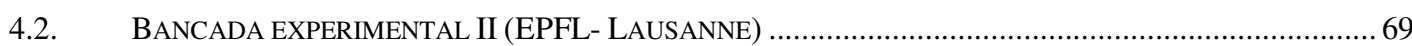




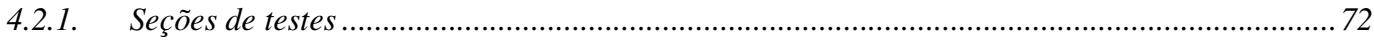

4.2.2. Sensores, controladores e sistema de aquisição de dados .................................................... 74

4.2.3. Condições experimentais ensaiadas ..................................................................................... 75

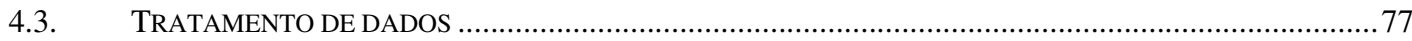

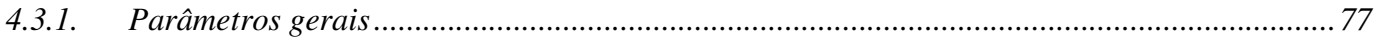

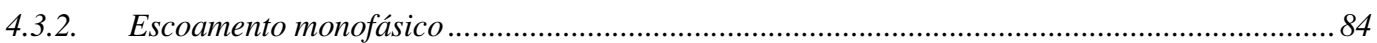

4.4. INCERTEZAS EXPERIMENTAIS E VALIDAÇÃO DO APARATO EXPERIMENTAL...................................85

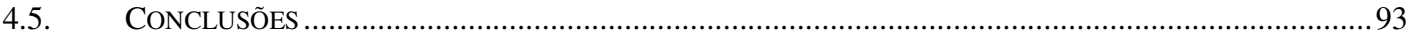

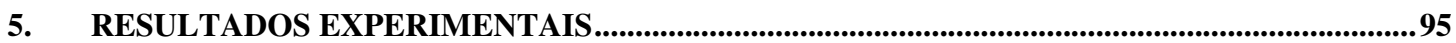

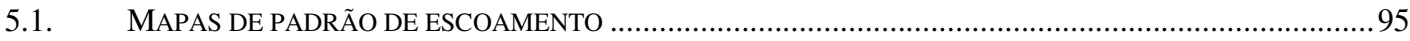

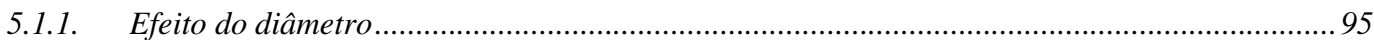

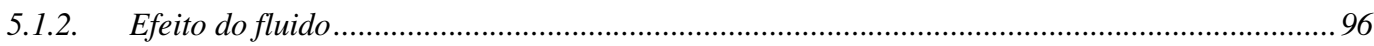

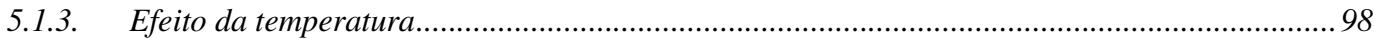

5.1.4. $\quad$ Avaliação de métodos de previsão ......................................................................................99

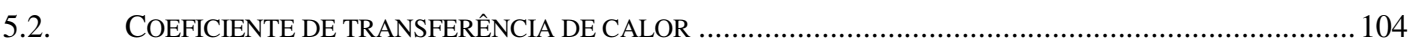

5.2.1. Coeficiente de transferência de calor ao redor do perímetro do tubo................................... 104

5.2.2. Efeito de entrada subresfriada e saturada ........................................................................... 106

5.2.3. Efeito da bancada experimental .......................................................................................... 107

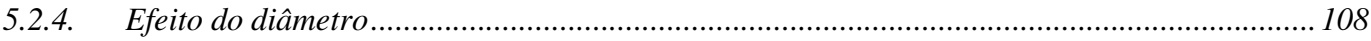

5.2.5. Efeito da velocidade mássica ...................................................................................... 109

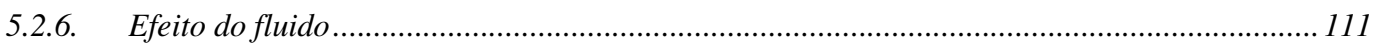

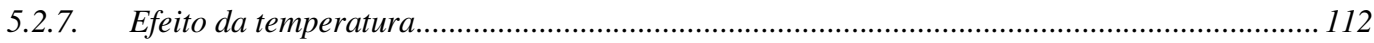

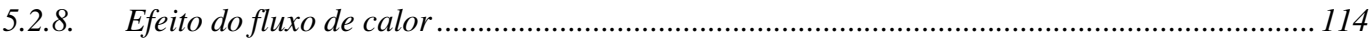

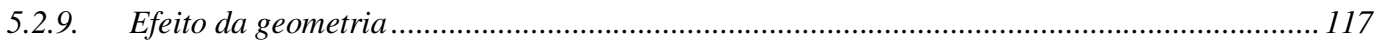

5.2.10. Avaliação dos métodos de previsão do CTC .......................................................................... 119

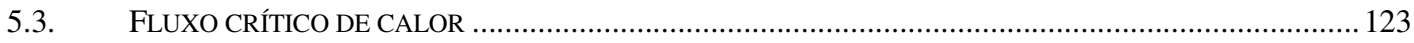

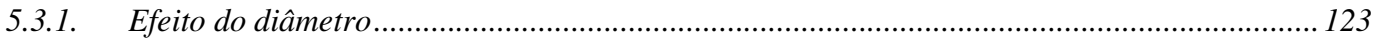

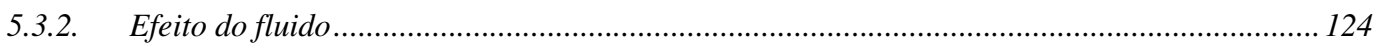

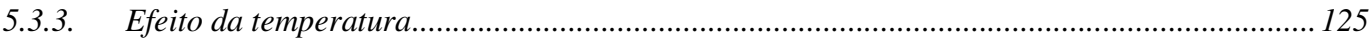

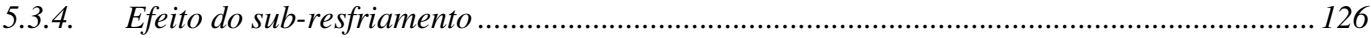

5.3.5. Efeito da velocidade mássica …......................................................................................... 127

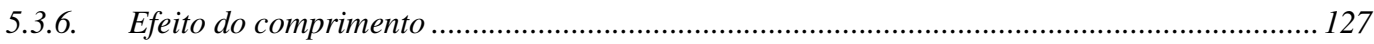

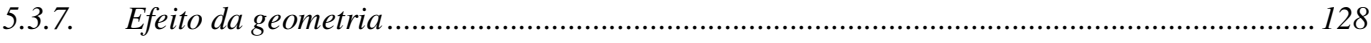

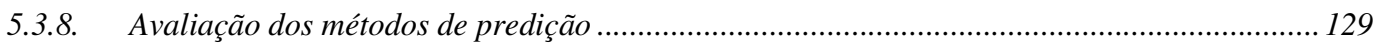

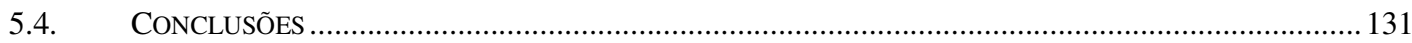

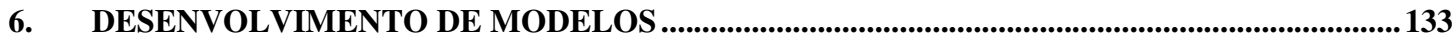

6.1. TRANSIÇÃO ENTRE MACRO E MICROCANAIS ......................................................................... 133

6.1.1. Critério de transição devido ao escoamento estratificado .................................................. 134 
6.1.2. Critério de transição devido à simetria do filme líquido..................................................... 137

6.2. COEFICIENTE DE TRANSFERÊNCIA DE CALOR .......................................................................... 139

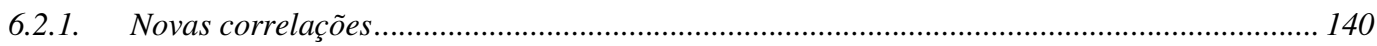

6.2.2. Novo modelo para escoamento anular ........................................................................... 142

6.2.3. Transferência de calor na região de pós-secagem da parede ................................................ 149

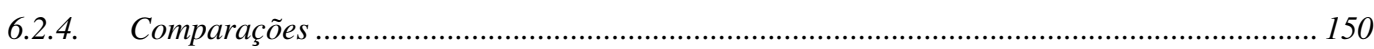

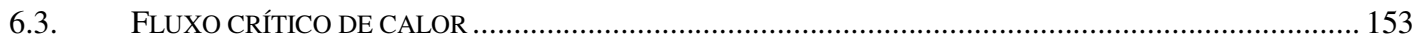

6.3.1. Desenvolvimento de correlações para FCC ................................................................... 154

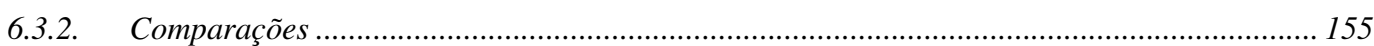

6.3.3. Aplicação em tubos não circulares ........................................................................... 158

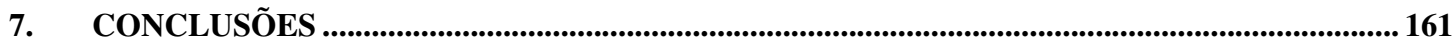

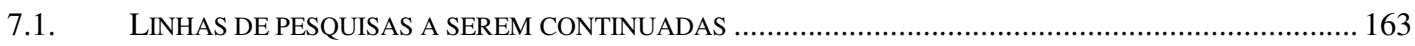

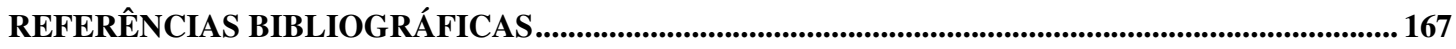

APÊNDICE A - CALIBRAÇÃ̃ DAS MEDIDAS DE TEMPERATURA ............................................... 177

APÊNDICE B - TABELAS DE RESULTADOS EXPERIMENTAIS................................................. 183

APÊNDICE C - CRONOGRAMA DOS TRABALHOS REALIZADOS ..........................................221

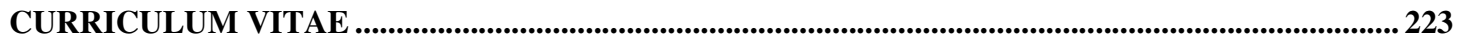


xxviii 


\section{INTRODUÇÃO}

Trocadores de calor constituídos de microcanais (denominação aqui adotada para se referir a canais com diâmetro hidráulico, $D_{h}$, inferior a $3 \mathrm{~mm}$ ) possuem vantagens explícitas em relação àqueles constituídos de macrocanais (diâmetros hidráulicos superiores a 3mm; KANDLIKAR, 2002). Dentre essas vantagens, a possibilidade de operar em pressões elevadas, devido às características estruturais do trocador de calor, e o fato de apresentarem uma área de contato por unidade de volume com o fluido refrigerante superior aos trocadores com tubos de dimensões convencionais. Destacam-se também por apresentarem, em condições similares, coeficientes de transferência de calor superiores, permitindo, segundo alguns estudos a remoção de fluxos de calor superiores a $10 \mathrm{MW} / \mathrm{m}^{2}$ (KANDLIKAR, 2005). Tais vantagens permitem trocadores compactos e minimizam tamanho, material utilizado em sua confecção e inventário de refrigerante no sistema, além de permitirem que tais trocadores sejam utilizados em condições onde espaço é um fator limitante. Atualmente, esses trocadores podem ser encontrados em várias aplicações, incluindo bombas de calor, sistemas de ar condicionado automotivo, resfriamento de componentes eletrônicos, resfriadores de sistemas laser de alta potência, células de energia e microrreatores em processos químicos. Também apresentam potencial para aplicação em painéis radiadores em veículos espaciais, controle térmico de satélites, sistemas residenciais de condicionamento de ar e resfriamento de células de combustível em reatores nucleares. Além dessas, novas aplicações vêm sendo propostas.

Evaporadores (e condensadores) constituídos de microcanais têm sido desenvolvidos heuristicamente, sem os benefícios oriundos de métodos de previsão para a transferência de calor e perda de pressão. É fato que a tecnologia existente para miniaturização destes trocadores ultrapassou o que pode ser modelado. Apenas recentemente métodos para previsão do Coeficiente de Transferência de Calor (CTC) foram propostos. Entretanto, grandes discrepâncias são verificadas, tanto quando se comparam os resultados experimentais obtidos por diferentes laboratórios em condições similares, como quando se consideram tais resultados e os métodos de previsão até então propostos. Além disso, apesar de o Fluxo Crítico de Calor 
(FCC) delimitar a faixa operacional na maioria das aplicações envolvendo tais trocadores, não se verifica na literatura um método generalizado que possa ser utilizado na sua previsão de forma confiável.

Também vale ressaltar que certos aspectos têm limitado a disseminação de evaporadores baseados em microcanais, dentre os quais o rápido crescimento de bolhas confinadas, segundo alguns autores denominadas "explosivas" (HETSRONI et al., 2005; CONSOLINI et al., 2007), que favorecem condições de fluxo crítico e proporcionam escoamentos reversos. Nesse contexto, a presente investigação tem como um de seus objetivos o desenvolvimento de modelos para a transferência de calor e para o fluxo crítico, o que se faz necessário para o desenvolvimento, otimização e projeto de evaporadores constituídos de microcanais.

Entende-se que o tema abordado nesta tese é de grande interesse para a indústria e a comunidade científica. Assim, na realização desta pesquisa buscou-se o domínio e o desenvolvimento de tecnologia relacionada a aplicações nas quais a remoção de grande quantidade de calor é um aspecto limitante à miniaturização. Esta tecnologia pode, ainda, servir de suporte ao desenvolvimento de outros setores, como as indústrias aeroespacial, nuclear, de células de combustíveis, de laser e da microeletrônica aplicada aos mais diversos setores.

\subsection{OBjetivos}

O presente trabalho de pesquisa tem como objetivo geral o estudo da transferência de calor em processos envolvendo a evaporação no interior de canais com diâmetro reduzido. Como objetivos específicos apresentam-se: (i) levantar um banco de dados extenso, que inclua coeficiente de transferência de calor e fluxo crítico baseados em resultados experimentais para a evaporação de refrigerantes halogenados em microcanais circulares e não circulares; (ii) analisar parametricamente os resultados experimentais, mediante o desenvolvimento de modelos baseados em padrões de escoamento para estimativa do coeficiente de transferência de calor e do fluxo crítico; (iii) desenvolver, tendo por base os resultados anteriores, critérios com suporte fenomenológico para a caracterização da transição entre macro e microcanais. 


\subsection{DESCRIÇÃo dOS CAPÍTULOS}

A estrutura deste trabalho é composta de: revisão bibliográfica, descrição das bancadas e dos procedimentos experimentais adotados, apresentação dos resultados experimentais, desenvolvimento de novos modelos e conclusões.

O capítulo 2 (Revisão bibliográfica) provê uma revisão da literatura sobre os aspectos fundamentais necessários ao desenvolvimento desta tese. Nele, são apresentados os fundamentos da ebulição convectiva, com a discussão dos principais mecanismos físicos relacionados. São descritos os critérios apresentados na literatura para a transição entre macro e microcanais e, também, são apresentados os padrões de escoamento verificados em escoamentos bifásicos e mapas desenvolvidos para suas previsões. O coeficiente de transferência de calor e o fluxo crítico são definidos e os principais fatores que os afetam são descritos. Uma revisão de correlações e modelos para a previsão desses parâmetros também é apresentada.

O capítulo 3 (Comparação entre dados experimentais da literatura e métodos de previsão para microcanais) apresenta uma comparação entre modelos para previsão do coeficiente de transferência de calor e fluxo crítico com dados experimentais levantados na literatura. O objetivo principal desse capítulo é identificar a existência de correlações ou modelos adequados para prever o CTC e o FCC em microcanais.

No capítulo 4 (Equipamento e procedimento experimental), são descritas as bancadas de testes utilizadas neste estudo de investigação da ebulição convectiva em microcanais e apresentados os detalhes das seções de testes e do sistema de visualização do escoamento por meio de uma câmera de alta velocidade. O sistema de aquisição de dados e todos os sensores e atuadores utilizados são detalhados. As condições experimentais ensaiadas são definidas e o procedimento de redução de dados explicado. Por último, são descritos os procedimentos utilizados para 0 cálculo das incertezas experimentais e apresentados os valores obtidos.

O capítulo 5 (Resultados experimentais) apresenta os resultados experimentais para CTC e FCC levantados. Também são discutidos os padrões de escoamento observados durante a campanha experimental e aspectos relacionados à presença de instabilidades no escoamento. 
No capítulo 6 (Desenvolvimento de modelos), são apresentados novos critérios para a transição entre macro e microcanal, e descritas as correlações para CTC e FCC propostas neste estudo. Com o objetivo de analisar os mecanismos físicos presentes, um novo modelo para cálculo do CTC em escoamento anular também é proposto.

Por fim, no capítulo 7 (Conclusões), são apresentadas as conclusões obtidas a partir da ampla revisão bibliográfica realizada e da análise dos resultados experimentais. Também são apresentadas sugestões e recomendações para trabalhos futuros. 


\section{REVISÃo BIBLIOGRÁFICA}

Neste capítulo são apresentados os fundamentos da ebulição convectiva e discutidos os principais mecanismos físicos indicados na literatura para transição entre macro e microcanais. O capítulo inclui ainda descrições para os padrões de escoamento observados em canais de reduzidos diâmetros e métodos para sua previsão. O coeficiente de transferência de calor e o fluxo crítico de calor são definidos e os principais fatores que os afetam durante a ebulição convectiva são identificados. Descrição das correlações e modelos para previsão do CTC e FCC também são apresentados.

\subsection{FUndAMENTOS DA EBULIÇÃo CONVECTIVA}

Ebulição convectiva é definida como a adição de calor a um escoamento forçado de líquido, de tal forma que ocorra geração de vapor (COLLIER; THOME,1994). Nesse mecanismo, a taxa de transferência de calor é dada pela combinação de efeitos de convecção forçada (devidos ao fluxo mássico imposto ao sistema) e de ebulição nucleada (devidos a ocorrência de nucleação de bolhas de vapor junto a parede). De forma geral, aplicações envolvendo ebulição convectiva se beneficiam em apresentar coeficientes de transferência de calor superiores aos de escoamentos monofásicos, porém apresentam uma perda de pressão também superior.

A ebulição convectiva pode ocorrer em condições sub-resfriada e saturada, dependendo da temperatura do fluido. A primeira é caracterizada por uma temperatura média do fluido, na seção transversal, inferior a temperatura de saturação relativa à pressão do escoamento, e na segunda o fluido se encontra à temperatura de saturação. Em ambos os casos, há existência simultânea das fases líquidas e vapor. A Figura 2.1 apresenta os padrões de escoamento durante a ebulição convectiva em macrotubos para escoamento na vertical e na horizontal. 

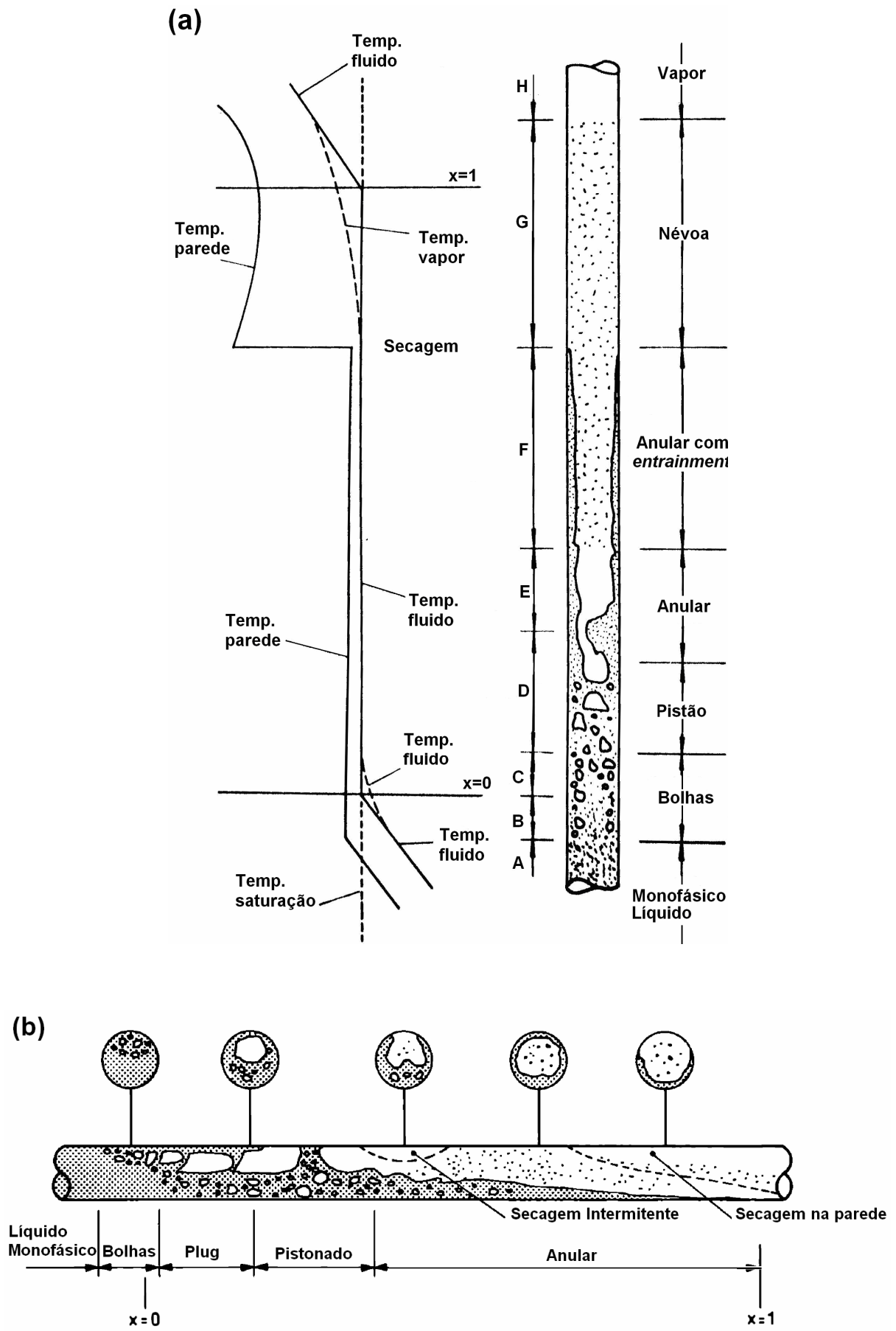

Figura 2.1 - Regimes de transferência de calor durante a ebulição convectiva: (a) escoamento vertical; (b) escoamento horizontal (COLLIER; THOME, 1999).

Analisando a Figura 2.1a, observa-se inicialmente que o líquido encontra-se em regime monofásico, transferindo calor por convecção forçada, região A. À medida que calor é transferido para o fluido, bolhas começam a formar com o líquido ainda no estado sub-resfriado, região $B$, denominada de escoamento em bolhas. $A$ 
partir desse ponto, com o incremento do título de vapor de equilíbrio termodinâmico, este padrão de escoamento passa a ocorrer em condições de fluido saturado. Nas regiões $\mathrm{B}$ e $\mathrm{C}$ os mecanismos de transferência de calor predominantes são similares aos observados em ebulição nucleada em piscina. Kandlikar (2005) sugere que esses mecanismos estão presentes também no regime anular, com formação de microbolhas no filme líquido junto à parede. $\mathrm{Na}$ região $\mathrm{D}, \mathrm{o}$ crescimento rápido das bolhas promove o seu coalescimento e a formação de pistões de vapor com diâmetro próximo ao do tubo. À medida que os pistões crescem, o mecanismo de transferência de calor por efeitos convectivos através do filme líquido, torna-se responsável por parcela significante do calor transferido. Com incrementos adicionais do título de vapor, o padrão de escoamento anular se estabelece, regiões $E$ e $F$, e o mecanismo de transferência de calor por convecção através do filme líquido se torna predominante. A evaporação de líquido ocorre livremente na interface líquido-vapor até o ponto onde ocorre a secagem total da superfície interna do tubo, região G. Nesta região, o coeficiente de transferência de calor decresce drasticamente resultando na elevação da temperatura da parede em casos de imposição do fluxo de calor. $\mathrm{Pe}$ quenas gotas de líquido suspensas no vapor, formadas no início da região anular, são observadas, sendo denominadas na literatura inglesa por entrainment, as quais eventualmente se depositam na parede do tubo causando seu resfriamento (BARBOSA et al., 2002). Finalmente, ocorre a evaporação de toda a fase líquida e o escoamento volta a ser monofásico com a fase vapor.

Uma condição singular onde também ocorre uma drástica redução do coeficiente de transferência de calor é a ebulição em filme. Nesta ocorre a formação de um filme de vapor entre a parede e a fase líquida, causando uma elevação rápida da temperatura da parede, o que pode levar eventualmente à queima do tubo (burnout). Essa situação pode tanto ocorrer em escoamentos sub-resfriados quanto em saturados com títulos de vapor reduzidos, sendo chamada de crise de ebulição ou DNB (Departure from Nucleated Boiling). Este efeito e o de secagem de parede são os mecanismos que limitam o valor máximo de transferência de calor para um determinado escoamento em um tubo, valor este denominado, no presente texto, de fluxo crítico de calor (FCC).

Um fator importante em ebulição convectiva é a determinação da região da superfície aquecida, a partir do qual o processo de nucleação de bolhas tem início. Para que haja o início da ebulição é necessário que a temperatura da parede exce- 
da a temperatura de saturação do fluido. Na ebulição convectiva sub-resfriada, a nucleação de bolhas se inicia com a temperatura média do líquido inferior à de saturação. Porém, na ebulição convectiva saturada, a formação de bolhas pode ocorrer com temperaturas médias do líquido superiores à de saturação. Este ponto onde ocorre a primeira formação de bolhas é chamado de ONB (Onset of Nucleate Boiling). Em ambos os casos, para ocorrer nucleação de bolhas é necessário que a temperatura da parede exceda um valor mínimo em relação à temperatura de saturação. Diversos autores propuseram critérios para cálculo da temperatura de ONB em canais convencionais, entre eles Bergles e Rohsenow (1964), Davis e Anderson (1966) e Kandlikar et al. (2005). Este último propôs, para o ONB, o critério expresso na equação (2-1).

$$
\Delta T_{s a t, O N B}=T_{p}-T_{s a t}=\sqrt{\frac{8,8 \cdot \sigma \cdot T_{s a t} \cdot q}{\rho_{v} \cdot i_{l v} \cdot k_{l}}}
$$

onde: $T_{p}$ é a temperatura na parede; $T_{\text {sat }}$ a temperatura de saturação (em K); q, o fluxo de calor. Nesta equação, as propriedades do fluido são calculadas para a pressão local do escoamento. Segundo Kandlikar (2005), esse critério pode ser aplicado, de forma geral, tanto em canais convencionais quanto em canais de diâmetro reduzido. A Figura 2.2 ilustra o superaquecimento da parede necessário para o início da ebulição do refrigerante $\mathrm{R} 134 \mathrm{a}$ com a variação da temperatura de saturação e do fluxo de calor.

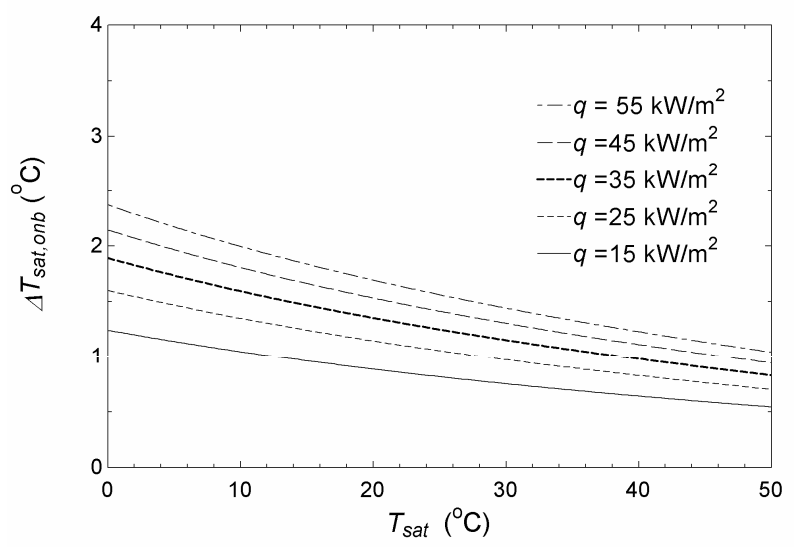

Figura 2.2 - Superaquecimento da parede necessário para início da ebulição com R134a (Kandlikar et al., 2005). 


\subsection{DistinçÕES ENTRE MACRO E MICROCANAIS}

$\mathrm{Na}$ ebulição convectiva no interior de canais, comportamentos distintos são verificados para a transferência de calor, perda de pressão e regimes de escoamento entre canais com dimensões convencionais e aqueles de dimensões reduzidas. Desta forma, nem todos os conceitos desenvolvidos para canais convencionais podem ser estendidos a microcanais. No entanto, apesar de alguns pesquisadores terem se dedicado ao tema, dimensões e condições experimentais que permitam caracterizar um critério de transição entre macro e microcanais não foram ainda identificadas. Dentre os estudos realizados, Mehendal, Jacobi e Shah (2000), baseados em tecnologias de fabricação e faixas de diâmetro encontradas em aplicações, sugeriram a seguinte classificação: microcanais (1 a 100 $\mu \mathrm{m})$; mesocanais $(100 \mu \mathrm{m}$ a $1 \mathrm{~mm})$, macrocanais (1 a $6 \mathrm{~mm})$ e canais convencionais $\left(D_{h}>6 \mathrm{~mm}\right)$. Kandlikar e Grande (2003), também baseados em faixas de diâmetros característicos de aplicações e dimensões nas quais a distância entre moléculas torna-se relevante, propuseram os seguintes critérios: canais convencionais $\left(D_{h}>3 \mathrm{~mm}\right)$; minicanais (3mm $\left.\geq D_{h}>200 \mu \mathrm{m}\right)$; microcanais $\left(200 \geq D_{h}>10 \mu \mathrm{m}\right)$; canais de transição divididos em microcanais de transição $\left(10 \geq D_{h}>1 \mu \mathrm{m}\right)$ e nanocanais de transição $\left(1 \geq D_{h}>0,1 \mu \mathrm{m}\right)$; e, canais moleculares $\left(0,1 \mu \mathrm{m} \geq D_{h}\right)$. Entretanto, destaca-se 0 fato de a transição entre macro e microcanais não poder ser caracterizada por um diâmetro específico ou, ainda, pela aplicação do evaporador, pois distintos comportamentos para CTC, FCC, queda de pressão e padrão de escoamento podem ser verificados para um diâmetro específico quando distintos fluidos são evaporados ou, ainda, quando um mesmo fluido é evaporado segundo distintas temperaturas de saturação. Além disso, o fluido refrigerante não reconhece, por exemplo, se o evaporador é um componente de sistema de condicionamento de ar automotivo ou de um sistema frigorífico de pequena capacidade. Dessa forma, conclui-se que um critério apropriado deve ser fenomenologicamente embasado.

Kew e Cornwell (1997), baseados em especulações sobre efeitos de confinamento de uma bolha no interior de um canal, propuseram critério segundo o qual conceitos macroscópicos seriam válidos apenas para canais com o número de confinamento dado pela equação (2-2), superiores a 0,5. Kew e Cornwell (1997) não 
apresentaram comparações envolvendo o critério proposto e comportamentos térmicos e hidrodinâmicos verificados na ebulição convectiva em macro e microcanais.

$$
C o=\frac{1}{D_{h}} \cdot \sqrt{\frac{4 \cdot \sigma}{g \cdot\left(\rho_{l}-\rho_{v}\right)}}>0,5
$$

Triplet et al. (1999) definiram microcanais como aqueles com diâmetro hidráulico inferior à constante de Laplace, dada pela equação (2-3).

$$
L=\sqrt{\frac{\sigma}{g \cdot\left(\rho_{l}-\rho_{v}\right)}}
$$

Considerando a estabilidade linear do escoamento estratificado, Brauner e Moalem-Marom (1992) definiram a transição com base no número de Eotvos, Eo. Segundo eles, em canais de diâmetros reduzidos, ocorre o predomínio de efeitos de tensão superficial. Este critério é dado pela equação (2-4), e condições onde Eo $>1$ seriam consideradas escoamentos em microcanais:

$$
E o=\frac{(2 \cdot \pi)^{2} \cdot \sigma}{\left(\rho_{l}-\rho_{v}\right) \cdot D_{h}^{2} \cdot g}>1
$$

Ao contrário de um valor fixo sugerido por Kandlikar e Grande (2003) para a transição entre canais convencionais e minicanais $(3 \mathrm{~mm})$, esses critérios apresentam valores entre $9 \mathrm{~mm}$, para R134a em temperaturas reduzidas, e valores inferiores a $1 \mathrm{~mm}$ no caso de temperaturas elevadas. A Figura 2.3 ilustra a variação dos diâmetros de transição entre macro e microcanais fornecidos por estes critérios para R134a e R245fa.
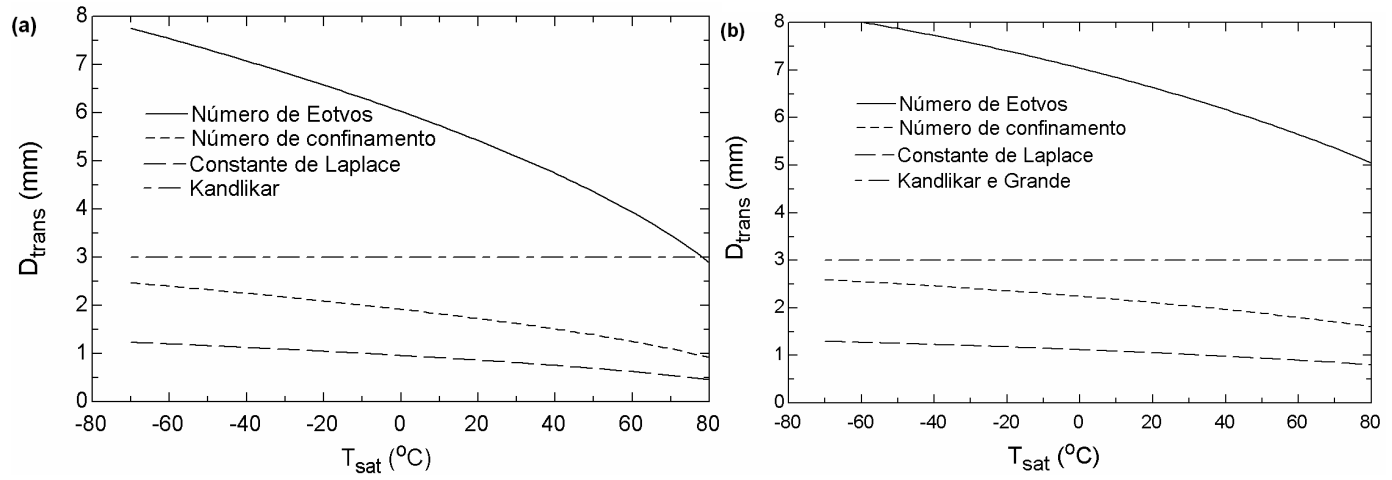

Figura 2.3 - Diâmetros de transição entre macro e microcanais para: (a) R134a; (b) R245fa

Celata (2008) verificou que, em condições de microgravidade, os critérios de transição mencionados anteriormente, baseados no confinamento de bolha no ca- 
nal, fornecem um diâmetro de transição infinito, ou seja, a ebulição convectiva em microgravidade seria sempre um fenômeno em micro-escala. Experimentos realizados por Celata et al. (2007) em microgravidade evidenciaram que o tamanho das bolhas depende não somente da gravidade, mas também do título de vapor e da velocidade do fluido e, portanto, esses parâmetros deveriam ser considerados para a criação de um critério de transição mais abrangente.

Kandlikar (2010) analisou a ordem de grandeza de várias forças associadas aos escoamentos bifásicos. A Figura 2.4 ilustra uma comparação entre forças de inércia, tensão superficial, cisalhamento, gravidade e variação da quantidade de movimento (momento) devido à evaporação na interface para vazão de $200 \mathrm{~kg} / \mathrm{m}^{2}$ s. Esta figura ilustra que com a redução do diâmetro, a força da tensão superficial se sobrepõe em relação à da gravidade. Também observa-se que em diâmetros em torno de $3 \mathrm{~mm}$ há um equilíbrio entre as forças de inércia, tensão superficial e gravidade.

No presente estudo, adotou-se o critério de $3 \mathrm{~mm}$ para a transição entre macro e microcanal, em vista da discordância dos vários critérios disponíveis. Esse critério também tem sido adotado por diversos outros autores (BERTSCH; GROLL; GARIMELLA, 2009; THOME; DUPONT; JACOBI, 2004; CHENG; RIBATSKI; THOME, 2007).

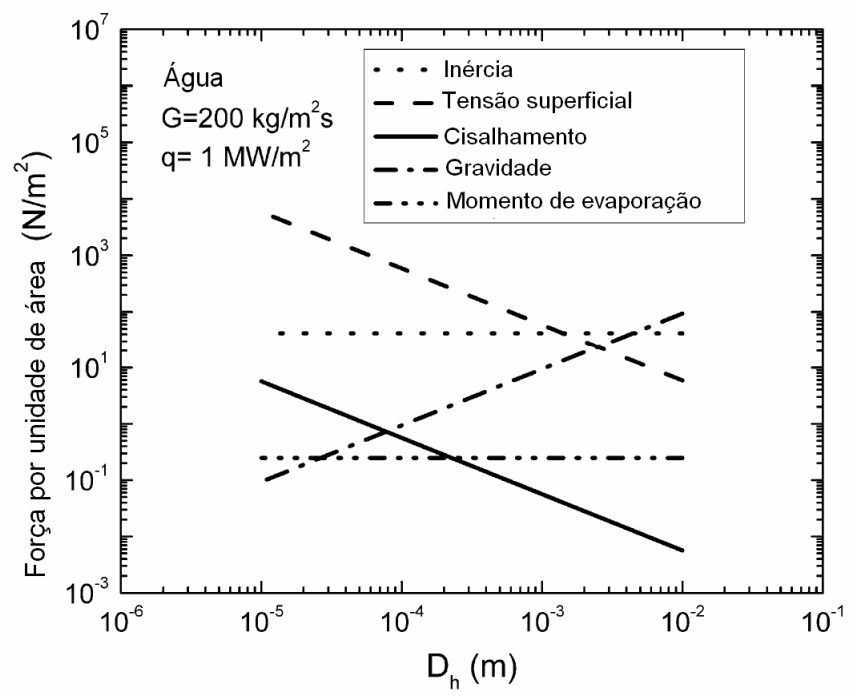

Figura 2.4 - Grandeza das forças associadas a escoamentos bifásicos (KANDLIKAR, 2010). 


\subsection{Padrões de escoamento}

Diversas classificações e terminologias têm sido adotadas para caracterizar padrões de escoamento bifásicos líquido/gás (FELCAR; RIBATSKI; JABARDO, 2007), a ponto de existir na literatura dez ou mais padrões de escoamento. Essa diversidade de denominações se deve em parte à tentativa de subclassificar os padrões de escoamentos como ocorre para as variações do escoamento anular (anular liso, anular ondulado, semi-anular). A presença ou não de transferência de calor (diabático/adiabático), ser o escoamento horizontal, vertical ou inclinado, a intensidade da aceleração gravitacional, ocorrer em macro ou microcanais, são parâmetros que influenciam o estabelecimento de um determinado padrão. Por exemplo, o padrão de escoamento estratificado não é observado para escoamento vertical e aparentemente também não ocorre em microcanais. A Figura 2.5 ilustra os padrões frequentemente indicados para escoamentos adiabáticos verticais e horizontais.

(a)
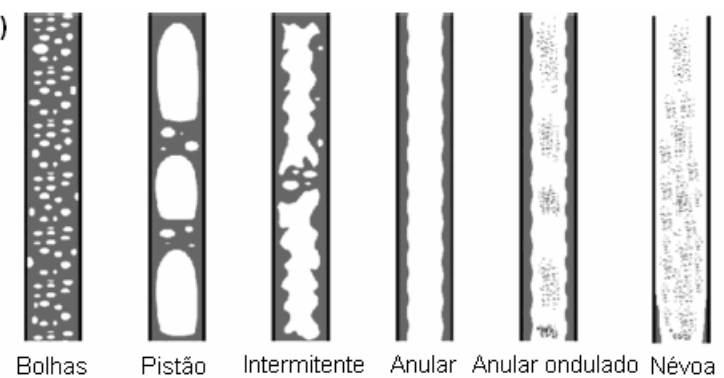

(b)
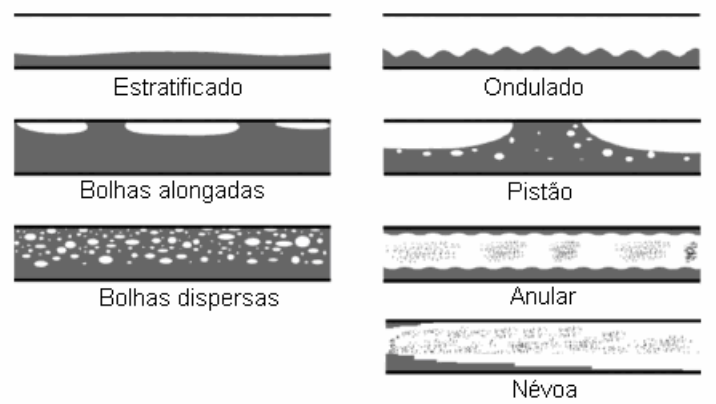

Figura 2.5 - Padrões de escoamentos adiabáticos: (a) vertical; (b) horizontal (CHENG; RIBATSKI; THOME, 2007).

Nota-se que no escoamento horizontal ocorre a estratificação do líquido na parte inferior do tubo devido a efeitos de empuxo. Para velocidades superficiais do líquido reduzidas, verifica-se o padrão estratificado em escoamentos horizontais. À 
medida que a velocidade das fases líquidas e gás se elevam, o padrão de escoamento se altera até alcançar o padrão anular. Neste, a passagem da fase gasosa sobre o filme líquido pode causar o desprendimento de gotas de líquido (entrainment), que passam a escoar junto da fase gasosa. Incrementos adicionais da velocidade da fase vapor tendem a causar incremento do entrainment até que a totalidade da fase líquida se torna dispersa na fase gasosa.

Em escoamentos diabáticos, padrões de escoamento similares são encontrados. A diferença é que, com a aplicação de calor, ocorre o incremento da parcela de vapor da mistura à medida que o fluido evapora ao longo do comprimento do tubo, enquanto que no escoamento adiabático a relação entre as massas da fase gasosa e total é aproximadamente constante ao longo do escoamento. Com o decréscimo do diâmetro do tubo, efeitos de tensão superficial se tornam superiores aos gravitacionais (KANDLIKAR, 2010) e a intensidade de estratificação da fase líquida reduzida. Na Figura 2.6 são apresentados os padrões de escoamento para o R134a em tubo horizontal de $0,5 \mathrm{~mm}$ observados por Revellin e Thome (2007a). Pode-se reparar que existe uma tendência da fase vapor se deslocar para a parte superior do tubo. Imagens do escoamento do R134a em um tubo horizontal de 2,1 mm, obtido na bancada experimental desenvolvida para este estudo, são apresentadas na Figura 2.7. Nesta figura, destaca-se a estratificação do escoamento, independentemente do padrão, com o líquido concentrando-se na parte inferior do tubo. Nessas duas figuras, com diâmetros típicos de microcanais segundo a classificação adotada neste trabalho $(D<3 \mathrm{~mm})$, os padrões de escoamento podem ser organizados nos seguintes grupos: em bolhas; pistonado; agitante; e, anular. (i) o padrão bolhas foi definido para a situação em que existem somente bolhas no escoamento com diâmetros inferiores ao diâmetro do tubo; (ii) o padrão pistonado, quando as bolhas apresentam diâmetros semelhantes aos do tubo; (iii) o padrão agitante, quando existe uma mistura de pistões e bolhas dispersas e (iv) o padrão anular, quando ocorre um filme líquido contínuo em contato com a parede junto de um núcleo de vapor contínuo. 


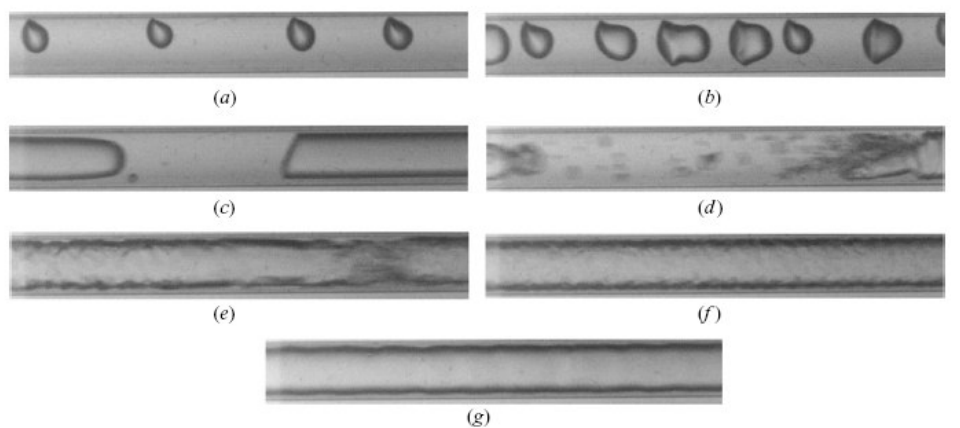

Figura 2.6 - Padrões de escoamento em microcanais horizontais. $D=0,5 \mathrm{~mm}, G=500 \mathrm{~kg} / \mathrm{m}^{2} \mathrm{~s}$, $T_{\text {sat }}=30^{\circ} \mathrm{C}$ (REVELLIN; THOME, 2007a): (a) bolhas; (b) bolhas; (c) pistonado; (d) agitante; (e) agitante; (f) anular; (g) anular.

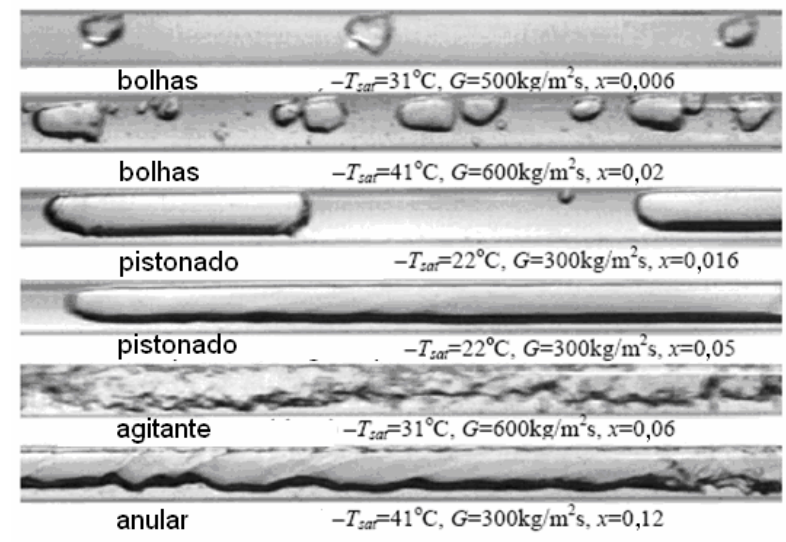

Figura 2.7 - Padrões de escoamento em microcanais horizontais. R134a, $D=2,1 \mathrm{~mm}$ (ARCANJO; TIBIRIÇÁ; RIBATSKI, 2010).

A análise dos padrões de escoamento permite identificar mecanismos físicos que expliquem os comportamentos de transferência de calor, queda de pressão e o processo de formação de bolhas. Dessa forma, conseguir prever corretamente o padrão de escoamento numa determinada situação torna possível a utilização de mecanismos físicos coerentes para a modelagem do fenômeno de interesse. Essa é a motivação para o desenvolvimento de métodos para a previsão de padrões de escoamentos bifásicos.

\subsubsection{MÉTOdOS PARA PREVISÃo dE PADRÃO DE ESCOAMENTO}

Mapas de padrão de escoamento são utilizados desde a década de 1950 para aplicações em escoamentos bifásicos. Baker (1954) propôs o primeiro mapa de escoamento referenciado nas velocidades superficiais das fases, baseado em um 
banco de dados contendo água, óleo e gás. Desde então, vários mapas e métodos de predição para caracterizar padrões de escoamentos bifásicos foram propostos, a maioria deles baseados em observações para canais com diâmetros superiores a 10mm (FELCAR; RIBATSKI; JABARDO, 2007). Para caracterizar as transições de padrões nesses mapas, normalmente são utilizados parâmetros tais como velocidades superficiais, velocidade mássica, fração de vazio e título de vapor. Cheng, Ribatski e Thome (2007) apresentaram uma ampla revisão sobre padrões de escoamento, contendo aspectos históricos da evolução dos métodos de caracterização dos padrões de escoamento e também o estado da arte da pesquisa nesse tema.

Taitel e Dukler (1976) foram os pioneiros ao desenvolver um método para previsão de padrões de escoamento baseado em mecanismos físicos. Nesse método, todos os parâmetros de interesse são adimensionalizados e comparados com curvas de transição fenomenologicamente embasadas. A Figura 2.8 apresenta o mapa obtido a partir desse método, desenvolvido para escoamento horizontal adiabático. Uma das características do método é que a transição do escoamento bolhas ou intermitente para anular ocorre para uma fração de vazio constante igual a $50 \%$. Tal fato não se verifica para escoamentos diabáticos em microcanais, como ilustrado por Revellin e Thome (2007a).

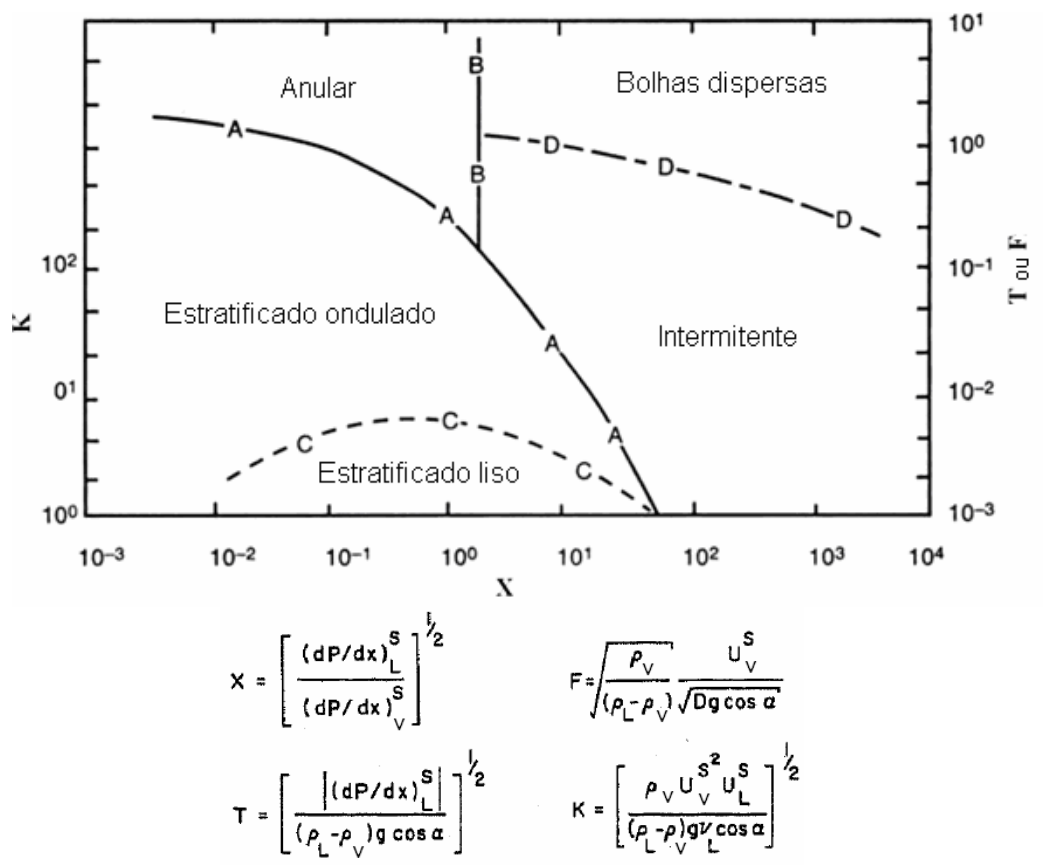

Figura 2.8 - Mapa de escoamento horizontal de Taitel e Dukler (1976). Fr, KX T, parâmetros adimensionais do modelo. 
Wojtan, Ursenbacher e Thome (2005) desenvolveram um procedimento para determinação de padrões de escoamento em tubos horizontais convencionais. Nesse procedimento, o escoamento é classificado segundo oito padrões distintos, a partir dos quais são modelados os processos de transferência de calor segundo a morfologia do escoamento. O método, cujo mapa de escoamentos resultantes encontrase ilustrado na Figura 2.9, baseia-se em resultados experimentais para os fluidos R22 e R410A levantados em tubos com diâmetros internos entre 8,0mm e 13,84mm. Devido às hipóteses adotadas para a sua elaboração e o banco de dados restrito a macrotubos, esse mapa não é aconselhado para canais de diâmetros reduzidos.

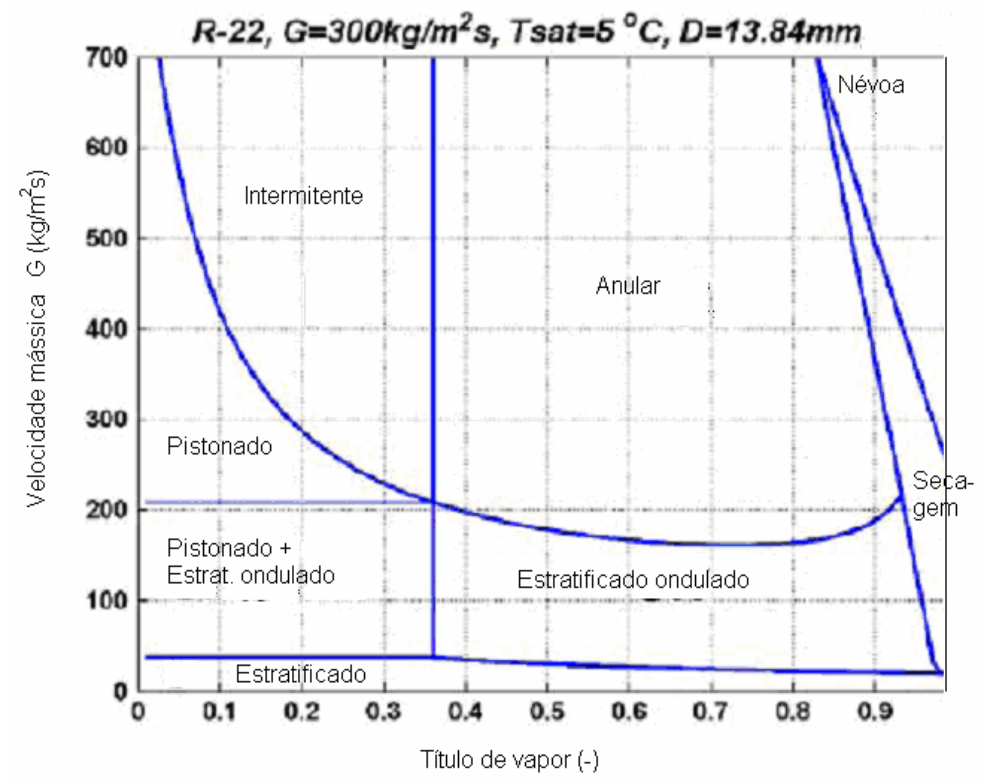

Figura 2.9 - Mapa de escoamentos de Wojtan, Ursenbacher e Thome (2005).

De acordo com Felcar, Ribatski e Jabardo (2007), o efeito de ângulo de contato e diâmetro do tubo são desprezíveis no estabelecimento dos regimes de padrão de escoamento para tubos da ordem de $10 \mathrm{~mm}$. Considerando que em microcanais o diâmetro do canal é próximo ou inferior ao comprimento de Laplace, o processo interfacial governado pela instabilidade de Taylor não se aplica a tubos capilares e, assim, segundo Triplett et al. (1999), os métodos de previsão de padrões de escoamento em macrocanais não se aplicam a microcanais, gerando a necessidade de desenvolvimento de métodos apropriados para canais de diâmetros reduzidos. 
Revellin e Thome (2007a) propuseram um método para previsões de padrões em microcanais, baseado em resultados para o escoamento estabelecido numa seção transparente, a jusante da seção aquecida, submetida a um processo de ebulição convectiva. Eles caracterizaram os seguintes padrões: bolhas, pistonado, anular e secagem da parede. Apesar das possíveis distinções de mecanismos físicos relacionadas à secagem de parede e ao fluxo crítico de calor, a transição de anular para secagem de parede foi caracterizada através da correlação desenvolvida por Wojtan, Revellin e Thome (2006) para a determinação do fluxo crítico em condições de escoamento saturado em microcanais. Nessa correlação, coeficientes empíricos foram ajustados com base em resultados experimentais para escoamentos em tubos com diâmetros de $0,5 \mathrm{~mm}$ e $0,79 \mathrm{~mm}$, utilizando os fluidos refrigerantes R134a e R245fa. Posteriormente, Ong e Thome (2011a) propuserem um aperfeiçoamento do mapa de Revellin e Thome (2007a), incluindo dados experimentais para tubos de 1,0 a 3,0mm de diâmetro com fluidos R134a, R236fa e R245fa, o que resultou no mapa mostrado na Figura 2.10.

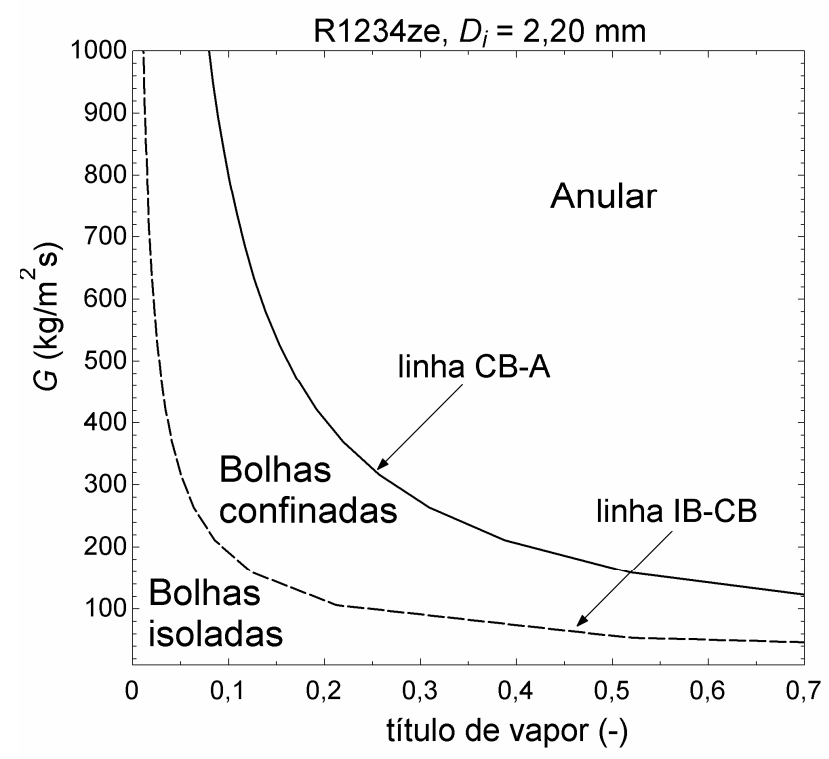

Figura 2.10 - Mapa de escoamento de Ong e Thome (2011a).

Felcar, Ribatski e Jabardo (2007) desenvolveram um procedimento para previsão de padrões de escoamento com base no modelo proposto por Taitel e Dukler (1976) para escoamentos horizontais. Modificações foram introduzidas nas transições estratificado/anular e intermitente/anular de forma a incorporar efeitos de ten- 
são superficial, ângulo de contato e escoamentos secundários. Resultados experimentais para escoamentos ar-água em microcanais foram utilizados no ajuste de coeficientes empíricos. A Figura 2.11 ilustra uma comparação entre o método proposto por Felcar, Ribatski e Jabardo (2007) e os resultados para escoamentos arágua. Arcanjo, Tibiriçá e Ribatski (2010) compararam seus resultados com este método para um tubo de $2,3 \mathrm{~mm}$ e obtiveram, relativamente aos métodos anteriores, uma boa concordância para os refrigerantes R134a e R245fa, conforme ilustrado na

\section{Figura 2.12.}

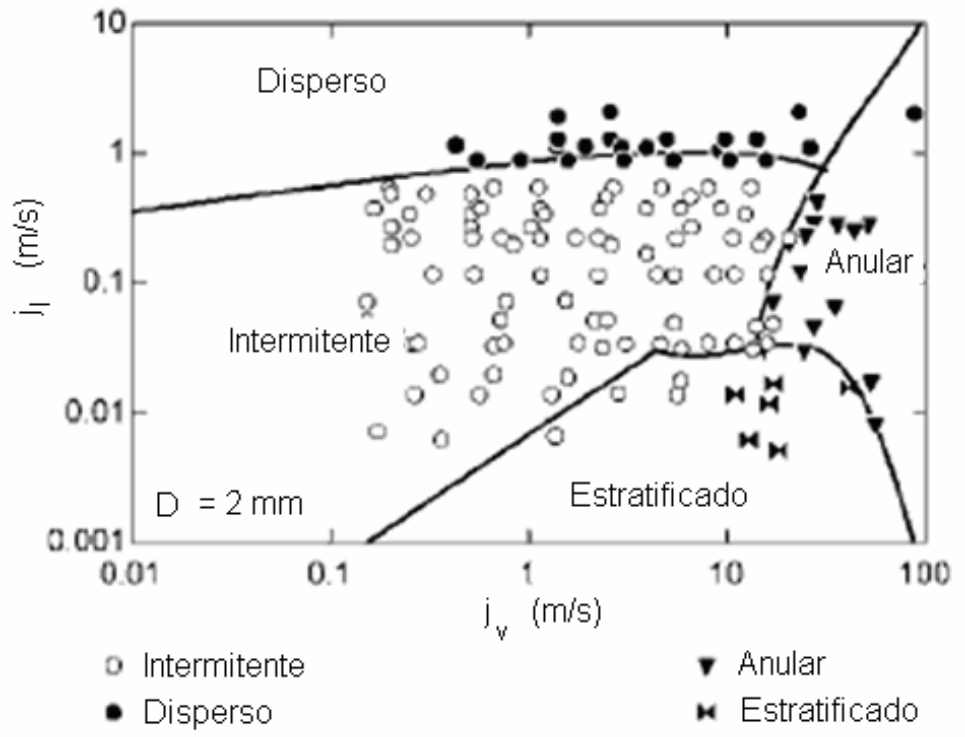

Figura 2.11 - Comparação entre o método de Felcar, Ribatski e Jabardo (2007) e dados experimentais ar-água.

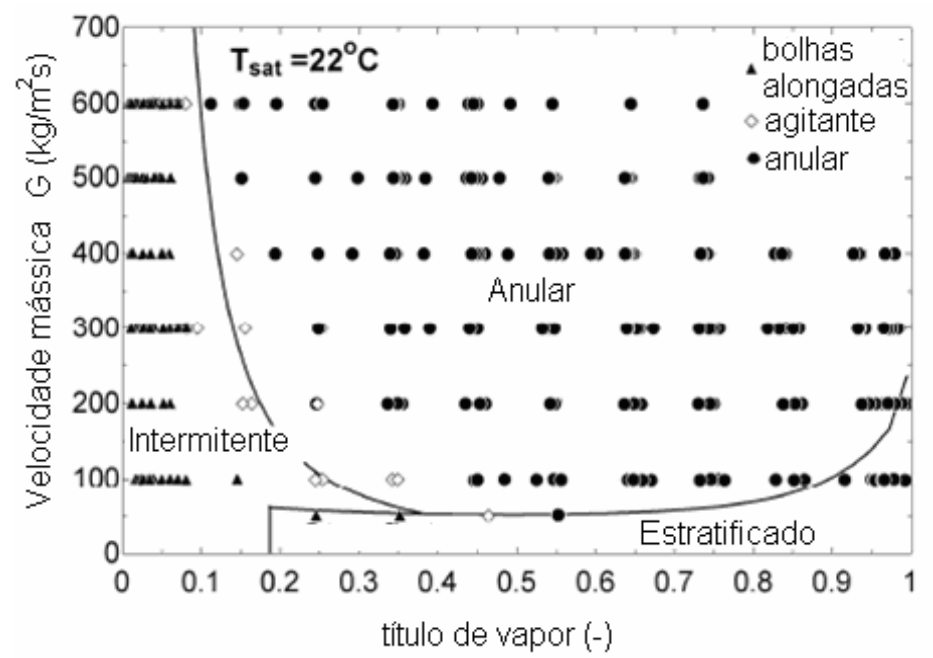

Figura 2.12 - Comparação entre o método de Felcar, Ribatski e Jabardo (2007) e resultados de Arcanjo, Tibiriçá e Ribatski, (2010) para o escoamento diabático com R134a, D=2,32mm. 
Tapia (2011) utilizou o algoritmo k-means para caracterizar os padrões de escoamento observados na mesma bancada experimental do presente trabalho. A caracterização dos padrões de escoamento envolveu o tratamento simultâneo de sinais provenientes de um par diodo/sensor-laser montados na seção de visualização transparente onde ocorre escoamento bifásico; um transdutor de pressão piezoelétrico de tamanho reduzido com o objetivo de determinar a variação local da pressão do escoamento; e de um microtermopar em contato com o fluido refrigerante. $A$ técnica de tratamento de dados utilizada envolveu a aglomeração progressiva de dados que apresentem características médias similares através do algoritmo $k$ means. Os resultados previstos pelo método objetivo apresentaram concordância com os dados caracterizados com base em visualizações.

\subsection{Coeficiente de tRANSFerÊNCIA DE CALOR}

O coeficiente de transferência de calor é definido pela lei de resfriamento de Newton como $h=\frac{q}{T_{p i}-T_{f}}$ e quanto maior o seu valor menor é a resistência térmica de transferência de calor entre um fluido e uma superfície. A resistência térmica, $R$, num processo de convecção é definida conforme a equação (2-5).

$$
R=\frac{1}{h \cdot A}
$$

O desenvolvimento de métodos que permitam o decréscimo da resistência térmica tem sido um desafio aos engenheiros envolvidos com projetos de trocadores de calor. A redução da resistência térmica através da elevação do coeficiente de transferência de calor permite o incremento da eficiência de resfriamento, minimizando a área de troca de calor e possibilitando elevar o grau de compacidade do trocador. A Tabela 2.1 apresenta o coeficiente de transferência de calor resultante de vários mecanismos de transferência de calor por convecção. Segundo esta tabela, a transferência de calor por ebulição convectiva é um dos mecanismos que proporciona CTC mais elevados. Valores de $h=30 \mathrm{~kW} / \mathrm{m}^{2} \mathrm{~K}$ podem ser facilmente obtidos em canais de diâmetros reduzidos, conforme os resultados de Consolini (2008) 
ilustrados na Figura 2.13, que realizou experimentos para um tubo de $0,5 \mathrm{~mm}$ de diâmetro com R134a.

Tabela 2.1 - Valores de coeficientes de transferência de calor através de mecanismos de convecção.

\begin{tabular}{lc}
\hline Mecanismo físico & $h\left(\mathrm{~W} / \mathrm{m}^{2} \mathrm{~K}\right)$ \\
\hline $\begin{array}{c}\text { Convecção natural } \\
\text { Gases }\end{array}$ & $5-25$ \\
Líquidos & $50-1000$ \\
Convecção forçada & \\
Gases & $25-250$ \\
Líquidos & \\
Canais convencionais & $50-10^{4}$ \\
$\quad$ Microcanais & $500-5.10^{5}$ \\
Ebulição nucleada & $300-5.10^{4}$ \\
Ebulição convectiva & $300-10^{6}$ \\
Condensação & $10^{3}-1,5.10^{5}$ \\
\hline
\end{tabular}

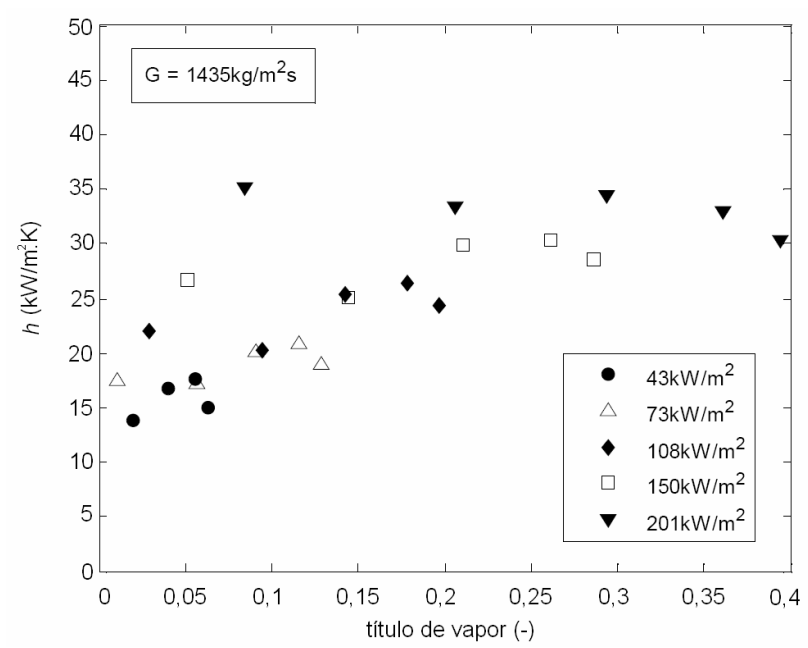

Figura 2.13 - Resultados de Consolini (2008), para ebulição convectiva em microcanais, com R134a, $D=0,5 \mathrm{~mm}$.

Como se pode ver na Tabela 2.1, elevados coeficientes de transferência de calor são obtidos experimentalmente para a ebulição convectiva no interior de microcanais. Mas, apesar dessa útil característica, a previsão teórica dos valores de CTC na ebulição convectiva em microcanais ainda é um grande desafio. Um dos fatos que explicam essa dificuldade é a existência de elevado número de parâme- 
tros que afetam o CTC. Entre eles, podem-se citar: fluxo de calor, velocidade mássica, título de vapor, temperatura de saturação, fluido, direção do escoamento (vertical, horizontal, inclinado), diâmetro e formato do canal (circular, quadrado, elíptico), aceleração gravitacional, instabilidade no escoamento, vibrações na tubulação, material e rugosidade interna do canal, caracterização da microestrutura da superfície, efeitos de ranhuras e estruturas de intensificação, presença de impurezas e, mais recentemente, a adição de nanopartículas ao escoamento como apresentado em Cabral e Ribatski (2010).

\subsubsection{MECANISMOS DE TRANSFERÊNCIA DE CALOR}

Os mecanismos de transferência de calor na ebulição convectiva em microcanais estão relacionados ao padrão de escoamentos estabelecido (RIBATSKI; WOJTAN; THOME, 2006). Para escoamento em bolhas, tanto com líquido subresfriado quanto saturado, mecanismos relacionados à nucleação de bolhas predominam, ocorrendo também transferência de calor por convecção forçada. A ebulição nucleada tem sido estudada há décadas, e novos mecanismos físicos têm sido identificados como responsáveis pela elevada taxa de transferência de calor observada, como em Demiray e Kim (2004), Myers et al. (2005) e Moghaddam e Kiger (2009), o que, por conseqüência, demonstra a necessidade de mais pesquisa para esse padrão de escoamento em ebulição convectiva.

No escoamento pistonado, Thome, Dupont e Jacobi (2004) consideram que os mecanismos predominantes são a condução, através do filme líquido presente entre a parede e o pistão de vapor, e a convecção forçada durante a passagem de um pistão de líquido. Kandlikar (2010) considera que o efeito de condução no filme líquido, conforme proposto por Thome, Dupont e Jacobi (2004), representa apenas $20 \%$ da transferência de calor total, sendo o restante devido, principalmente, a efeitos de condução transiente no líquido superaquecido presente na região frontal ao pistão de vapor. Schweizer, Freystein e Stephan (2010) realizaram experimentos com câmera infravermelha sobre um canal retangular de $0,5 \mathrm{~mm}$ de altura observando a variação total da temperatura da parede do canal durante a passagem de uma bolha alongada. Eles observaram que fluxos de calor superiores ocorriam à frente do pistão e não na região posterior, conforme sugerido em Thome, Dupont e Jacobi (2004). A Figura 2.14 ilustra o campo de temperaturas obtido por Schweizer, 
Freystein e Stephan (2010) e as imagens do escoamento a partir de uma câmera de alta velocidade obtida concomitantemente as imagens de infravermelho.
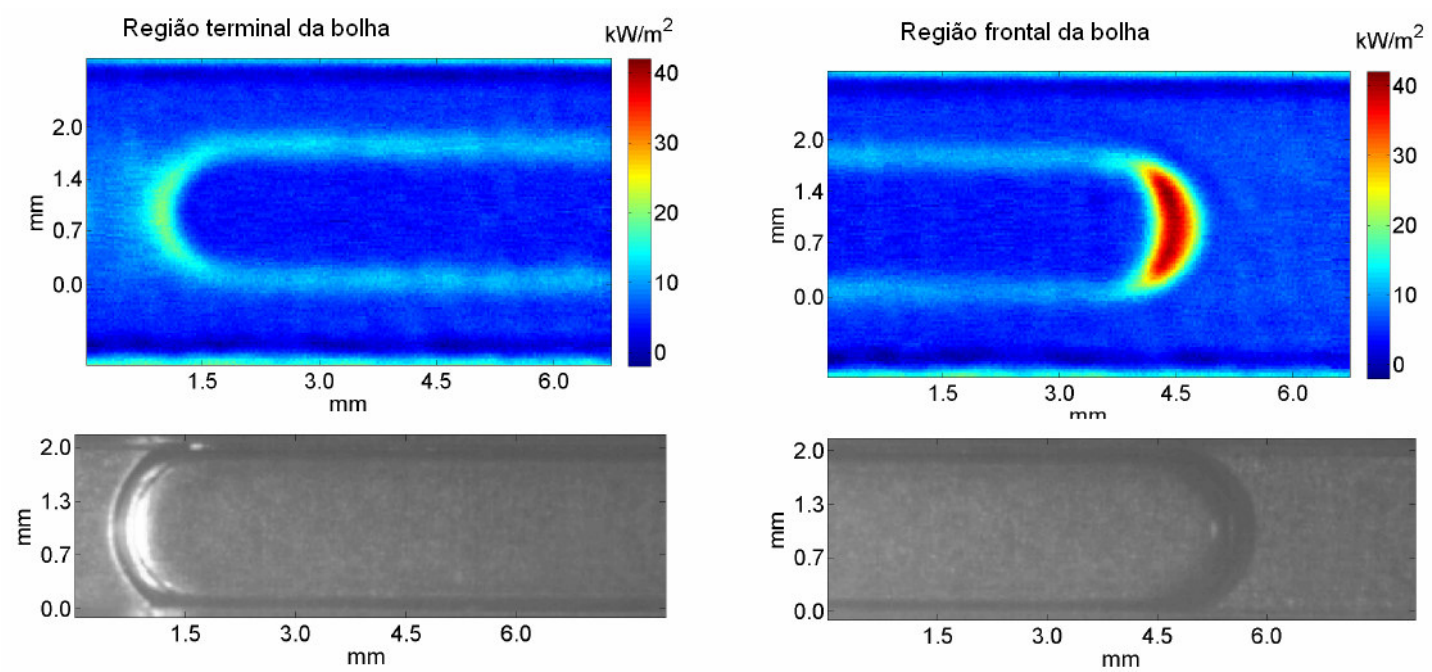

Figura 2.14 - Campo de temperatura a partir de imagens em infravermelho e as respectivas imagens obtidas do escoamento com câmera de alta velocidade.

No escoamento anular, o mecanismo predominante é a condução através do filme líquido com evaporação na interface (QU e MUDAWAR, 2003). Kandlikar et al. (2005) observaram a nucleação de microbolhas no filme líquido e, com base nesse resultado, sugeriram o efeito conjugado de condução e nucleação de bolhas como responsável pela elevada transferência de calor em microcanais.

No escoamento em névoa, a transferência de calor monofásica através do mecanismo de convecção forçada do vapor é intensificada pela deposição e consequente evaporação de gotas de líquido na superfície do tubo.

Uma melhor compreensão dos mecanismos de transferência de calor na última década tem levado ao desenvolvimento de modelos mecanísticos de previsão da transferência de calor; além disso, campanhas experimentais amplas têm sido executadas para gerar correlações para previsão do CTC. Sob esse conceito, uma abordagem bastante utilizada é a proposição de correlações que ponderem efeitos de ebulição nucleada e convecção forçada. 


\subsubsection{CORRELAÇÕES E MODELOS PARA PREVISÃo DO COEFICIENTE DE TRANS- FERÊNCIA DE CALOR}

Métodos para previsão do coeficiente de transferência de calor durante a ebulição convectiva podem ser classificados em três grupos: modelos fenomenológicos; métodos semi-empíricos; métodos empíricos. O primeiro grupo baseia-se na modelagem física do fenômeno, considerando as equações de conservação de massa, quantidade de movimento e energia solucionadas segundo condições de contorno adequadas. O segundo grupo geralmente usa uma fundamentação teórica embasada em critérios físicos para construção do modelo, ajustando, ao final, coeficientes com base em um banco de dados experimentais. O terceiro é baseado na observação experimental de quais parâmetros estão relacionados com o processo em questão e, a partir daí, uma correlação envolvendo grupos adimensionais é ajustada aos dados experimentais. A Tabela 2.2 apresenta um resumo de alguns dos métodos para cálculo do CTC levantados nesta pesquisa bibliográfica.

Tabela 2.2 - Métodos para o cálculo do coeficiente de transferência de calor em ebulição convectiva.

\begin{tabular}{|c|c|c|}
\hline Autor & $\begin{array}{l}\text { Classifica- } \\
\text { ção }\end{array}$ & Aplicação \\
\hline Chen (1966) & Empírico & Ebulição convectiva em macrocanais \\
\hline $\begin{array}{l}\text { Liu e Winterton } \\
\text { (1991) }\end{array}$ & Empírico & Ebulição convectiva em macrocanais \\
\hline Qu e Mudawar (2003) & $\begin{array}{l}\text { Fenômeno- } \\
\text { lógico }\end{array}$ & $\begin{array}{l}\text { Ebulição convectiva em microcanais para es- } \\
\text { coamento anular em microcanais }\end{array}$ \\
\hline $\begin{array}{l}\text { Zhang, Hibiki e Mi- } \\
\text { shima (2004) }\end{array}$ & Empírico & Ebulição convectiva em microcanais \\
\hline $\begin{array}{l}\text { Thome, Dupont e Ja- } \\
\text { cobi }(2004)\end{array}$ & $\begin{array}{l}\text { Semi- } \\
\text { empírico }\end{array}$ & $\begin{array}{l}\text { Ebulição convectiva em microcanais para es- } \\
\text { coamento pistonado }\end{array}$ \\
\hline $\begin{array}{l}\text { Kandlikar e Balasu- } \\
\text { bramanian (2004) }\end{array}$ & Empírico & Ebulição convectiva em microcanais \\
\hline $\begin{array}{l}\text { Saitoh, Daiguji e Hira- } \\
\text { ra (2007) }\end{array}$ & Empírico & $\begin{array}{l}\text { Ebulição convectiva em microcanais e macro- } \\
\text { canais com R134a. }\end{array}$ \\
\hline $\begin{array}{l}\text { Bertsch, Groll e Ga- } \\
\text { rimella (2009) }\end{array}$ & Empírico & Ebulição convectiva em microcanais. \\
\hline $\begin{array}{l}\text { Cioncolini e Thome } \\
\text { (2011) }\end{array}$ & $\begin{array}{l}\text { Semi- } \\
\text { empírico }\end{array}$ & $\begin{array}{l}\text { Ebulição convectiva durante escoamento anu- } \\
\text { lar }\end{array}$ \\
\hline
\end{tabular}


$\mathrm{Na}$ ebulição convectiva, diferentes mecanismos predominam segundo as condições de título de vapor, fluxo de calor e níveis de velocidade mássica. Com títulos de vapor reduzidos, efeitos de nucleação prevalecem, enquanto para títulos elevados o CTC é controlado por efeitos convectivos. Tais comportamentos são normalmente considerados no desenvolvimento de métodos de previsão para o CTC. Para Chen (1966), um dos pioneiros a adotar tal abordagem, o CTC é dado de acordo com a equação (2-6),

$$
h_{t p}=S \cdot h_{n b}+F \cdot h_{s p}
$$

onde: $h_{n b}$, é dado pela correlação de ebulição nucleada em piscina, proposta por Foster e Zuber (1955); $h_{s p}$ é o CTC monofásico, calculado segundo a correlação de Dittus e Boelter (1930), considerando todo o escoamento como líquido. Nesse método, $S$ é um fator de supressão da ebulição nucleada, que leva em conta gradientes próximos à parede devido aos movimentos do fluido, os quais tendem a suprimir o número de núcleos ativos de bolhas. O fator de intensificação, $F$, considera o incremento dos efeitos convectivos, relativos ao escoamento monofásico do líquido, promovido pela aceleração do escoamento relacionado ao processo de evaporação. Desde sua proposta, diversos autores têm ajustados seus bancos de dados segundo correlações do tipo proposto por Chen (1966). Essa abordagem é frequentemente adotada também para a ebulição convectiva em microcanais.

Liu e Winterton (1991) desenvolveram um método para prever o CTC em ebulição convectiva subresfriada e saturada baseado no método de Chen. Em seu método, as contribuições da ebulição nucleada e convecção são ponderadas segundo um expoente assintótico igual a 2 . O termo convectivo deste método, $h_{s p}$, foi calculado através da correlação de Dittus e Boelter (1930) e o de ebulição nucleada, $h_{n b}$, através da correlação do Cooper (1984). Eles ajustaram o método utilizando um banco de dados experimental envolvendo aproximadamente 5000 resultados, nove fluidos refrigerantes e diâmetros internos de tubos variando de 2,92mm a $32 \mathrm{~mm}$.

O método para CTC para microcanais de Kandlikar e Balasubramanian (2004) é uma versão modificada do método anterior para canais convencionais apresentada por Kandlikar (1991). As principais modificações estão relacionadas ao fato de considerar na nova versão a possibilidade de escoamento laminar e desprezar efeitos de estratificação devido à gravidade. Nessa correlação para microcanais, 
os valores das constantes empíricas para o par fluido/material de superfície foram mantidos similares aos valores propostos anteriormente para canais convencionais.

Zhang, Hibiki e Mishima (2004) modificaram o método de Chen (1966) com o propósito de desenvolver uma correlação para ebulição convectiva em microcanais. $\mathrm{Na}$ sua abordagem, a correlação de Foster e Zuber (1955) foi mantida para o termo de ebulição nucleada. Para determinar o fator de intensificação convectivo e o CTC monofásico, foram considerados regimes de escoamentos das fases líquido e vapor laminar e turbulenta. Eles comparam esse método com dados experimentais da literatura para água, $\mathrm{R} 11, \mathrm{R} 12$ e $\mathrm{R} 113$, concluindo que seu método prevê adequadamente os comportamentos do CTC em microcanais.

Thome, Dupont e Jacobi (2004) desenvolveram um modelo que descreve a transferência de calor durante a passagem cíclica de bolhas alongadas em microcanais, Figura 2.15. Nesse modelo, o coeficiente de transferência de calor médio no tempo é obtido durante a passagem cíclica de (i) um pistão de líquido, (ii) evaporação do filme líquido entre a parede e o tubo de uma bolha alongada, e (iii) um pistão de vapor quando presente. O modelo inclui cinco parâmetros experimentais obtidos por Dupont, Thome e Jacobi (2004) usando um banco de dados obtidos na literatura abrangendo sete laboratórios independentes com 1591 resultados experimentais. Uma representação esquemática do modelo é ilustrada na Figura 2.15.

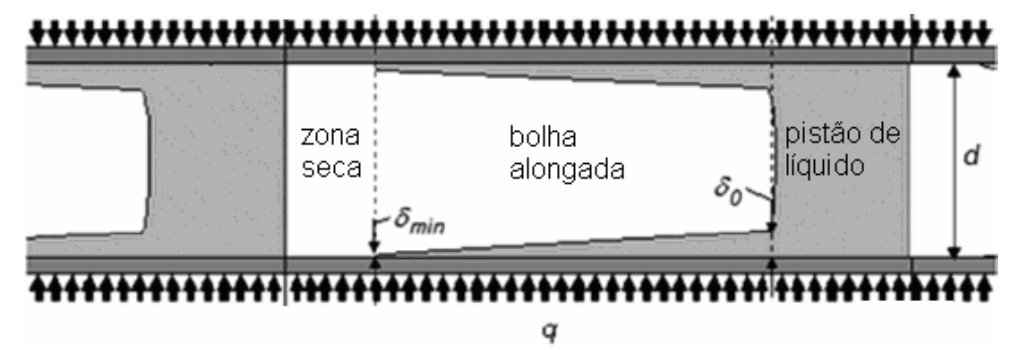

Figura 2.15 - llustração esquemática do modelo de 3 zonas, proposto por Thome, Dupont e Jacobi (2004).

Mediante modificação da correlação de Chen (1966) e com base em dados para R134a, Saitoh, Daiguji e Hihara (2007) propuseram uma correlação utilizando dados experimentais para tubos com diâmetros de 0,51 a $11 \mathrm{~mm}$, válida para ebulição convectiva em macro e microcanais. Nesse método, ênfase foi dada em capturar o efeito do diâmetro do tubo no CTC através do número de Weber. O termo convectivo desse método, $h_{s p}$, foi calculado através da correlação de Dittus e Boelter 
(1930) e o de ebulição nucleada, $h_{n b}$, através da correlação do Stephan e Abdelsalam (1980). Coeficientes empíricos foram ajustados com base em banco de dados experimental levantados por esses autores.

Recentemente, Bertsch, Groll e Garimella (2009) propuseram um método baseado em Chen (1966) utilizando dados experimentais da literatura para diâmetros hidráulicos variando de 0,16 a 2,92mm, incluindo 3899 dados experimentais e 12 fluidos, obtendo um erro médio de previsão inferior a $30 \%$ para este banco de dados.

Qu e Mudawar (2003) propuseram um modelo para transferência de calor considerando a evaporação progressiva da película líquida durante o padrão anular. Assumiram que o mecanismo dominante de transferência de calor no escoamento anular é a condução através do filme líquido, para escoamento termicamente desenvolvido. Assim, para determinar o coeficiente de transferência de calor, utilizaram a equação (2-7),

$$
h=\frac{k}{\delta}
$$

onde: $k$ é a condutividade térmica da fase líquida e $\delta$ é a espessura do filme líquido. O modelo compõe-se de quatro equações diferenciais envolvendo conservação de massa, energia e quantidade movimento para as fases vapor e líquida, cuja solução é necessária para determinar a espessura do filme líquido. Foram incluídos efeitos relacionados ao desprendimento e à deposição de gotas e desprezados efeitos de tensão superficial na interface líquido/gás. Vale ressaltar que o fenômeno de deposição de gotas pode explicar comportamento observado em microcanais para títulos de vapor elevados, que consiste num incremento substancial do coeficiente de transferência de calor com a elevação do título, após seu drástico decréscimo relacionado a condições de secagem de parede. O modelo teórico de Revellin e Thome (2007b) foi desenvolvido para cálculo do fluxo crítico de calor em microcanais, assumindo que este ocorra durante o padrão de escoamento anular liso. Esse modelo teórico resulta num sistema de cinco equações diferencias que permitem determinar a espessura do filme líquido, as velocidades médias na seção transversal das fases líquida e gasosa e as quedas de pressão para cada fase. Teoricamente, esse modelo também poderia ser utilizado para estimar o CTC em escoamentos anulares de forma análoga ao modelo proposto por Qu e Mudawar (2003). 
Cioncolini e Thome (2011) propuseram um método baseado em modelo algébrico de turbulência para escoamento anular onde é possível calcular os perfis de temperatura e velocidade do filme líquido, além da espessura média do filme líquido, fração de vazio e coeficiente de transferência de calor. Cioncolini e Thome (2011) citam que os modelos algébricos são os mais simples entre os modelos de turbulência até então propostos. Esse modelo não inclui efeitos do fluxo de calor e, segundo seus autores, apresenta acuracidade próxima das melhores correlações disponíveis.

\subsection{FLUXO CRÍTICO DE CALOR}

O fluxo crítico de calor (FCC) está geralmente associado com um drástico decréscimo do coeficiente de transferência de calor e o aumento da temperatura na superfície. Quando calor é dissipado em um dispositivo onde o parâmetro imposto é o fluxo de calor, como microprocessadores e elementos combustíveis em reatores nucleares, exceder o FCC pode resultar em danos irreversíveis ao sistema térmico. Dessa forma, o FCC é o máximo valor seguro que o dispositivo pode operar. Devido a esse motivo, esse tema tem atraído grande atenção do meio acadêmico na área de transferência de calor e também dos setores industriais envolvidos com dissipação de fluxos de calor elevados.

Como na previsão do CTC, diversos fatores influenciam o valor do FCC. Dentre eles podem-se citar: velocidade mássica, título de entrada, relação comprimento aquecido/diâmetro do tubo, propriedades dos fluidos, formato do canal, presença de instabilidades no escoamento, etc.

\subsubsection{MECANISMOS DO FLUXO CRÍTICO DE CALOR}

Na ebulição em piscina, a condição de FCC é observada quando o fornecimento de líquido à superfície é bloqueado pela presença de uma camada de vapor de tal forma que o calor é transferido da superfície para o líquido por condução e convecção através da camada de vapor. À medida que o superaquecimento da parede se eleva, a radiação se torna o principal mecanismo de transferência de calor.

$\mathrm{Na}$ ebulição convectiva, os mecanismos relacionados com o surgimento do FCC são dependentes do estado do fluido operante. Mecanismos distintos são ob- 
servados em condições subresfriadas e saturadas. A condição subresfriada referese quando o FCC de calor ocorre em condições de título de vapor termodinâmico, na saída da seção de testes, inferiores a zero. Esse cenário é observado para elevadas velocidades mássicas e graus de subresfriamento na entrada da seção de testes e reduzidas razões entre o comprimento aquecido e o diâmetro do tubo. $\mathrm{O}$ FCC em condições saturadas ocorre quando o título de vapor termodinâmico na saída da seção de testes é superior a zero. A Figura 2.16 ilustra esses mecanismos. Para FCCs saturados, pelo menos três mecanismos são encontrados na literatura. O primeiro é a secagem completa do filme líquido próximo à parede, ocorrendo a títulos de vapor elevados, conforme ilustrado na Figura 2.16. O segundo mecanismo, descrito por Revellin e Thome (2007b), considera que a presença de ondulações na interface do filme líquido pode levar à secagem prematura da superfície, devido à reduzida espessura do filme alcançada nos vales das ondulações, conforme ilustrado na Figura 2.17. O terceiro mecanismo, similar aos mecanismos de FCC sub-resfriado, ocorre a títulos de vapor ligeiramente acima de zero.
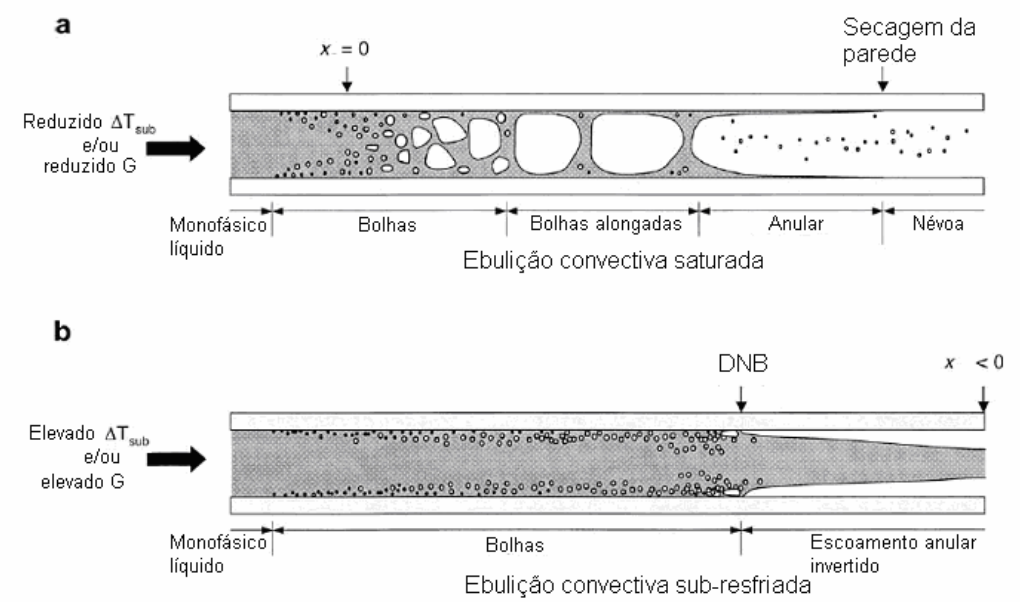

Figura 2.16 - Mecanismo de FCC em escoamento (a) saturado e (b) sub-resfriado, segundo Lee e Mudawar (2009).

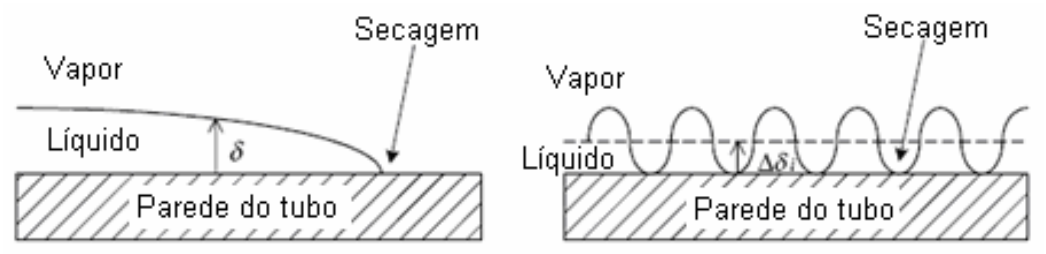

Figura 2.17 - Secagem de parede com e sem ondas interfaciais (REVELLIN; THOME, 2007b) 
Para FCC sub-resfriado, a formação do escoamento em filme de vapor, ou crise da ebulição, como visto na Figura 2.16, é o fenômeno relacionado à brusca redução da transferência de calor. Três mecanismos principais apresentados por Lee e Mudawar (1988) demonstram como pode ocorrer a formação desse filme de vapor: camada limite de separação que, devido às forças de aceleração do vapor surgindo junto à parede, faz com que o líquido seja separado da parede; aglomeração de bolhas de vapor, onde ocorre uma secagem local devido à coalescência de um número elevado de bolhas junto à superfície; evaporação do filme líquido em volta de um pistão de vapor, onde ocorre secagem do filme líquido junto à parede, antes que o próximo pistão de líquido sub-resfriado alcance essa posição. Mecanismos similares foram considerados por diversos autores no desenvolvimento de modelos de FCC (KATTO; OHNO, 1984; CELATA; KATTO; MARIANI, 1999; LEE; MUDAWAR, 2009).

\subsubsection{CORRELAÇÕES E MODELOS PARA PREVISÃO DO FLUXO CRÍTICO DE CALOR}

Devido a complexidade de modelar o FCC em ebulição convectiva, os métodos para sua previsão são geralmente baseados em correlações empíricas baseadas em grupos adimensionais, os quais incluem os principais parâmetros que influenciam o FCC. Devido a diferenças entre os mecanismos, correlações distintas são ajustadas para FCC sub-resfriado e para o FCC saturado, sendo a maioria delas desenvolvidas para estudos focados em aplicações nucleares e tendo a água como fluido refrigerante. Entretanto, esse cenário vem se modificando, principalmente pela necessidade de se dissipar fluxos de calor elevados em microprocessadores. Dessa forma, dados experimentais passaram a ser levantados para uma ampla faixa de fluidos e diâmetros reduzidos. No Quadro 2.1 listam-se métodos de previsão de FCC da literatura, que apresentaram melhores previsões, segundo a presente pesquisa, em aplicações envolvendo microcanais.

Uma correlação generalizada para FCC em ebulição convectiva em tubos verticais uniformemente aquecidos, baseada em números adimensionais, foi proposta por Katto e Ohno (1984). Trata-se de uma correlação amplamente utilizada e ajustada a partir de um extenso banco de dados levantados em uma série de estudos realizados pelo primeiro autor. 
Em 1987, Shah propôs uma nova versão de sua correlação para a previsão do FCC para escoamentos verticais em tubos aquecidos uniformemente abrangendo condições saturadas e subresfriadas. Essa correlação é baseada em dados de 62 fontes independentes, incluindo 23 fluidos (água, refrigerantes, líquidos criogênicos, metais líquidos), diâmetros de 0,315 até $37,5 \mathrm{~mm}$, comprimentos de 1,3 até 940 vezes o diâmetro, pressões reduzidas de 0,0014 até 0,96, títulos de vapor de entrada entre -4 e 0,85. Erros médios absolutos de 16\% foram obtidos por Shah (1987), quando comparando sua correlação à totalidade de seus dados experimentais, enquanto a correlação de Katto e Ohno (1984), segundo Shah (1987), apresentou $22,3 \%$.

Quadro 2.1 - Métodos avaliados para o cálculo do fluxo crítico de calor.

\begin{tabular}{ll}
\hline Autor & Aplicação \\
\hline Katto e Ohno (1984) & FCC sub-resfriado em macrocanais escoamento vertical \\
Shah (1987) & FCC sub-resfriado e saturado em macrocanais escoamento vertical \\
Bowers e Mudawar (1994) & FCC sub-resfriado em multi-microcanais \\
Hall e Mudawar (2000) & FCC sub-resfriado macro e microcanais \\
Qu e Mudawar (2004) & FCC sub-resfriado em macrocanais escoamento vertical \\
$\begin{array}{l}\text { Wojtan, Revellin e Thome } \\
\text { (2006) }\end{array}$ & FCC saturado em microcanais \\
Zhang et al. (2006) & FCC saturado microcanais \\
Sarma et al. (2006) & FCC sub-resfriado e saturado em macro e microcanais \\
Revellin e Thome (2007b) & FCC saturado em microcanais \\
Ong e Thome (2011b) & FCC saturado em microcanais \\
\hline
\end{tabular}

Hall e Mudawar (2000), tendo por base 5544 pontos experimentais para escoamentos com água, desenvolveram um método para prever FCC em condições subresfriadas. Zhang et al. (2006) comparam um banco de dados obtido da literatura para condições saturadas e subresfriadas de FCC e métodos para sua previsão; o banco de dados continha resultados apenas para água e cobria diâmetros hidráulicos de $0,33 \mathrm{~mm}$ a 6,22mm, e concluíram que os métodos de Hall e Mudawar (2000) e Shah (1987), ambos baseados em dados para macro e microcanais, previram razoavelmente o FCC em condições subresfriada e saturada, respectivamente. É im- 
portante destacar que o banco de dados utilizado por Zhang et al. (2006) continha a maioria dos dados experimentais utilizados por Hall e Mudawar (2000).

Bowers e Mudawar (1994) desenvolveram uma correlação para FCC baseado em dados de escoamento saturado de R113 para dois distintos dissipadores de calor com canais circulares de $2,54 \mathrm{~mm}$ e $0,510 \mathrm{~mm}$. Posteriormente, Qu e Mudawar (2004) desenvolveram uma correlação baseada em Katto e Ohno (1984), considerando apenas resultados experimentais para diâmetros inferiores a 1,0mm. Ele utilizaram dados próprios para a água, levantados em dissipadores de calor compostos de multi-microcanais, e também para o R-113, levantados em estudo prévio de Bowers e Mudawar (1994).

Wojtan, Revellin e Thome (2006), com base em dados próprios para R134a e R245fa em microcanais com diâmetro de 0,5 e 0,8mm, ajustaram a correlação de Katto e Ohno (1984) e propuseram uma nova correlação para FCC em condições saturadas. Conseguiram prever seu banco de dados com erro médio absoluto de $7,6 \%$ utilizando essa nova correlação.

Zhang et al. (2006) propuseram uma correlação baseada em parâmetros adimensionais, utilizando uma rede neural artificial para identificar os parâmetros adimensionais predominantes em FFC saturado. Utilizaram banco de dados com mais de 2000 pontos experimentais para água e diâmetros variando entre 0,33 a $6,22 \mathrm{~mm}$. Essa correlação previu o banco de dados com erro de $16,8 \%$ e é recomendada por seus autores para aplicações com tubos de reduzido diâmetro.

Sarma et al. (2006), utilizando-se de dados para água levantados na literatura, propuseram duas correlações distintas para FCC saturado e sub-resfriado, cobrindo diâmetros de macro e microcanais. Os autores concluíram que as correlações válidas para microcanais também são válidas para canais convencionais até $37,5 \mathrm{~mm}$.

Posteriormente, Revellin e Thome (2007b) desenvolveram um modelo teórico para a previsão do FCC saturado, em condições estáveis e aquecimento uniforme em microcanais circulares. O método baseia-se no mecanismo de secagem local do filme líquido durante escoamento anular ondulado, conforme ilustrado na Figura 2.17, quando a espessura do filme líquido no vale das ondas interfaciais alcançam um valor limite de secagem. O modelo é baseado nas equações de conservação de massa, momento, energia, na equação de Laplace-Young e numa expressão semi- 
empírica para a altura das ondas da interface líquido-vapor. A validação do modelo foi realizada comparando a solução numérica do sistema não linear de cinco equações diferenciais, com um banco de dados experimental incluindo três diferentes refrigerantes (R134a, R245fa, e R113) de dois laboratórios independentes. Revellin e Thome (2007b) também concluíram que poderiam prever FCC saturado para canais retangulares usando a largura do canal como a dimensão característica em seu modelo unidimensional. Comparando resultados de FCC para R236fa em multimicrocanais contra métodos para previsão do FCC da literatura, Agostini et al. (2007) consideraram o método de previsão de Wojtan, Revellin e Thome (2006) como o melhor, seguido do modelo de Revellin e Thome (2007b), com uma diferença marginal entre os resultados alcançados por eles. Ong e Thome (2011b) modificaram a correlação de Wojtan, Revellin e Thome (2006), utilizando novos dados para tubos de 1,0, 2,2 e 3,0mm e adicionaram o número de confinamento, Co, com o intuito de capturar efeitos de transição entre micro e macrocanais, tal como a simetria do filme líquido no escoamento anular que ocorre em escoamentos em microcanais.

\subsection{CONCLUSÕES}

- Foram identificados na literatura critérios que permitem o cálculo do diâmetro de tubo a partir do qual mecanismos físicos associados a ebulição convectiva em microcanais começam a diferir dos mecanismos encontramos em escoamentos em macrocanais horizontais. À medida que se reduz o diâmetro do canal, os efeitos gravitacionais têm sua preponderância reduzida em relação aos efeitos de tensão superficial. Entretanto, tal transição não é caracterizada apenas através do confinamento de uma bolha em um tubo, assumindo-se que condições de ebulição em piscina, efeitos inerciais e de molhabilidade também devem ser considerados. $\mathrm{Na}$ literatura, geralmente adota-se o diâmetro de $3 \mathrm{~mm}$ como critério de transição entre macro e microcanal, critério este relacionado principalmente a questões de aplicação.

- Métodos de previsão de padrões de escoamento para ebulição convectiva em microcanais disponíveis na literatura, geralmente foram desenvolvidos de forma semi-empírica com ajuste de coeficientes através de banco de dados experimen- 
tais restritos, refletindo, dessa forma, as características dos resultados utilizados em sua formulação.

- Verifica-se um número crescente de métodos para previsão do coeficiente de transferência de calor em ebulição convectiva em microcanais. Correlações empíricas, semi-empíricas e modelos fenomenológicos têm sido apresentados. Modelos apropriados para cada padrão de escoamento têm sido propostos, entretanto tais métodos falham ao tentar prever resultados distintos daqueles presentes no banco de dados utilizado em seu desenvolvimento.

- Grandes avanços tem ocorrido na identificação dos mecanismos relacionados ao fluxo crítico de calor em microcanais. Mecanismos distintos foram identificados em condições saturadas e subresfriadas e, atualmente, correlações semiempíricas têm sido desenvolvidas com a intenção de capturar seus efeitos. 


\section{COMPARAÇÃO ENTRE DADOS EXPERIMENTAIS DA LITERATURA E MÉTODOS DE PREVISÃO PARA MICROCANAIS}

Este capítulo trata da avaliação dos métodos para previsão do CTC e do FCC por meio de comparações com resultados experimentais levantados na literatura. $O$ objetivo principal do capítulo é identificar métodos de previsão do CTC e do FCC que possam ser indicados como ferramentas de projetos para trocadores de calor, tendo como base a ebulição convectiva em microcanais.

\subsection{TRANSFERÊNCIA DE CALOR}

Um extenso levantamento de dados experimentais na literatura foi realizado envolvendo resultados para o CTC durante a ebulição convectiva em microcanais. Essa base de dados contém mais de 2500 resultados experimentais e inclui 15 fluidos, velocidades mássicas de 50 a $1600 \mathrm{~kg} / \mathrm{m}^{2} \mathrm{~s}$ e CTC de até $40 \mathrm{~kW} / \mathrm{m}^{2} \mathrm{~K}$. Os dados foram analisados segundo as características geométricas das seções de testes, intervalos de velocidade mássica e fluxo de calor. Esses resultados foram segregados segundo os padrões de escoamento bolhas, bolhas alongadas (pistonado), anular e em névoa, utilizando mapas de escoamento para microcanais. Assim, modelos de previsão do coeficiente de troca de calor específicos para cada padrão foram avaliados através de comparações com os resultados experimentais. Também foram analisadas correlações específicas para microcanais, que não consideram padrões de escoamento.

\subsubsection{BANCO DE DADOS}

O Quadro 3.1 apresenta uma descrição sucinta do banco de dados obtidos na literatura a partir de tabelas e gráficos. Foram levantados resultados para a ebulição convectiva saturada de quinze fluidos refrigerantes, diâmetros hidráulicos variando de 0,4 a 3,6mm, geometrias de seção circular e retangular, comprimento da seção de testes variando de 75 a $3000 \mathrm{~mm}$, velocidades mássicas de 50 a 
$1635 \mathrm{~kg} / \mathrm{m}^{2} \mathrm{~s}$, fluxos de calor de 3 a $201 \mathrm{~kW} / \mathrm{m}^{2}$ e títulos de vapor de até $98 \%$ para escoamentos verticais e horizontais.

Embora a rugosidade superficial seja um fator relevante na determinação do coeficiente de transferência de calor para a ebulição convectiva em microcanais (QI et al., 2007), conforme ilustrado no Quadro 3.1, apenas um reduzido número de trabalhos forneceu tal característica.

Por meio de análise detalhada dos dados levantados na literatura, buscou-se identificar tendências similares obtidas por autores distintos para o coeficiente de transferência de calor com a variação dos parâmetros experimentais. Geralmente o coeficiente de transferência de calor eleva-se com o fluxo de calor, excetuando-se condições de títulos elevados em que efeitos de secagem de parede predominam. Resultados conflitantes foram observados em relação aos efeitos da velocidade mássica. Incrementos do CTC com a velocidade mássica foram indicados nas referências (PAMITRAN; CHOI, 2003; OWHAIB; PALM, 2003). Tran, Wambsganss e France (1996) e Qi et al. (2007) observaram redução do CTC com o incremento da velocidade mássica. No caso do diâmetro hidráulico, tanto a elevação como a redução do CTC, através do seu incremento, foram indicadas (QI et al., 2007). Coeficientes de transferência de calor superiores parecem ocorrer para títulos de vapor inferiores a 0,4 .

Diferenças significantes foram observadas entre os resultados de Owhaib e Palm (2003) e Agostini e Bontemps (2005), levantados para condições experimentais próximas, com Agostini e Bontemps (2005) obtendo um CTC 100\% superior ao de Owhaib e Palm (2003). O fato de Agostini e Bontemps (2005) terem utilizado microcanais com seção retangular e Owhaib e Palm (2003) circulares pode justificar parcialmente tal diferença. As arestas da seção retangular tendem a favorecer o surgimento de cavidades ativas e de regiões de filme de espessura inferior entre arestas, com ambos os efeitos elevando o valor do CTC. Fatores como instabilidades nos escoamento (KAKAC; BON, 2008; RIBATSKI; WOJTAN; THOME, 2006) podem também estar relacionados às divergências de tendências de resultados entre os autores, assim como erros experimentais e de regressão de dados, conforme indicado em Ribatski et al. (2007). 
Quadro 3.1 - Descrição de estudos envolvendo medição do coeficiente de transferência de calor em microcanais levantados neste estudo.

\begin{tabular}{|c|c|c|c|c|c|c|c|c|c|c|c|c|}
\hline Autor & Fluido & $\mathrm{G}\left(\mathrm{kg} \cdot \mathrm{m}^{-2} \mathrm{~s}^{-1}\right)$ & $\begin{array}{l}\mathrm{D}_{\mathrm{h} .} \mathrm{L}^{-1}(\mathrm{~mm}) / \\
\text { no. de canais }\end{array}$ & $\mathrm{T}_{\text {sat }}\left({ }^{\circ} \mathrm{C}\right)$ & $q\left(k W .^{m-2}\right)$ & $x(\%)$ & $\mathrm{h}\left(\mathrm{W} \cdot{ }^{\mathrm{m-2}} \mathrm{K}^{-1}\right)$ & $\begin{array}{c}\mathrm{Ra} \\
(\mu \mathrm{m})\end{array}$ & Direção & $\begin{array}{l}\text { Material } \\
\text { seção }\end{array}$ & $\begin{array}{l}\text { Geometria da } \\
\text { seção }\end{array}$ & $\begin{array}{l}\text { Método de } \\
\text { aquecimento }\end{array}$ \\
\hline $\begin{array}{c}\text { Wambsganss et al. } \\
\text { (1993) }\end{array}$ & R113 & $50-300$ & $2,9 / 368 / 1$ & $53-60$ & $8,8-90,75$ & $1,0-88,0$ & $1100-6300$ & - & Horizontal & $\begin{array}{c}\text { Aço } \\
\text { inoxidável }\end{array}$ & Circular & $\begin{array}{l}\text { a Própria seção } \\
\text { de teste }\end{array}$ \\
\hline $\begin{array}{l}\text { Tran, Wambsganss e } \\
\text { France (1996) }\end{array}$ & $\mathrm{R} 12$ & $63-300$ & 2,$4 ; 2,5 / 900 / 1$ & 34 & $7,5-59,4$ & $19,0-76,0$ & $\begin{array}{c}2100-10400 / \\
6,0-18,0\end{array}$ & - & Horizontal & Latão & Circular & $\begin{array}{l}\text { a Própria seção } \\
\text { de teste }\end{array}$ \\
\hline Yan e Lin (1998) & R134a & $50-100-200$ & 2/100/28 & $5-15-31$ & $5-15-20$ & $8,0-89,0 / 3$ & $\begin{array}{c}1200-6300 / \\
6\end{array}$ & - & Horizontal & - & Circular & $\begin{array}{l}\text { a Própria seção } \\
\text { de teste }\end{array}$ \\
\hline $\begin{array}{l}\text { Bao, Fletcher e Haynes } \\
(2000)\end{array}$ & $\begin{array}{c}\text { R123 } \\
\text { R11 }\end{array}$ & $\begin{array}{l}167-452 \\
167-550\end{array}$ & $2 / 270 / 1$ & $\begin{array}{l}67-81 \\
57-76\end{array}$ & $\begin{array}{c}39-125 \\
52-125\end{array}$ & $\begin{array}{l}1,0-68,0 \\
0,7-84,0\end{array}$ & $\begin{array}{l}4800-14100 / \\
6300-13100\end{array}$ & - & Horizontal & Cobre & Circular & $\begin{array}{l}{ }^{\mathrm{D}} \text { Resistência } \\
\text { externa }\end{array}$ \\
\hline $\begin{array}{c}\text { Lin, Kew e Cornwell } \\
\text { (2001) }\end{array}$ & R141b & 510 & $1,1 / 380 / 1$ & 47,5 & 18-72 & $0,7-88$ & $1400-5900$ & - & Vertical & - & Circular & 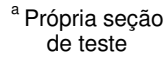 \\
\hline $\begin{array}{c}\text { Agostini e Bontemps } \\
\text { (2005) }\end{array}$ & R134a & $83 ; 467$ & $\begin{array}{c}0,8 ; 2 / \\
690 ; 695 / 11 ; 18\end{array}$ & 9,3 & $4,4-14,6$ & $0,4-86,0$ & $\begin{array}{c}1000-10800 / \\
3,0-7,5\end{array}$ & $<1$ & Vertical & Alumínio & Retangular & $\begin{array}{l}\text { a Própria seção } \\
\text { de teste }\end{array}$ \\
\hline Pamitran e Choi (2003) & $\begin{array}{l}\text { R410A } \\
\text { R407C }\end{array}$ & $300-600$ & $\begin{array}{l}1,5 ; 3 / 1500- \\
3000 / 1\end{array}$ & 10 & $\begin{array}{c}10 \\
5 ; 15\end{array}$ & $\begin{array}{c}1,0-87 \\
2,0-87 / 1,5- \\
10\end{array}$ & $\begin{array}{c}340-6500 \\
600-6300 / 2,5- \\
10,0\end{array}$ & - & Horizontal & $\begin{array}{l}\text { Aço } \\
\text { inoxidável }\end{array}$ & Circular & $\begin{array}{l}\text { a Própria seção } \\
\text { de teste }\end{array}$ \\
\hline Owhaib e Palm (2003) & R134a & $100-500$ & $0,8-1,2-1,7 / 310 / 1$ & 24 & 10 a 30 & $0,5-63$ & $1750-9500 / 17$ & - & Vertical & $\begin{array}{l}\text { Aço } \\
\text { inoxidável }\end{array}$ & Circular & $\begin{array}{l}\text { a Própria seção } \\
\text { de teste }\end{array}$ \\
\hline Yang e Fujita (2004) & R113 & $100 ; 200$ & 0,$4 ; 1,9 ; 3,6 / 100 / 1$ & 52 & $20-90$ & $0,8-89,0$ & $189-10000$ & - & Horizontal & Cobre & Retangular & $\begin{array}{l}{ }^{\mathrm{b}} \text { Resistência } \\
\text { elétrica }\end{array}$ \\
\hline Kim, Sim e Min (2004) & R22 & $200-600$ & $1,4 / 455 / 7$ & $5 ; 15$ & $5 ; 10 ; 15$ & $20,0-84,0$ & $2700-7400$ & - & Horizontal & Alumínio & Retangular & Água aquecida \\
\hline Bang e Choo (2004) & R22 & 600 & $1,7 / 305 / 1$ & 9,5 & $5,0-30$ & $10,0-81,0$ & $1000-4700$ & - & Horizontal & $\begin{array}{l}\text { Alumínio, } \\
\text { cobre, latẫo }\end{array}$ & Circular & $\begin{array}{l}{ }^{\mathrm{D}} \text { Resistência } \\
\text { elétrica }\end{array}$ \\
\hline Yun et al. (2004) & $\mathrm{R} 410 \mathrm{~A}$ & $200-400$ & $1,4 / 7$ & $5 ; 10$ & $10 ; 15 ; 20$ & $\begin{array}{c}0,5-86 / \\
4\end{array}$ & $8700-19800 / 9,5$ & - & Horizontal & - & Retangular & $\begin{array}{l}\text { a Própria seção } \\
\text { de teste }\end{array}$ \\
\hline Sobierska et al. (2006) & Água & $81-693$ & $1,2 / 300 / 1$ & 91 & $20-101$ & $0,1-44,0$ & $6000-16900$ & $<1$ & Vertical & Cobre & Retangular & $\begin{array}{l}\text { a Própria seção } \\
\text { de teste }\end{array}$ \\
\hline Diaz e Schmidt (2007) & Etanol & $100-500$ & $0,59 / 200 / 1$ & 76 & $11-188$ & $0,04-63,0$ & $4900-20800 / 15$ & - & Vertical & Níquel & Retangular & $\begin{array}{l}\text { a Própria seção } \\
\text { de teste }\end{array}$ \\
\hline Qi et al. (2007) & $\mathrm{N}_{2}$ & $460-1685$ & $\begin{array}{l}0,5 ; 1,0 ; 1,9 / \\
250 / 1\end{array}$ & $\begin{array}{l}-177- \\
-190\end{array}$ & $81-135$ & $\begin{array}{c}1,0-79,0 / \\
3,2\end{array}$ & $2400-40000 / 8,5$ & 0,$6 ; 2,3$ & Vertical & $\begin{array}{c}\text { Aço } \\
\text { inoxidável }\end{array}$ & Circular & $\begin{array}{l}{ }^{\mathrm{D}} \text { Resistência } \\
\text { elétrica }\end{array}$ \\
\hline Consolini (2008) & $\begin{array}{l}\text { R134a } \\
\text { R236fa } \\
\text { R245fa }\end{array}$ & $\begin{array}{c}309-1435 \\
386-957 \\
305-812\end{array}$ & $\begin{array}{l}0,5 ; 0,8 / \\
75 / 1\end{array}$ & $\begin{array}{l}30 \\
30 \\
31\end{array}$ & $\begin{array}{c}12-201 \\
44-109 \\
3-113\end{array}$ & $\begin{array}{l}0,2-68,0 / \\
5,0-25,0\end{array}$ & $\begin{array}{c}1600-35500 \\
400-14500 \\
750-10300 / 3,5-\end{array}$ & 2,$4 ; 1,8$ & Horizontal & $\begin{array}{c}\text { Aço } \\
\text { inoxidável }\end{array}$ & Circular & $\begin{array}{l}\text { a Própria seção } \\
\text { de teste }\end{array}$ \\
\hline Ong (2010) & $\begin{array}{l}\text { R134a } \\
\text { R236fa } \\
\text { R245fa }\end{array}$ & $199-1608$ & 1,$03 ; 2,20,3,04$ & $\begin{array}{l}25 \\
31 \\
35\end{array}$ & $10-220$ & $0-90$ & $1000-25000$ & $\begin{array}{l}0,595 ; \\
0,827 \\
0,796\end{array}$ & Horizontal & $\begin{array}{c}\text { Aço } \\
\text { inoxidável }\end{array}$ & Circular & $\begin{array}{l}\text { a Própria seção } \\
\text { de teste }\end{array}$ \\
\hline
\end{tabular}

a A própria seção de testes é utilizada como resistência elétrica para gerar o aquecimento através de efeito Joule.

Uma resistência elétrica externa a seção de testes gera o aquecimento. 


\subsubsection{COMPARAÇÃO ENTRE MÉTODOS DE PREVISÃo DO CTC COM RESULTADOS EXPERIMENTAIS DA LITERATURA}

A Tabela 3.1 apresenta os resultados da comparação dos resultados experimentais com os valores estimados por meio dos métodos de previsão. O erro médio, $\varepsilon$, e a fração de dados previstos com erro inferior a $30 \%, \lambda$, dos valores experimentais foram adotados como parâmetros estatísticos na avaliação dos métodos. Os resultados apresentados nesta tabela envolvem comparações realizadas individualmente para cada estudo experimental e também para a totalidade dos dados levantados. Todos os resultados do banco de dados foram avaliados com as correlações empíricas e semi-empíricas. Os modelos teóricos de Revellin e Thome (2007b) e Qu e Mudawar (2003) foram avaliados para uma base de dados restrita após a segregação dos dados segundo padrões de escoamento.

Numa análise da Tabela 3.1, verifica-se que nenhum dos métodos avaliados proporciona estimativas razoáveis para o CTC durante a ebulição convectiva no interior de microcanais. Previsões próximas aos resultados experimentais são observadas quando se compara o método ao banco de dados utilizado no ajuste de seus coeficientes empíricos, como no modelo de Thome, Dupont e Jacobi (2004) para os dados de Wambsganss et al. (1993), Tran, Wambsganss e France (1996) e Lin, Kew e Cornwell (2001).

A correlação de Saitoh, Daiguji e Hihara (2007) desenvolvida com base em experimentos próprios e de outros autores para o R134a, apresentou resultados relativamente razoáveis $(\varepsilon=68,1 \%, \lambda=43,5 \%)$ para a totalidade do banco de dados. Entretanto, desvios inferiores são observados quando comparada a resultados envolvendo apenas o R134a (OWHAIB; PALM, 2003; YAN; LIN, 1998; AGOSTINI; BONTEMPS, 2005; CONSOLINI, 2008), conforme ilustrado na Figura 3.1.

A correlação de Liu e Winterton (1991), desenvolvida para ebulição convectiva em macrocanais, não proporcionou previsões satisfatórias. Isso permite especular que os mecanismos físicos relevantes em microcanais não são predominantes em macrocanais. 
Tabela 3.1 - Resultados da comparação entre o banco de dados descrito no Quadro 3.1 e os métodos para previsão do CTC.

\begin{tabular}{|c|c|c|c|c|c|c|c|c|}
\hline \multirow[b]{2}{*}{ Autor } & \multirow[b]{2}{*}{$\begin{array}{l}\text { № de } \\
\text { dados }\end{array}$} & & \multicolumn{6}{|c|}{ Correlações } \\
\hline & & & $\begin{array}{l}\text { Zhang et } \\
\text { al. } \\
(2004)\end{array}$ & $\begin{array}{l}\text { Thome, } \\
\text { Dupont e } \\
\text { Jacobi } \\
(2004)\end{array}$ & $\begin{array}{l}\text { Kandlikar e } \\
\text { Balasubma- } \\
\text { ranian (2004) }\end{array}$ & $\begin{array}{l}\text { Liu e } \\
\text { Winterton } \\
(1991)\end{array}$ & $\begin{array}{l}\text { Qi et al. } \\
(2007)\end{array}$ & $\begin{array}{l}\text { Saitoh, } \\
\text { Daiguji e } \\
\text { Hihara } \\
(2007)\end{array}$ \\
\hline \multirow[t]{2}{*}{ Wambsganss et al. (1993) } & 150 & $\varepsilon$ & 27,5 & 15,7 & 49,4 & 39,3 & 1539,6 & 26,8 \\
\hline & & $\lambda$ & 65,3 & 89,3 & 11,3 & 38,0 & 17,3 & 68,0 \\
\hline \multirow{2}{*}{$\begin{array}{l}\text { Tran, Wambsganss e } \\
\text { France (1996) }\end{array}$} & 87 & $\varepsilon$ & 14,3 & 10,5 & 68,4 & 24,9 & 317,7 & 11,0 \\
\hline & & $\lambda$ & 86,2 & 100,0 & 0,0 & 64,4 & 4,6 & 98,9 \\
\hline \multirow[t]{2}{*}{ Yan e Lin (1998) } & 119 & $\varepsilon$ & 22,3 & 40,7 & 59,8 & 31,8 & 396,5 & 29,1 \\
\hline & & $\lambda$ & 84,9 & 52,1 & 3,4 & 51,3 & 0,8 & 65,5 \\
\hline \multirow{2}{*}{$\begin{array}{l}\text { Bao, Fletcher e Haynes } \\
(2000)\end{array}$} & 101 & $\varepsilon$ & 21,8 & 11,6 & 41,7 & 37,8 & 190,0 & 15,8 \\
\hline & & $\lambda$ & 73,3 & 96,0 & 21,8 & 53,5 & 20,8 & 93,1 \\
\hline \multirow[t]{2}{*}{ Lin, Kew e Cornwell (2001) } & 90 & $\varepsilon$ & 136,8 & 29,7 & 22,9 & 309,2 & 437,6 & 114,6 \\
\hline & & $\lambda$ & 2,2 & 68,9 & 72,2 & 0,0 & 0,0 & 1,1 \\
\hline \multirow{2}{*}{$\begin{array}{l}\text { Agostini e Bontemps } \\
\text { (2005). }\end{array}$} & 196 & $\varepsilon$ & 51,6 & 48,9 & 66,8 & 55,0 & 184,4 & 56,1 \\
\hline & & $\lambda$ & 25,5 & 25,0 & 10,2 & 34,7 & 13,3 & 24,0 \\
\hline \multirow[t]{2}{*}{ Pamitran e Choi (2003) } & 164 & $\varepsilon$ & 115,1 & 109,9 & 69,8 & 98,2 & 1159,1 & 76,7 \\
\hline & & $\lambda$ & 17,7 & 18,3 & 39,6 & 30,5 & 0,0 & 45,1 \\
\hline \multirow[t]{2}{*}{ Owhaib e Palm (2003) } & 109 & $\varepsilon$ & 22,8 & 57,0 & 45,6 & 67,3 & 258,7 & 20,2 \\
\hline & & $\lambda$ & 73,4 & 34,9 & 29,4 & 31,2 & 13,8 & 75,2 \\
\hline \multirow[t]{2}{*}{ Yang e Fujita (2004) } & 477 & $\varepsilon$ & 61,0 & 46,5 & 71,7 & 43,1 & 885,4 & 80,9 \\
\hline & & $\lambda$ & 44,0 & 42,6 & 14,5 & 61,2 & 13,8 & 36,7 \\
\hline \multirow[t]{2}{*}{ Kim, Sim e Min (2004) } & 41 & $\varepsilon$ & 36,7 & 28,7 & 26,3 & 44,1 & 474,6 & 20,5 \\
\hline & & $\lambda$ & 48,8 & 56,1 & 70,7 & 41,5 & 0,0 & 78,0 \\
\hline \multirow[t]{2}{*}{ Bang e Choo (2004) } & 110 & $\varepsilon$ & 273,1 & 114,1 & 209,1 & 260,0 & 1995,3 & 207,4 \\
\hline & & $\lambda$ & 0,0 & 0,0 & 0,0 & 0,0 & 0,0 & 0,0 \\
\hline \multirow[t]{2}{*}{ Yun et al. (2004) } & 156 & $\varepsilon$ & 47,8 & 40,3 & 69,4 & 43,5 & 64,0 & 57,8 \\
\hline & & $\lambda$ & 12,2 & 26,9 & 0,0 & 23,1 & 34,6 & 0,6 \\
\hline \multirow[t]{2}{*}{ Sobierska et al. (2006) } & 138 & $\varepsilon$ & 74,3 & 178,0 & 83,9 & 159,8 & 44,4 & 49,6 \\
\hline & & $\lambda$ & 34,1 & 0,0 & 29,0 & 14,5 & 5,1 & 36,2 \\
\hline \multirow[t]{2}{*}{ Diaz e Schmidt (2007) } & 379 & $\varepsilon$ & 31,5 & 144,0 & 220,1 & 274,2 & 397,9 & 80,0 \\
\hline & & $\lambda$ & 50,7 & 14,8 & 0,8 & 8,2 & 2,1 & 27,2 \\
\hline \multirow[t]{2}{*}{ Qi et al. (2007) } & 183 & $\varepsilon$ & 111,5 & 52,0 & 140,7 & 1723,9 & 118,7 & 85,6 \\
\hline & & $\lambda$ & 26,8 & 21,9 & 20,2 & 0,0 & 39,3 & 43,2 \\
\hline \multirow[t]{2}{*}{ Consolini (2008) * } & 154 & $\varepsilon$ & 32,6 & 30,3 & 37,1 & 342,9 & 43,9 & 23,8 \\
\hline & & $\lambda$ & 40,3 & 57,8 & 48,1 & 0,0 & 44,2 & 72,7 \\
\hline \multirow[t]{2}{*}{ Total } & 2654 & $\varepsilon$ & 68,8 & 72,1 & 94,8 & 272,9 & 530,5 & 68,1 \\
\hline & & $\lambda$ & 43,2 & 39,0 & 18,1 & 27,6 & 15,1 & 43,5 \\
\hline
\end{tabular}

*Somente dados com R134a 


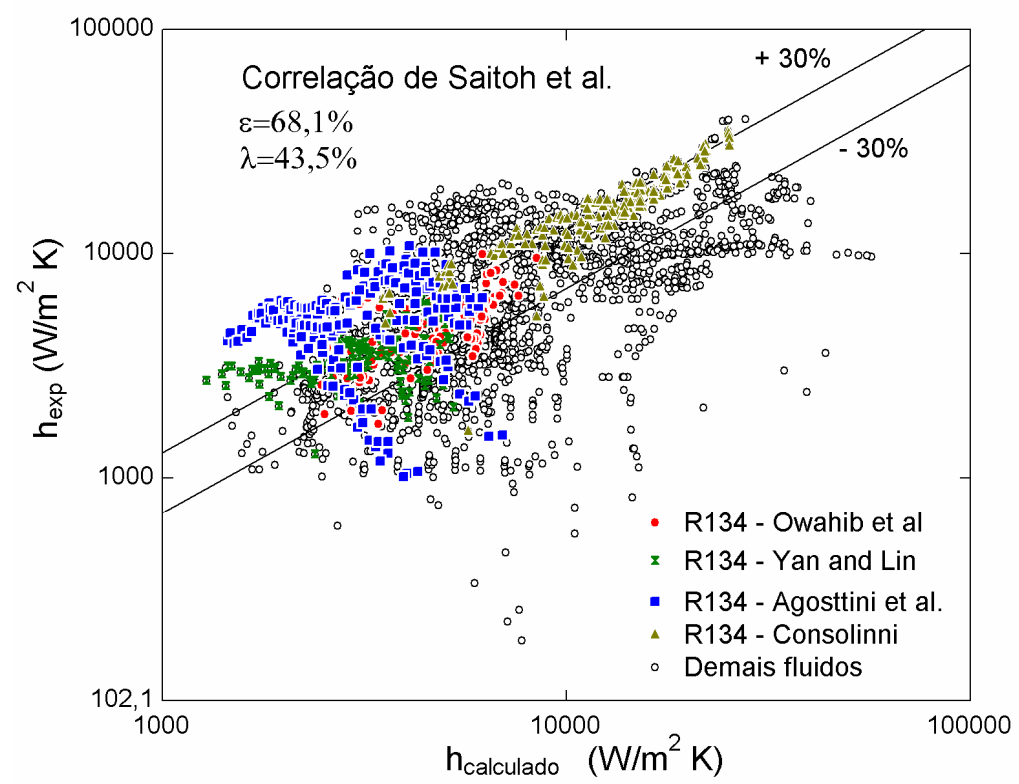

Figura 3.1 - Comparação da correlação de Saitoh, Daiguji e Hihara (2007) com o banco de dados experimentais levantados para este estudo.

O mapa de escoamento para microcanais de Revellin e Thome (2007a) foi utilizado para classificar o padrão de escoamento do banco de dados apresentado no Quadro 3.1. A Tabela 3.2 apresenta os resultados das comparações das correlações empíricas e semi-empíricas com os dados segregados segundo o padrão de escoamento.

No padrão bolhas, esperava-se que a correlação de Cooper (1984) apresentasse melhores resultados, pois o efeito de ebulição nucleada é considerado por diversos autores (QI et al., 2007; DIAZ; SCHMIDT, 2007) como o principal mecanismo de transferência de calor para este padrão.

O modelo semi-empírico de Thome, Dupont e Jacobi (2004), desenvolvido para escoamentos em bolhas alongadas, não previu razoavelmente resultados para esse padrão de escoamento. Uma explicação para tal resultado pode estar relacionada ao fato da utilização, por estes autores, de um banco de dados com maior abrangência que o utilizado por Thome, Dupont e Jacobi (2004) e, dessa forma, os coeficientes empíricos por eles propostos em seu modelo não se adéquam aos resultados da literatura levantados no presente estudo.

Resultados estimados a partir do modelo teórico para escoamento anular de Revellin e Thome (2007b) encontram-se ilustrados na Figura 3.2. Nesta, eles são 
comparados aos resultados experimentais de Consolini (2008). Para essa comparação, o CTC foi dado pela razão entre $k_{l}$ e $\delta$, onde a espessura do filme foi calculada a partir do modelo de Revellin e Thome (2007b). Nessa figura, nota-se que os resultados fornecidos pelo modelo são de uma ordem de grandeza inferiores aos experimentais. O modelo teórico para regime anular de Qu e Mudawar (2003) também apresentou erros elevados para os dados classificados como regime anular.

Tabela 3.2 - Comparação entre os métodos de previsão e o banco de dados, com classificação segundo padrões de escoamento utilizando Revellin e Thome (2007a).

\begin{tabular}{|c|c|c|c|c|c|c|c|c|c|c|}
\hline \multirow[b]{2}{*}{$\begin{array}{c}\text { Padrão/ } \\
\text { №-pontos }\end{array}$} & & \multicolumn{7}{|c|}{ Correlação } & \multirow[b]{2}{*}{$\begin{array}{l}\text { Qi et al. } \\
\text { (2007) }\end{array}$} & \multirow[b]{2}{*}{$\begin{array}{c}\text { Saitoh, } \\
\text { Daiguji } \\
\text { Hihara } \\
(2007) \\
\end{array}$} \\
\hline & & $\begin{array}{l}\text { Cooper } \\
\text { (1984) }\end{array}$ & $\begin{array}{c}\text { Dittus e } \\
\text { Boelter } \\
(1930)\end{array}$ & $\begin{array}{c}\text { Gnielinski } \\
(1976)\end{array}$ & $\begin{array}{c}\text { Zhang, } \\
\text { Hibiki e } \\
\text { Mishima e } \\
(2004)\end{array}$ & $\begin{array}{c}\text { Thome, } \\
\text { Dupont e } \\
\text { Jacobi } \\
(2004)\end{array}$ & $\begin{array}{c}\text { Kandlikar e } \\
\text { Balasub- } \\
\text { maranian } \\
(2004)\end{array}$ & $\begin{array}{c}\text { Liu e } \\
\text { Winterton } \\
\text { (1991) }\end{array}$ & & \\
\hline Bolhas/ & $\varepsilon$ & 42,4 & - & - & 41,5 & 122,3 & 535,0 & 205,3 & 748,6 & 38,2 \\
\hline 231 & $\lambda$ & 40,3 & - & - & 38,1 & 31,6 & 28,6 & 18,2 & 10,4 & 48,5 \\
\hline Pistonado/ & $\varepsilon$ & 43,4 & - & - & 51,2 & 76,1 & 349,4 & 133,2 & 554,2 & 46,5 \\
\hline 1331 & $\lambda$ & 41,3 & - & - & 45,1 & 37,0 & 16,6 & 31,6 & 10,2 & 42,7 \\
\hline Anular/ & $\varepsilon$ & - & - & - & 74,2 & 61,5 & 5010,4 & 341,3 & 427,3 & 81,0 \\
\hline 1041 & $\lambda$ & - & - & - & 42,5 & 43,3 & 19,1 & 28,7 & 22,9 & 43,3 \\
\hline Névoa/ & $\varepsilon$ & - & 71,1 & 73,5 & - & - & - & - & - & - \\
\hline 204 & $\lambda$ & - & 9,8 & 7,8 & - & - & - & - & - & - \\
\hline
\end{tabular}

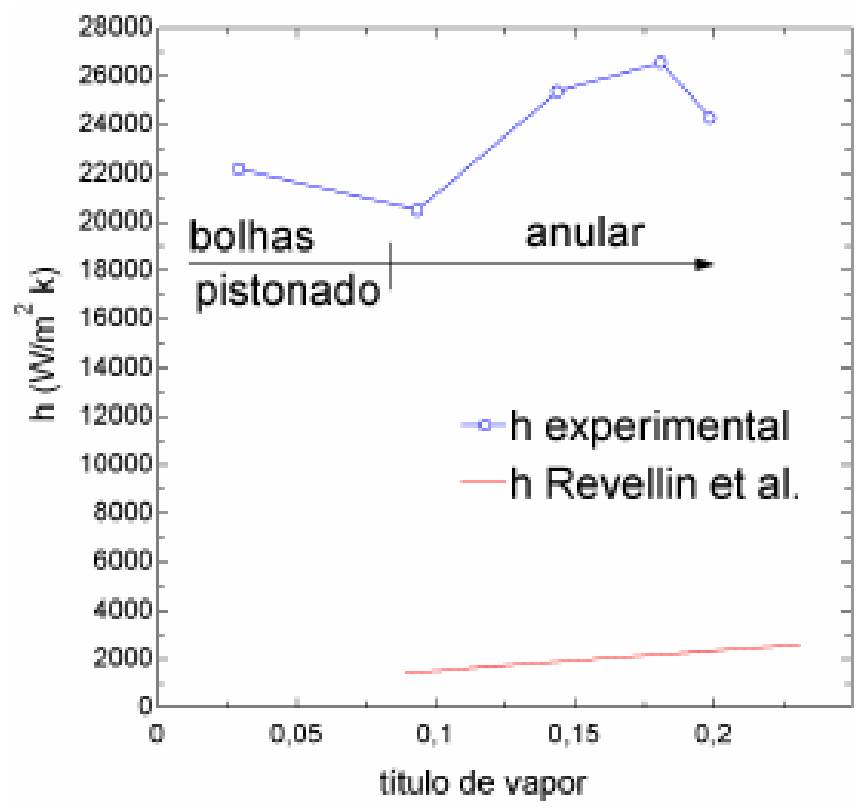

Figura 3.2 - Comparação entre o modelo de Revellin e Thome (2007b) para escoamento anular e os dados de Consollini (2008). (R134a, $D=0,5 \mathrm{~mm} ; q=108 \mathrm{~kW} / \mathrm{m}^{2} ; G=1435 \mathrm{~kg} / \mathrm{m}^{2} \mathrm{~s}$; $L=75 \mathrm{~mm}$ ). Padrão de escoamento determinado segundo Revellin e Thome (2007a). 
Para o escoamento em névoa, devido à inexistência de um modelo específico para esse padrão em microcanais, adotou-se para comparação o modelo para cálculo do CTC dado segundo os métodos de Gnielinski (1976) e Dittus e Boelter (1930), com as propriedades de transporte calculadas segundo o modelo homogêneo. Entretanto tal procedimento não forneceu previsões próximas aos resultados experimentais conforme apresentado na Tabela 3.2. Observando-se detalhadamente os resultados, em termos de comportamento do CTC, percebeu-se que parcela significativa dos dados classificados segundo Revellin e Thome (2007a), como póssecagem de parede, apresentam comportamento típico de transição entre anular e névoa, isto é, o coeficiente de transferência de calor decresce progressivamente com a elevação do título de vapor, até que ocorra a completa secagem da parede. Resultados experimentais com títulos de vapor próximos a 1, e classificados como névoa pelo mapa de Revellin e Thome (2007a), foram previstos razoavelmente pelo modelo homogêneo através das correlações de Gnielinski (1976) e Dittus e Boelter (1930). Outro fator não considerado nesta análise, e que pode influenciar consideravelmente o valor do CTC no regime em névoa, é a deposição na superfície aquecida de gotas de líquido suspensas no vapor. Cheng et al. (2008) indicaram a elevação do CTC com o título de vapor, para valores elevados de título de vapor, comportamento segundo eles relacionado a tal mecanismo.

\subsection{FLUXO CRÍTICO DE CALOR}

Resultados experimentais para o FCC em microcanais, para configurações em um único e em múltiplos microcanais, foram levantados da literatura. $O$ banco de dados obtido dessa forma contém mais de 1000 resultados experimentais e compreende tanto resultados de FCC sub-resfriado como saturado, cobrindo 7 fluidos, ampla faixa de velocidades mássicas e valores FCC de até $276 \mathrm{MW} / \mathrm{m}^{2}$. Nove métodos de previsão de FCC para canais convencionais e microcanais foram comparados ao banco de dados experimentais levantado. 


\subsubsection{BANCO DE DADOS}

O banco de dados experimental aqui compilado, e descrito no Quadro 3.2, compreende dados de FCC saturado e sub-resfriado e foi obtido de tabelas e gráficos da literatura. Exceto pelos dados de Lazareck e Black (1982) e parte dos resultados de Lowdermilk, Lanzo e Siegel (1958), a maioria dos estudos listados no Quadro 3.2 foram realizados em seções de teste com diâmetro hidráulico entre $240 \mu \mathrm{m}$ e $3 \mathrm{~mm}$. O banco de dados do Quadro 3.2 cobre 6 fluidos (água, R113, $\mathrm{R} 134 \mathrm{a}, \mathrm{R} 123, \mathrm{CO}_{2}$ e hélio), faixa de velocidade mássica de 10,5 a $134000 \mathrm{~kg} / \mathrm{m}^{2} \mathrm{~s}$, temperaturas de saturação correspondentes a pressões reduzidas de $4,5 \times 10^{-7} \mathrm{a}$ 0,7672 , diâmetros hidráulicos de até $0,2 \mathrm{~mm}$, subresfriamentos na entrada da seção de testes chegando ao valor de $329^{\circ} \mathrm{C}$ (operação próxima ao ponto crítico da água) e fluxos críticos de calor de até $276 \mathrm{MW} / \mathrm{m}^{2}$. Os ensaios foram conduzidos em configuração de único e de múltiplos microcanais; todas as superfícies de testes foram aquecidas aplicando-se corrente contínua à seção de testes.

Quadro 3.2 - Banco de dados para FCC em microcanais.

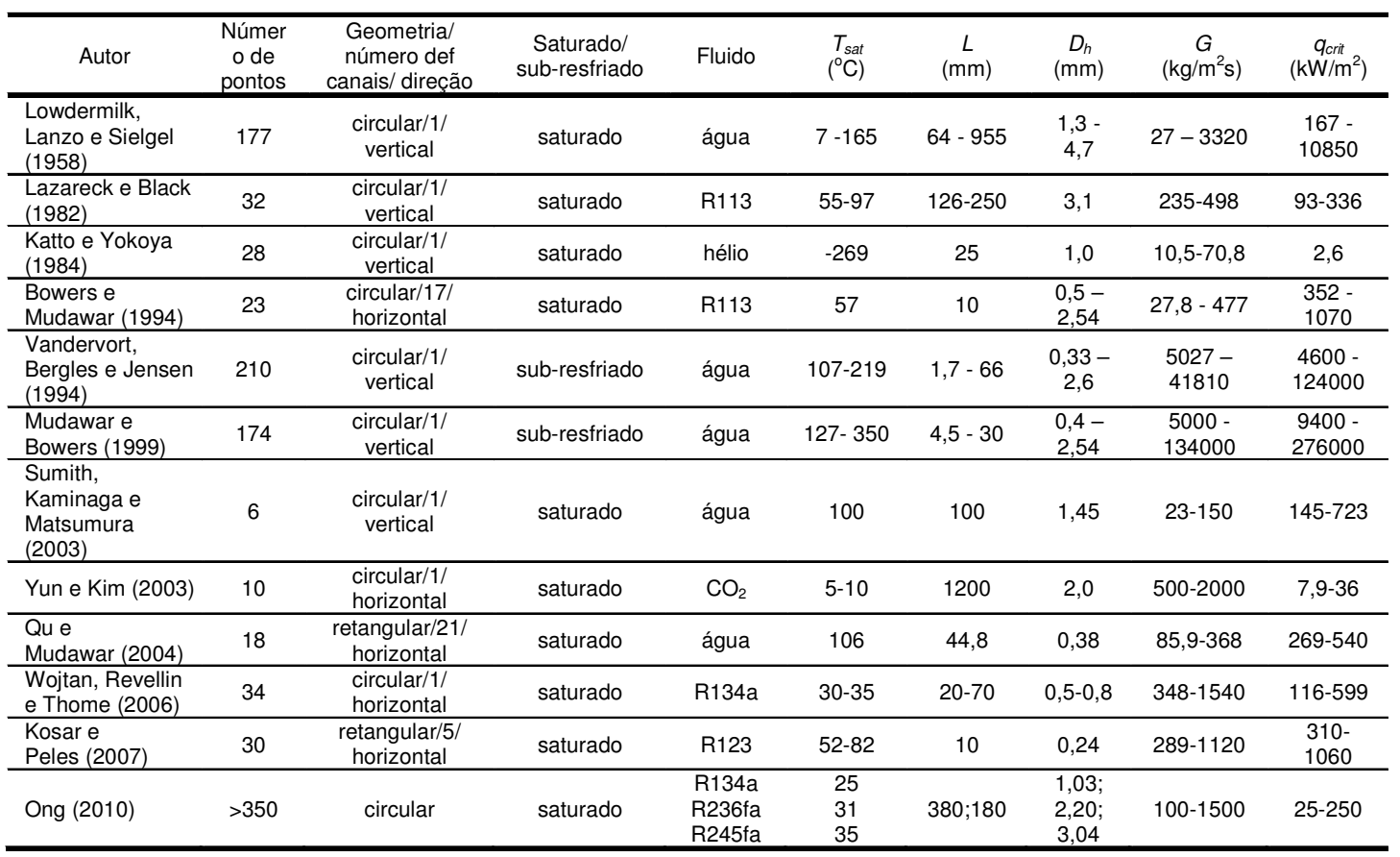




\subsubsection{COMPARAÇÃO ENTRE MÉTOdOS DE PREVISÃO DO FCC COM RESULTADOS EXPERIMENTAIS DA LITERATURA}

Nove métodos para previsão de FCC foram avaliados através de comparações com os dados experimentais descritos no Quadro 3.2. A Tabela 3.3 apresenta os resultados estatísticos dessa análise, para o banco de dados abrangendo resultados para condições saturada e subresfriada. O método de Shah (1987) apresentou a maior parcela de dados prevista com erro inferior a $\pm 30 \%$ e o menor erro médio absoluto. No caso de dados somente saturados, o método de Revellin e Thome (2007b) apresentou previsões mais próximas aos resultados, segundo os critérios estatísticos utilizados. Entretanto, ao contrário de outros métodos, deve ser mencionado que o modelo de Revellin e Thome (2007b) foi avaliado sem a inclusão dos dados de Qu e Mudawar (2004) e Lowdermilk, Lanzo e Siegel (1958), devido ao fato de que para esses bancos de dados não ocorreu convergência na solução numérica desse modelo. O método de Zhang et al. (2006) também apresentou resultados razoáveis para FCC saturado. Assim, considerando que sua análise envolveu um banco de dados mais extenso, e por apresentar uma implementação simples, esse método é indicado aqui para previsão de FCCs saturados em microcanais. Para FCC sub-resfriado, o método proposto por Hall e Mudawar (2000) apresentou desvios em relação aos dados experimentais inferiores aos demais.

Tabela 3.3 - Comparação dos métodos de previsão de FCC com os dados experimentais descritos no Quadro 3.2.

\begin{tabular}{|c|c|c|c|c|c|c|c|c|c|c|c|}
\hline & $\begin{array}{l}\mathrm{N}^{0} \text { de } \\
\text { pontos }\end{array}$ & & $\begin{array}{c}\text { Katto e } \\
\text { Ohno } \\
(1984)\end{array}$ & $\begin{array}{l}\text { Shah } \\
(1987)\end{array}$ & $\begin{array}{c}\text { Bowers e } \\
\text { Mudawar } \\
(1994)\end{array}$ & $\begin{array}{c}\text { Hall e } \\
\text { Mudawar } \\
(2000)\end{array}$ & $\begin{array}{l}\text { Qu e } \\
\text { Mudawar } \\
(2004)\end{array}$ & $\begin{array}{l}\text { Sarma et } \\
\text { al. (2006) }\end{array}$ & $\begin{array}{c}\text { Wojtan, } \\
\text { Revellin } \\
\text { e Thome } \\
(2006)\end{array}$ & $\begin{array}{l}\text { Zhang et al. } \\
\qquad(2006)\end{array}$ & $\begin{array}{l}\text { Revellin } \\
\text { e Thome } \\
(2007)\end{array}$ \\
\hline \multirow{2}{*}{ Sat+Sub } & & $\varepsilon(\%)$ & 62,2 & 38,4 & - & - & - & 54,1 & - & - & - \\
\hline & 748 & $\lambda(\%)$ & 45,3 & 59,7 & - & - & - & 16,2 & - & - & - \\
\hline \multirow[b]{2}{*}{ Saturado } & & $\varepsilon(\%)$ & 54,7 & 49,1 & 124,3 & - & 1856,4 & 63,6 & 60,6 & 45,6 & $20,8^{*}$ \\
\hline & 348 & $\lambda(\%)$ & 54,8 & 56,3 & 19,5 & - & 11,5 & 14,1 & 58,1 & 65,8 & $81,5^{*}$ \\
\hline & & $\varepsilon(\%)$ & 68,8 & 29,1 & - & 22,8 & - & 45,9 & - & - & - \\
\hline Subresfriado & 400 & $\lambda(\%)$ & 37.0 & 62,7 & - & 77,7 & - & 18,0 & - & - & - \\
\hline
\end{tabular}

*Avaliado sem os bancos de dados de Qu e Mudawar (2004) e Lowdermilk, Lanzo e Siegel (1958).

Os métodos mencionados acima também foram comparados com 300 dados experimentais levantados para macrocanais por Pioro et al. (2002) e Katto e Yokoya (1982), com diâmetro hidráulicos de 6,92mm e 5,0mm, respectivamente. A correla- 
ção de Shah (1987) foi capaz de prever esses resultados com razoável precisão, apresentando, $\varepsilon=16,8 \%$ e $\lambda=86,3 \%$.

Comparações individuais para os bancos de dados também foram conduzidas. De acordo com essas comparações, o método de Shah (1987) apresenta as melhores previsões dos resultados de Katto e Yokoya (1982), Bowers e Mudawar (1994), Pioro et al. (2002) e Sumith, Kaminaga e Matsumura (2003). Resultados satisfatórios foram também observados nas comparações envolvendo o método de Shah (1987) com os dados experimentais de Lowdermilk, Lanzo e Siegel (1958), Vandervort, Bergles e Jensen (1994) e Wojtan, Revellin e Thome (2006), apresentando $\lambda$ superior a $70 \%$. Adicionalmente, constatou-se que o método de FCC proposto por Revellin e Thome (2007b), embora desenvolvido para a configuração de um único microcanal, apresentou resultados satisfatórios para configurações de multicanais, prevendo, com reduzida margem de erro, resultados independentes para esta configuração. Vale ressaltar que um número reduzido de resultados para multicanais foram considerados por Revellin e Thome (2007b) para o ajuste da correlação da altura de ondas na interface. Tal fato se torna curioso, pois interações entre microcanais vizinhos e a configuração do distribuidor do dissipador de calor baseado em multicanais podem afetar o processo de ebulição, a distribuição do escoamento bifásico através dos microcanais e, consequentemente, o valor do FCC.

\subsection{Conclusões}

- Foram levantados na literatura mais de 2500 dados experimentais para o coeficiente de transferência de calor durante a ebulição convectiva no interior de microcanais. Esses resultados foram analisados, segregados segundo padrões de escoamento e comparados a valores estimados através de correlações e modelos disponíveis na literatura. Dessa análise comparativa, conclui-se que, de uma forma geral, os métodos disponíveis falharam na previsão da transferência de calor durante a ebulição convectiva em microcanais. A correlação proposta por Saitoh, Daiguji e Hihara (2007) para a ebulição convectiva no interior de microcanais, baseada exclusivamente em resultados para o R134a, apresentou previsões melhores que as demais quando comparadas ao banco de dados em sua totalidade. A correlação de Cooper (1984) desenvolvida para a ebulição nucleada em piscina 
apresentou as melhores previsões do CTC para os padrões de escoamento em bolhas e bolhas alongadas, embora para este último padrão, a nucleação de boIhas não parece ser um mecanismo relevante.

- Métodos de previsão de transferência de calor adequados para cada padrão de escoamento estão em desenvolvimento, mas os métodos disponíveis ainda não podem ser adotados como ferramentas confiáveis de projeto.

- A comparação do banco de dados de FCC para microcanais, obtido na literatura com nove métodos de previsão, revelou que a correlação de Shah (1987) estima os dados experimentais envolvendo resultados para condições saturadas e subresfriadas com desvios inferiores aos demais. O método de Zhang et al. (2006) mostrou-se mais adequado para o banco de dados envolvendo apenas resultados para condições de FCC saturado e a correlação de Hall e Mudawar (2004) para FCC sub-resfriado. 


\section{EQUIPAMENTO E PROCEDIMENTO EXPERIMENTAL}

Este capítulo descreve as bancadas utilizadas para a obtenção dos resultados experimentais, o procedimento experimental adotado e características da seção de testes e do sistema de visualização do escoamento com a câmera de alta velocidade. São descritos o sistema de aquisição de dados, os sensores e atuadores utilizados. As condições experimentais ensaiadas são definidas e a redução de dados é detalhada. Por último, são apresentadas as incertezas experimentais e a validação do aparato experimental. É importante ressaltar que duas bancadas experimentais foram utilizadas, a primeira sobre responsabilidade do Professor Gherhardt Ribatski situada no campus da USP de São Carlos e a segunda sobre responsabilidade do Professor John Richard Thome, situada no LTCM/EPFL, em Lausanne, Suíça. A utilização de duas bancadas independentes permitiu avaliar a repetibilidade dos resultados experimentais em laboratórios distintos, fato que ainda não havia sido realizado segundo a literatura sobre microcanais.

\subsection{BANCADA EXPERIMENTAL I (USP-SÃo CARLOS)}

A Figura 4.1 apresenta o diagrama esquemático do circuito de testes utilizado. $O$ aparato experimental inclui ainda um circuito auxiliar que atua no controle térmico (resfriamento e aquecimento) do fluido refrigerante no circuito de testes. A Figura 4.2 apresenta a fotografia da bancada construída. Para a promoção do deslocamento do fluido de testes é utilizada uma microbomba, com a vazão de refrigerante sendo regulada por um variador de frequência, através da rotação da bomba. Assim, o fluido refrigerante escoa a partir do tanque aquecido sendo sub-resfriado no trocador de calor "iv", tendo, a seguir, sua vazão mássica determinada pelo medidor do tipo "Coriolis". A partir disso, o fluido refrigerante escoa através da válvula tipo agulha I que tem como função não apenas o ajuste da vazão, mas também impor uma queda de pressão ao fluido circulante, reduzindo a propagação de instabilidades a partir da superfície de testes comumente verificadas na evaporação em microcanais. Em seguida, o refrigerante é novamente sub-resfriado e sua entalpia es- 
timada na entrada do pré-aquecedor, com a determinação de sua temperatura e pressão.

(T) termopar
(P) transdutor de pressao
Tr terma-resistencias
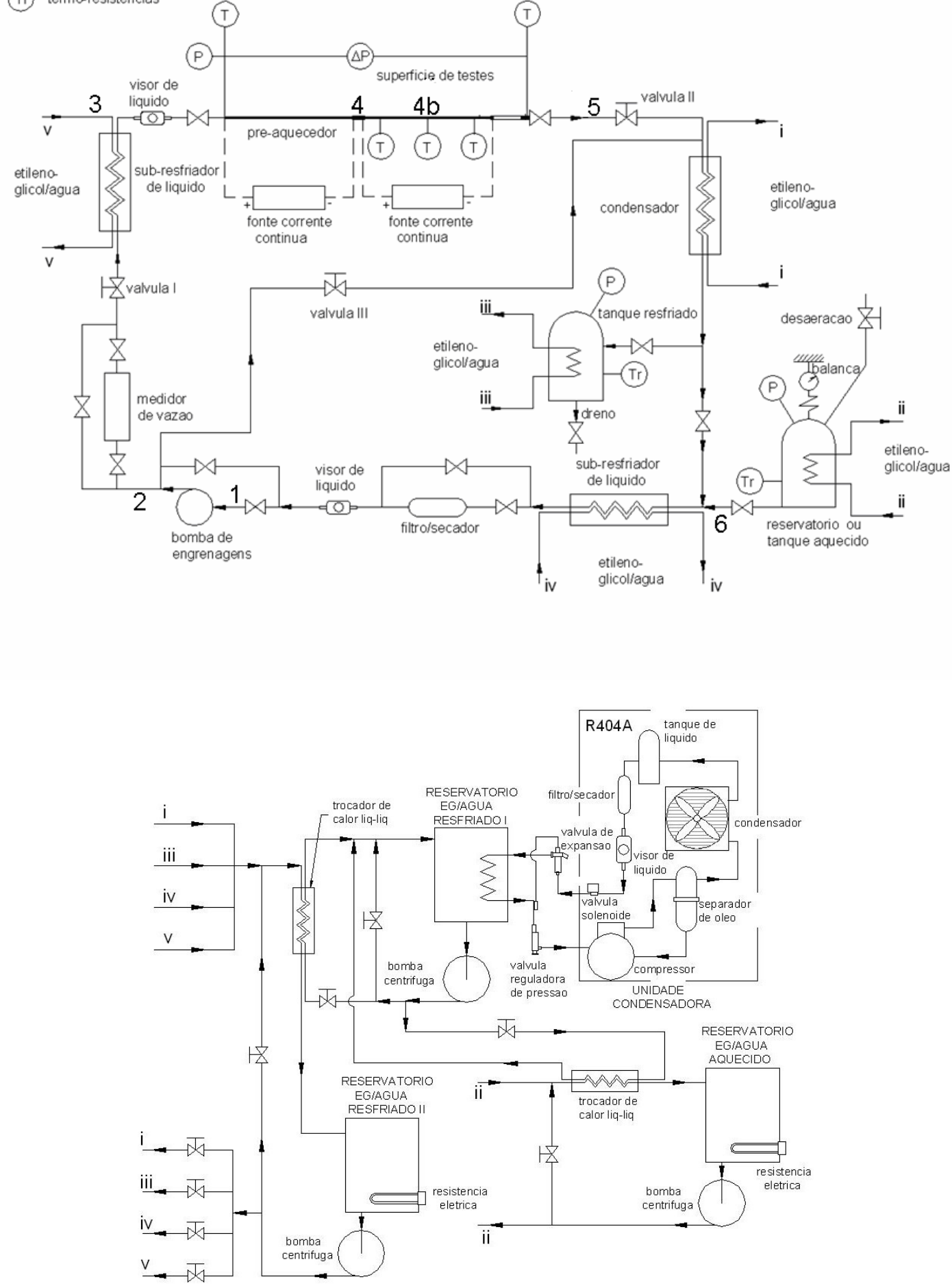

Figura 4.1 - Diagrama esquemático da seção de testes e circuito auxiliar. 
No pré-aquecedor, o fluido de testes é aquecido até a condição de ensaio, onde através de balanço de energia pode-se estimar sua entalpia na entrada da superfície de testes. A superfície de testes e o pré-aquecedor são aquecidos por efeito Joule, com a aplicação de corrente contínua direta. A potência fornecida é estimada a partir dos valores de corrente e tensão medidos pela fonte de alimentação. Na saída da seção de testes, pressão e temperatura são novamente determinadas, respectivamente por um medidor de pressão diferencial e um termopar. Um microtransdutor de pressão também foi instalado permitindo a observação de fenômenos de alta freqüência.

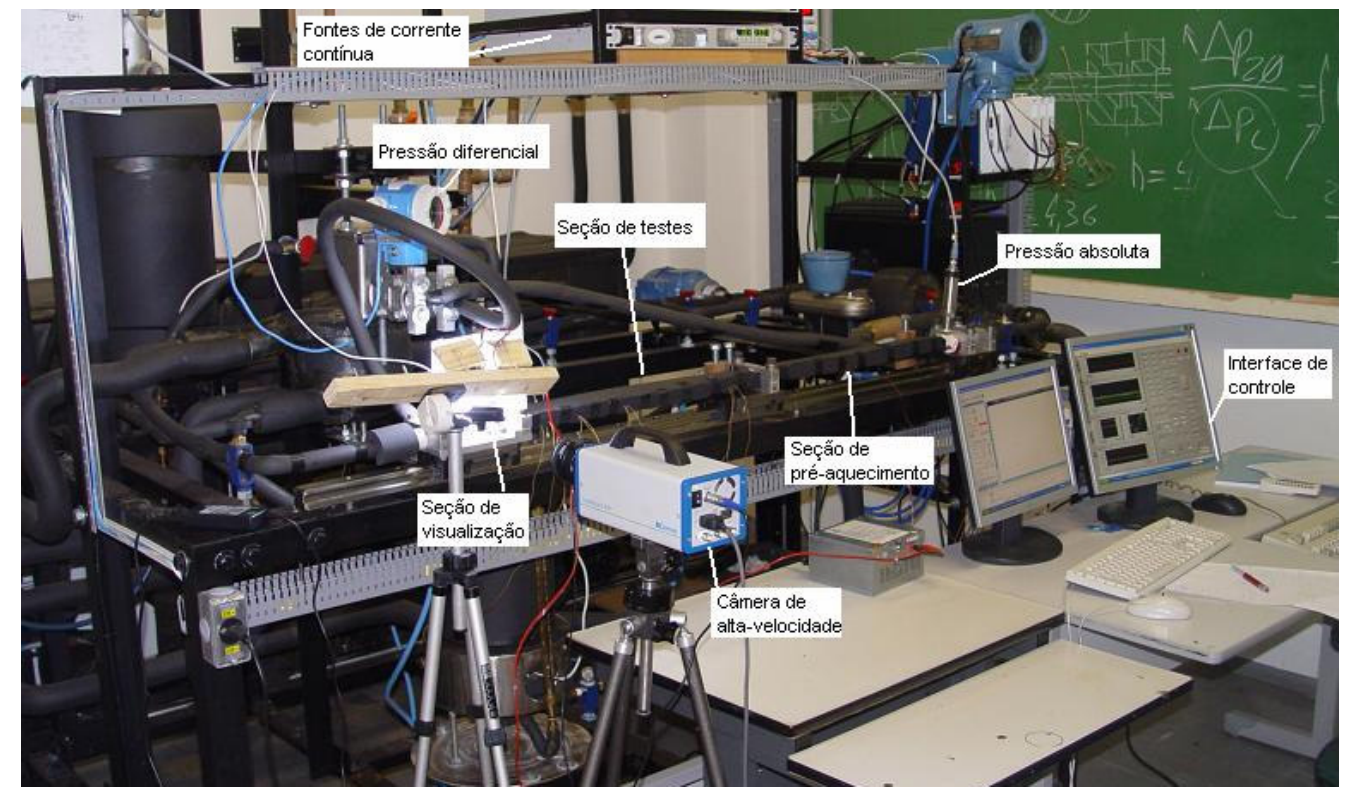

Figura 4.2 - Vista da bancada experimental utilizada.

Termopares tipo $\mathrm{K}$ distribuídos ao longo da superfície de testes são utilizados na determinação da temperatura superficial. Após passar pela superfície de testes, o refrigerante escoa através de uma seção transparente, onde imagens do escoamento são obtidas através de uma câmera digital de "vídeo-tape" rápido. A queda de pressão na superfície de testes e de pré-aquecimento é determinada por um transdutor de pressão diferencial. Após a seção de visualização, o refrigerante escoa pela válvula do tipo agulha II, com funções similares à válvula I, onde é condensado no trocador de calor "i" retornando a bomba de engrenagens. A pressão de operação na seção de testes é imposta através do reservatório (também denominado de tanque aquecido) com a retirada ou adição de fluido ao circuito de testes. Controlado- 
res PID, baseados no sinal de temperatura fornecido por termo-resistências localizadas nos tanques (ver Figura 4.1), atuando em resistências elétricas localizadas no circuito auxiliar, controlam a temperatura das soluções de etileno-glicol/água que escoam em serpentinas localizadas no interior dos tanques aquecido e resfriado, de forma a manter a pressão em seus interiores no valor desejado. Tais dispositivos são também utilizados na manobra de refrigerante na seção de testes.

O diagrama pressão-entalpia $(p-v)$ do circuito principal, relacionado a Figura 4.1 é mostrado na Figura 4.3 para o caso onde o fluido entra sub-resfriado na seção de testes. Nesta, o líquido da entrada da bomba, ponto 1, é comprimido até a pressão de saída da bomba em 2. Posteriormente ela passa por um sub-resfriador chegando ao ponto 3 , onde se encontra o pré-aquecedor. Neste, o grau de subresfriamento é ajustado antes de entrar na seção de testes em 4. Em 4b, o fluido se encontra na pressão de saturação e continua a evaporar até 5 , na saída da seção de testes, onde a temperatura medida é a temperatura de saturação utilizada como referência no experimentos. A partir de 5, o fluido é condensado até chegar no ponto 6 , onde ele se encontra à pressão do reservatório em estado de líquido saturado. Entre 6 e 1, o fluido é novamente sub-resfriado e o processo reiniciado.

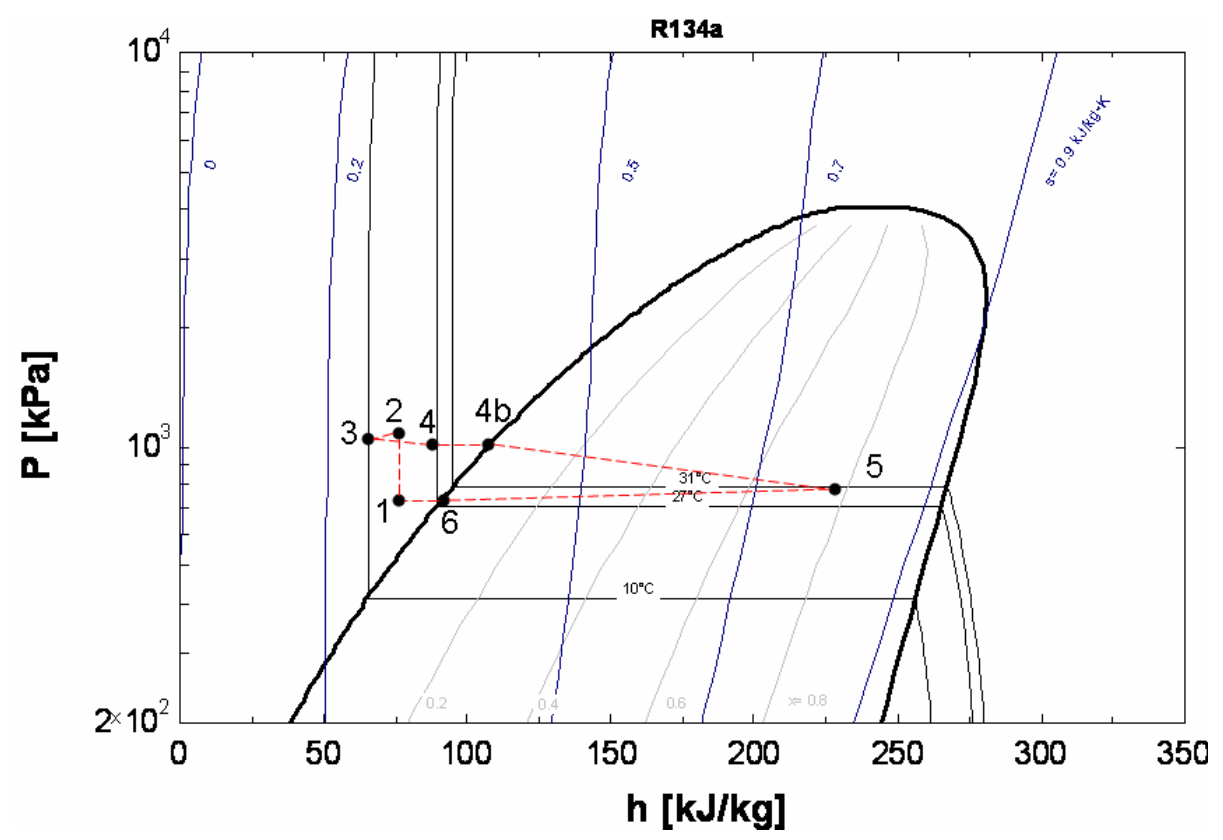

Figura 4.3 - Diagrama p-v do circuito de testes para R134a. 


\subsubsection{SEÇÃo dE TESTES}

\subsubsection{Tubo de $2,32 \mathrm{~mm}$}

A Figura 4.4 apresenta detalhes da instalação dos termopares e sensores de pressão utilizados nos ensaios com o tubo de $2,32 \mathrm{~mm}$. Tanto a seção de testes como a de pré-aquecimento são tubos circulares de $500 \mathrm{~mm}$ de comprimento, em aço inoxidável, com diâmetro interno de 2,32 $\mathrm{mm}$ e espessura da parede de $0,325 \mathrm{~mm}$. Os comprimentos aquecidos na seção de testes e no pré-aquecedor foram respectivamente $464 \mathrm{~mm}$ e $463 \mathrm{~mm}$. A rugosidade foi avaliada na superfície interna de um tubo similar ao usado nos experimentos através de um rugosímetro Taylor e Robson obtendo-se uma rugosidade média de $R a=0,33 \mu \mathrm{m}$.

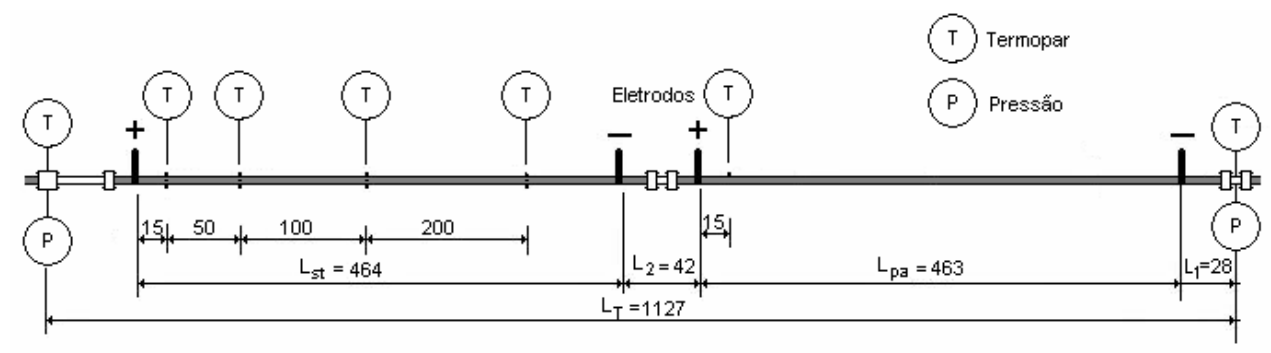

(a)

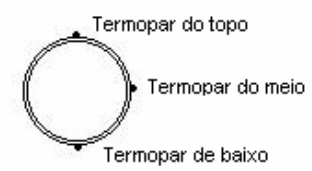

(b)

Figura 4.4 - Detalhes da seção de testes e do posicionamento dos termopares.

Foram instalados 12 termopares do tipo K (diâmetro da junção quente de $0,25 \mathrm{~mm}$ ) ao longo da superfície da seção de testes. Estes termopares foram colocados ao longo de 4 seções distintas do tubo, dispostos $90^{\circ}$ um do outro, do topo a base, como indicado na Figura 4.4b. Desta forma é possível verificar diferenças entre o coeficiente de transferência de calor ao longo do perímetro do tubo. A distribuição dos termopares ao longo da superfície de testes possibilita a determinação do CTC para distintos títulos de vapor para uma mesma condição de ensaio, já que o título de vapor eleva-se a medida que o fluido recebe calor do tubo. Para fixar os termopares adotou-se o seguinte procedimento: primeiro os termopares foram posicionados a $90^{\circ}$ um do outro numa seção, sendo então envoltos por três voltas de fita 
de kapton tensionadas. Por fim, um anel de vedação de borracha (o-ring) de diâmetro inferior ao tubo, foi posto sobre a fita, aumentando a pressão de contato. Através deste método buscou-se minimizar a resistência térmica de contato entre o tubo e o termopar. Todos os termopares foram isolados eletricamente da superfície de testes através de uma reduzida camada de esmalte para evitar interferência da fonte de corrente elétrica nas medidas. No pré-aquecedor instalou-se um termopar na superfície superior somente com a finalidade de detectar uma temperatura excessiva que pudesse danificar o tubo e suas conexões. Após a instalação dos termopares, ambas as seções foram envoltas com espuma isolante térmica Armaflex, conforme ilustrado na Figura 4.5.

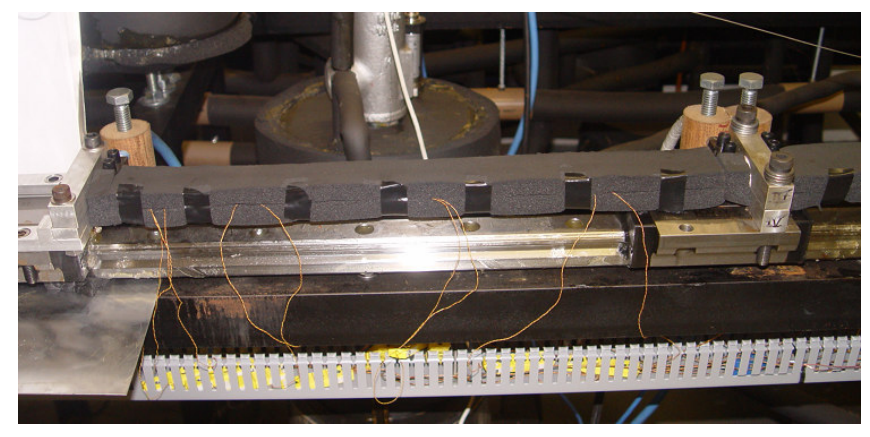

Figura 4.5 - Seção de testes com isolamento.

Para o isolamento da seção avaliou-se o raio crítico de isolamento com o objetivo de verificar o incremento da resistência térmica pelo material isolante. Para o diâmetro utilizado $\left(D_{i}=2,32 \mathrm{~mm}\right)$ considerando-se um CTC de convecção de $11 \mathrm{~W} / \mathrm{m}^{2} \mathrm{~K}$, estimado a partir da correlação de Churchill e Chu (1975) para convecção natural e um $k_{i s o}=0,03 \mathrm{~W} / \mathrm{m}$.K, obteve-se o raio crítico de isolamento igual a $2,7 \mathrm{~mm}$. O raio crítico de isolamento é dado por:

$$
r_{c r i t}=\frac{k_{i s o}}{h_{a r}}
$$

A Figura 4.6 ilustra a variação da resistência térmica total de isolamento por unidade de comprimento em função da espessura do isolamento. Nota-se que a partir de aproximadamente $8 \mathrm{~mm}$ de isolamento, a resistência térmica é superior a do tubo sem isolamento. A espuma utilizada para isolar apresenta espessura superior a $16 \mathrm{~mm}$ reduzindo desta forma a troca de calor com o ambiente externo. 
Próximo as tomadas de pressão na entrada e saída do conjunto de préaquecedor e seção de testes, foram instalados termopares no interior da tubulação a fim de determinar a temperatura do fluido. Nos experimentos realizados, o fluido entrava sub-resfriado no pré-aquecedor. Determinada a temperatura e a pressão na entrada do pré-aquecedor é possível calcular o estado termodinâmico do fluido antes dele alcançar a seção de testes, e assim efetuar corretamente o balanço de energia.

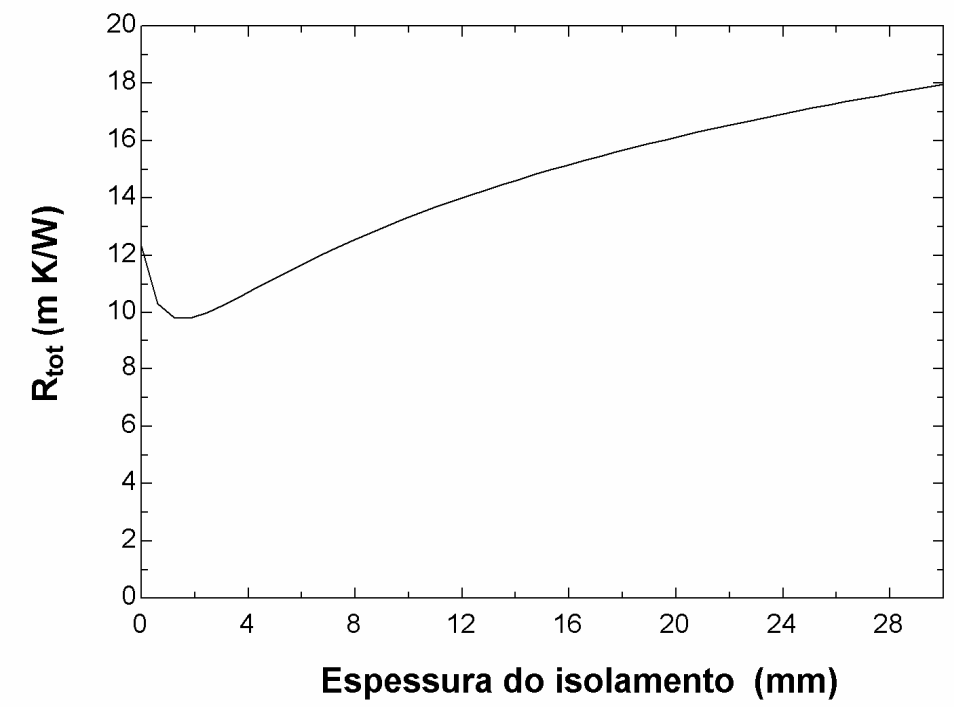

Figura 4.6 - Resistência total por unidade de comprimento em função da espessura de isolamento do tubo.

Cuidado especial foi adotado na determinação do posicionamento axial da última seção de medida de temperatura na superfície da seção de testes, localizada próxima a seção de visualização. Esta seção de medida deve se encontrar o mais próximo possível da entrada da seção de visualização para que a configuração do escoamento visualizado seja próxima ao padrão na região de leitura de temperatura dos termopares. Entretanto, entre a seção de visualização e a seção de testes existe o eletrodo metálico proveniente da fonte de corrente que está em contato direto com a superfície do tubo da seção de testes. Este eletrodo funciona como uma aleta entre o tubo e o ambiente, interferindo na temperatura do tubo na suas proximidades. Com intuito de determinar o comprimento do trecho de tubo termicamente afetado pelo eletrodo, uma modelagem em elemento finitos da troca de calor foi reali- 
zada. A Figura 4.7 ilustra o modelo simulado e o resultado desta simulação para condição de contorno crítica, onde ocorrem os maiores gradientes de temperatura axiais no tubo. Nesta simulação foi considerado uma eletrodo de $3 \mathrm{~mm}$ de largura em contato com a superfície do tubo, de forma que o eletrodo funcionasse como uma aleta de alta eficiência, mantendo a superfície do tubo em contato com ela a mesma temperatura ambiente, esta adotada em $22^{\circ} \mathrm{C}$. A região da seção de testes recoberta com isolamento foi admitida adiabática. Desta forma, a perda de calor devido ao efeito aleta foi superestimada.

A simulação indicou que a partir de uma distância de $15 \mathrm{~mm}$ do eletrodo, o efeito de aleta no campo de temperaturas do tubo, torna-se desprezível, conforme ilustrado na Figura 4.8.

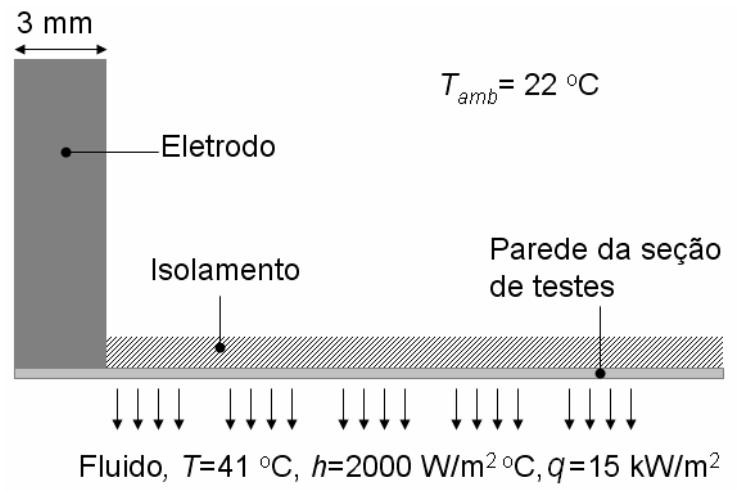

Figura 4.7 - Modelo para avaliação do efeito do eletrodo no campo de temperaturas da superfície de testes.

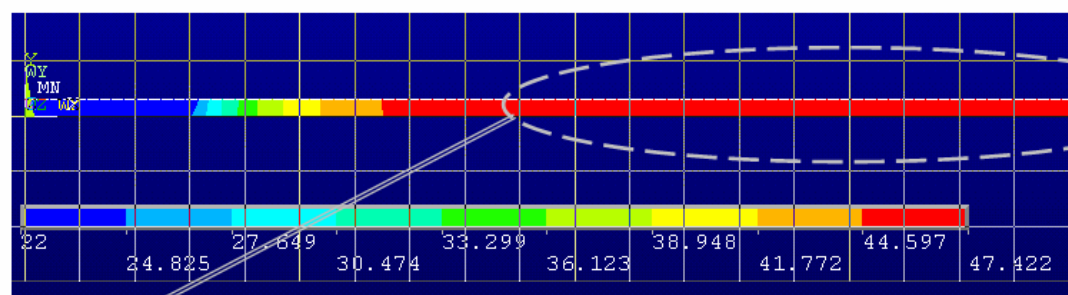

(a)

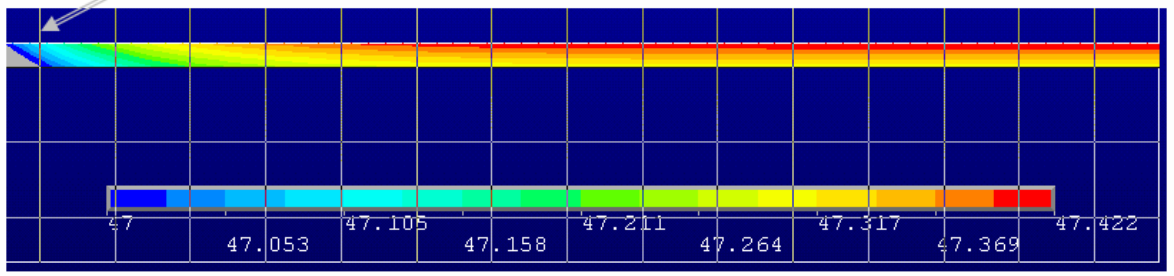

(b)

Figura 4.8 - (a) simulação em elementos finitos (Ansys) da distribuição de temperatura ao longo da seção de testes junto ao eletrodo; (b) ampliação da área circulada (1mm por divisão horizontal). 
O comprimento de desenvolvimento térmico é outro fator importante a se considerar nas medições experimentais. A teoria clássica para escoamento monofásico, que aborda a transferência de calor na região de desenvolvimento, mostra que nesta região sempre há um incremento do coeficiente de transferência de calor em relação ao escoamento completamente desenvolvido (BEJAN, 1995). Para escoamentos bifásicos, não se verificam resultados que possam ser utilizados para prever o comprimento de desenvolvimento térmico. Isto se deve aos vários fenômenos, geralmente acoplados entre si, que ocorrem em escoamentos bifásicos, tal como formação e crescimento de bolhas, propagação de ondas de interface, padrões de escoamento diversos, ocorrência de entreinament, o que dificulta a proposição de um critério de desenvolvimento térmico para estes escoamentos. Pode-se questionar se há como definir uma condição de desenvolvimento térmico para escoamentos em ebulição convectiva, sem se considerar um padrão de escoamento específico. Desta forma, o comprimento de desenvolvimento térmico monofásico foi considerado no presente estudo para indicar tal condição para escoamento bifásico.

Para escoamento laminar, segundo Bejan (1995), o comprimento de desenvolvimento térmico para fluxo de calor constante é dado pela equação(4-2),

$$
\frac{L_{\text {des, }, \text { lam }}}{D}=0,05 \cdot \operatorname{Re}_{D} \cdot \operatorname{Pr}
$$

e para escoamento turbulento é dado pela equação (4-3),

$$
\frac{L_{\text {des }, \text { turb }}}{D}<60
$$

A Figura 4.9 ilustra a variação do comprimento de desenvolvimento térmico laminar e turbulento em função do número de Reynolds em um tubo de 2,32mm para $\mathrm{R} 134 \mathrm{a}$ a temperatura de $30^{\circ} \mathrm{C}$.

Conforme ilustrado na Figura 4.9, para escoamentos laminares, comprimentos de desenvolvimento elevados são esperados. Para $R e$ inferiores a 1000 este comprimento pode ser desenvolvido na seção de pré-aquecimento. No caso de escoamento turbulento o comprimento de desenvolvimento térmico é de $138 \mathrm{~mm}$ e pode ser alcançado em um comprimento inferior ao das posições onde ocorrem as medidas de temperatura na superfície da seção de testes. 


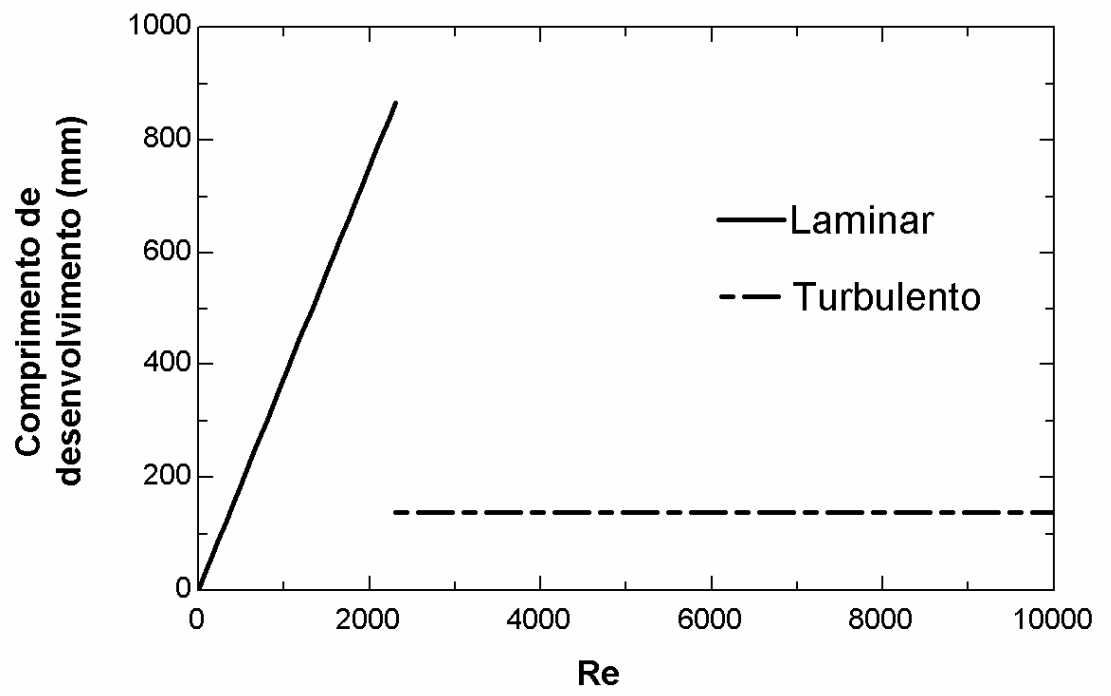

Figura 4.9 - Comprimento de desenvolvimento térmico para o tubo de 2,32mm em função do número de Reynolds para fluido R134a.

Em escoamentos monofásicos com transferência de calor existe um gradiente de temperatura do fluido ao longo do comprimento do tubo devido ao aquecimento do fluido. Esta variação da temperatura do fluido causa também um gradiente de temperatura axial na parede do tubo, promovendo assim um, fluxo de calor axial. Dependendo da condutividade térmica e da espessura da parede, este fluxo de calor axial pode se tornar considerável, devendo ser contabilizado para o adequado cálculo de transferência de calor entre a parede e o fluido. Em escoamentos monofásicos, a condução axial pode ser avaliada por meio do número de condução axial, $M$, definido em Celata et al. (2006) para tubos circulares por meio da equação (4-4).

$$
M=\left(\frac{k_{w}}{k_{l}}\right) \cdot\left(\frac{D_{o}^{2}-D_{i}^{2}}{D_{i} \cdot L}\right) \cdot \frac{1}{\operatorname{Re}_{D} \cdot \operatorname{Pr}}>10^{-2}
$$

Para valores de $M$ superiores a $10^{-2}$, a condução axial torna-se relevante e não pode ser desprezada. Utilizando-se R134a a $31^{\circ} \mathrm{C}, k_{f}=0,08 \mathrm{~W} / \mathrm{m} . \mathrm{K}$, $k_{w}=16 \mathrm{~W} / \mathrm{m} . \mathrm{K}, D_{o}=2,9 \mathrm{~mm}, D_{i}=2,3 \mathrm{~mm}, L=463 \mathrm{~mm}, \operatorname{Pr}=3,2$ e $R e_{D}=100$ obtém-se um valor de $M=0,0018$, valor inferior a $10^{-2}$, concluindo-se que efeitos de condução axial para as condições consideradas são desprezíveis. Em geral, na ebulição convectiva, 
o gradiente de temperatura axial é muito inferior ao do escoamento monofásico, excetuando-se as condições de secagem da parede onde tal efeito pode ser relevante.

$\mathrm{O}$ aquecimento do fluido devido à dissipação viscosa em canais de diâmetros reduzidos pode se tornar um parâmetro relevante na estimativa da temperatura local do fluido refrigerante, pois em microcanais a queda de pressão tende a ser elevada. Esse efeito pode ser avaliado por meio de um balanço de energia entre a entrada e a saída da seção de testes. Considerando o escoamento monofásico e adiabático obtém-se a equação (4-5).

$$
\begin{aligned}
& i_{e n t}=i_{s a i} \\
& u_{e n t}+p_{e n t} v_{e n t}=u_{s a i}+p_{s a i} v_{s a i}
\end{aligned}
$$

Calculando o incremento da energia interna para R134a a $8 \mathrm{MPa}$, subresfriado a $31^{\circ} \mathrm{C}$ e com uma perda de pressão de $100 \mathrm{kPa}$, obtém-se um aquecimento devido a efeitos viscosos da ordem de $0,01^{\circ} \mathrm{C}$. As maiores perdas de pressão encontradas durante a campanha experimental para $D=2,32 \mathrm{~mm}$ foram da ordem de $80 \mathrm{kPa}$ em condições de escoamento bifásico. Para escoamento monofásico com este diâmetro, a perda de pressão foi inferior a $10 \mathrm{kPa}$. O resultado dessa análise permite desprezar efeitos de aquecimento relacionados à dissipação viscosa.

\subsubsection{Tubo de $1,10 \mathrm{~mm}$}

A Figura 4.10 apresenta detalhes da instalação dos termopares e sensores de pressão utilizados nos ensaios para o tubo de $1,10 \mathrm{~mm}$. Tanto a seção de testes como a de pré-aquecimento são tubos circulares de $200 \mathrm{~mm}$ de comprimento, em aço inoxidável, com diâmetro interno de $1,10 \mathrm{~mm}$ e espessura da parede de $0,185 \mathrm{~mm}$. O comprimento aquecido na seção de testes utilizados nos experimentos foi de $143 \mathrm{~mm}$ e $145 \mathrm{~mm}$ no pré-aquecedor. A rugosidade foi avaliada na superfície interna de um tubo similar ao usado nos experimentos através de um profilômetro óptico obtendo-se uma rugosidade média de $R a=0,39 \mu \mathrm{m}$. 


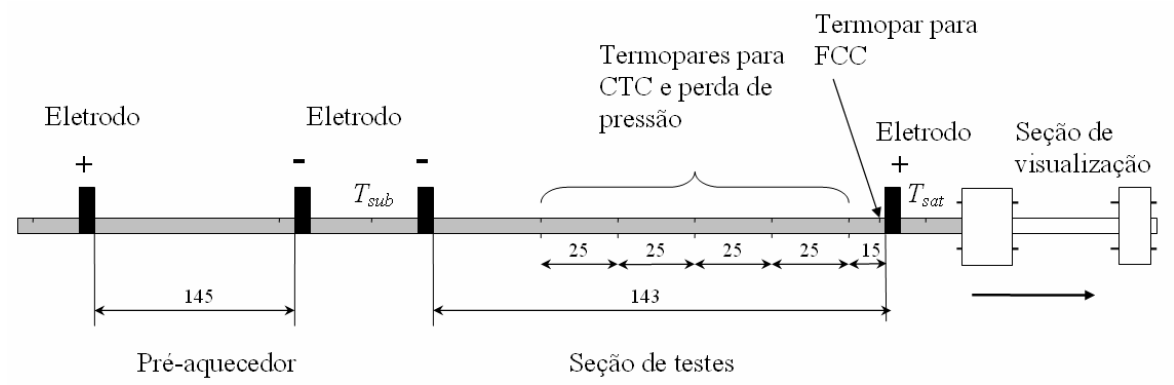

(a)

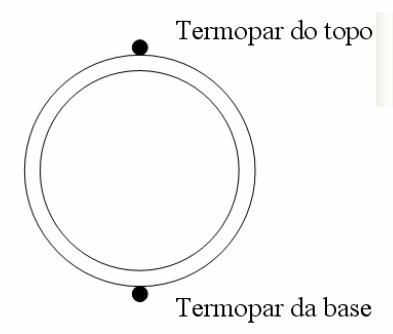

(b)

Figura 4.10 - Detalhes da seção de testes e o posicionamento dos termopares.

Foram instalados 12 termopares do tipo K (diâmetro da ponta de $0,125 \mathrm{~mm}$ ) ao longo da superfície da seção de testes. Esses termopares foram colocados em 6 seções distintas do tubo, dispostos $180^{\circ}$ um do outro, no topo e na base, como indicado na Figura 4.10b. Para fixar os termopares, adotou-se o seguinte procedimento: primeiro os termopares foram posicionados a $180^{\circ}$ um do outro numa seção, sendo então envoltos por três voltas de fita de kapton tensionadas. Por fim, um anel de vedação de borracha (o-ring), de diâmetro inferior ao tubo, foi posto sobre a fita, aumentando a pressão de contato. Com esse procedimento, buscou-se minimizar a resistência de contato entre o tubo e o termopar. Todos os termopares foram isolados eletricamente da superfície de testes, por meio de uma reduzida camada de tinta esmalte para evitar interferência da fonte de corrente nas medidas. No préaquecedor, instalou-se um termopar na superfície superior somente com a finalidade de detectar uma temperatura excessiva que possa danificar o tubo e suas conexões. Após a instalação dos termopares, ambas as seções foram envoltas com espuma isolante térmica Armaflex, conforme ilustrado na Figura 4.11. 


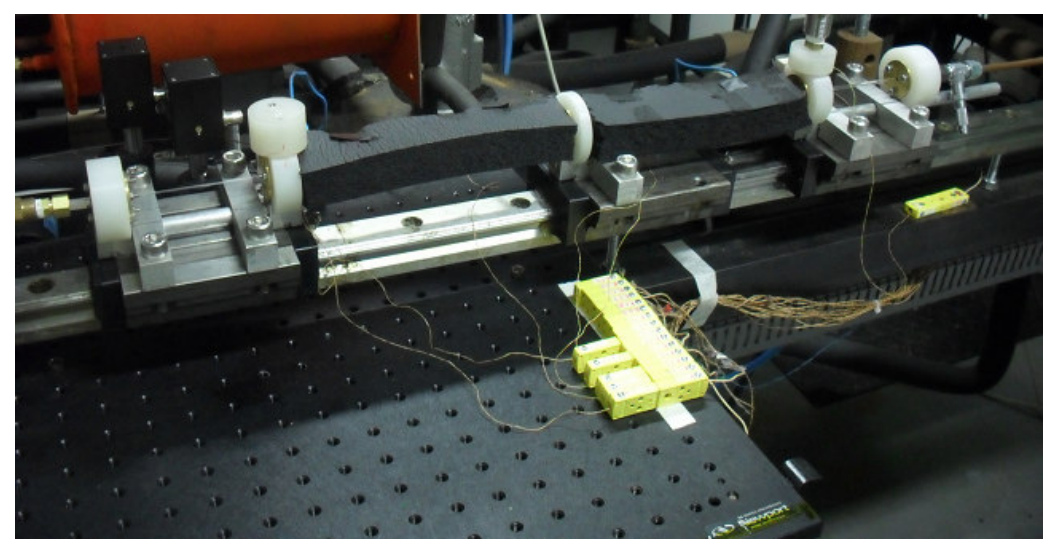

Figura 4.11 - Seção de testes, pré-aquecimento e visualização de 1,10mm após o isolamento.

Para o isolamento da seção, avaliou-se o raio crítico de isolamento com o objetivo de verificar o incremento da resistência térmica pela espuma. Para o tubo utilizado, $D_{i}=1,10 \mathrm{~mm}$, considerando-se um CTC de convecção de $18 \mathrm{~W} / \mathrm{m}^{2} \mathrm{~K}$, obtido através de Churchill e Chu (1975), e um $k_{\text {iso }}=0,03 \mathrm{~W} / \mathrm{m} . \mathrm{K}$, encontrou-se o raio crítico de isolamento igual usando-se a equação (4-6).

$$
r_{\text {crit }}=\frac{k_{\text {iso }}}{h_{\text {ar }}}=\frac{0,03}{18}=1,67 \mathrm{~mm}
$$

A Figura 4.12 ilustra a variação da resistência térmica total de isolamento em função da espessura do isolamento. Nota-se que a partir de $8 \mathrm{~mm}$ de isolamento a resistência térmica é superior a do tubo sem isolamento. A espuma utilizada para isolar apresenta espessura superior a $16 \mathrm{~mm}$, reduzindo, dessa forma, perdas de calor para o ambiente externo.

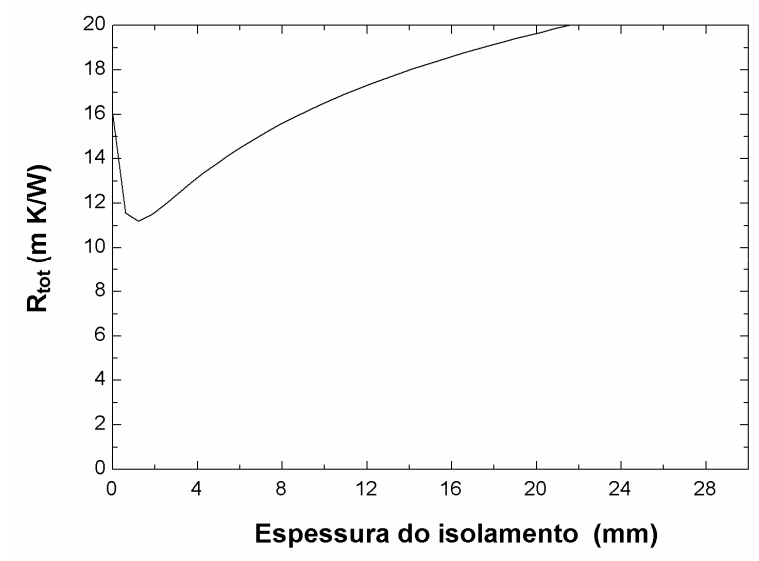

Figura 4.12 - Resistência total por unidade de comprimento em função da espessura de isolamento para o tubo $1,10 \mathrm{~mm}$. 
A Figura 4.13 mostra o comprimento de desenvolvimento térmico laminar e turbulento para o tubo de $1,10 \mathrm{~mm}$, fluido $\mathrm{R} 134 \mathrm{a}$, temperatura de $30^{\circ} \mathrm{C}$ para escoamento monofásico em função do número de Reynolds.

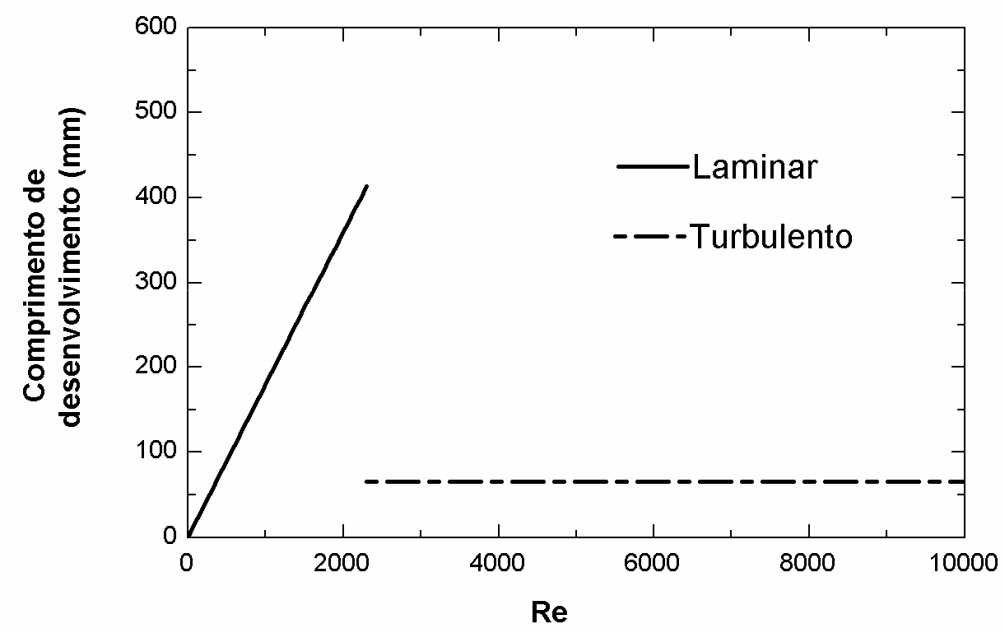

Figura 4.13 - Comprimento de desenvolvimento térmico para o tubo de 1,10mm em função do número de Reynolds para fluido R134a.

Conforme ilustrado na Figura 4.13, comprimentos de desenvolvimento elevados se verificaram para o caso de escoamento laminar. No caso de escoamento turbulento, o comprimento de desenvolvimento térmico é de $66 \mathrm{~mm}$ e pode ser alcançado num comprimento inferior ao das posições das últimas medidas de temperatura na superfície da seção de testes. É importante ressaltar novamente que, em escoamentos bifásicos, um critério relacionado ao comprimento de desenvolvimento térmico ainda não foi definido, pois este depende da configuração dos padrões do escoamento em estudo.

A condução axial de calor na parede do tubo, em condições de gradiente de temperatura na parede devido ao aquecimento do fluido ao longo do comprimento no escoamento monofásico, foi avaliada de acordo com a equação (4-4). Utilizandose R134a a $31^{\circ} \mathrm{C}, k_{f}=0,08 \mathrm{~W} / \mathrm{m} . \mathrm{K}, k_{w}=16 \mathrm{~W} / \mathrm{m} . \mathrm{K}, D_{0}=1,47 \mathrm{~mm}, D_{1}=1,10 \mathrm{~mm}, L=200 \mathrm{~mm}$, $\operatorname{Pr}=3,2$ e $R e=100$ obtém-se um valor de $M=0,0029$, inferior a $10^{-2}$, concluindo-se que efeitos de condução axial na parede são desprezíveis, também para esse diâmetro.

Através de uma análise similar a realizada para o tubo de 2,32 $\mathrm{mm}$ com base na maior queda de pressão verificada para este diâmetro, inferiores a $130 \mathrm{kPa}$ em 
condições bifásicas, verifica-se um aquecimento máximo devido à dissipação viscosa da ordem de $0,015^{\circ} \mathrm{C}$ para R134a, ligeiramente superior ao do tubo de 2,32mm. Dessa forma, pode-se considerar desprezível para a análise efetuada.

\subsubsection{SEÇÃo de VISUALIZAÇÃo de ESCOAMENTO}

\subsubsection{Tubo de $2,32 \mathrm{~mm}$}

A seção de visualização para a seção de testes de $2,32 \mathrm{~mm}$ é um tubo transparente de sílica fundida com diâmetro interno de $2,1 \mathrm{~mm}$ e externo de 2,4mm tendo comprimento de $85 \mathrm{~mm}$ e estando localizado a jusante da seção de testes. Essa seção transparente foi unida à seção de testes por meio de uma flange de PVC que pressiona anéis de borracha (o-rings) contra a parede externa dos tubos, vedando a conexão. A jusante do tubo de vidro está instalado um micro-transdutor de pressão, o termopar imerso no fluido e a tomada de pressão do sensor diferencial, conforme ilustrado na Figura 4.14.

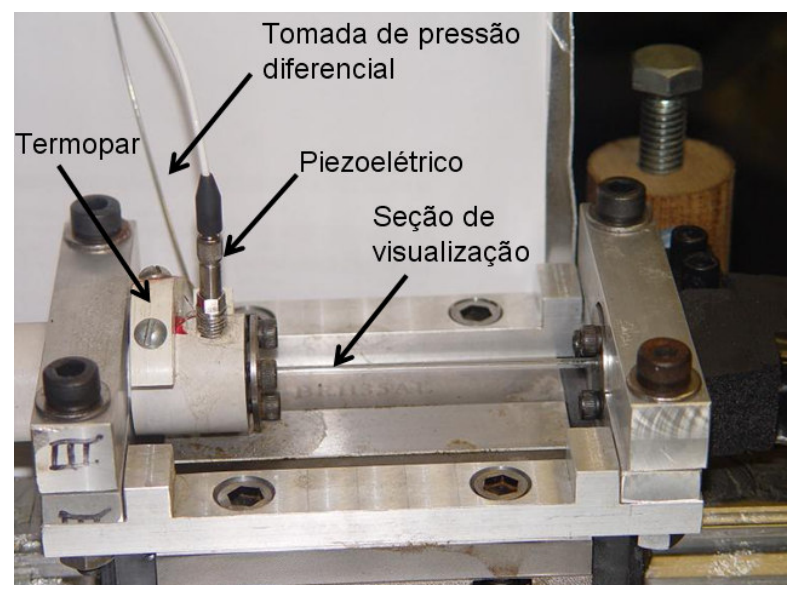

Figura 4.14 - Imagem da seção de visualização para seção de testes de $D_{=}=2,32 \mathrm{~mm}$.

Para registro de imagens dos padrões de escoamento formados, foi utilizada uma câmera de alta velocidade da OPtronics, modelo CamRecord600, com capacidade de captura de até 100000 imagens por segundo, ilustrada na Figura 4.15. Conforme indicado na Tabela 4.1, a resolução da imagem capturada decresce com o incremento da taxa de aquisição. Em testes realizados com a câmera, percebeuse que uma resolução de 50 pixels na vertical é o mínimo suficiente para se obser- 
var escoamentos em bolhas, pistonado e anular, sem que haja comprometimento da qualidade. Analogamente, os testes revelaram que velocidades de até 10000 imagens por segundo são suficientes para observar a maioria dos fenômenos do escoamento, tais como ondulações de interface e coalescência de bolhas. Para a observação adequada de gotículas de líquido (entrainment) durante o escoamento anular com velocidades mássicas elevadas, taxas de aquisição de imagens superiores foram necessárias. Uma lente objetiva AF MICRO NIKKOR de 60mm, com razão de reprodução de 1:1, permite visualizar tubos de $400 \mu \mathrm{m}$ de diâmetro com uma resolução de 50 pixels vertical.

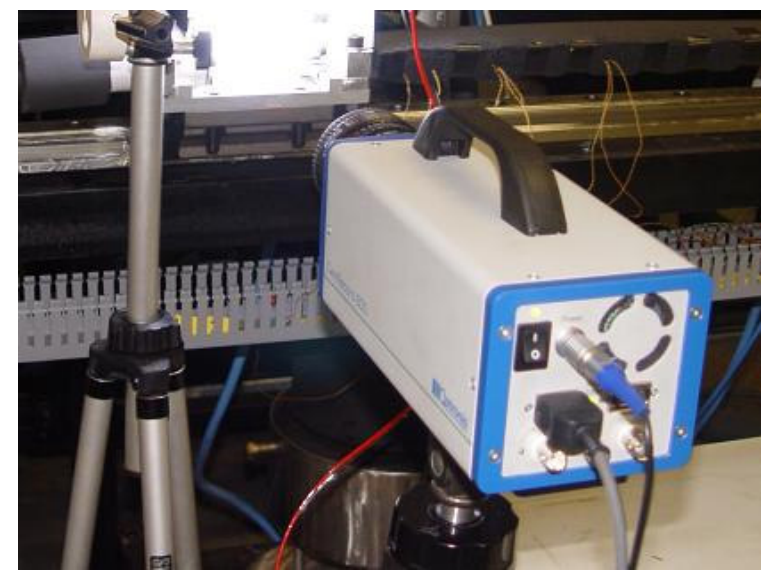

Figura 4.15 - Posicionamento da câmera de alta velocidade junto à seção de visualização.

Tabela 4.1 - Relação entre as resoluções verticais e horizontais, em função da frequência de aquisição da câmera utilizada.

\begin{tabular}{ccc}
\hline Resolução vertical (pixels) & Resolução horizontal (pixels) & $\begin{array}{c}\text { Frequência máxima de } \\
\text { aquisição (quadros/s) }\end{array}$ \\
\hline 1024 & 1280 & 500 \\
\hline 512 & 1280 & 1000 \\
\hline 256 & 1280 & 2000 \\
\hline 128 & 1280 & 4000 \\
\hline 50 & 1280 & 5000 \\
\hline 48 & 80 & 10000 \\
\hline 4 & 1280 & 100000 \\
\hline
\end{tabular}


Uma dificuldade adicional a se considerar filmagens em altas velocidades é a potência luminosa necessária para registrar as imagens. Quanto maior a taxa de aquisição, maior deverá ser a potência de iluminação sobre o objeto. No caso da utilização de lâmpada halógena, elas fornecem a iluminação necessária, entretanto, apresentam o inconveniente de emitir altas taxas de radiação térmica, podendo promover a evaporação do fluido de teste ao longo da seção de visualização. Dessa forma, no presente estudo foram utilizados LEDs de alto brilho. Duas placas foram construídas, contendo um total de 100 LEDs brancos (6W de potência elétrica) provendo a iluminação necessária, com uma geração de calor reduzida.

A Figura 4.16 apresenta imagens obtidas pela câmera. Cada foto foi obtida à velocidade de 3000 imagens por segundo, com resolução de 1280x50 pixels.

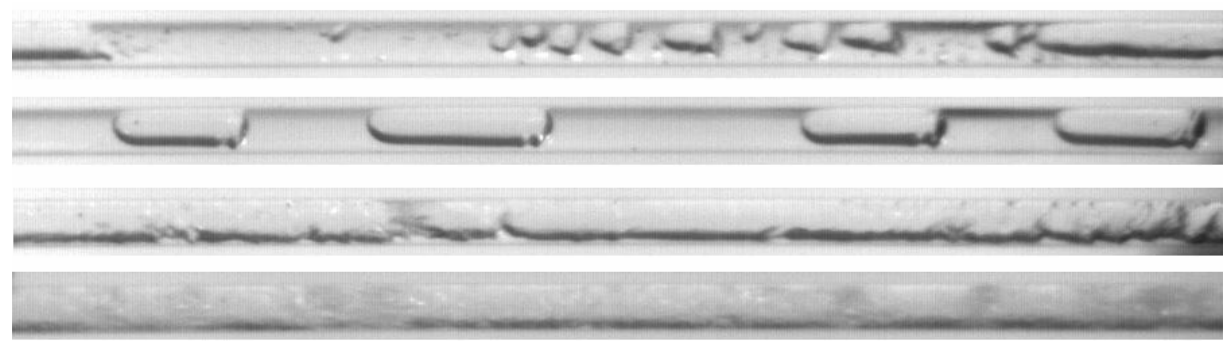

Figura 4.16 - Padrões de escoamento filmados na bancada experimental (de cima para baixo: bolhas, bolhas alongadas, agitante, anular), $D=2,10 \mathrm{~mm}$. Velocidade de captura de 3000 imagens por segundo e resolução de 1280 x 50 pixels.

\subsubsection{Tubo de $1,10 \mathrm{~mm}$}

A seção de visualização para a seção de testes de $1,1 \mathrm{~mm}$ é um tubo transparente de sílica fundida com diâmetro interno de 1,0mm e externo de 1,2mm, tendo comprimento de $85 \mathrm{~mm}$ e estando posicionada a jusante da seção de testes (Figura 4.17). Essa seção transparente foi unida à seção de testes por meio de uma flange de PVDF que pressiona anéis de borracha (o-rings) contra a parede externa dos tubos, vedando a conexão. Para esse diâmetro, o sensor piezoelétrico não foi utilizado e os procedimentos com a câmera de alta velocidade foram similares aos do tubo de $2,32 \mathrm{~mm}$. 


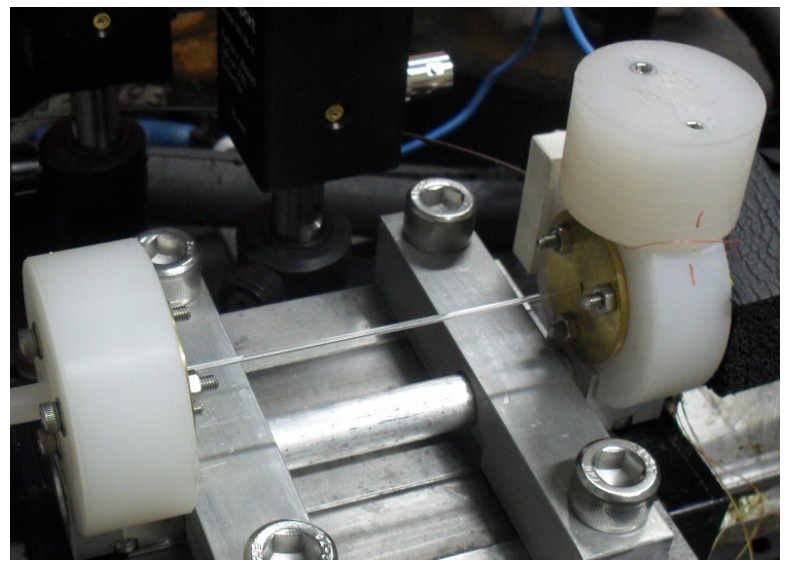

Figura 4.17 - Seção transparente de visualização tubo de 1,00mm.

\subsubsection{SENSORES, CONTROLADORES E SISTEMA DE AQUISIÇÃO DE DADOS}

A aquisição de dados e controle do sistema foi realizada por meio de placas de aquisição da National Instruments e programação em Labview. O Quadro 4.1 apresenta a lista completa de sensores e atuadores utilizados na bancada.

A placa de aquisição da National Instruments utilizada foi a PCI-6021 e o kit de condicionamento de sinal SCXI-1000, com os seguintes condicionadores de sinal: SCXI-1140 (8 entradas Sample/Hold), SCXI-1142 (8 canais com filtro passa baixo $20 \mathrm{kHz}$ ), SCXI-1180 (ligação direta com os terminais), SCXI-1102 (32 canais de termopares). Esses blocos foram ligados aos seguintes terminais, respectivamente: SCXI-1304, SCXI-1302 e SCXI-1303. O módulo SCXI-1142 foi conectado em cascata com o módulo SCXI-1140 para atuar como filtro. A Figura 4.18 apresenta o diagrama esquemático da ligação dos sensores com sistema de aquisição.

A Figura 4.19 apresenta a interface do software em Labview para aquisição dos dados e controle da bancada experimental. Através desta interface, a vazão e potência aplicada à seção de testes e de pré-aquecimento são controladas, determinando assim a condição de operação do sistema. Todos os outros parâmetros da bancada (temperaturas, pressões, vazão, fluxo de calor) são monitorados em tempo real e podem ser gravados em arquivo, com taxa de aquisição superior a $100 \mathrm{~Hz}$. $\mathrm{O}$ programa calcula em tempo real o coeficiente de troca de calor e o título de vapor na posição do último termopar localizado próximo a saída da seção de testes. As propriedades termodinâmicas e de transporte são calculadas mediante uma interface desenvolvida entre o Labview e o Refprop 7, programa este que fornece valores 
precisos das propriedades de diversos refrigerantes. Funções de calibração do sinal adquirido foram introduzidas no programa de aquisição, corrigindo, assim, erros sistemáticos do sistema de aquisição e dos sensores.

Quadro 4.1 - Sensores e atuadores utilizados na bancada experimental.

\begin{tabular}{|c|c|c|c|c|}
\hline Sensores/Atuadores & Modelo & Quantidade & Tipo de sinal & Função \\
\hline Termopares & Tipo K- Omega & 16 & voltagem & $\begin{array}{l}\text { Medir temperaturas da seção de } \\
\text { testes }\end{array}$ \\
\hline Pressão absoluta & $\begin{array}{l}\text { Endress+Hauser } \\
\text { PMP131 }\end{array}$ & 3 & 4- $20 \mathrm{~mA}$ & $\begin{array}{l}\text { Determinar pressão nos tanques } \\
\text { e na entrada da seção de testes }\end{array}$ \\
\hline Pressão diferencial & $\begin{array}{l}\text { Endress+Hauser } \\
\text { Deltabar S }\end{array}$ & 1 & $4-20 \mathrm{~mA}$ & $\begin{array}{l}\text { Determinar queda de pressão na } \\
\text { seção de testes }\end{array}$ \\
\hline Pressão dinâmica & $\begin{array}{l}\text { PCB Piezotronics } \\
105 \mathrm{C} 03\end{array}$ & 1 & voltagem & $\begin{array}{l}\text { Determinar pressão na saída da } \\
\text { seção de testes, verificar efeitos } \\
\text { de instabilidade }\end{array}$ \\
\hline Vazão (Coriolis) & $\begin{array}{l}\text { Micro Motion mode- } \\
\text { lo } 2700\end{array}$ & 1 & $4-20 \mathrm{~mA}$ & $\begin{array}{l}\text { Determinar vazão do fluido na } \\
\text { seção de testes }\end{array}$ \\
\hline Fonte elétrica DC & $\begin{array}{l}\text { Lambda } \\
\text { Genesys 750W DC }\end{array}$ & 2 & $\begin{array}{l}\text { digital/RS- } \\
232\end{array}$ & $\begin{array}{l}\text { Aquecimento da seção de testes } \\
\text { e de pré-aquecimento }\end{array}$ \\
\hline $\begin{array}{l}\text { Inversor/ } \\
\text { Microbomba }\end{array}$ & $\begin{array}{l}\text { ABB-ACS150/ Mi- } \\
\text { cropump }\end{array}$ & 1 & voltagem & Promover escoamento de fluido \\
\hline
\end{tabular}

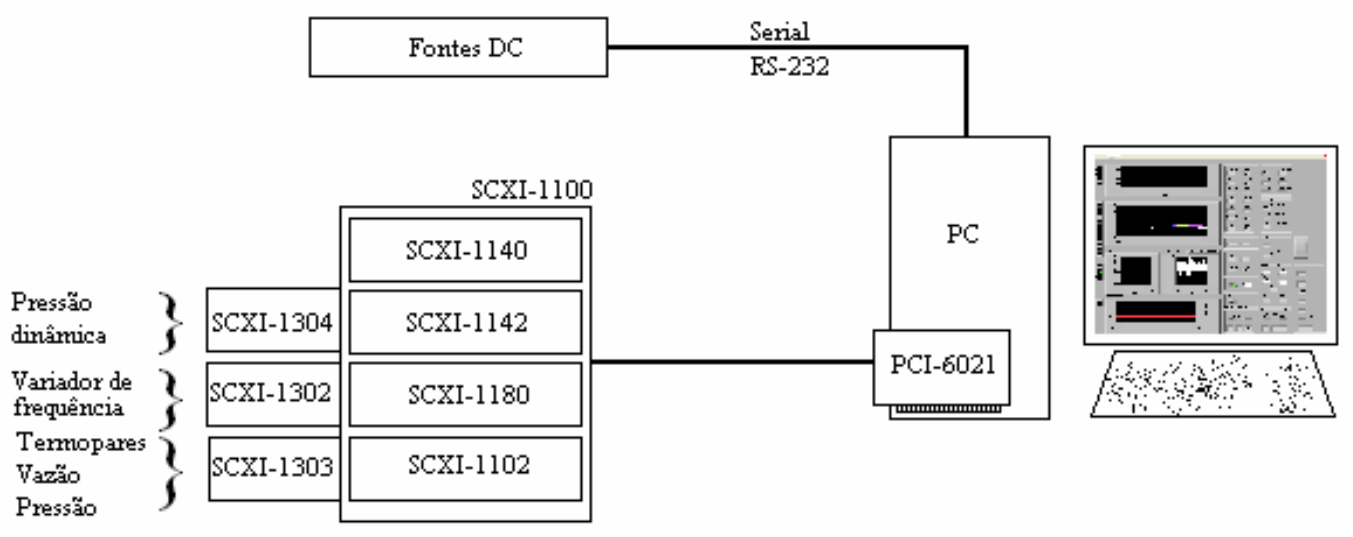

Figura 4.18 - Sensores e atuadores ligados ao sistema de aquisição. 


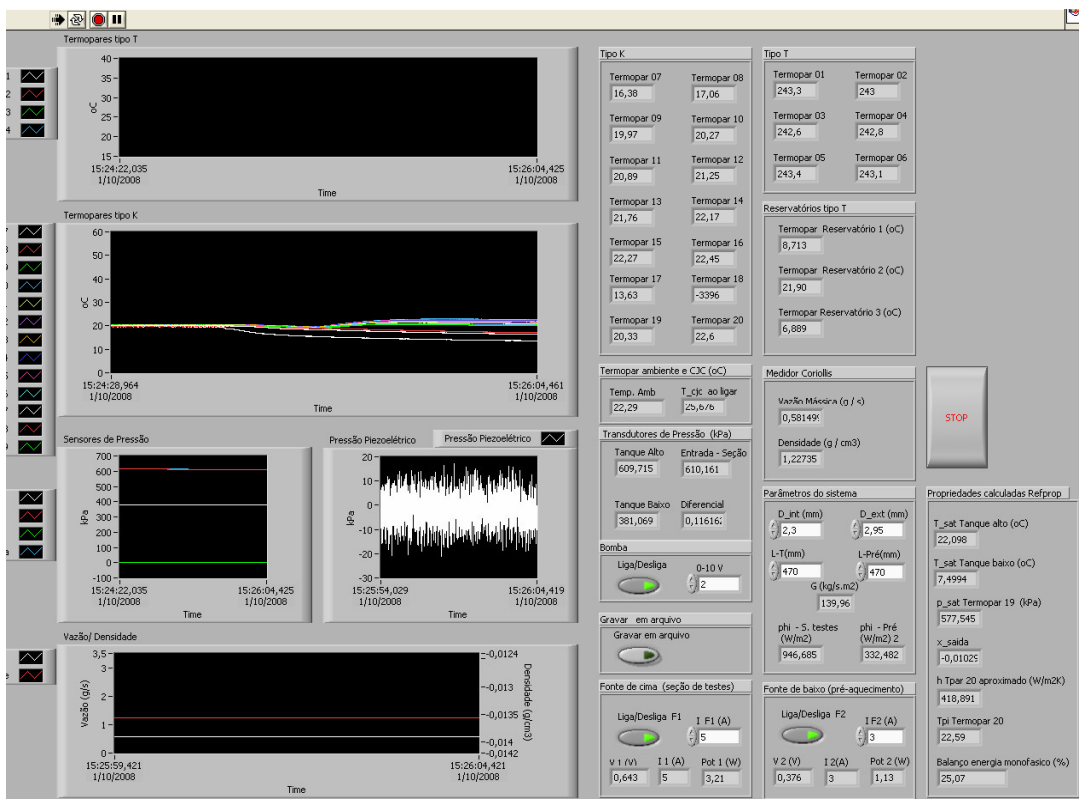

Figura 4.19 - Interface do programa de aquisição e controle da bancada experimental.

Todos os canais de temperatura onde estavam conectados os termopares tiveram a temperatura indicada corrigida através do procedimento de calibração descrito no Apêndice A. Gráficos de todos os parâmetros medidos na base tempo são apresentados na interface, permitindo observar fenômenos transientes, tais como instabilidades e condição de operação em regime. O programa conta com sistema de proteção de alta temperatura na seção de testes; assim, caso os termopares indiquem temperatura excessiva, as fontes de corrente contínua são desligadas automaticamente. Um controlador PI (Proporcional Integral) implementado no Labview controla a velocidade mássica no sistema. Esse controlador atua no inversor de frequência para manter a velocidade mássica imposta pelo operador constante, pois foi observado que aumentando-se o fluxo de calor a vazão tende a diminuir se o sinal aplicado ao inversor de frequência for mantido constante. Tal comportamento decorre do aumento da queda de pressão que exige um incremento da potência de alimentação da microbomba para manter a vazão. 


\subsubsection{Procedimento eXPerimental}

\subsubsection{Escoamento monofásico}

Os experimentos foram conduzidos primeiro fixando-se a pressão de saturação no tanque de refrigerante aquecido (ver Figura 4.1) com o controle da sua temperatura através da solução de etileno-glicol e água. Esse tanque contém refrigerante no estado saturado. Uma vez estabelecida a pressão de saturação do refrigerante no circuito, a velocidade mássica desejada é ajustada pelo controlador $\mathrm{PI}$, conectado ao inversor de frequência que atua na microbomba. A seguir, a temperatura de sub-resfriamento da entrada é fixada através do sub-resfriador localizado a montante do pré-aquecedor. Na sequência, o fluxo de calor desejado é aplicado na seção de testes e no pré-aquecedor variando a potência fornecida pelas duas fontes de corrente contínua. Em geral, os fluxos de calor nas seções de testes e de préaquecimento foram mantidos próximos, de forma que o comprimento de desenvolvimento térmico ocorresse no pré-aquecedor. A potência de aquecimento aplicada foi limitada de forma a garantir um sub-resfriamento na saída da seção de testes superior a $2^{\circ} \mathrm{C}$, evitando condições com formação de vapor, o que resultaria em erros no balanço de energia. Repetia-se este procedimento para cada pressão, vazão, sub-resfriamento e fluxo de calor desejados.

\subsubsection{Escoamento bifásico (Ebulição convectiva)}

Os experimentos eram iniciados fixando a temperatura no tanque de refrigerante aquecido (ver Figura 4.1). Dessa forma, estabeleciam-se a temperatura de saturação e, consequentemente, a pressão do fluido no circuito de testes. O estabelecimento da temperatura se dá através de uma solução de etileno-glicol e água com temperatura controlada, circulando no interior de uma serpentina localizada no interior do tanque de refrigerante aquecido. Uma vez atingida a pressão de saturação do refrigerante no circuito, a velocidade mássica é ajustada através do controlador PI ligado ao inversor de frequência que atua na microbomba. Em seguida, iniciase o aquecimento no pré-aquecedor, fornecendo-se a potência necessária de forma a alcançar o sub-resfriamento ou o título de vapor requerido na entrada da seção de testes. A seguir, o fluxo de calor desejado na seção de testes é aplicado, variando- 
se a potência fornecida pela fonte de corrente contínua. Incrementos do título de vapor, para um fluxo de calor fixo na seção de testes, são obtidos aumentando-se a potência fornecida pelo pré-aquecedor, mantendo-se os demais parâmetros fixos. $O$ título de vapor no final da seção de visualização é calculado em tempo real pelo sistema de monitoramento, de tal forma a permitir o ajuste preciso da condição de ensaio desejada (fluxo de calor, vazão, temperatura de saturação e título de vapor).

Os dados experimentais utilizados para a redução de dados eram gravados apenas após assegurada a condição de regime permanente, caracterizadas por variações nas temperaturas indicadas através dos termopares inferiores à incerteza de suas medidas, isto é, $0,15^{\circ} \mathrm{C}$. Geralmente tal condição se verificava após 15 minutos da imposição de novos parâmetros de ensaio.

Durante a calibração dos termopares e a campanha experimental, o ambiente contendo a bancada experimental foi mantido a uma temperatura de $22^{\circ} \mathrm{C}$ por um sistema de condicionamento de ar. Tal procedimento foi adotado com o propósito de minimizar possíveis efeitos da variação da temperatura ambiente na repetitividade das medidas.

\subsubsection{CONDIÇÕES EXPERIMENTAIS ENSAIADAS}

Ensaios monofásicos e bifásicos foram realizados neste estudo. O objetivo dos ensaios monofásicos foi a avaliação da coerência dos resultados obtidos pelo aparato experimental. Para isso, comparações dos valores medidos foram feitas com previsões teóricas de transferência de calor, queda de pressão e a avaliação do calor fornecido ao fluido em relação à parcela dissipada para o ambiente por meio de balanço de energia.

\subsubsection{Ensaios para escoamento monofásico}

Durante o levantamento experimental para condições monofásicas, variaramse os seguintes parâmetros experimentais: diâmetro interno do tubo, fluido refrigerante, velocidade mássica, pressão absoluta, $p_{a b s}$, sub-resfriamento na saída da seção de testes, $\Delta T_{\text {sub }}$, e fluxo de calor. A Tabela 4.2 apresenta as condições para as quais os ensaios foram realizados. 
Tabela 4.2 - Faixas dos parâmetros experimentais ensaiados com escoamento monofásico.

\begin{tabular}{cccccc}
\hline $\begin{array}{c}D_{i} \\
(\mathrm{~mm})\end{array}$ & Fluido & $\begin{array}{c}G \\
\left(\mathrm{~kg} / \mathrm{m}^{2} \mathrm{~s}\right)\end{array}$ & $\begin{array}{c}p_{\text {abs }} \\
(\mathrm{kPa})\end{array}$ & $\begin{array}{c}\Delta T_{\text {sub }} \\
\left({ }^{\circ} \mathrm{C}\right)\end{array}$ & $\begin{array}{c}q \\
\left(\mathrm{~kW} / \mathrm{m}^{2}\right)\end{array}$ \\
\hline 2,32 & $\begin{array}{c}\text { R134a } \\
\text { R245fa }\end{array}$ & $50-700$ & $110-1000$ & $2-10$ & $2,5-30$ \\
\cline { 5 - 6 } & & $50-800$ & & $2-10$ & $2,5-30$ \\
\hline
\end{tabular}

\subsubsection{Ensaios para escoamento bifásico}

Para a campanha experimental envolvendo ebulição convectiva, variaram-se os seguintes parâmetros experimentais: diâmetro interno do tubo, fluido refrigerante, velocidade mássica, temperatura de saturação, título de vapor e fluxo de calor. A Tabela 4.3 apresenta as condições para as quais os ensaios foram realizados na bancada localizada na EESC-USP.

Tabela 4.3 - Faixas dos parâmetros experimentais ensaiados com escoamento bifásico.

\begin{tabular}{|c|c|c|c|c|c|}
\hline $\begin{array}{c}D_{i} \\
(\mathrm{~mm})\end{array}$ & Fluido & $\begin{array}{c}G \\
\left(\mathrm{~kg} / \mathrm{m}^{2} \mathrm{~s}\right)\end{array}$ & $\begin{array}{l}T_{\text {sat }} \\
\left({ }^{\circ} \mathrm{C}\right)\end{array}$ & $\begin{array}{c}X_{\text {saida }} \\
(-)\end{array}$ & $\begin{array}{c}q \\
\left(\mathrm{~kW} / \mathrm{m}^{2}\right)\end{array}$ \\
\hline 2,32 & R134a & $50-600$ & & & $5,0-55,0$ \\
\hline 1,10 & R245fa & $50-1000$ & 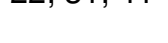 & (ס) & $15-200$ \\
\hline
\end{tabular}

\subsection{BANCADA EXPERIMENTAL II (EPFL- LAUSANNE)}

Neste estudo também foram realizados ensaios em uma segunda bancada experimental localizada no Laboratory of Heat and Mass Transfer (LTCM) da École Polytechnique Fédérale de Lausanne (EPFL), Suíça, sob coordenação do professor John Richard Thome. Tais ensaios, realizados durante estágio doutoral, tiveram a finalidade de investigar a influência da geometria do canal no CTC e no FCC, em canais horizontais com dimensões características próximas à transição macromicrocanais. Também se buscou avaliar possíveis diferenças entre resultados levantados por um operador em condições experimentais similares em bancadas distintas, pois é frequente, na literatura, encontrar dados com tendências díspares provenientes de laboratórios distintos, conforme ilustrado em Ribatski, Wojtan e Thome (2006). 
Os canais de geometria não circular avaliados tratam-se de tubos achatados como ilustrado na Figura 4.20. Como forma de avaliar o efeito da geometria, de forma independente dos outros parâmetros do escoamento, adotou-se que os canais achatados deveriam ter a mesma área interna da seção transversal. A mesma área interna implica que os canais devem ter o mesmo diâmetro equivalente, $D_{e q}$, que é o diâmetro de um canal circular com a mesma área interna de um canal não circular, dado pela equação (4-7).

$$
D_{e q}=\sqrt{\frac{4 \cdot A_{s e c ̧ a \tilde{o}}}{\pi}}
$$

Assim, dois tubos achatados foram avaliados, cada um sob duas orientações da seção transversal distintas, horizontal e vertical, totalizando 4 razões altura/largura (H/W) diferentes:1/4, 1/2, 2 e 4, todas com o mesmo diâmetro equivalente de $2,20 \mathrm{~mm}$. Canais circulares também foram ensaiados nessa bancada: um de $1,00 \mathrm{~mm}$ de diâmetro e outro de 2,20mm. Esse último, devido ao seu diâmetro equivalente de $2,20 \mathrm{~mm}$, foi utilizado nas comparações contra os tubos achatados.

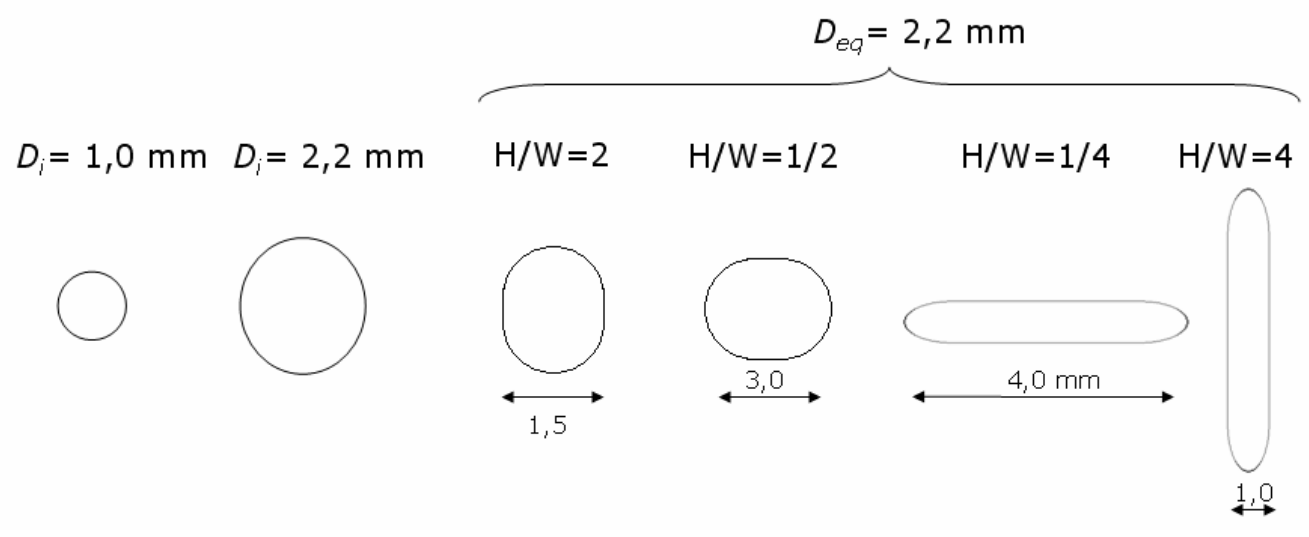

Figura 4.20 - Perfis dos canais avaliados na bancada experimental II (LTCM-EPFL).

A bancada experimental II tem configuração e operação similar à bancada experimental I, Figura 4.21. As diferenças se dão no controle de vazão e de potência da seção de testes, ambas com operação manual no caso da bancada II. Uma microbomba também promove o escoamento de fluido refrigerante na bancada II e um banho termostático controla a pressão do reservatório de fluido refrigerante. A Figura 4.22 apresenta uma fotografia dessa bancada. 


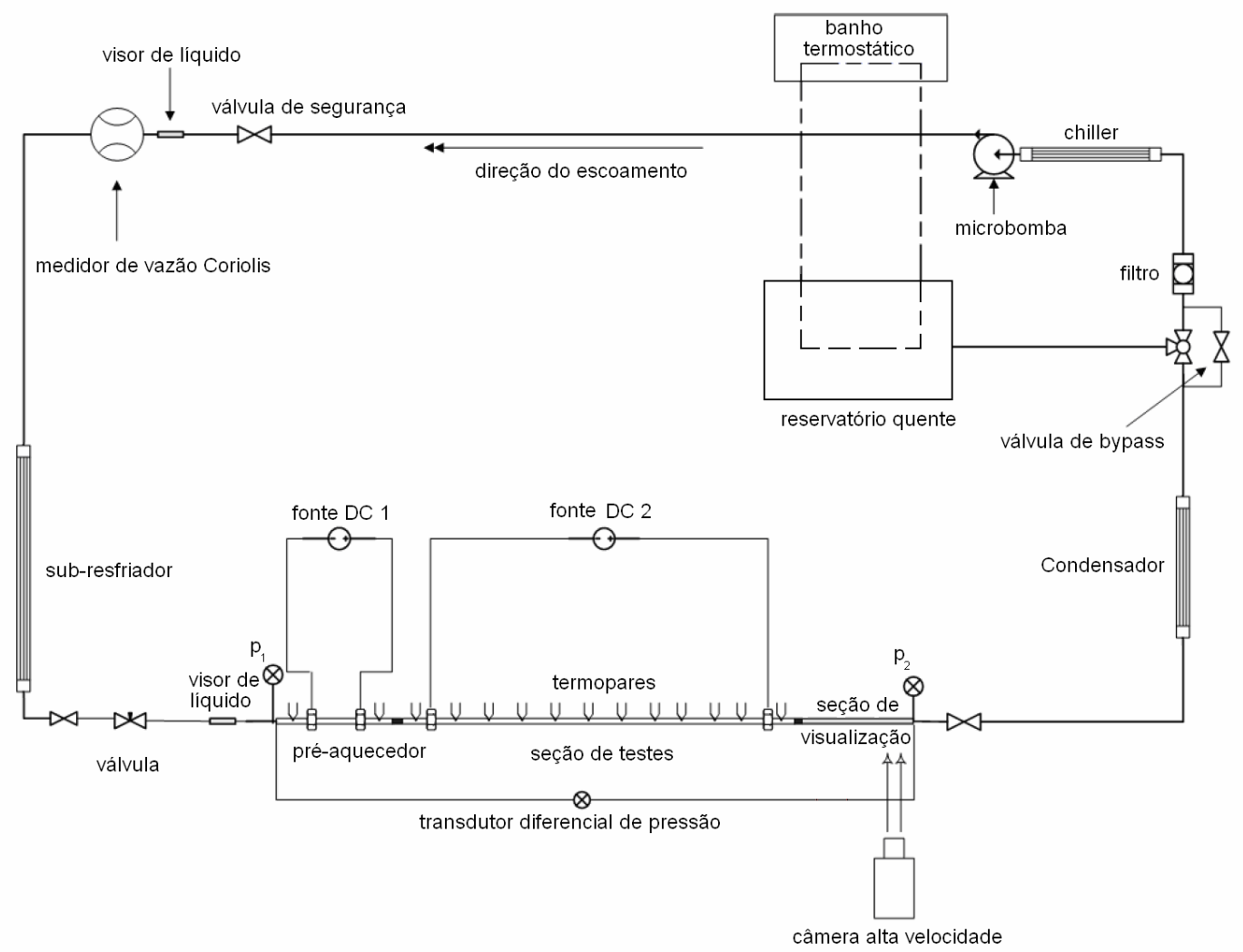

Figura 4.21 - Diagrama esquemático da bancada experimental II (LTCM-EPFL).

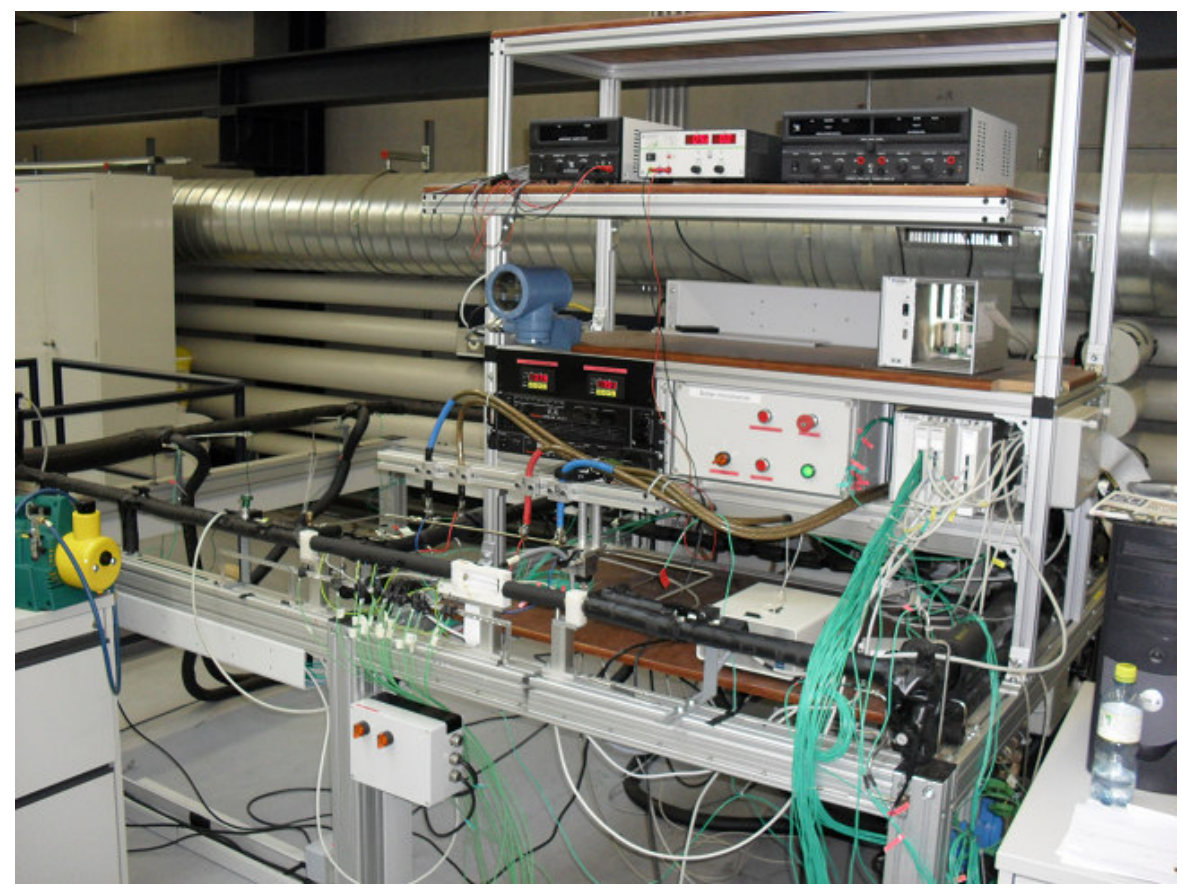

Figura 4.22 - Fotografia da bancada experimental II (LTCM-EPFL). 


\subsubsection{SEÇÕES DE TESTES}

\subsubsection{Canais circulares}

A Figura 4.23 apresenta detalhes da instalação dos termopares utilizados nos ensaios com o tubo de 2,20mm. Tanto a seção de testes como a de préaquecimento são canais circulares em aço inoxidável, com diâmetro interno de $2,20 \mathrm{~mm}$ e espessura da parede de $0,1 \mathrm{~mm}$. O comprimento aquecido na seção de testes utilizados nos experimentos foi de $361 \mathrm{~mm}$ e no pré-aquecedor $90 \mathrm{~mm}$. A rugosidade na superfície interna do tubo foi avaliada através da técnica de interferometria (optical phase shifting and white light vertical scanning interferometer technique) resultando no valor RMS (Root Mean Square) de 0,827 $\mu \mathrm{m}$.

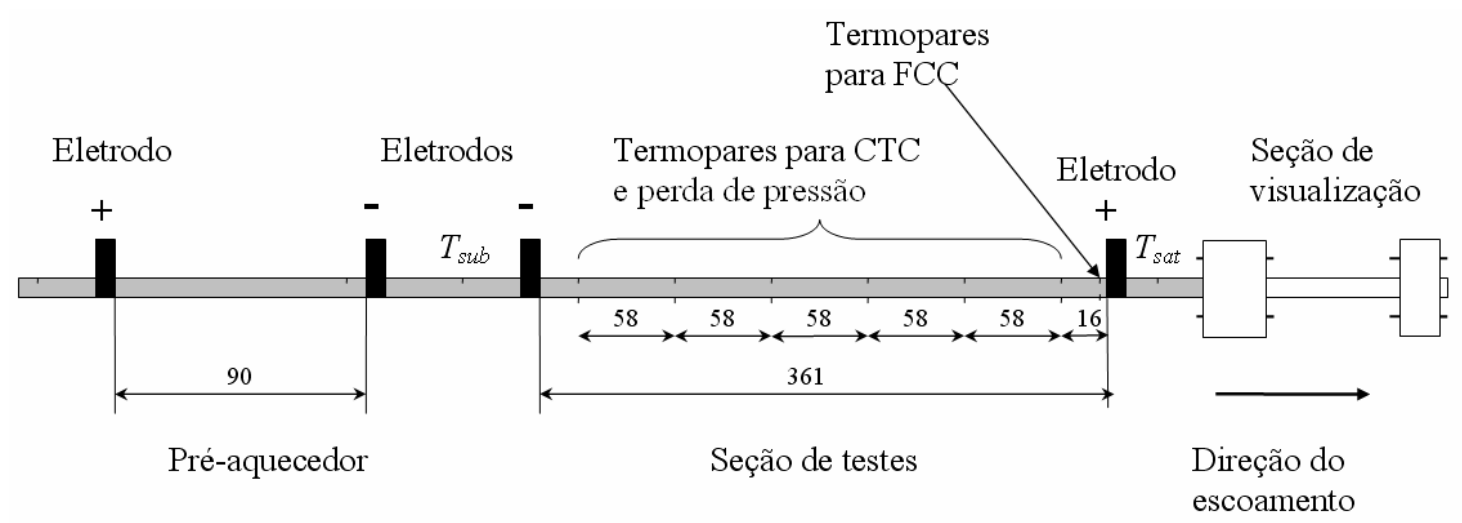

Figura 4.23 - Detalhes da seção de testes e o posicionamento dos termopares no canal de 2,20mm.

Foram instalados 12 termopares do tipo $\mathrm{K}$ (diâmetro da ponta de $0,25 \mathrm{~mm}$ ) ao longo da superfície da seção de testes, Figura 4.23. Esses termopares foram colocados em 6 seções distintas do tubo, dispostos $180^{\circ}$ um do outro, no topo e na base. Um termopar foi posicionado na parte final externa superior da seção de testes com o objetivo de medir o fluxo crítico de calor. Para medir as temperaturas de entrada e saída, respectivamente, na seção de testes foram instalados um termopar na parte superior do tubo assim posicionados: um $20 \mathrm{~mm}$ a montante da região aquecida da seção de testes, e outro $20 \mathrm{~mm}$ a jusante da região aquecida da seção de testes, ambos em regiões adiabáticas. Todos os termopares foram envoltos por voltas de fita de kapton tensionadas junto de um anel de vedação de borracha (oring) de diâmetro inferior ao tubo para aumentar a pressão de contato. Os termopa- 
res utilizados nessa bancada foram da marca Thermocoax, vindos de fábrica com isolamento elétrico superficial, não sendo necessário adicionar qualquer tipo de isolante elétrico. No pré-aquecedor instalou-se um termopar na superfície superior, somente com a finalidade de detectar uma temperatura excessiva que pudesse danificar o tubo e suas conexões. Após a instalação dos termopares, ambas as seções foram envoltas com espuma isolante térmica, conforme ilustrado na Figura 4.22. Para o tubo de $1,00 \mathrm{~mm}$, foi utilizada configuração similar ao do tubo de $2,20 \mathrm{~mm}$, como ilustrado na Figura 4.24. A rugosidade na superfície interna do tubo de $1,00 \mathrm{~mm}$ foi avaliada resultando no valor RMS (Root Mean Square) em torno de $0,596 \mu \mathrm{m}$.

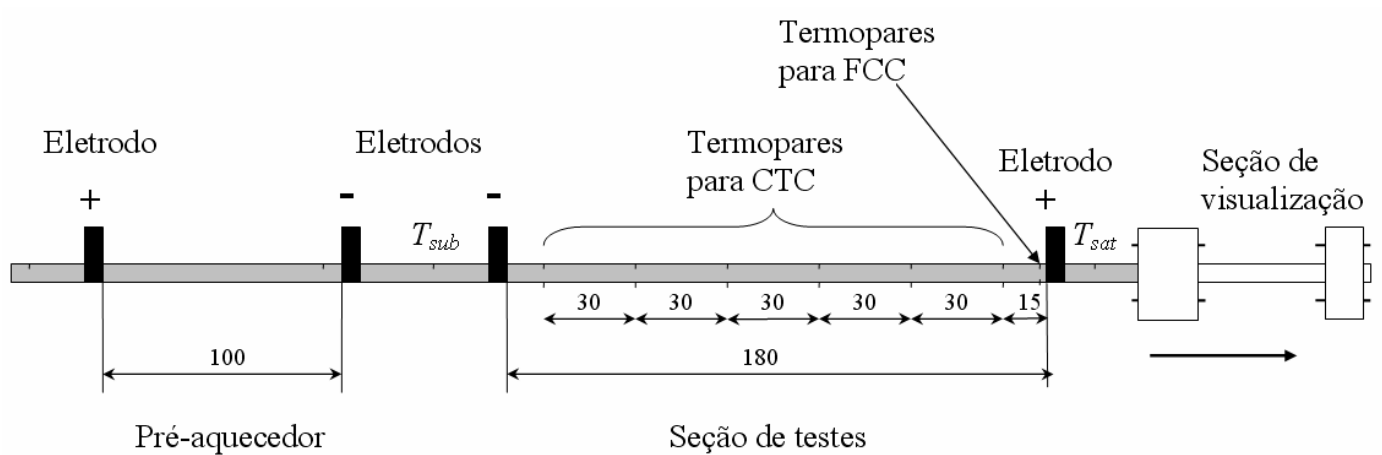

Figura 4.24 - Detalhes da seção de testes e posicionamento dos termopares no canal de 1,00mm.

\subsubsection{Canais não circulares}

Dois canais não circulares ilustrados esquematicamente na Figura 4.20 foram ensaiados. Estes canais foram obtidos deformando um primeiro tubo circular de diâmetro interno original $D_{i, \text { orig }}=3,00 \mathrm{~mm}$ e um segundo tubo de diâmetro interno original $D_{i, o r}=2,35 \mathrm{~mm}$ até se obter o diâmetro equivalente de $2,20 \mathrm{~mm}$. O tubo $D_{i, \text { orig }}=3,00 \mathrm{~mm}$ formou os canais com relação $(\mathrm{H} / \mathrm{W})=1 / 4$ e 4 , enquanto o tubo com $D_{i, \text { orig }}=2,35 \mathrm{~mm}$ formou os canais com relação $(\mathrm{H} / \mathrm{W})=1 / 2$ e 2, conforme ilustrado na Figura 4.20. Nesse processo de deformação, assumiu-se que o perímetro e a espessura do tubo se mantiveram constantes, fato admissível considerando-se que a espessura da parede era reduzida. Uma vista explodida da montagem do tubo achatado com $(H / W)=1 / 4$ está ilustrada na Figura 4.25. As extremidades do tubo foram mantidas circulares, facilitando a conexão com o circuito externo. Tanto a seção de 
testes como a de pré-aquecimento foram montadas no mesmo tubo, em aço inoxidável, não havendo juntas entre as duas partes. O comprimento aquecido na seção de testes utilizado nos experimentos de CTC foi de $361 \mathrm{~mm}$ e $90 \mathrm{~mm}$ no préaquecedor, e o comprimento da parte achatada era de $540 \mathrm{~mm}$. A instalação dos termopares sobre a superfície, nos ensaios com os tubos achatados, foi similar à do tubo circular de 2,20mm.

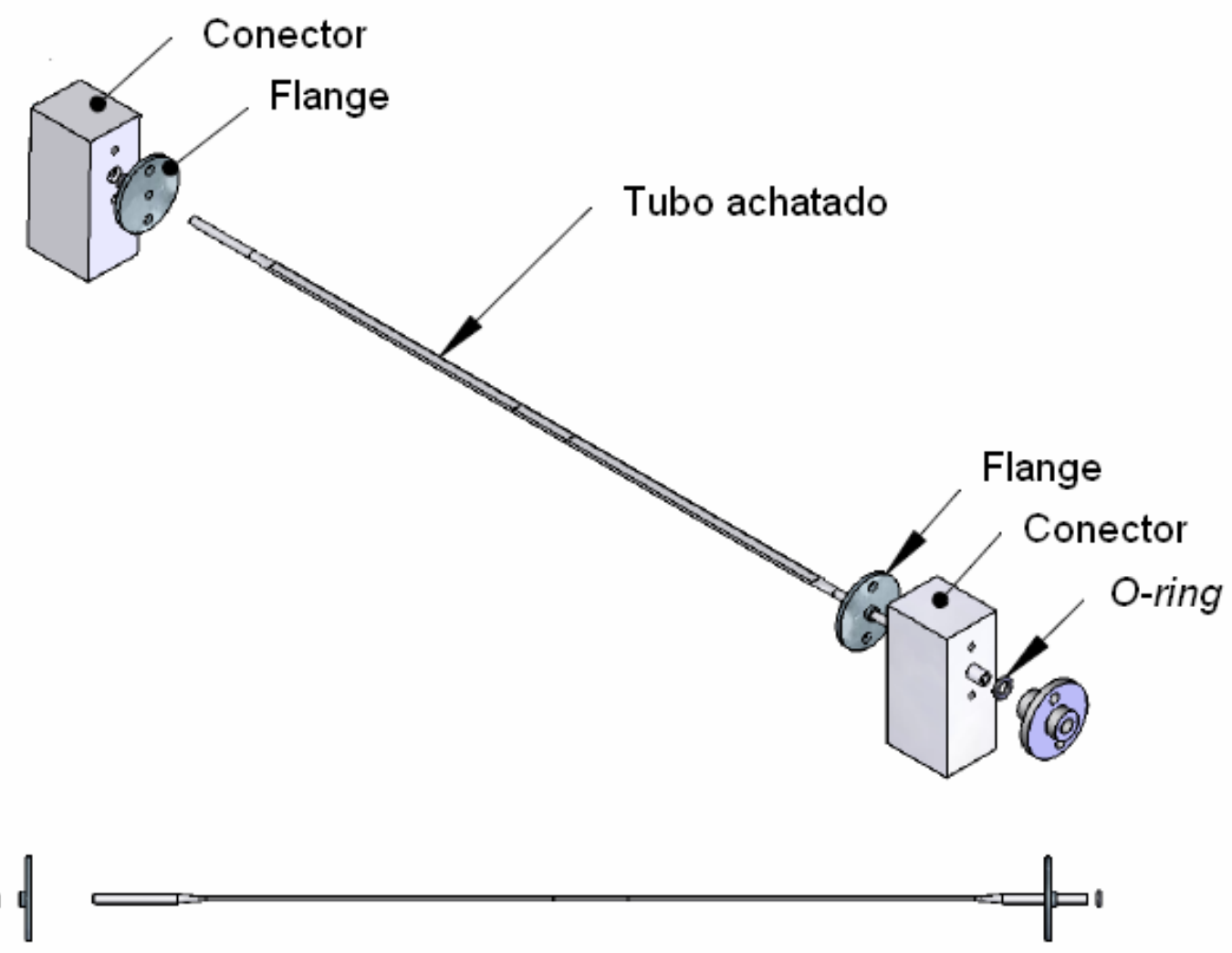

Figura 4.25 - Vista explodida da montagem do tubo achatado com $(H / W)=1 / 4$. Obs.: nesta ilustração, o comprimento do tubo não está em escala.

\subsubsection{SENSORES, CONTROLADORES E SISTEMA DE AQUISIÇÃO DE DADOS}

$\mathrm{Na}$ bancada II, a aquisição de dados foi realizada utilizando-se placas de aquisição da National Instruments com chassi SCXI-1000, contendo o condicionador de sinal SCXI-1102 (entradas analógicas) e o bloco de terminal SCXI-1303, com programação em Labview 7.

Foram utilizados 16 termopares da marca Thermocoax, com diâmetro de junta quente de $0,25 \mathrm{~mm}$, isolados eletricamente pelo fabricante. $O$ sensor de pressão 
absoluta é da marca Keller, modelo PAA 33 80794.5-10, e o sensor de pressão diferencial é um Keller, modelo Series PD - 39X, com operação entre 0-5bar. O medidor de vazão, do tipo coriolis, é um Micromotion, modelo CMF010m 2700, e as fontes de corrente DC eram: Sorensen dlm32-95, na seção de testes, com capacidade de até 95A, e, Sorensen DCS8-125E, no pré-aquecedor, com capacidade de até 125A. O programa de aquisição de dados salvava os dados numa frequência de aquisição de até $10 \mathrm{~Hz}$, limitada pela leitura do sinal de vazão através de protocolo digital.

\subsubsection{CONDIÇÕES EXPERIMENTAIS ENSAIADAS}

\subsubsection{Ensaios para escoamento monofásico}

Durante o levantamento experimental para condições monofásicas, os seguintes parâmetros foram variados: diâmetro interno do tubo, fluido refrigerante, velocidade mássica, pressão absoluta, sub-resfriamento na saída da seção de testes, e fluxo de calor. A Tabela 4.4 apresenta a faixa em que esses parâmetros foram ensaiados.

Tabela 4.4 - Faixas dos parâmetros experimentais ensaiados com escoamento monofásico.

\begin{tabular}{|c|c|c|c|c|c|}
\hline $\begin{array}{c}D_{i} \\
(m m)\end{array}$ & Fluido & $\begin{array}{c}\mathrm{G} \\
\left(\mathrm{kg} / \mathrm{m}^{2} \mathrm{~s}\right)\end{array}$ & $\begin{array}{c}\mathrm{p}_{\mathrm{abs}} \\
(\mathrm{kPa})\end{array}$ & $\begin{array}{c}\Delta \mathrm{T}_{\text {sub }} \\
\left({ }^{\circ} \mathrm{C}\right)\end{array}$ & $\begin{array}{c}q \\
\left(\mathrm{~kW} / \mathrm{m}^{2}\right)\end{array}$ \\
\hline 2,20 & $\begin{array}{c}\text { R134a } \\
\text { R245fa } \\
\text { R1234ze }\end{array}$ & $50-1500$ & $200-1000$ & $4-10$ & $2,5-50$ \\
\hline 1,00 & $\begin{array}{c}\text { R134a } \\
\text { R245fa } \\
\text { R1234ze }\end{array}$ & $50-1500$ & $200-1000$ & $4-10$ & $2,5-50$ \\
\hline $\begin{array}{l}\text { Tubo achatado } \\
D_{i, \text { orig }}=2,35 \mathrm{~mm}\end{array}$ & $\begin{array}{l}\text { R134a } \\
\text { R245fa }\end{array}$ & $50-1500$ & $200-1000$ & $4-10$ & $2,5-50$ \\
\hline $\begin{array}{l}\text { Tubo achatado } \\
D_{i, \text { orig }}=3,0 \mathrm{~mm}\end{array}$ & $\begin{array}{l}\text { R134a } \\
\text { R245fa }\end{array}$ & $50-1500$ & $200-1000$ & $4-10$ & $2,5-50$ \\
\hline
\end{tabular}




\subsubsection{Ensaios para escoamento bifásico}

Para a campanha experimental, segundo condições de ebulição convectiva, os seguintes parâmetros foram variados: diâmetro interno do tubo, fluido refrigerante, velocidade mássica, temperatura de saturação, título de vapor e fluxo de calor. A Tabela 4.5 apresenta as condições experimentais para as quais os ensaios foram executados.

Tabela 4.5 - Faixas dos parâmetros experimentais ensaiados com escoamento bifásico.

\begin{tabular}{|c|c|c|c|c|c|}
\hline $\begin{array}{c}D_{i} \\
(m m)\end{array}$ & Fluido & $\begin{array}{c}\mathrm{G} \\
\left(\mathrm{kg} / \mathrm{m}^{2} \mathrm{~s}\right)\end{array}$ & $\begin{array}{l}T_{\text {sat }} \\
\left({ }^{\circ} \mathrm{C}\right)\end{array}$ & $\begin{array}{c}\mathrm{X}_{\text {saida }} \\
(-)\end{array}$ & $\begin{array}{c}q \\
\left(\mathrm{~kW} / \mathrm{m}^{2}\right)\end{array}$ \\
\hline & R134a & & & & \\
\hline \multirow[t]{3}{*}{2,20} & $\mathrm{R} 245 \mathrm{fa}$ & $50-1500$ & $25 ; 31 ; 35$ & $0,05-0,99$ & $5,0-250$ \\
\hline & R1234ze & & & & \\
\hline & $\mathrm{R} 134 \mathrm{a}$ & & & & \\
\hline \multirow[t]{2}{*}{1,00} & $\mathrm{R} 245 \mathrm{fa}$ & $50-1500$ & $25 ; 31 ; 35$ & $0,05-0,99$ & $5,0-250$ \\
\hline & R1234ze & & & & \\
\hline Tubo achatado & $\mathrm{R} 134 \mathrm{a}$ & \multirow{2}{*}{$50-1500$} & \multirow{2}{*}{31} & \multirow{2}{*}{$0,05-0,99$} & \multirow{2}{*}{$5,0-250$} \\
\hline$D_{i, \text { orig }}=2,35 \mathrm{~mm}$ & R245fa & & & & \\
\hline Tubo achatado & $\mathrm{R} 134 \mathrm{a}$ & \multirow{2}{*}{$50-1500$} & \multirow{2}{*}{31} & \multirow{2}{*}{$0,05-0,99$} & \multirow{2}{*}{$5,0-250$} \\
\hline$D_{i, \text { orig }}=3,00 \mathrm{~mm}$ & $\mathrm{R} 245 \mathrm{fa}$ & & & & \\
\hline
\end{tabular}

Vale destacar, que o $\mathrm{R} 1234 z e(E)$ é um novo refrigerante desenvolvido para substituir o R134a, que é amplamente utilizado. Durante o desenvolvimento desse fluido, buscou-se obter um refrigerante com reduzido impacto ambiental e com desempenho similar ao R134a em suas aplicações. Como consequência desse esforço, o R1234ze(E) tem o ODP (potencial de destruição de ozônio) igual a zero, o mesmo do R134a, e um GWP (potencial de aquecimento global) de apenas 6, muito inferior ao valor de 1430 do R134a (ambos considerando um horizonte de tempo de 100 anos). O GWP é um índice usado para comparar o potencial de um gás em produzir efeito estufa, cuja referência é o $\mathrm{CO}_{2} \mathrm{com}$ valor de 1 . Isso significa que $1 \mathrm{~kg}$ de R1234ze(E) produz o mesmo efeito de aquecimento global de $6 \mathrm{~kg}$ de $\mathrm{CO}_{2}$. Outro importante parâmetro a favor do R1234ze(E) é o tempo de vida atmosférica: 14 dias, contra 14 anos do R134a. 


\subsection{Tratamento de dados}

Este item descreve as hipóteses adotadas e os procedimentos para tratamento dos dados utilizados para determinação dos resultados experimentais apresentados nesta tese.

\subsubsection{PARÂMETROS Gerais}

\subsubsection{Velocidade mássica}

A velocidade mássica é a razão entre a vazão mássica, $\dot{m}$, medida pelo medidor Coriolis e a área interna da seção transversal do tubo, $A_{i}$, conforme as equações (4-8) e (4-9).

$$
\begin{aligned}
G & =\frac{\dot{m}}{A_{i}} \\
A_{i} & =\frac{\pi \cdot D_{i}^{2}}{4}
\end{aligned}
$$

\subsubsection{Fluxo de calor}

O fluxo de calor, $q$, nas seções de testes e de pré-aquecimento, é dado pela razão entre a potência elétrica aplicada na seção, $P$, e a área superficial interna do tubo, $A_{s}$, considerando-se apenas a região aquecida. A potência elétrica é calculada diretamente pelo produto entre a tensão e a corrente, fornecidas pela fonte de corrente contínua. As fontes de correntes utilizadas permitem a medição da tensão localmente no ponto de contato do eletrodo e o tubo de testes, evitando-se, assim, erros relacionados à queda de tensão nas fontes, conforme as equações (4-10), (411), (4-12), (4-13).

$$
\begin{aligned}
& q_{s t}=\frac{P_{s t}}{A_{s, s t}} \\
& q_{p a}=\frac{P_{p a}}{A_{s, p a}} \\
& A_{s, s t}=\pi \cdot D_{i} \cdot L_{s t}
\end{aligned}
$$




$$
A_{s, p a}=\pi \cdot D_{i} \cdot L_{p a}
$$

Para fins de cálculo, considera-se que o fluxo de calor é uniforme ao longo do tubo e que perdas de calor para o ambiente na região aquecida do tubo são desprezadas. Para assumir esta hipótese, algumas verificações foram feitas:

- efeito de condução axial no tubo;

- efeito de resistência térmica do isolamento no fluxo de calor;

- efeito de aleta dos termopares.

Esses três efeitos combinados contribuem com menos de $1 \%$ de perda de calor para fluxos de calor acima de $10 \mathrm{~kW} / \mathrm{m}^{2}$ para o tubo de $2,32 \mathrm{~mm}$, considerando condições extremas de operação da bancada. Para fluxos inferiores, esse efeito torna-se relevante, apresentando valores substanciais para fluxos inferiores a $2,5 \mathrm{~kW} / \mathrm{m}^{2}$.

Gradientes de coeficiente de transferência de calor ao longo do perímetro do tubo resultam numa não uniformidade da temperatura superficial em uma seção transversal, originando estimativas incorretas do fluxo de calor devido a condução de calor ao longo do perímetro do tubo. Esses gradientes ocorrem em situações em que o escoamento bifásico não é uniforme na seção transversal do tubo, tal como em escoamentos com efeitos de estratificação. Nesses casos, não é correta a utilização de um único termopar para determinação da temperatura superficial, procedimento comumente utilizado. A Figura 4.26 apresenta a distribuição de temperatura ao longo da parede de um tubo submetido a transferência de calor não uniforme com o fluido a uma temperatura de $41^{\circ} \mathrm{C}$. A região superior interna do tubo está submetida a um CTC de $6 \mathrm{~kW} / \mathrm{m}^{2}$, enquanto a outra metade está submetida a um CTC de $2 \mathrm{~kW} / \mathrm{m}^{2}$. Toda a superfície externa do tubo é adiabática e existe uma geração interna de calor de $10^{8} \mathrm{~W} / \mathrm{m}^{3}$ (equivalente a um fluxo médio de $35 \mathrm{~kW} / \mathrm{m}^{2}$ para o tubo de 2,32mm ensaiado). Verifica-se, pelas isotermas, que ocorrem gradientes de temperatura positivos a partir da região superior do tubo.

A Figura 4.27 apresenta a parcela do fluxo de calor que ocorre na direção vertical resultante dessa simulação. Segundo a figura, a parcela do fluxo de calor na direção vertical transmitido para o fluido, na região superior do tubo, é de $39,25 \mathrm{~kW} / \mathrm{m}^{2}$, enquanto na região inferior é $25,4 \mathrm{~kW} / \mathrm{m}^{2}$. Caso não ocorresse esse efeito de condução ao longo do perímetro, o fluxo de calor seria $35 \mathrm{~kW} / \mathrm{m}^{2}$ em toda a 
região interna do tubo. Para materiais de condutividade térmica superior, como o cobre, esse efeito tende a se intensificar. É importante destacar que para experimentos com velocidades mássicas mais elevadas esse efeito tende a ser reduzido, fato pelo qual se priorizou ensaios experimentais neste trabalho com velocidades mássicas mais elevadas, $\mathrm{G}>200 \mathrm{~kg} / \mathrm{m}^{2} \mathrm{~s}$.

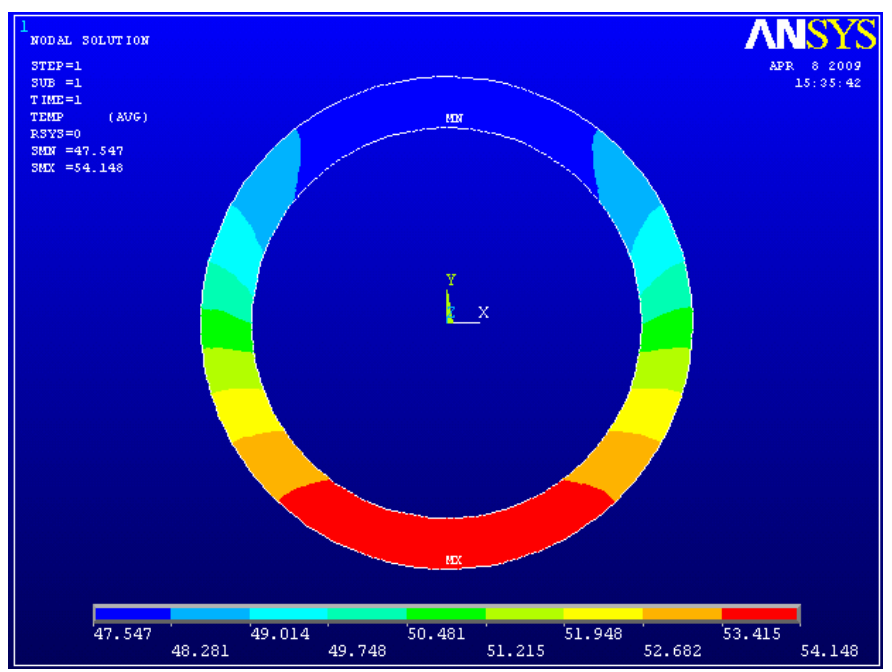

Figura 4.26 - Resultado, em elementos finitos, no tubo de 2,32mm, mostrando a distribuição de temperatura na parede do tubo na presença de convecção assimétrica em relação ao eixo- $x$ no interior do tubo.

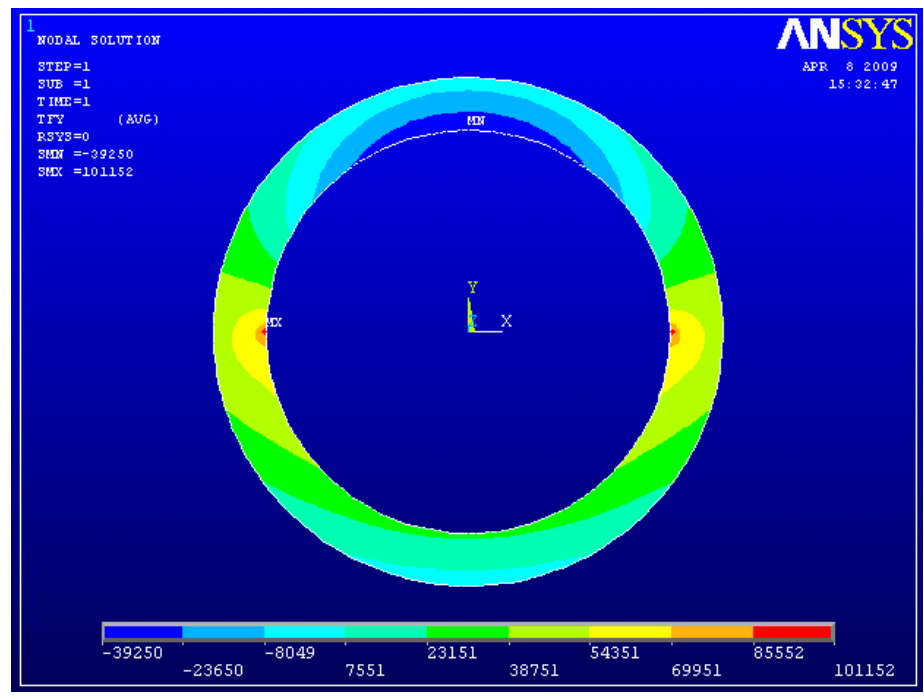

Figura 4.27 - Valores do fluxo de calor na direção Y, correspondente às condições simuladas na Figura 4.26. 


\subsubsection{Comprimento monofásico na seção de pré-aquecimento}

O comprimento monofásico na seção de pré-aquecimento é calculado através da solução de um sistema de três equações, equações (4-14) a (4-16). A região na qual o escoamento se torna saturado é onde a temperatura e a pressão termodinâmica local no canal se igualam à condição de saturação (desprezando-se efeitos de superaquecimento junto à superfície). A temperatura local do fluido no préaquecedor é calculada mediante um balanço de energia, enquanto que a pressão local é estimada a partir da queda de pressão assumindo um fator de atrito de Darcy dado por 64/Re para $R e<2300$ e a correlação de Petukov (1970) para $R e>2300$. Nesse cálculo, as propriedades do fluido foram estimadas com relação à temperatura de entrada no pré-aquecedor, pois mesmo considerando uma variação de $20^{\circ} \mathrm{C}$ na temperatura, o erro na queda de pressão é inferior a $2 \%$. Nas equações (4-14) a (4-16), $L_{1}$, é o comprimento não aquecido antes da seção de pré-aquecimento, como indicado na Figura 4.4. A temperatura de saturação na equação (4-16) é estimada por intermédio de software para cálculos de propriedades termodinâmicas, tal como EES (2009) ou Refprop (2008).

$$
\begin{aligned}
& q_{p a} \cdot \pi \cdot D_{i} \cdot L_{\text {mono }}=G \cdot A_{i} \cdot\left[i_{L}\left(T=T_{\text {sat }}\right)-i_{L, e n}\right] \\
& p_{\text {sat }}=p_{\text {en }}-\frac{f \cdot\left(L_{\text {mono }}+L_{1}\right) \cdot G^{2}}{2 \cdot D_{i} \cdot \rho_{L, e n t}} \\
& T_{\text {sat }}=\text { temperatura }_{\text {sat }}\left(p=p_{\text {sat }}\right)
\end{aligned}
$$

\subsubsection{Pressão do fluido}

A pressão ao longo da seção de testes é calculada assumindo-se uma variação linear da pressão na região de escoamento bifásico. Para isso, deve-se saber a

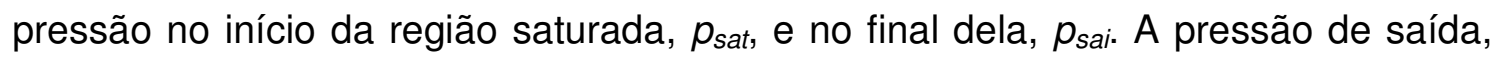

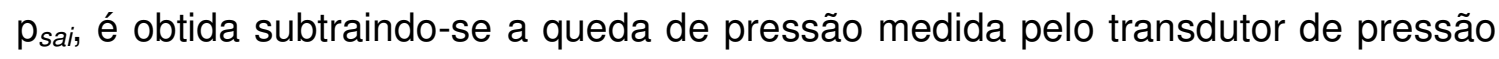
diferencial, $\Delta p$, da pressão na entrada, $p_{\text {ent }}$, determinada por um sensor de pressão

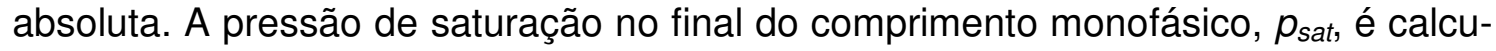
lada pelo sistema de equações (4-14) a (4-16). Assim, a pressão num determinado comprimento $z$, na seção de testes, é obtida por meio das equações (4-17) a (4-18). 


$$
\begin{aligned}
& p(z)=p_{\text {sai }}+\left(p_{\text {sat }}-p_{\text {sai }}\right) \cdot \frac{L_{\text {sat }}-\left(z+L_{2}+L_{p a}-L_{\text {mono }}\right)}{L_{\text {sat }}} \\
& p_{\text {sai }}=p_{\text {ent }}-\Delta p \\
& L_{\text {sat }}=L_{T}-\left(L_{\text {mono }}+L_{1}\right)
\end{aligned}
$$

sendo $L_{1}$ e $L_{2}$ comprimentos não aquecidos, como indicados na Figura 4.4.

\subsubsection{Temperatura do fluido}

A temperatura de saturação numa posição $z$, ao longo da seção de testes, é calculada diretamente com EES (2009) ou Refprop (2008), a partir da pressão de saturação local, de acordo com a equação (4-19).

$$
T_{\text {sat }}(z)=\text { temperatura }_{\text {sat }}(p=p(z))
$$

\subsubsection{Título de vapor}

O título de vapor local é determinado por um balanço de energia entre a entrada do pré-aquecedor e a posição $z$ ao longo da seção de testes. A entalpia na entrada da seção de testes, $i_{\text {ent,st }}$, pode ser razoavelmente aproximada pela entalpia do líquido saturado à temperatura da entrada, segundo as equações (4-20) a (423).

$$
\begin{aligned}
& x(z)=\frac{i(z)-i_{L}(z)}{i_{L V}(z)} \\
& i(z)=\frac{P_{s t}(z)}{G \cdot A_{i}}+i_{\text {ent,st }} \\
& P_{s t}(z)=q_{s t} \cdot \pi \cdot D_{i} \cdot z \\
& i_{e n t, s t}=\frac{P_{p a}}{G \cdot A_{i}}+i_{e n t}
\end{aligned}
$$

O título de vapor na entrada da seção de vidro é calculado diretamente pelo balanço de energia ao longo de toda seção de pré-aquecimento e de testes, segundo a equação (4-24). 


$$
x_{s a i}=\frac{\left(\frac{P_{s t}+P_{p a}}{G \cdot A_{i}}+i_{e n t}\right)-i_{L, s a i}}{i_{L V, s a i}}
$$

\subsubsection{Coeficiente de transferência de calor}

O coeficiente de transferência de calor local é calculado segundo a lei de resfriamento de Newton, de acordo com a equação (4-25).

$$
h(z)=\frac{q_{s t}}{T_{p i}(z)-T_{s a t}(z)}
$$

sendo: $q_{s t}$ o fluxo de calor na seção de testes, dado pela equação (4-10); $T_{\text {sat }}(z)$, a temperatura de saturação local na posição $z$, calculada de acordo com a equação (4-19); e, $T_{p i}$, a temperatura interna local da parede, estimada através da lei de Fourier, considerando condução unidimensional e superfície externa adiabática, segundo as equações (4-26) e (4-27),

$$
\begin{aligned}
& T_{p i}(z)=T_{s}(z)+\frac{E_{g}}{4 \cdot k_{p}} \frac{\left(D_{e}^{2}-D_{i}^{2}\right)}{4}-\frac{E_{g}}{2 \cdot k_{p}} \frac{D_{e}^{2}}{4} \cdot \ln \left(\frac{D_{e}}{D_{i}}\right) \\
& E_{g}=\frac{P_{s t}}{\pi\left(\frac{D_{e}^{2}-D_{i}^{2}}{4}\right) \cdot L_{s t}}
\end{aligned}
$$

nas quais: $T_{s}(z)$ é a temperatura na superfície externa do tubo, medida pelos termopares fixados na superfície da seção de testes; $E_{g}$ é a geração interna de calor do tubo, relacionada à potência fornecida pela fonte de corrente contínua. Adotou-se a condutividade térmica para o aço inoxidável AISI-304, material do tubo, igual a $k_{p}=16,3 \mathrm{~W} / \mathrm{m} . \mathrm{K}$.

O coeficiente de transferência de calor médio ao longo do perímetro de uma seção específica da seção de testes é dado pela equação (4-28),

$$
\bar{h}(z)=\frac{h_{\text {topo }}(z)+2 \cdot h_{\text {lateral }}(z)+h_{\text {base }}(z)}{4}
$$

onde: $h_{\text {topo }}, h_{\text {lateral }}, h_{\text {base }}$ são os coeficientes locais de transferência de calor, calculados de acordo com os termopares posicionados, respectivamente, no topo, 
na lateral e na base do tubo, para uma determinada posição $z$ (ver Figura 4.4). No caso de ensaios onde se utilizou somente dois termopares, um no topo e outro na base, o coeficiente de transferência de calor médio ao longo do perímetro de uma seção específica da seção de testes é dado pela equação (4-29).

$$
\bar{h}(z)=\frac{h_{\text {topo }}(z)+h_{\text {base }}(z)}{2}
$$

\subsubsection{Fluxo crítico de calor (FCC)}

O fluxo crítico de calor foi calculado utilizando a mesma expressão apresentada para o cálculo do fluxo de calor na seção de testes, equação (4-10). Para medir o FCC, a potência aplicada a seção de testes foi incrementada em pequenos valores, sempre controlando os outros parâmetros do experimento de forma a mantê-los constante. Nesta campanha experimental o FCC foi definido para a situação em que a temperatura da parede, medida pelo termopar localizado no fim da seção de testes, alcançasse $40 \mathrm{~K}$ de superaquecimento (ver Figura 4.23 e Figura 4.24). Este procedimento foi usado para evitar detecções errôneas do FCC devido a oscilações de temperatura da parede, que são comuns em condições de secagem da parede relativas a altos títulos de vapor.

Uma curva de superaquecimento da parede versus fluxo de calor durante a ebulição convectiva, com velocidade mássica de $200 \mathrm{~kg} / \mathrm{m}^{2}$ s para $\mathrm{R} 134$ a é mostrada na Figura 4.28. Antes da ocorrência do FCC, o superaquecimento da parede é inferior a $10 \mathrm{~K}$. Acima do valor de $55 \mathrm{~kW} / \mathrm{m}^{2}$, um pequeno incremento do fluxo de calor causa um drástico aumento do superaquecimento da parede. Para esta condição, o fluxo de calor é caracterizado neste trabalho como FCC, no qual, para as condições da Figura 4.28 e com um superaquecimento $\Delta T_{\text {sup }}=$ $39 \mathrm{~K}$ resultou em um valor de $58 \mathrm{~kW} / \mathrm{m}^{2}$. 


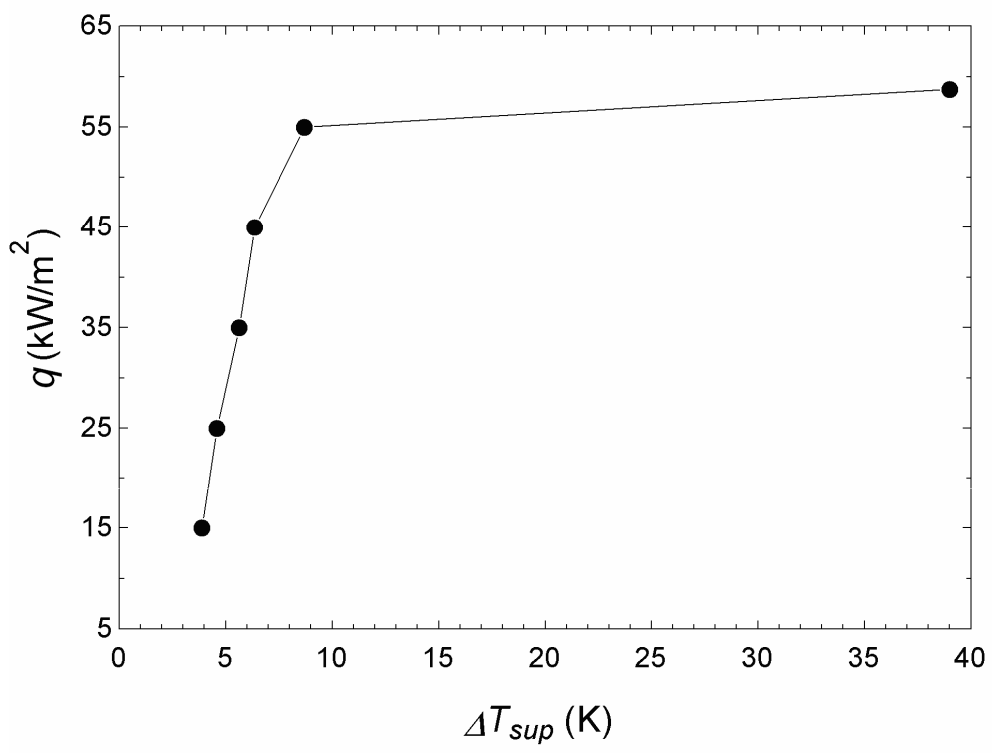

Figura 4.28 - Superaquecimento da parede para R134a para $\mathrm{G}=200 \mathrm{~kg} / \mathrm{m}^{2} \mathrm{~s}, T_{\text {sat }}=31^{\circ} \mathrm{C}, \mathrm{L}_{\mathrm{a}}$ que $=361 \mathrm{~mm}, T_{\text {sub }}=4 \mathrm{~K}$.

\subsubsection{ESCOAMENTO MONOFÁSICO}

\subsubsection{Velocidade mássica e fluxo de calor}

A velocidade mássica e o fluxo de calor são calculados da mesma forma que no escoamento bifásico, por meio das equações (4-8) e (4-10).

\subsubsection{Balanço de energia}

O balanço de energia monofásico, $(\Delta E / E)$, é realizado num volume de controle que engloba as seções de pré-aquecimento e de testes. Nesse balanço, a potência fornecida pelas fontes de corrente contínua, $P_{\text {elet, }}$ é comparada com a potência calculada através da variação da entalpia do fluido ao longo deste volume de controle, $P_{\text {inter, }}$ conforme as equações (4-30) a (4-32). Os termopares na entrada do préaquecedor e na saída da seção de testes permitem determinar as respectivas entalpias, $i_{e n t}$ e $i_{\text {sai }}$, na condição monofásica, considerando-se estas similares ao do líquido saturado à mesma temperatura.

$$
\frac{\Delta E}{E}=\frac{\left(P_{\text {inter }}-P_{\text {elet }}\right)}{P_{\text {elet }}}
$$




$$
\begin{aligned}
& P_{\text {inter }}=G \cdot A_{i} \cdot\left(i_{s a i}-i_{e n t}\right) \\
& P_{\text {elet }}=P_{s t}+P_{p a}
\end{aligned}
$$

\subsubsection{Temperatura do fluido ao longo da seção de testes}

A temperatura do fluido numa posição $z$, ao longo da seção de testes, é determinada através do balanço de energia num volume de controle que se inicia na posição $z$ e termina ao final da seção de testes, onde são determinadas a pressão e a temperatura do fluido. Considera-se adiabática toda a região após a seção de testes e a entalpia na saída, $i_{\text {sai }}$, é determinada pela temperatura medida pelo termopar imerso na saída da seção de visualização. Como a entalpia do liquido sub-resfriado praticamente não varia com a pressão, ela pode ser aproximada pela entalpia do líquido saturado à mesma temperatura. Assim, a temperatura numa posição $z$ é dada pelas equações (4-33) e (4-34).

$$
\begin{aligned}
& i(z)=i_{\text {sai }}-\frac{q_{s t} \cdot \pi \cdot D_{i} \cdot\left(L_{s t}-z\right)}{G \cdot A_{i}} \\
& T(z)=\text { temperatura }(i(z) ; x=0)
\end{aligned}
$$

\subsubsection{Coeficiente de transferência de calor}

O coeficiente de transferência de calor para escoamento monofásico é calculado da mesma forma que o bifásico, exceto que neste a temperatura do fluido na posição $z$ é obtida pela equação (4-34).

\subsection{INCERTEZAS EXPERIMENTAIS E VALIDAÇÃO DO APARATO EXPERIMENTAL}

As incertezas experimentais foram avaliadas pelo método de propagação de incertezas descrito em Moffat (1988). Considerando que toda medida $X_{i}$ apresenta uma incerteza $\delta X_{i}$, uma variável $R=R\left(X_{1}, X_{2}, \ldots, X_{n}\right)$, função de $N$ variáveis independentes $X_{i}$, terá a incerteza dada pela equação (4-35). 


$$
\delta R=\left[\sum_{i=1}^{N}\left(\frac{\partial R}{\partial X_{i}} \delta X_{i}\right)^{2}\right]^{1 / 2}
$$

Os erros dos instrumentos de medição utilizados nos experimentos estão listados nas Tabela 4.6 e Tabela 4.7. Esses erros foram levantados a partir das especificações técnicas dos manuais ou dos certificados de calibração dos instrumentos utilizados. O erro de temperatura dos termopares foi determinado por meio do procedimento de calibração descrito no apêndice A.

Tabela 4.6 - Incerteza dos parâmetros experimentais bancada experimental I.

\begin{tabular}{cccc}
\hline Parâmetro & Incerteza & Parâmetro & Incerteza \\
\hline$D$ & $20 \mu \mathrm{m}$ & $\Delta p$ & $150 \mathrm{~Pa}$ \\
$L$ & $1,0 \mathrm{~mm}$ & $q$ & $0,8 \%$ \\
$p$ & $4,5 \mathrm{kPa}$ & $T$ & $0,15^{\circ} \mathrm{C}$ \\
$\dot{m}$ & $0,1 \%$ & & \\
\hline
\end{tabular}

Tabela 4.7- Incerteza dos parâmetros experimentais bancada experimental II.

\begin{tabular}{cccc}
\hline Parâmetro & Incerteza & Parâmetro & Incerteza \\
\hline$D$ & $20 \mu \mathrm{m}$ & $\Delta p$ & $1 \mathrm{kPa}$ \\
$L$ & $1,0 \mathrm{~mm}$ & $q$ & $0,8 \%$ \\
$p$ & $500 \mathrm{~Pa}$ & $T$ & $0,15^{\circ} \mathrm{C}$ \\
$\dot{m}$ & $0,1 \%$ & & \\
\hline
\end{tabular}

Aplicando a equação (4-35) aos parâmetros velocidade mássica, fluxo de calor, título de vapor e coeficiente de transferência de calor, obtiveram-se as incertezas relativas $\frac{\delta R}{R}$, em porcentagem, indicadas na Tabela 4.8 e Tabela 4.9.

Tabela 4.8 - Incerteza dos parâmetros experimentais G, $q$, x e $h$, na bancada I.

\begin{tabular}{cccc}
\hline Parâmetro & Incerteza & Parâmetro & Incerteza \\
\hline$G$ & $1,7 \%$ & $x$ & $<5 \%$ \\
$q$ & $1,2 \%$ & $h$ & $<30 \%$ \\
\hline
\end{tabular}


Tabela 4.9 - Incerteza dos parâmetros experimentais $G, q, x \mathrm{e}$ $h$, na bancada II.

\begin{tabular}{cccc}
\hline Parâmetro & Incerteza & Parâmetro & Incerteza \\
\hline$G$ & $2 \%$ & $x$ & $<5 \%$ \\
$q$ & $2,6 \%$ & $h$ & $<20 \%$ \\
\hline
\end{tabular}

O fluxo crítico de calor tem a incerteza dada aproximadamente pela incerteza do fluxo de calor $q$. Considerando que a secagem da parede possa promover efeitos de condução axial na parede do tubo, a incerteza do FCC, na prática, deve ser ligeiramente superior à do fluxo de calor apresentada nas tabelas acima.

Como o título de vapor e o CTC dependem de vários parâmetros experimentais, a incerteza relativa depende da condição experimental ensaiada. Sendo assim, os valores apresentados nas Tabela 4.8 e Tabela 4.9 foram as maiores incertezas do banco de dados obtido. As incertezas no CTC da bancada II são inferiores à da bancada I devido à realização de experimentos com velocidades mássicas e fluxos de calor superiores.

Para assegurar a acuracidade na estimativa do título de vapor e avaliar a taxa efetiva de transferência de calor para o fluido refrigerante, uma análise do balanço de energia monofásico foi realizada com base na equação 4-29. Como se pode ver na Figura 4.29, as perdas de calor decrescem com o incremento da velocidade mássica e observam-se taxas efetivas de transferência de calor para o ambiente inferiores a $10 \%$ para $G \geq 100 \mathrm{~kg} / \mathrm{m}^{2} \mathrm{~s}$ e $5 \%$ para $G \geq 400 \mathrm{~kg} / \mathrm{m}^{2} \mathrm{~s}$. Perdas superiores ocorreram para $G=50 \mathrm{~kg} / \mathrm{m}^{2} \mathrm{~s}$.

A Figura 4.30 ilustra resultados a partir dos quais se buscou avaliar a variação da perda de calor com a temperatura do líquido na saída da seção de testes, mantendo-se a temperatura externa em $22^{\circ} \mathrm{C}$ e a de entrada do pré-aquecedor em $13^{\circ} \mathrm{C}$. Verifica-se que quanto mais próxima for a temperatura de saída à do ambiente, menores as perdas de calor. Este experimento demonstrou que ensaios bifásicos realizados a $T_{\text {sat }}=22^{\circ} \mathrm{C}$ devem apresentar perdas de calor inferiores para o ambiente, e, assim, tornar próximas as estimativas do título de vapor a do valor real. Para escoamentos em ebulição convectiva, o CTC interno é muito superior ao do monofásico, tornando as perdas de calor para o ambiente inferiores. 


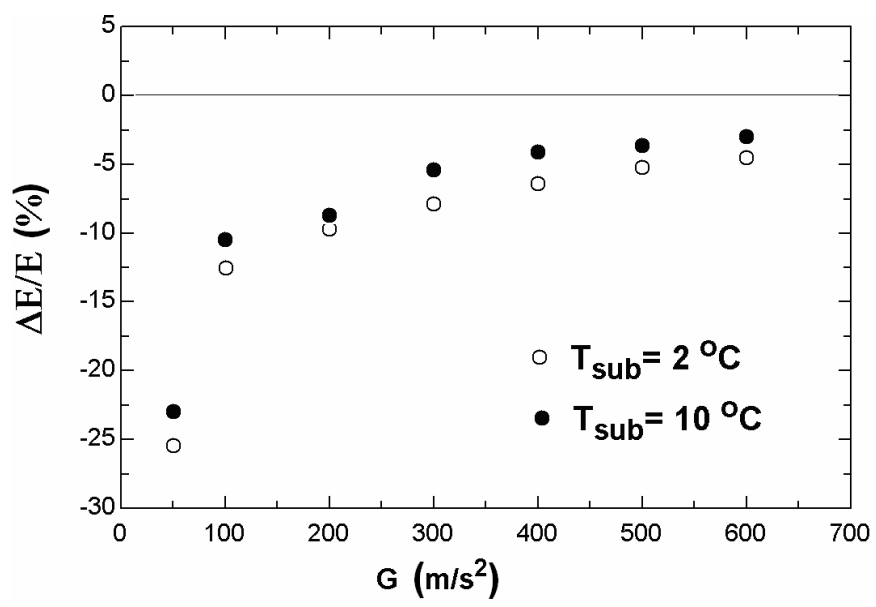

Figura 4.29 - Avaliação do balanço de energia monofásico para temperaturas de subresfriamento na saída da seção de testes, $T_{\text {sub,sai, }}$ de 2 e $10^{\circ} \mathrm{C}$.

(R134a, $D=2,32 \mathrm{~mm}, T_{\text {ent }}=16^{\circ} \mathrm{C}, p=10^{6} \mathrm{~Pa}, q_{s t}=q_{p a}$ ).
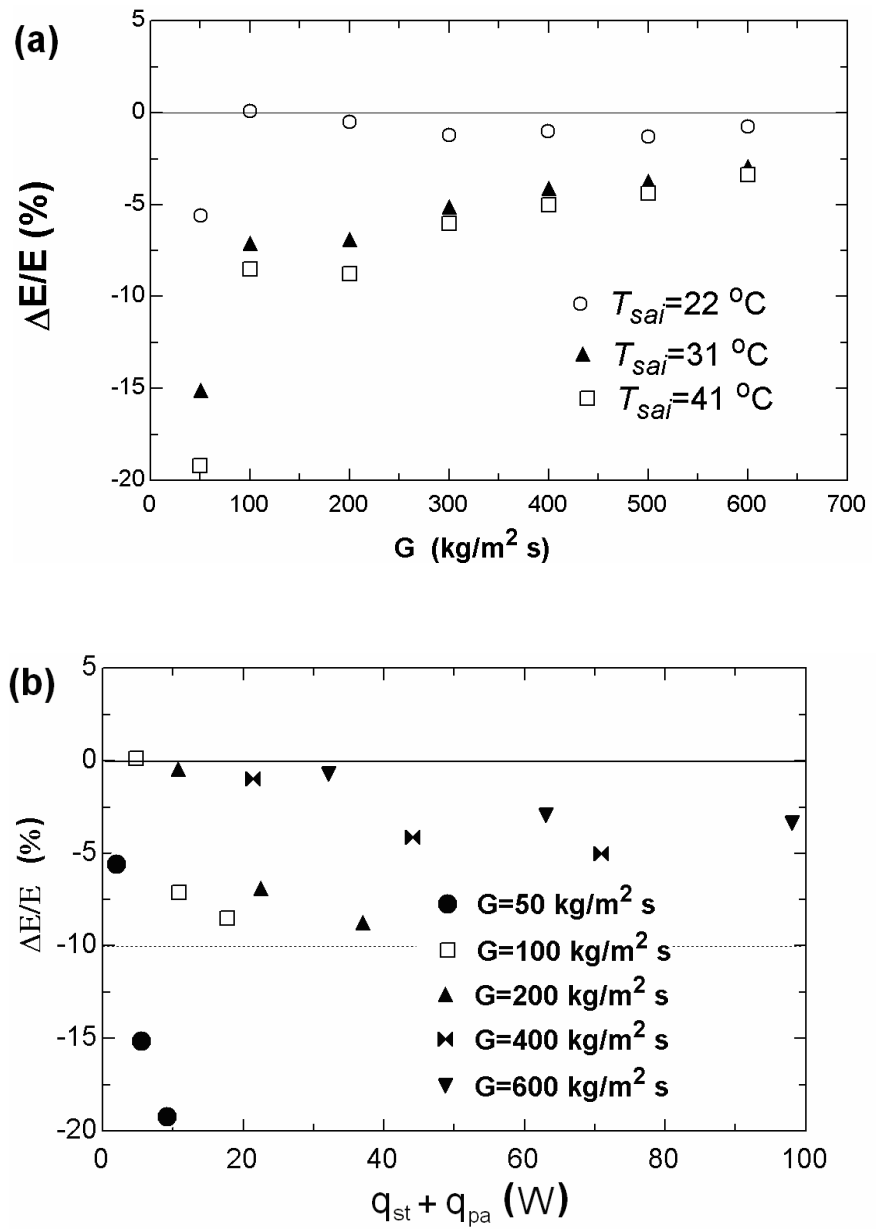

Figura 4.30 - Avaliação do balanço de energia monofásico (R134a, $D=2,3 \mathrm{~mm}$, $T_{\text {ent }}=13^{\circ} \mathrm{C}$ ): (a) função da velocidade mássica e temperatura de saída; (b) função da potência aplicada e velocidade mássica. 
Foram ainda realizados experimentos monofásicos de medida do CTC e de queda de pressão. Compararam-se esses resultados com valores fornecidos pelas correlações de Gnielinski (1976) e Petukhov (1970), respectivamente. Para Re laminar, foi utilizado um fator de atrito tipo Darcy, $f=64 / R e$. A Figura 4.31(a) ilustra coincidências satisfatórias entre o CTC experimental e os valores calculados através das correlações. Para queda de pressão, os resultados também são satisfatórios, conforme ilustrado na Figura 4.31(b), considerando-se o fato de nenhum parâmetro experimental ter sido ajustado.
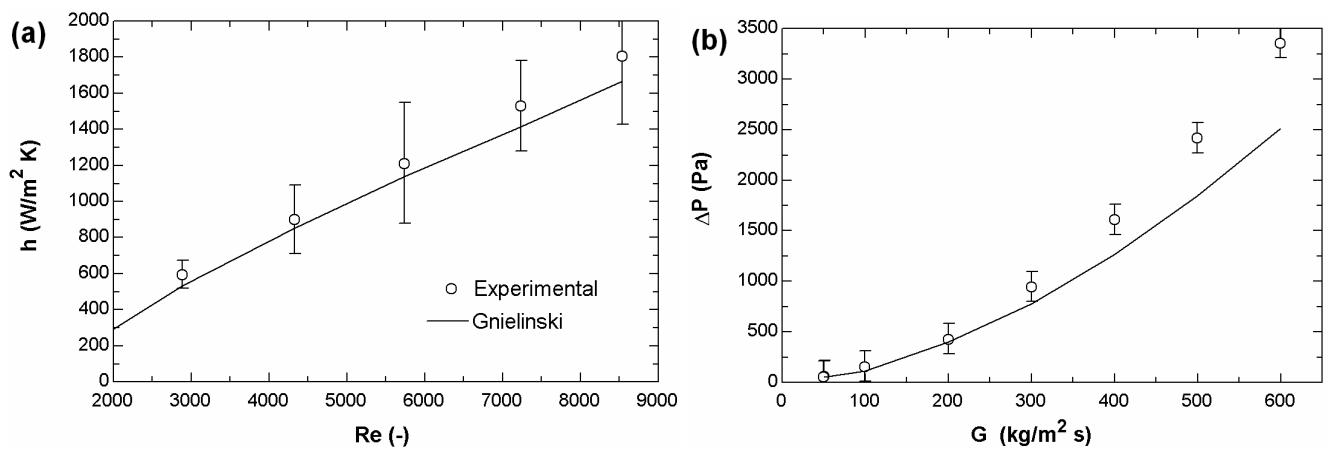

Figura 4.31 - (a) Comparação entre CTC experimental monofásico e o previsto pela correlação de Gnielinski (1976) (R134a, $\left.D=2,32 \mathrm{~mm}, \mathrm{~T}_{\text {sai }}=40^{\circ} \mathrm{C}\right)$; (b) Comparação entre a perda de pressão experimental monofásica e a prevista teoricamente (R134a, $\left.D=2,32 \mathrm{~mm}, \mathrm{~T}_{\text {sai }}=40^{\circ} \mathrm{C}\right)$.

De modo geral, os ensaios revelaram resultados similares para validação, independentemente do fluido e diâmetros ensaiados, conforme Figura 4.32 e Figura 4.33.
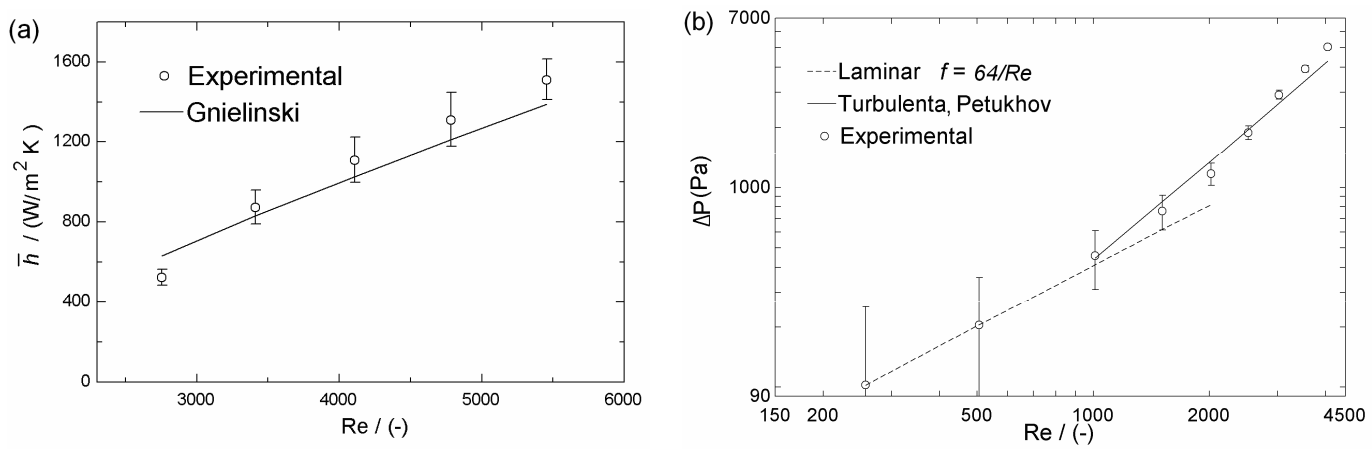

Figura 4.32 - (a) Comparação entre CTC experimental monofásico e o predito pela correlação de Gnielinski (1976) (R24fa, $D=2,32 \mathrm{~mm}, \mathrm{~T}_{\text {sai }}=31^{\circ} \mathrm{C}$ ); (b) Comparação entre a perda de pressão experimental monofásica e a prevista teoricamente (R245fa, $D=2,32 \mathrm{~mm}$, $\left.\mathrm{T}_{\text {sai }}=31^{\circ} \mathrm{C}\right)$. 

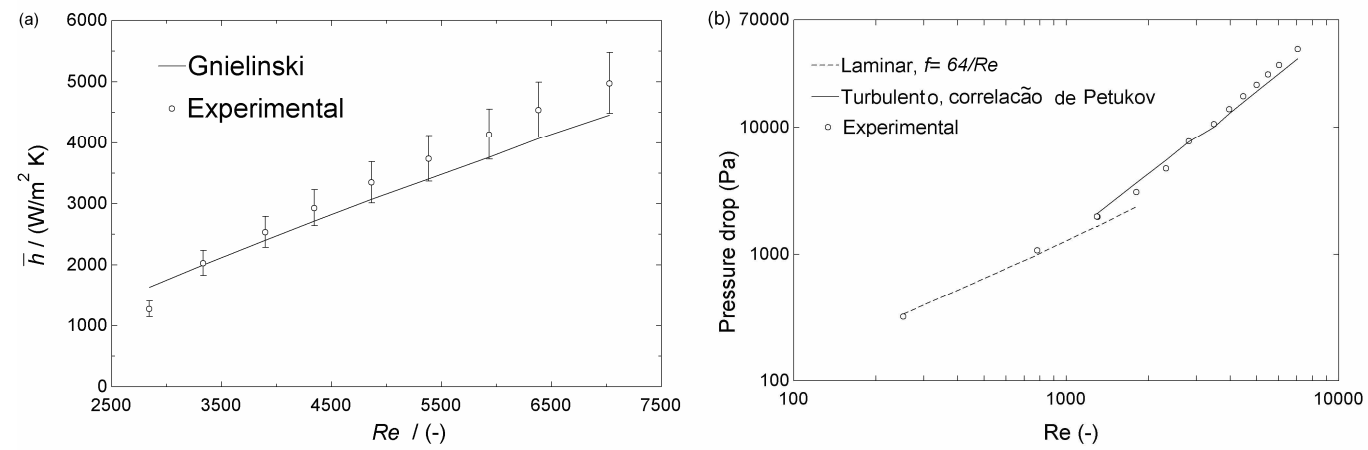

Figura 4.33 - (a) Comparação entre CTC experimental monofásico e o previsto pela correlação de Gnielinski (1976) (R245fa, $\left.D=1,10 \mathrm{~mm}, \mathrm{~T}_{\text {sai }}=31^{\circ} \mathrm{C}\right)$; (b) Comparação entre a perda de pressão experimental monofásica e a prevista teoricamente (R245fa, $D=1,10 \mathrm{~mm}$, $\left.\mathrm{T}_{\text {sai }}=31^{\circ} \mathrm{C}\right)$.

Com a finalidade de verificar os experimentos realizados neste estudo, foi realizada uma comparação contra resultados disponíveis na literatura para ebulição convectiva em condições similares. Na Figura 4.34, resultados levantados no presente estudo são comparados com os obtidos por Yan e Lin (1998). Verifica-se uma concordância razoável entre esses resultados, apesar do fato de Yan e Lin (1998) terem ensaiado multi-microcanais circulares de diâmetro interno igual a 2,0mm.

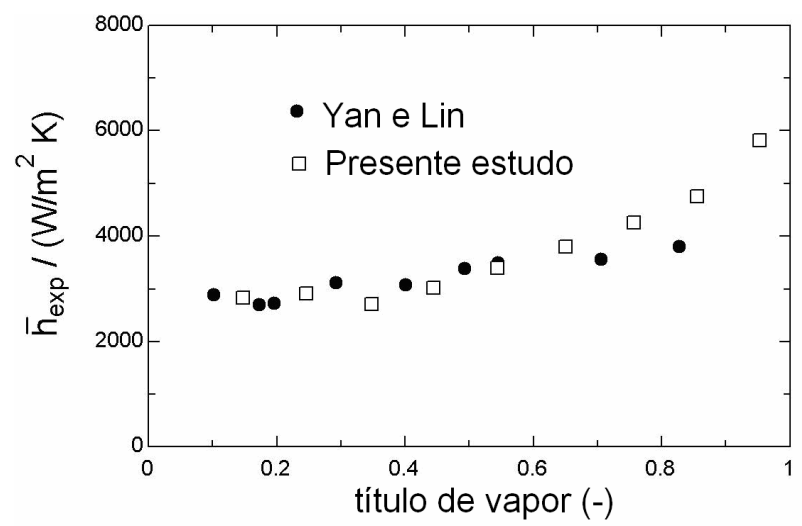

Figura 4.34 - Comparação entre dados da literatura (YAN; LIN, 1998) e os obtidos no presente estudo $\left(\mathrm{G}=200 \mathrm{~kg} / \mathrm{m}^{2} \mathrm{~s}, q=5 \mathrm{~kW} / \mathrm{m}^{2}, T_{\text {sat }}=31^{\circ} \mathrm{C}\right)$.

Para validar as medidas de CTC fornecidas pelos termopares em posições axiais distintas ao longo da seção de testes, é apresentada uma comparação na Figura 4.35. Nela, são comparados resultados de $\bar{h}$, fornecidos pelos termopares posicionados a $15 \mathrm{~mm}$ e a $65 \mathrm{~mm}$ do final da seção de testes em condições similares de velocidade mássica, temperatura de saturação e títulos de vapor próximos. Segundo a Figura 4.35, a diferença entre os CTCs fornecidos através destes termopa- 
res encontra-se dentro da incerteza dos resultados experimentais. Esse resultado evidencia que a escolha da distância de $15 \mathrm{~mm}$ entre a última seção de termopares foi apropriada, sendo o efeito de aleta do eletrodo desprezível nessa posição.

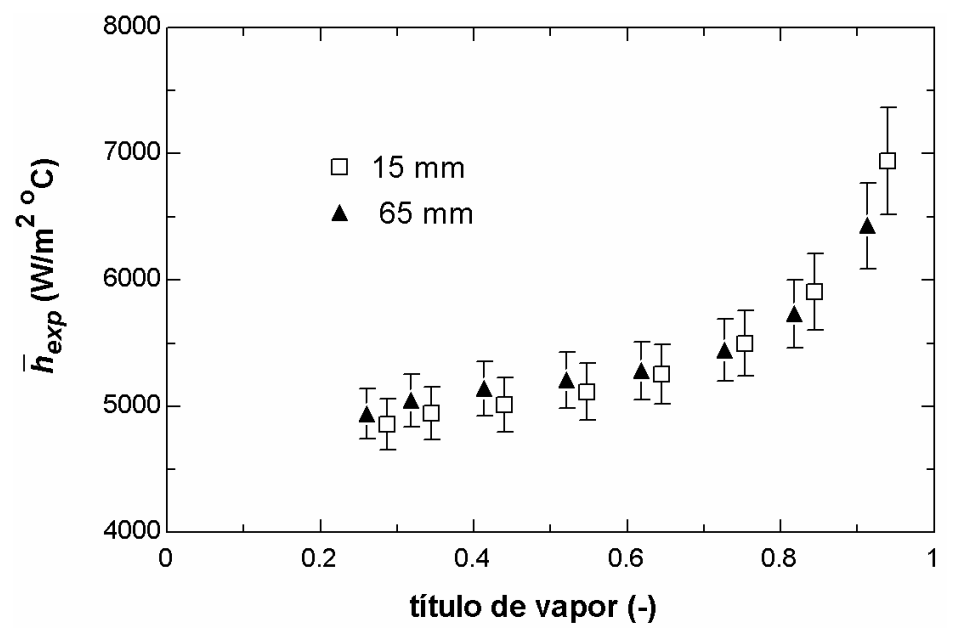

Figura 4.35 - Comparação entre $\bar{h}$ medidos em posições axiais distintas do tubo $\left(\mathrm{G}=300 \mathrm{~kg} / \mathrm{m}^{2} \mathrm{~s}, q=15 \mathrm{~kW} / \mathrm{m}^{2}, T_{\text {sat }}=41^{\circ} \mathrm{C}\right)$

Com o objetivo de verificar a repetitividade dos resultados experimentais, na Figura 4.36 são comparados resultados para condições experimentais similares, levantadas com espaçamento superior a 2 meses. Nessa figura, verifica-se que apesar do período entre ensaios, os resultados são similares. Ao longo desse período, diversos ensaios foram realizados e não ocorreu substituição de fluido refrigerante.

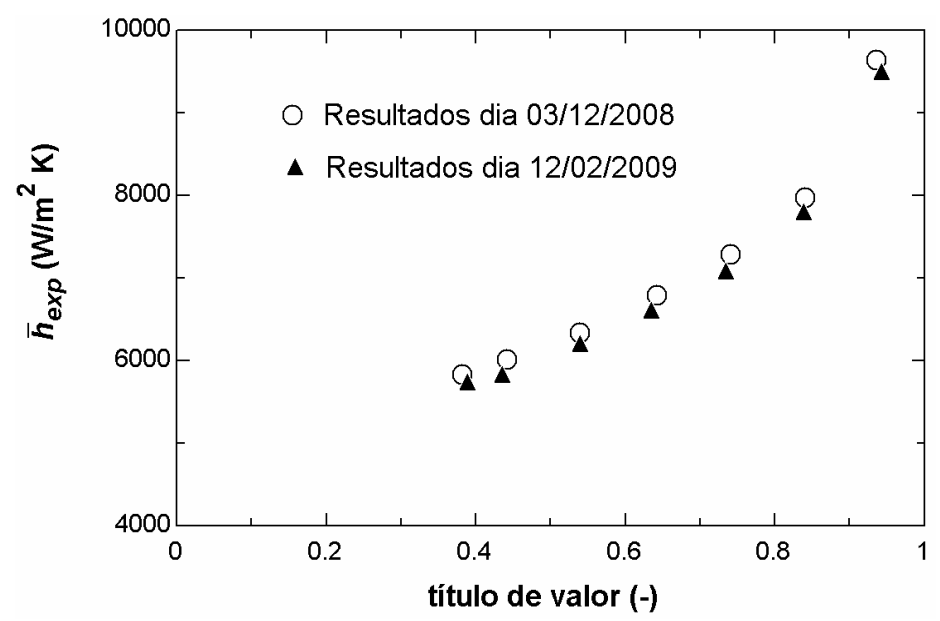

Figura 4.36 - Repetitividade dos ensaios experimentais bifásicos $\left(\mathrm{G}=400 \mathrm{~kg} / \mathrm{m}^{2} \mathrm{~s}\right.$, $\mathrm{T}_{\text {sat }}=22^{\circ} \mathrm{C}, q=35 \mathrm{~kW} / \mathrm{m}^{2}$ ) 
Instabilidades térmicas relacionadas a volumes compressíveis, também chamadas de 'ebulição explosiva', são fenômenos comuns em ebulição convectiva em microcanais. Essas instabilidades podem promover variações elevadas de pressão e temperatura no escoamento e parecem explicar algumas das discrepâncias observadas entre resultados de diferentes autores, como discutido em Consolini (2008). Durante a campanha experimental do presente estudo, as flutuações na temperatura do fluido e na pressão estiveram dentro da incerteza das medidas dos transdutores.

Na presente pesquisa, também foi realizada investigação da queda de pressão bifásica para os tubos ensaiados. Tibiriçá e Ribatski (2011) e Tibiriçá, Diniz da Silva e Ribatski (2011) apresentaram resultados dessa investigação para o tubo de 2,32mm. A hipótese de gradiente de pressão constante ao longo da região saturada foi verificada. Pressões locais estimadas das medidas de temperatura dos termopares da superfície do tubo durante escoamento saturado adiabático foram usadas para verificar essa hipótese. A Figura 4.37 apresenta uma curva da pressão local versus a distância da saída da seção de testes, de acordo com os resultados experimentais e a hipótese de queda de pressão linear. De acordo com a figura, a hipótese de gradiente de pressão constante pode ser considerada para as faixas de queda de pressão obtidas na campanha experimental.

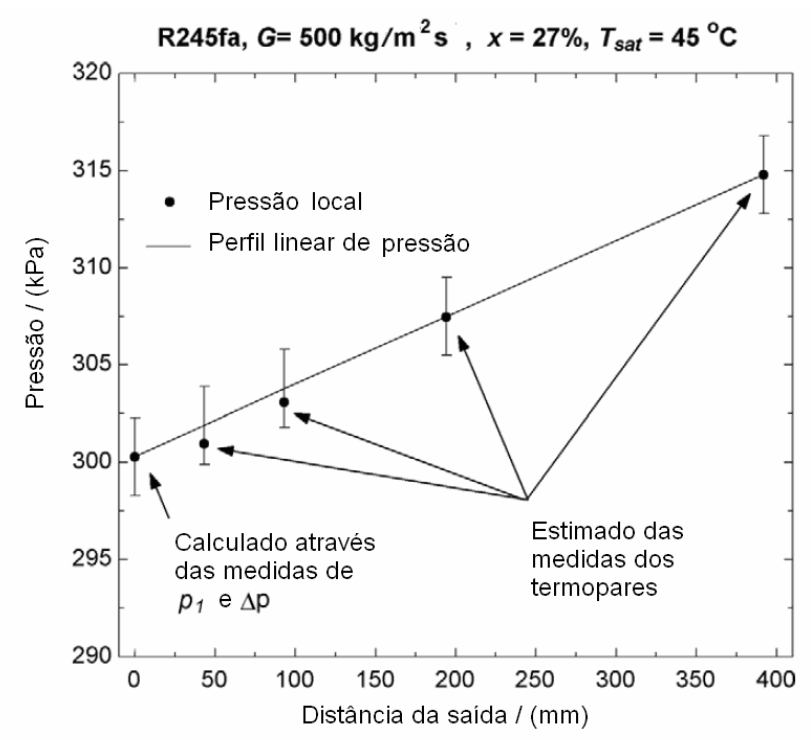

Figura 4.37 - Comparação entre a hipótese de queda de pressão linear utilizada para o cálculo da temperatura de saturação ao longo da seção de testes e as medidas de pressão derivadas das temperaturas da superfície do tubo no escoamento em ebulição convectiva adiabática. R245fa no tubo de 2,32mm, em Tibiriçá e Ribatski (2011). 


\subsection{Conclusões}

Os procedimentos e equipamentos experimentais utilizados durante os ensaios em microcanais foram apresentados. As hipóteses consideradas para o tratamento dos dados experimentais foram descritas e as incertezas experimentais fornecidas. Recomenda-se atenção especial a condições de variações do CTC ao longo do perímetro do tubo, pois, nessa condição, conforme ilustrado, ocorre condução de calor circunferencial que afeta a acuracidade do fluxo de calor. Tal condição não foi mencionada ou observada na maioria dos trabalhos similares da literatura. As bancadas experimentais foram validadas através dos ensaios monofásicos para CTC, queda de pressão e balanço de energia. Procedimentos de validação em ebulição convectiva também foram realizados. 


\section{RESULTADOS EXPERIMENTAIS}

Este capítulo apresenta os resultados experimentais para CTC e FCC durante a ebulição convectiva levantados neste estudo. Também são apresentados os padrões de escoamento observados e discutidos aspectos envolvendo instabilidades no escoamento.

\subsection{MAPAS DE PADRÃO DE ESCOAMENTO}

Mapas de padrão de escoamento foram levantados utilizando-se câmera de alta velocidade para os canais circulares com diâmetros internos $D_{i}=1,00 ; 1,10 ; 2,20$; e 2,32 mm. Esses experimentos tiveram o intuito de investigar o efeito do diâmetro, fluido, temperatura, vazão e título de vapor nas transições entre os seguintes padrões de escoamentos observados para esses tubos: bolhas, pistonado, agitante e anular. O padrão estratificado não foi observado na presente campanha experimental. Os tubos achatados, devido à dificuldade em se fabricar a seção transparente de visualização no formato desses canais, não tiveram seus padrões observados.

\subsubsection{EFEITO DO DIÂMETRO}

Em microcanais, de forma análoga ao observado na literatura para macrocanais, como em Barbieri, Jabardo e Bandarra Filho (2008), o incremento do diâmetro tende a elevar o título da transição entre os padrões intermitente e anular. $\mathrm{Na}$ Figura 5.1, comparando-se os títulos de transição intermitente-anular para o tubo de $1,00 \mathrm{~mm}$ e o tubo de $2,20 \mathrm{~mm}$, a $31^{\circ} \mathrm{C}$, observa-se um incremento de $3 \%$ no título de vapor de transição com o aumento do diâmetro, portanto dentro da faixa de incerteza das estimativas do título de vapor. Para as transições entre os regimes bolhas, pistonado e agitante, parece ocorrer uma redução do título de vapor de transição com o incremento do diâmetro. Isso permite especular que para uma determinada velocidade mássica, os padrões bolhas, pistonado e agitante tendem a não ocorrer com a redução do diâmetro, tornando assim o padrão anular predominante, mesmo para títulos de vapor reduzidos. Para ambos os diâmetros, o incremento da veloci- 
dade mássica causa uma redução do título de vapor da transição de todos os padrões, tornando o padrão anular predominante sobre toda a faixa de títulos de vapor.
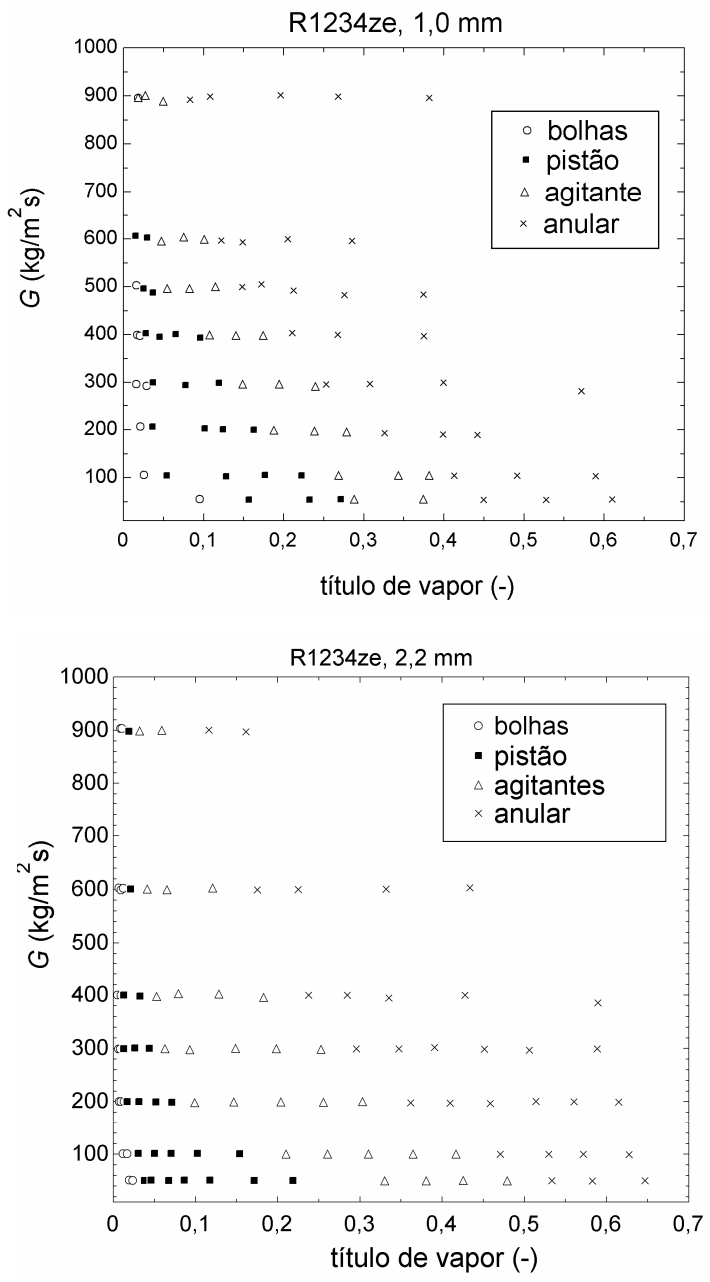

Figura 5.1 - Padrões de escoamento para R1234ze(E) em canais de $1,00 \mathrm{~mm}$ e $2,20 \mathrm{~mm}, T_{\text {sat }}=31^{\circ} \mathrm{C}$.

\subsubsection{EFEITO dO FLUIDO}

A Figura 5.2 apresenta os mapas de padrões de escoamento para os três fluidos avaliados neste trabalho, para o diâmetro de $1,00 \mathrm{~mm}$ a $31^{\circ} \mathrm{C}$. Na figura, observa-se que as curvas de transição dependem do título de vapor e da vazão mássica para todos os fluidos. Verifica-se também que os títulos de transição entre os padrões de escoamento decrescem progressivamente do R134a ao R1234ze e R245fa. 

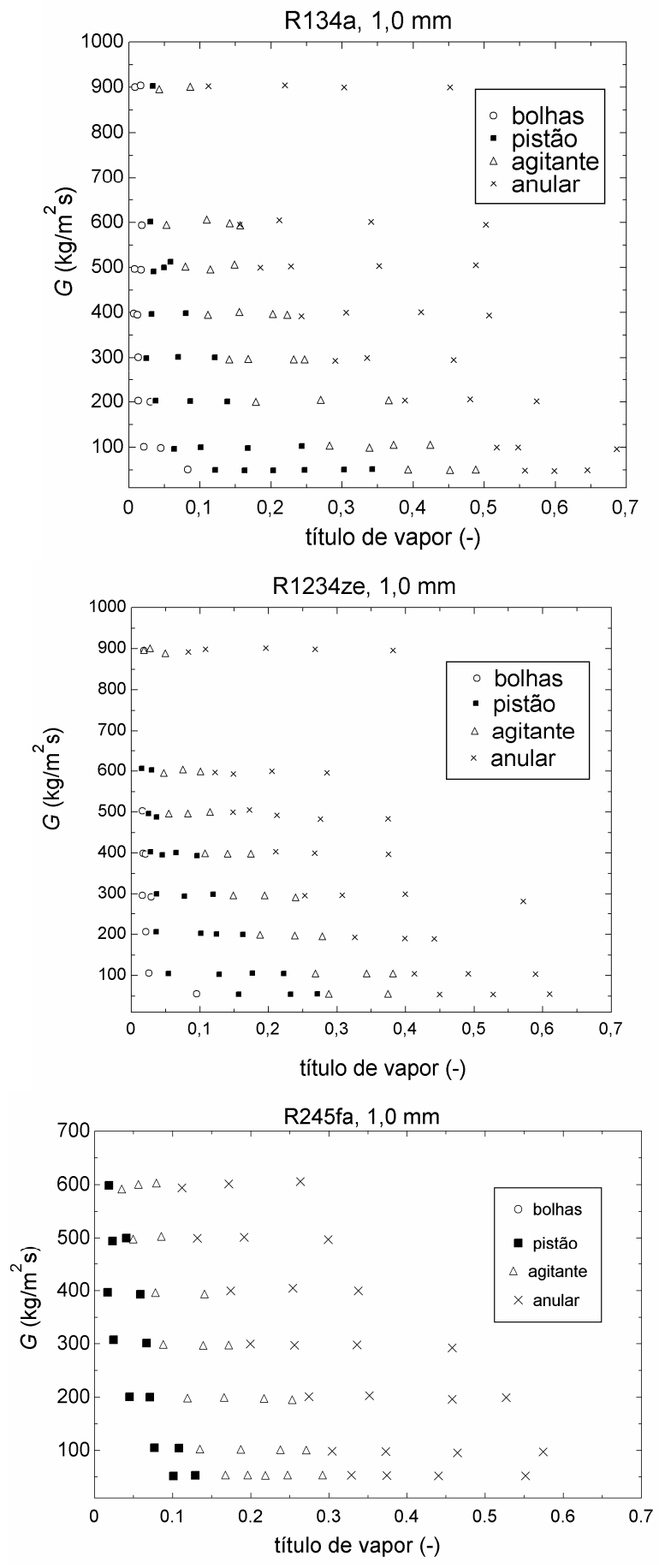

Figura 5.2 - Mapas de padrão de escoamento para R1234ze, R134 e R245fa. $\left(T_{\text {sat }}=31^{\circ} \mathrm{C}, D_{i}=1,00 \mathrm{~mm}\right)$. 
A Tabela 5.1 apresenta propriedades de transporte e termodinâmicas para os três fluidos a $31^{\circ} \mathrm{C}$. Esse decréscimo do título de transição está relacionado ao incremento do volume específico da fase vapor com a redução da pressão do fluido refrigerante. Com o incremento do volume específico do vapor, eleva-se a velocidade superficial desta fase e seus efeitos inerciais, rompendo, desse modo, pontes de líquido observadas durante os escoamentos em bolhas alongadas e agitante. Comportamentos similares também foram observados para o tubo de 2,32mm utilizando R134a e R245fa.

Tabela 5.1 - Propriedades dos fluidos R1234ze, R134a e R245fa a $31^{\circ} \mathrm{C}$.

\begin{tabular}{|c|c|c|c|c|c|c|c|}
\hline & $\begin{array}{c}\boldsymbol{T} \\
\left({ }^{\circ} \mathrm{C}\right)\end{array}$ & $\begin{array}{c}\boldsymbol{P} \\
(\mathrm{MPa})\end{array}$ & $\begin{array}{c}\boldsymbol{v}_{\boldsymbol{I}} \\
10^{3} \cdot\left(\mathrm{m}^{3} / \mathrm{kg}\right)\end{array}$ & $\begin{array}{c}\boldsymbol{v}_{\boldsymbol{v}} \\
10^{3}\left(\mathrm{~m}^{3} / \mathrm{kg}\right)\end{array}$ & $\begin{array}{c}\boldsymbol{h}_{l v} \\
(\mathrm{~kJ} / \mathrm{kg})\end{array}$ & $\begin{array}{c}\boldsymbol{\mu}_{l} \\
(\mu \mathrm{Pa}-\mathrm{s})\end{array}$ & $\begin{array}{c}\boldsymbol{\sigma} \\
(\mathrm{mN} / \mathrm{m})\end{array}$ \\
\hline R134a & 31 & 0.8 & 0,85 & 25,64 & 172 & 181 & 7.3 \\
\hline R1234ze & 31 & 0.6 & 0,88 & 32,26 & 162 & 188 & 7.7 \\
\hline R245fa & 31 & 0,18 & 0,76 & 95,42 & 186 & 374 & 13,2 \\
\hline
\end{tabular}

\subsubsection{EFEITO DA TEMPERATURA}

A Figura 5.3 ilustra efeitos da temperatura de saturação na transição entre padrões de escoamento para os refrigerantes R134a e R245fa no canal de $D_{i}=2,32 \mathrm{~mm}$. De acordo com essa figura, para uma mesma velocidade mássica, as transições ocorrem a títulos de vapor superiores, com o incremento da temperatura de saturação. Tal comportamento decorre do decréscimo do volume específico com o incremento da temperatura de saturação, reduzindo efeitos inerciais relacionados à velocidade do vapor no núcleo do escoamento. 


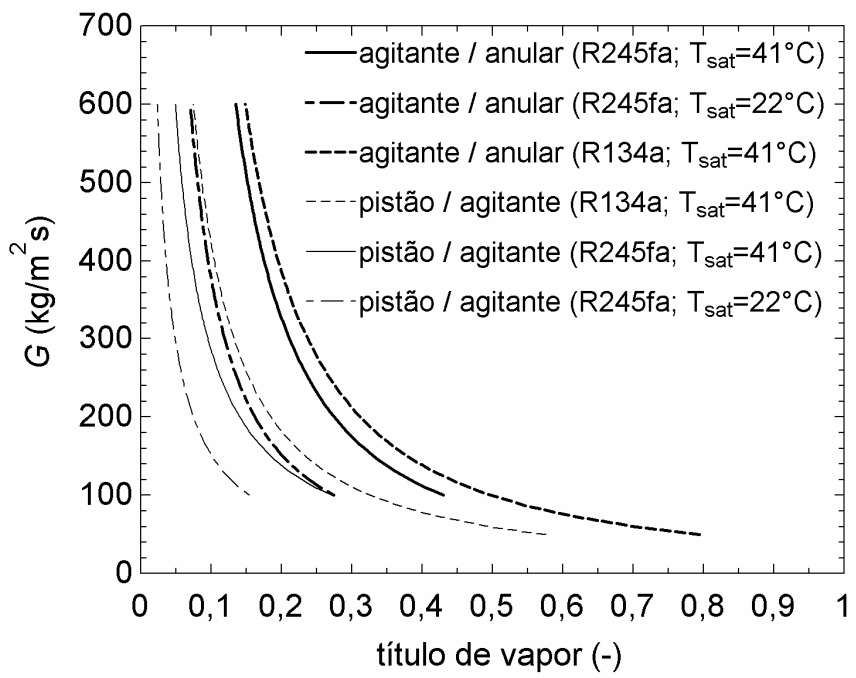

Figura 5.3 - Curvas de transição, comparando efeito da temperatura de saturação para R134a e R245fa.

\subsubsection{AvaliaçÃo de MÉtOdos de PREVISÃo}

Neste item, os métodos de previsão de padrões de escoamento propostos por Barnea, Luninski e Taytel (1983), Revellin e Thome (2007a), Felcar, Ribatski e Jabardo (2007) e Ong e Thome (2011a) são comparados aos resultados experimentais levantados no presente estudo. As Figura 5.4 a Figura 5.7 ilustram essas comparações.

De acordo com a Figura 5.4, Barnea, Luninski e Taytel (1983) indicam, de forma análoga aos resultados experimentais levantados no presente estudo, a não ocorrência de escoamento estratificado. Cenário similar foi observado para as temperaturas de saturação de 31 e $41^{\circ} \mathrm{C}$. Na figura, nota-se que o método de Barnea, Luninski e Taytel (1983) não representa satisfatoriamente a transição entre o padrão intermitente (bolhas alongadas mais agitante) e o anular. Ele também não captura 0 decréscimo do título de vapor de transição entre os padrões intermitente e anular com o incremento da velocidade mássica, pois prevê um título de vapor de transição constante. Esse resultado está relacionado com hipóteses de uma relação linear entre as velocidades superficiais de vapor e líquido e uma fração de vazio de transição fixa. A combinação de ambas as hipóteses resulta em um título de vapor de transição constante. 


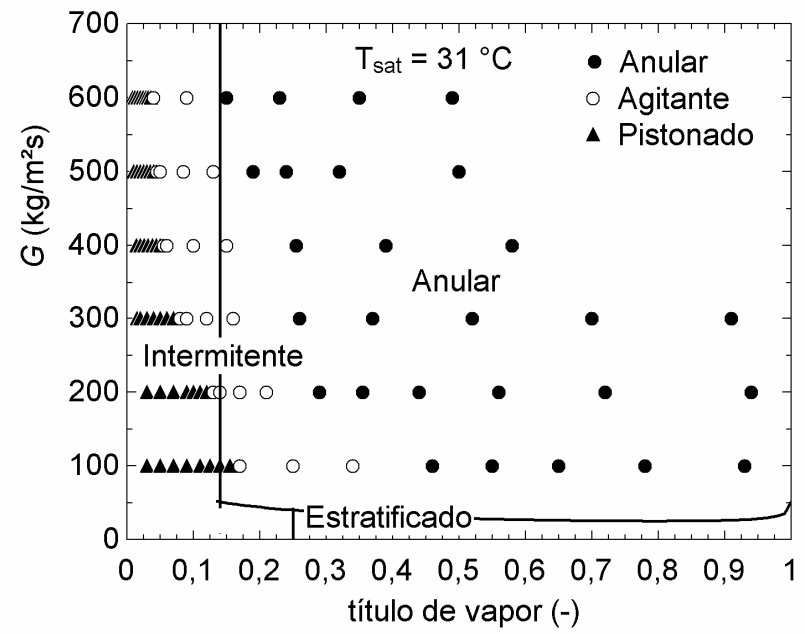

Figura 5.4 - Comparação entre o método de Barnea, Luninski e Taytel (1983) e dados experimentais para R245fa, $D=2,32 \mathrm{~mm}$.

A Figura 5.5 ilustra uma comparação entre os resultados para padrão de escoamento e as linhas de transição baseadas no método de Revellin e Thome (2007a), para temperatura de saturação de $31^{\circ} \mathrm{C}$. Nessa figura, IB, CB e A referemse aos regimes de bolhas isoladas, bolhas coalescentes e anular, respectivamente. Revellin e Thome (2007a) e, posteriormente, Ong e Thome (2011a), segregaram o padrão de bolhas alongadas em dois regimes: (i) regime de bolhas isoladas, caracterizado pela taxa de geração de bolhas superior à taxa de coalescência de bolhas e (ii) regime de bolhas coalescentes, caracterizado pela taxa de coalescência de boIhas superior à de geração. De acordo com a Figura 5.5, para os dados experimentais e um dado título, a transição intermitente (agitante e bolhas alongadas) e anular ocorre a velocidades mássicas inferiores às fornecidas pelo método. Como discutido anteriormente, para uma velocidade mássica fixa e independentemente do refrigerante, a transição entre intermitente e anular, segundo os resultados experimentais, ocorre em títulos de vapor superiores com o incremento da temperatura de saturação. Segundo o método de Revellin e Thome (2007a), tal comportamento ocorre apenas para R245fa, enquanto comportamento oposto é proporcionado por este método para o R134a. De acordo com os resultados experimentais, o regime de secagem foi observado somente para títulos de vapor superiores a $80 \%$, enquanto, segundo Revellin e Thome (2007a), a região de secagem ocupa quase toda a parte superior direita do mapa de padrão de escoamento. A transição para escoamento estratificado não é fornecida por este método, dado que ele é baseado em dados 
experimentais para tubos com diâmetros inferiores a $1 \mathrm{~mm}$, condição na qual o escoamento estratificado não se verifica para esses fluidos.
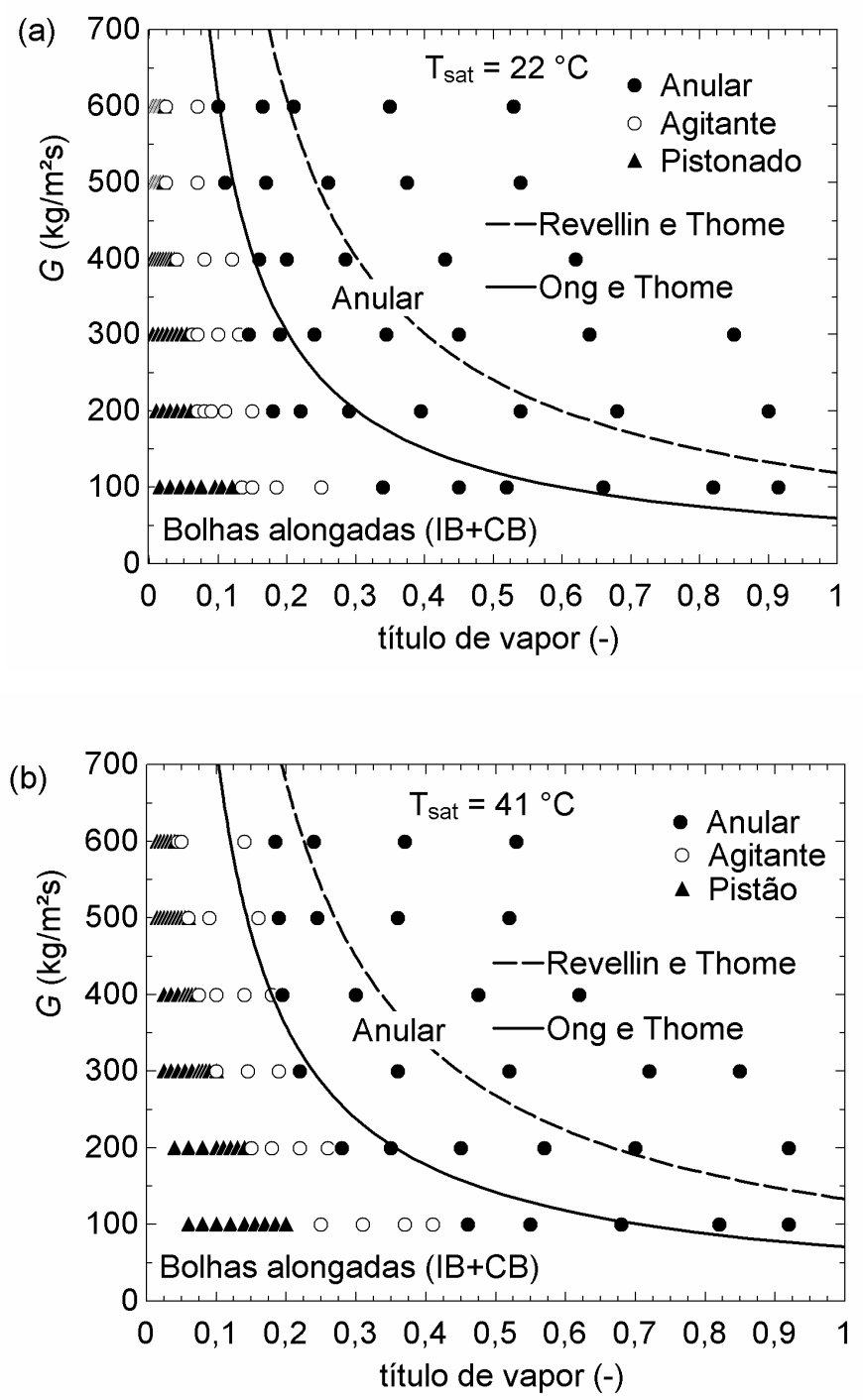

Figura 5.5 - Comparação entre os métodos preditivos (linhas) de Revellin e Thome (2007a) e Ong e Thome (2011a) e os dados experimentais (símbolos), para R245fa e $\mathrm{D}=2,32 \mathrm{~mm}$.

A Figura 5.6 apresenta comparações entre o banco de dados e as transições, segundo o método de Felcar, Ribatski e Jabardo (2007). De forma geral, Felcar, Ribatski e Jabardo (2007), preveem razoavelmente os dados do presente estudo. A transição intermitente-anular foi satisfatoriamente capturada, com o método prevendo o decréscimo de título de vapor para transição entre intermitente anular com o incremento da velocidade mássica. $O$ incremento do título de vapor de transição entre os padrões intermitente e anular com a elevação da temperatura de satu- 
ração, segundo os resultados experimentais, é superior ao estimado pelo método. Tal comportamento demonstra uma imprecisão desse método com o incremento da temperatura de saturação. O método de Felcar, Ribatski e Jabardo (2007) também sugere a ausência de escoamento estratificado durante o escoamento bifásico dos refrigerantes R134a e R245fa em um tubo de 2,32mm. Para altos títulos de vapor e velocidades mássicas inferiores a $100 \mathrm{~kg} / \mathrm{m}^{2} \mathrm{~s}$, de acordo com a Figura 5.6, o método de Felcar, Ribatski e Jabardo (2007) falha na previsão do escoamento anular, sendo, portanto, sua utilização não indicada para a previsão de padrões de escoamento nessas condições.

(a)
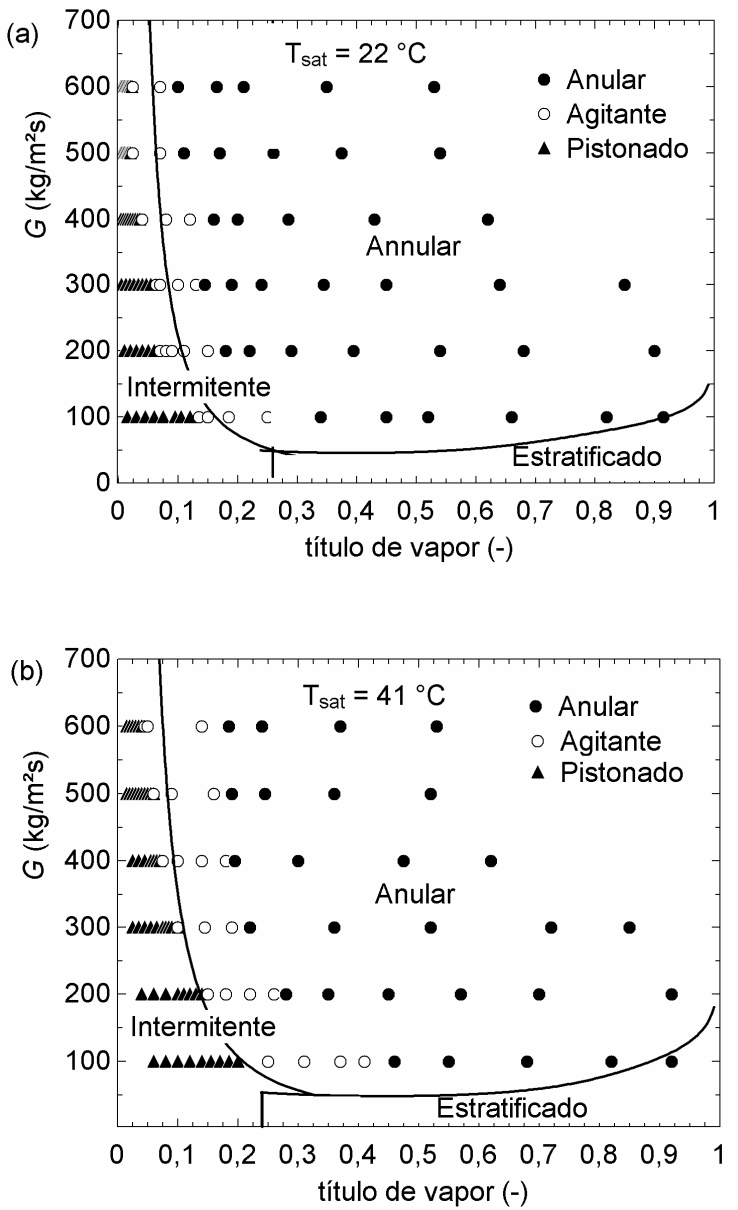

Figura 5.6 - Comparação entre o método de Felcar, Ribatski e Jabardo (2007) e dados experimentais, R134a e $D=2,32 \mathrm{~mm}$.

Os resultados de padrões de escoamento identificados visualmente também foram comparados com o método de Ong e Thome (2011a) (Figura 5.7). As linhas de transição determinam o limite entre bolhas intermitentes (IB), bolhas confinadas 
(CB) e anular (A). Essas linhas de transição de Ong e Thome (2011a) foram desenvolvidas usando dados de padrões de escoamento identificados com a análise de sinais provenientes de lasers atravessando o escoamento na seção transparente, o que evita a interpretação subjetiva dos padrões de escoamento. A linha IB-CB é relacionada com a máxima frequência de bolhas, enquanto que a transição de bolhas para pistonado, nesse banco de dados experimental, refere-se à condição em que o comprimento das bolhas torna-se superior ao diâmetro do canal. A linha CB-A indica quando a frequência do sinal do laser se aproxima de zero. A transição de agitante para anular, no presente estudo, refere-se a quando o núcleo de vapor no escoamento torna-se contínuo no tempo. Apesar de terem sido distintos os métodos utilizados para identificar os padrões de escoamento, houve concordância entre os dados experimentais e as linhas teóricas de transição para média e altas velocidades mássicas nas transições bolhas-pistão e agitante-anular, para os diâmetros e fluidos avaliados.
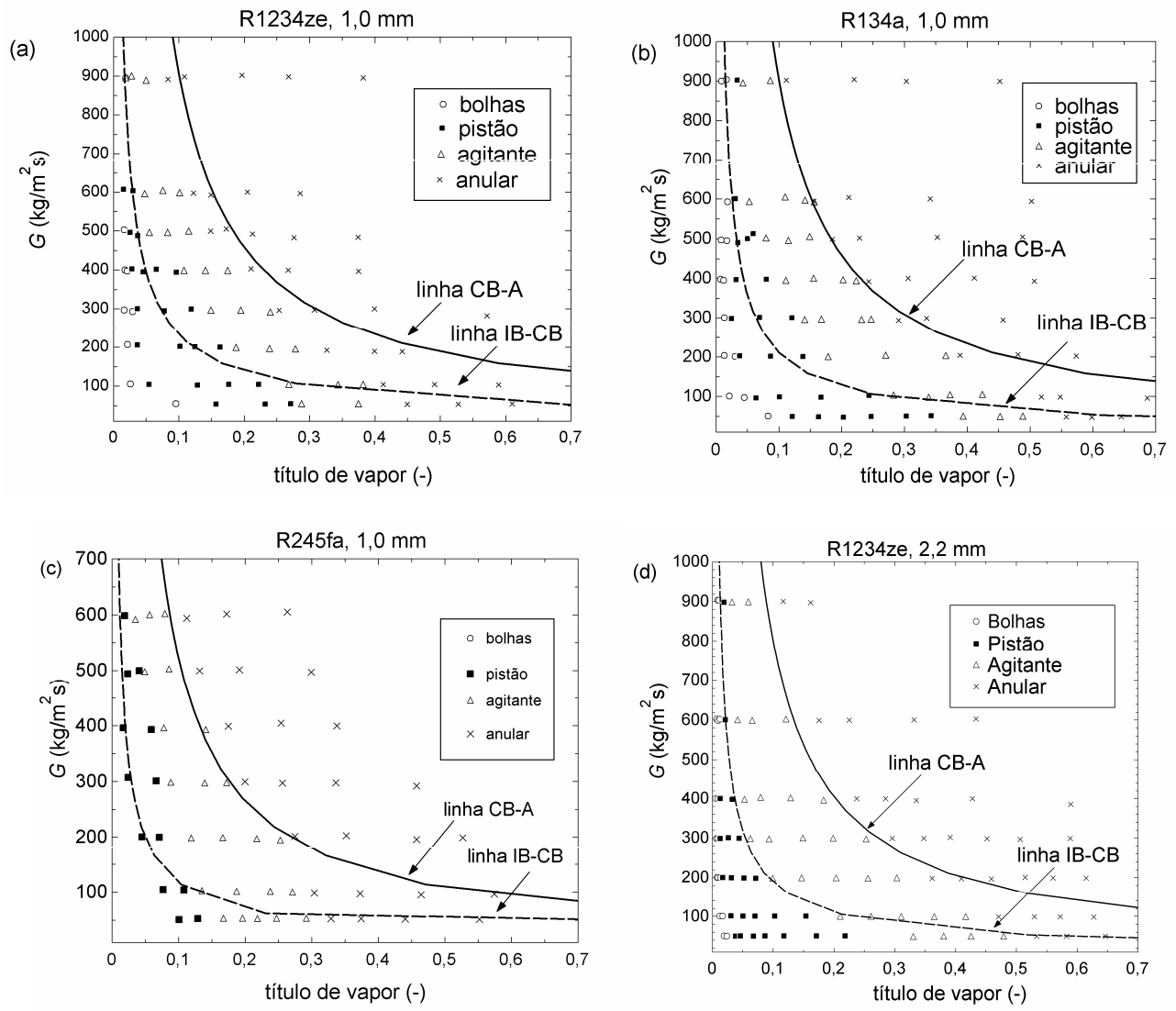

Figura 5.7 - Comparação entre o método de Ong e Thome (2011a) e dados experimentais de Tibiriçá, Ribatski e Thome, (2011) para R134a, R1234ze e R245fa. 


\subsection{Coeficiente de tRANSFERÊNCIA de CALOR}

Os resultados a seguir apresentados para o CTC foram calculados utilizando o procedimento descrito no capítulo 4. A faixa de condições experimentais ficou restrita às condições operacionais limites dos aparatos experimentais. Foram determi-

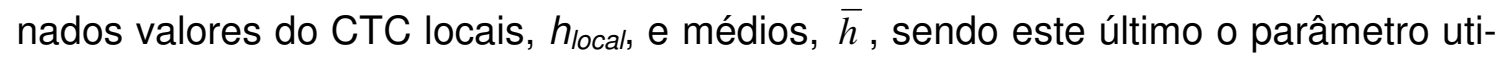
lizado nas comparações com os métodos de previsão.

\subsubsection{COEFICIENTE de tRanSFERÊNCIA de CALOR AO REDOR dO PERÍMETRO DO TUBO}

A Figura 5.8 ilustra o efeito do título de vapor no CTC ao longo do perímetro da seção de testes. Medidas de CTC no topo, na lateral e na base do tubo testado para termopares localizados a $15 \mathrm{~mm}$ de distância do fim da região aquecida são apresentados. A Figura 5.8 também apresenta imagens dos escoamentos bifásicos correspondentes às medidas de CTC. As imagens foram obtidas pela câmera de alta velocidade posicionada $50 \mathrm{~mm}$ a jusante das medidas de CTC.

De acordo com a figura, efeitos de estratificação do líquido estão presentes e um filme líquido mais espesso é observado na região inferior do tubo. Esse comportamento afeta a medida de transferência de calor da seguinte forma para este diâmetro e velocidade mássica: (i) para medida de $h$ na região inferior do tubo, o CTC se eleva até títulos de vapor de 0,85, enquanto que para a medida de $h$ na região superior, $h$ decresce até títulos da ordem de 0,70; (ii) para títulos de vapor acima de 0,85 , há decréscimo progressivo no $h$ medido ,. Esse comportamento permite inferir a ocorrência de secagem progressiva da parede superior do tubo, devido à baixa vazão desse experimento e, posteriormente, no meio e na base do tubo. É importante enfatizar que escoamentos estratificados não foram detectados na campanha experimental para o tubo de $2,32 \mathrm{~mm}$.

Efeito similar encontra-se ilustrado para R245fa na Figura 5.9, porém com velocidade mássica superior, condição na qual os efeitos de estratificação do escoamento decrescem. Além disso, o volume específico do R245fa, na fase vapor, é superior ao do R134a, significando incrementos adicionais da velocidade desta fase, favorecendo a uniformidade do filme líquido ao longo do perímetro do tubo em uma 
mesma seção transversal. Tal comportamento resulta em em variações inferiores do CTC ao longo do perímetro do tubo.

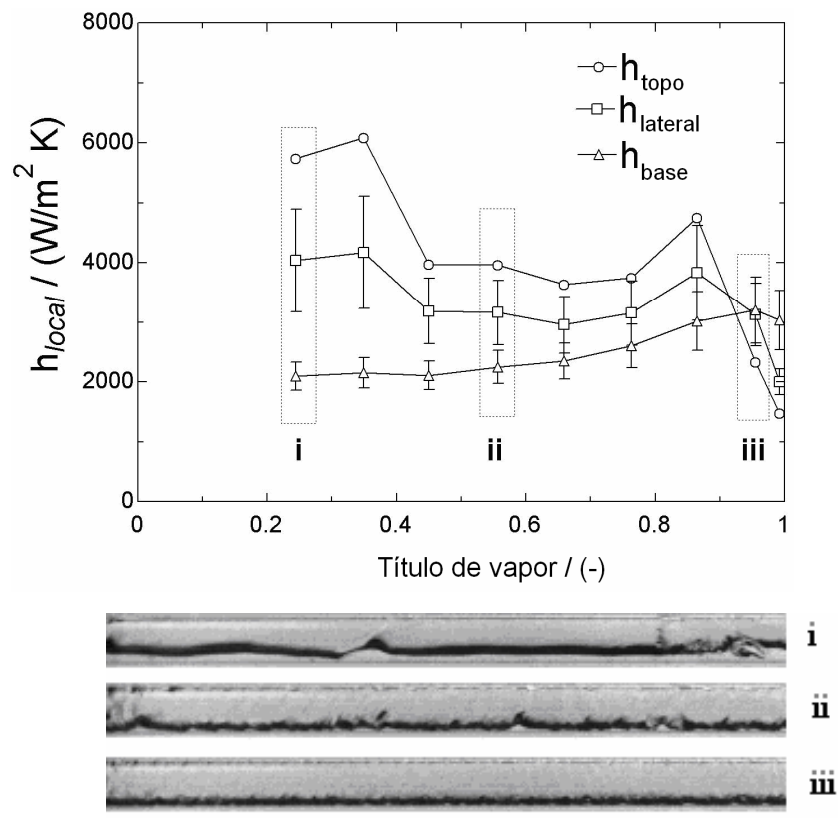

Figura 5.8 - Distribuição do CTC ao longo do perímetro do tubo e imagens do escoamento bifásico correspondentes (R134a, $D=2,32 \mathrm{~mm}, \mathrm{G}=100 \mathrm{~kg} / \mathrm{m}^{2} \mathrm{~s}, q=5 \mathrm{~kW} / \mathrm{m}^{2}$, $\left.\mathrm{T}_{\mathrm{sat}}=22^{\circ} \mathrm{C}\right)$.
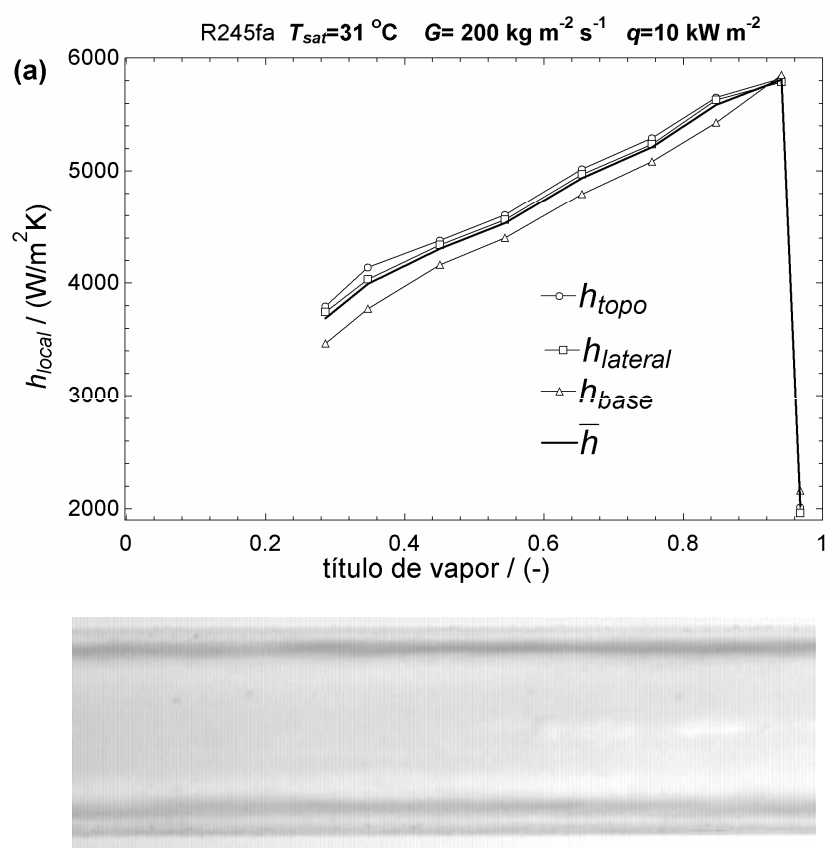

Figura 5.9 - CTC ao longo do perímetro do tubo e imagem do escoamento bifásico correspondente para R245fa a $\mathrm{G}=200 \mathrm{~kg} / \mathrm{m}^{2} \mathrm{~s}, q=10 \mathrm{~kW} / \mathrm{m}^{2}, x=35 \%, T_{\text {sat }}=31^{\circ} \mathrm{C}$. 


\subsubsection{EFEITO DE ENTRADA SUBRESFRIADA E SATURADA}

Dois procedimentos foram utilizados para levantar os resultados de CTC durante a ebulição convectiva. No primeiro, o fluido entra na condição sub-resfriada na seção de testes, sendo, então, evaporado; no segundo procedimento, o fluido é evaporado já no pré-aquecedor, entrando em condição saturada na seção de testes. Esse segundo método tem a vantagem de permitir alcançar títulos de vapor elevados, independentemente do fluxo de calor aplicado à seção de testes, algo que só poderia ser alcançado com o primeiro procedimento mediante incremento do comprimento aquecido. Porém, como nesse segundo método o fluxo de calor na seção de testes difere do fluxo na seção de pré-aquecimento, o fluxo de calor não é uniforme ao longo de toda a região bifásica.

Dessa forma, ensaios foram realizados com o intuito de avaliar o efeito da adoção de procedimentos experimentais distintos relacionados à condição de entrada do fluido na seção de testes. A Figura 5.10 ilustra uma curva de CTC para o $\mathrm{R} 134 \mathrm{a}$ em tubo de 1,00mm, considerando os dois procedimentos. Na figura, os dados para títulos inferiores a $25 \%$ foram obtidos com o primeiro procedimento, enquanto que os dados com títulos de vapor superiores foram obtidos com o segundo procedimento. Observa-se que a curva de CTC é contínua, indicando que o efeito da condição de entrada, e consequentemente dos dois procedimentos utilizados, não afeta os resultados experimentais para as condições avaliadas.

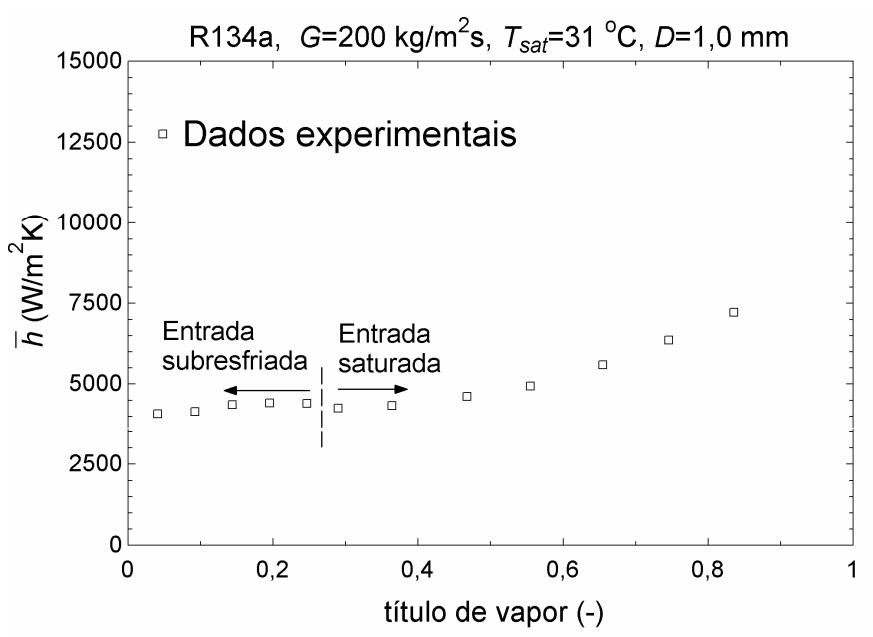

Figura 5.10 - Efeito da condição de entrada do fluido na seção de testes no CTC. (R134a, $D=1,00 \mathrm{~mm}, G=200 \mathrm{~kg} / \mathrm{m}^{2} \mathrm{~s}, q=15 \mathrm{~kW} / \mathrm{m}^{2}$ ). 


\subsubsection{EFEITO DA BANCADA EXPERIMENTAL}

Um dos objetivos da presente pesquisa foi avaliar a diferença entre resultados experimentais levantados em laboratórios distintos, pois, de acordo com Ribatski, Wojtan e Thome (2006), é comum a discrepância de resultados experimentais em condições similares provenientes de diferentes laboratórios. Assim, resultados obtidos na bancada I (EESC-USP-Brasil) e na bancada II (LTCM-EPFL-Suíça) foram comparados para condições similares. A Figura 5.11 ilustra valores do CTC levantados para o diâmetro de 2,32mm na bancada I e 2,20 na bancada II. Observa-se que apesar dos resultados serem levantados em bancadas distintas, eles são razoavelmente próximos, com resultados ligeiramente superiores na bancada da EESCUSP para títulos de vapor a partir de $60 \%$. Esse fato pode estar associado à diferença do comprimento aquecido, conforme observado por Karayiannis, Mahmoud e Kenning (2011), já que a bancada da EESC-USP apresenta um comprimento aquecido total (seção de testes + pré-aquecedor) igual a $967 \mathrm{~mm}$, enquanto a bancada do LTCM-EPFL é de $451 \mathrm{~mm}$.

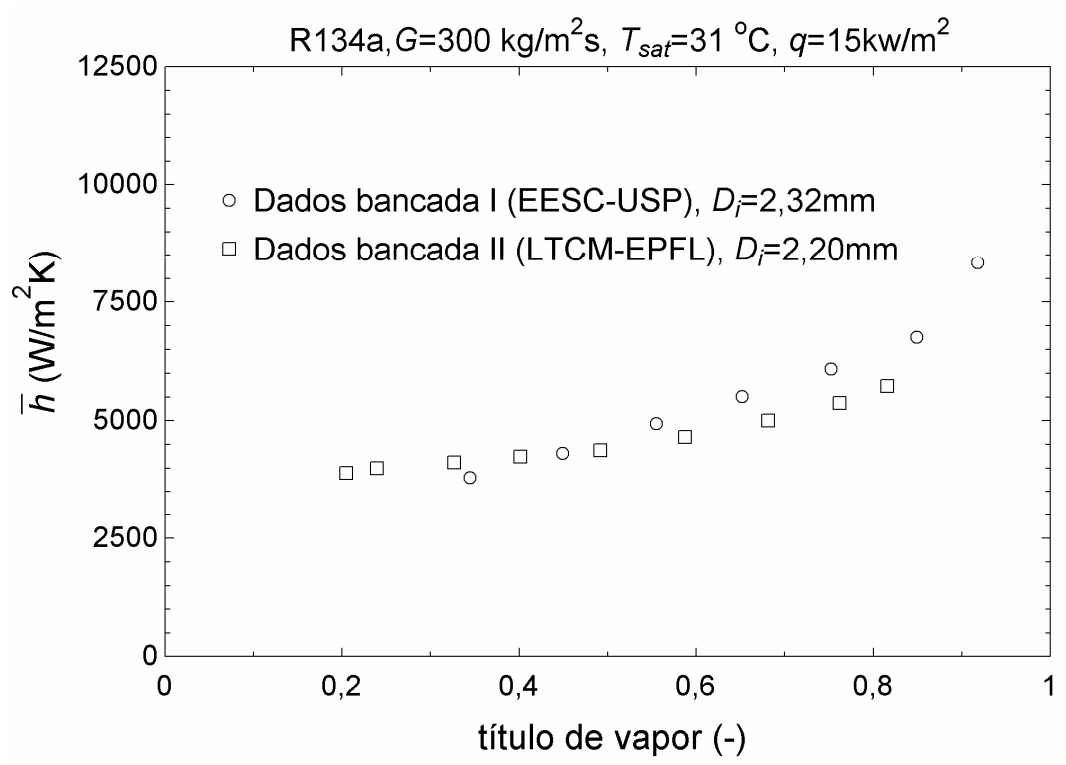

Figura 5.11 - Comparações de dados experimentais levantados na EESC-USP e no LTCMEPFL. 


\subsubsection{EFEITO dO DIÂMETRO}

Considerando que um dos principais mecanismos de transferência de calor durante a ebulição convectiva é a condução através do filme líquido, é de se esperar que, com a redução do diâmetro, a espessura do filme líquido se reduza e assim o CTC aumente. Nesse sentido, determinando-se a espessura do filme líquido durante o escoamento anular por meio da correlação de fração de vazio de Rouhani e Axelsson (1970) para o diâmetro de $2,0 \mathrm{~mm}$ nas condições $x=80 \%, G=300 \mathrm{~kg} / \mathrm{m}^{2} \mathrm{~s}$ e $T_{\text {sat }}=31^{\circ} \mathrm{C}$, obtém-se uma espessura de filme de $38 \mu \mathrm{m}$, enquanto que para um diâmetro de 1,00mm, em condições similares, obtém-se uma espessura de filme de $23 \mu \mathrm{m}$, ou seja, uma razão de 1,65 entre elas. Porém, na prática, durante a ebulição convectiva observa-se um incremento menor do CTC como observado nas Figura 5.12 e Figura 5.13. Observa-se que para títulos de vapor superiores, o efeito do diâmetro se torna superior. Tendência similar foi observada por Saitoh, Daiguji e Hihara (2007), comparando o desempenho de tubos com diâmetros de 0,51 a 3,1 mm. Ong (2010) verificou tendência similar com o R245fa, enquanto para o R134a observou decréscimo do CTC com a redução do diâmetro. Na Figura 5.12, para o título de vapor de $80 \%$, observa-se um CTC $50 \%$ superior para o tubo de $1,00 \mathrm{~mm}$ de diâmetro. Resultados similares são observados para R245fa na Figura 5.13.

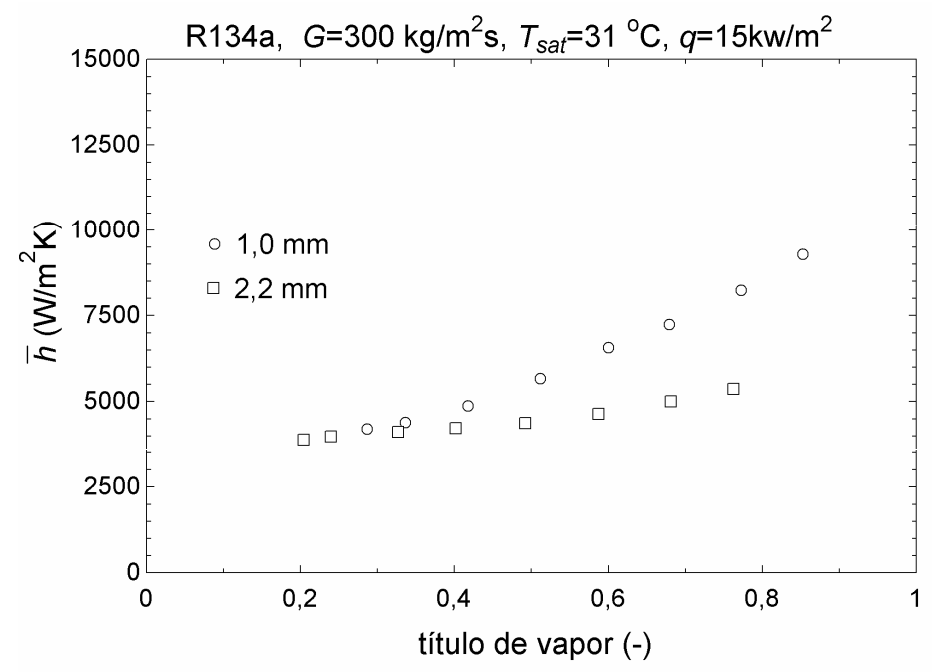

Figura 5.12 - Efeito do diâmetro no CTC para R134a. 


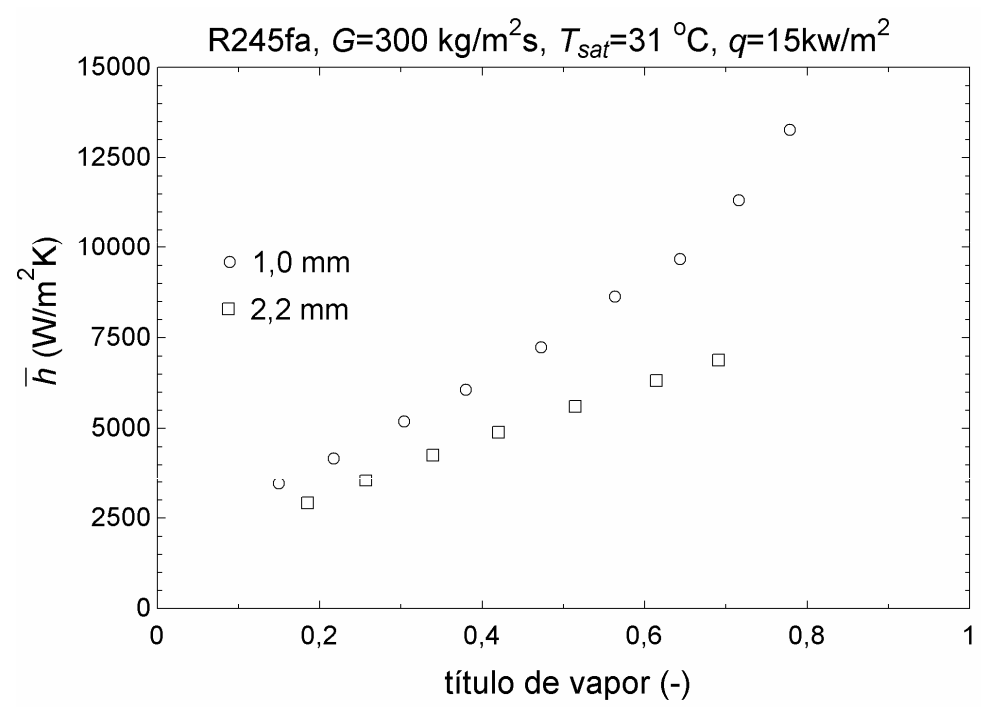

Figura 5.13 - Efeito do diâmetro no CTC para R245fa.

\subsubsection{EFEITO DA VELOCIDADE MÁSSICA}

As Figura 5.14 a Figura 5.16 ilustram o efeito da velocidade mássica no CTC para diferentes condições experimentais. Segundo essas figuras, de forma geral o CTC aumenta com o incremento da velocidade mássica. Esse efeito é mais pronunciado para títulos de vapor superiores. Comportamentos distintos em relação ao efeito do título de vapor são observados para um nível de velocidade mássica a partir de $200 \mathrm{~kg} / \mathrm{m}^{2}$ s para tubo de $2,32 \mathrm{~mm}$ utilizando R134a. Para velocidades mássicas superiores a este valor, o CTC eleva-se com o incremento do título de vapor até valores da ordem de $90 \%$. Para velocidades mássicas inferiores a $200 \mathrm{~kg} / \mathrm{m}^{2} \mathrm{~s}$, o CTC decresce com o incremento do título de vapor e podendo-se associar este fato a maior estratificação do filme líquido em baixa velocidades. O incremento do CTC com a elevação da velocidade mássica manteve-se independentemente do nível de fluxo de calor. Comportamentos distintos do CTC com o título de vapor segundo uma velocidade mássica de $200 \mathrm{~kg} / \mathrm{m}^{2} \mathrm{~s}$ também foram observados por Saitoh, Daiguji e Hihara (2007) em seus experimentos com tubo de $D_{i}=3 \mathrm{~mm}$ para o R134a. 


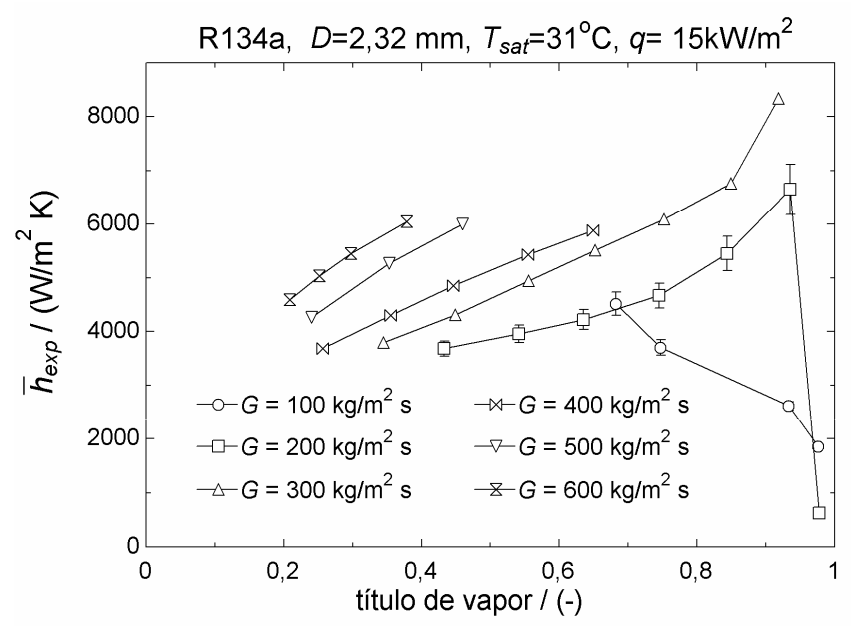

Figura 5.14 - llustração do efeito da velocidade mássica no CTC (D=2,32mm, R134a, $T_{\text {sat }}=31^{\circ} \mathrm{C}, q=15 \mathrm{~kW} / \mathrm{m}^{2}$ ).

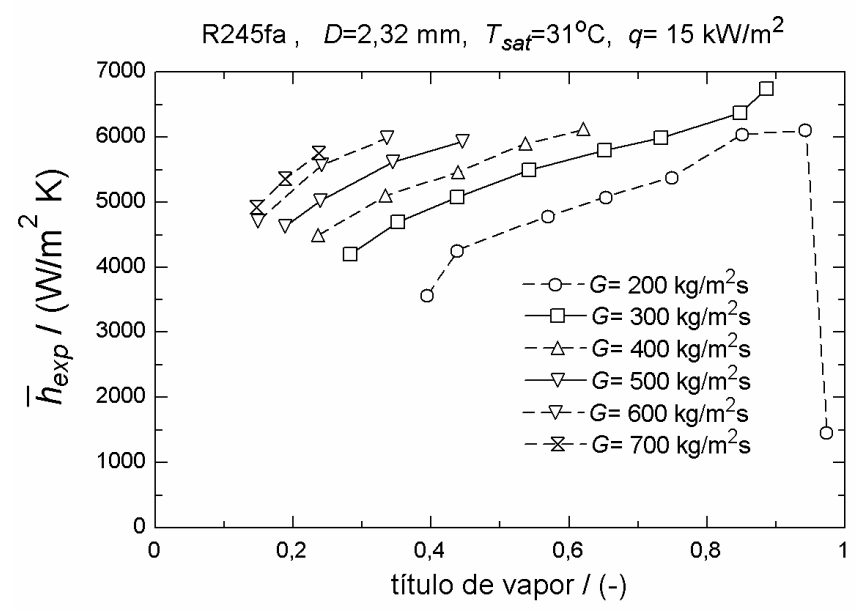

Figura 5.15 - llustração do efeito da velocidade mássica no CTC $(D=2,32 \mathrm{~mm}, R 245 f a$, $\left.T_{\text {sat }}=31^{\circ} \mathrm{C}, q=15 \mathrm{~kW} / \mathrm{m}^{2}\right)$.

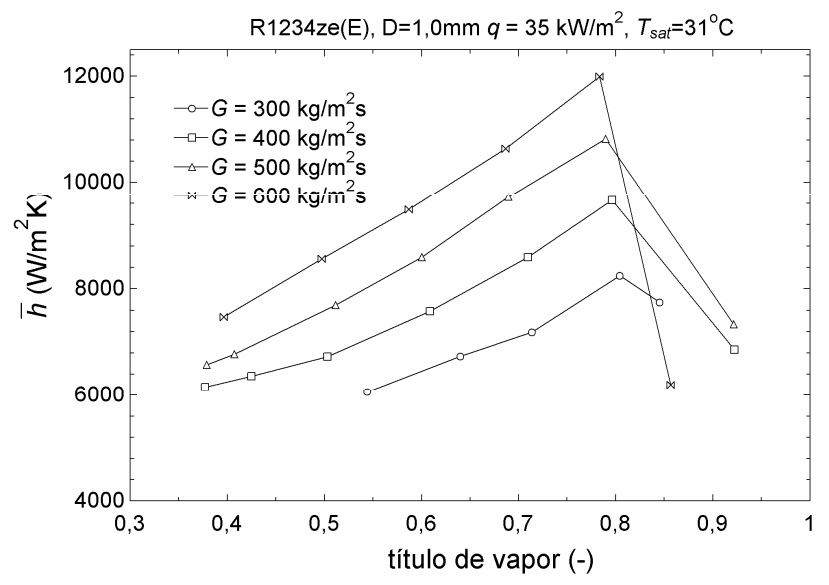

Figura 5.16 - llustração do efeito da velocidade mássica no CTC $(D=1,00 \mathrm{~mm}, \mathrm{R} 1234 z e(E)$, $T_{\text {sat }}=31^{\circ} \mathrm{C}, q=35 \mathrm{~kW} / \mathrm{m}^{2}$ ). 


\subsubsection{EFEITO dO FLUIDO}

A Figura 5.17 compara o CTC dos fluidos R134a, R245fa e R1234ze para o diâmetro $1,00 \mathrm{~mm}$ a $31^{\circ} \mathrm{C}$. Observa-se que, nessa condição experimental, os fluidos com maior pressão reduzida (R134a e R1234ze) apresentam CTCs superiores para títulos de vapores reduzidos. Tal comportamento é similar ao observado para ebulição nucleada e sugere a predominância desse mecanismo em títulos de vapor reduzidos. À medida que o título de vapor se eleva, efeitos convectivos se intensificam e, com o desenvolvimento do escoamento anular, tornam-se preponderantes os efeitos relacionados à condutividade térmica e à razão de deslizamento das fases. $\mathrm{O}$ fluido R245fa apresenta a condutividade térmica da fase líquida similar ao R134a, porém possui volume específico de vapor superior, o que resulta numa velocidade superior para essa fase e numa maior intensificação de efeitos convectivos (ver Tabela 5.2). Isso resulta, para títulos de vapor elevados, num CTC superior para o R245fa, seguido do R134a e do R1234ze(E). A Figura 5.18 apresenta uma comparação entre R134a e R1234ze(E) para uma condição de fluxo de calor e velocidade mássica distinta da Figura 5.17, com os pontos experimentais em sua maioria em escoamento anular. Na figura, verifica-se que o R134a apresenta CTC ligeiramente superior ao $\mathrm{R} 1234 z e(E)$, dentro da faixa de títulos de vapor ilustrada. Também se verifica que a secagem da parede ocorre a títulos de vapor ligeiramente inferiores para o $\mathrm{R} 1234 \mathrm{ze}(\mathrm{E})$, fato que pode ser relacionado ao valor inferior de calor latente de evaporação do R1234ze(E).

Tabela 5.2 - Propriedades dos fluidos R134a, R1234ze(E) e R245fa, a $31^{\circ} \mathrm{C}$.

\begin{tabular}{|c|c|c|c|c|c|c|c|c|}
\hline & $\begin{array}{c}\boldsymbol{T} \\
\left({ }^{\circ} \mathrm{C}\right)\end{array}$ & $\begin{array}{l}p_{r} \\
(-)\end{array}$ & $\begin{array}{c}\rho_{l} \\
\left(\mathrm{~kg} / \mathrm{m}^{3}\right)\end{array}$ & $\begin{array}{c}\rho_{v} \\
\left(\mathrm{~kg} / \mathrm{m}^{3}\right)\end{array}$ & $\begin{array}{c}h_{l v} \\
(\mathrm{~kJ} / \mathrm{kg})\end{array}$ & $\begin{array}{c}\boldsymbol{\mu}_{l} \\
(\mu \mathrm{Pa} . \mathrm{s})\end{array}$ & $\begin{array}{c}\boldsymbol{k}_{\boldsymbol{l}} \\
(\mathrm{mW} / \mathrm{mK})\end{array}$ & $\begin{array}{c}\boldsymbol{\sigma} \\
(\mathrm{mN} / \mathrm{m})\end{array}$ \\
\hline R134a & 31 & 0,195 & 1183 & 39 & 172 & 181 & 79 & 7.3 \\
\hline R1234ze & 31 & 0,159 & 1139 & 31 & 162 & 188 & 61 & 7.7 \\
\hline R245fa & 31 & 0,050 & 1322 & 10 & 186 & 374 & 79 & 13,2 \\
\hline
\end{tabular}




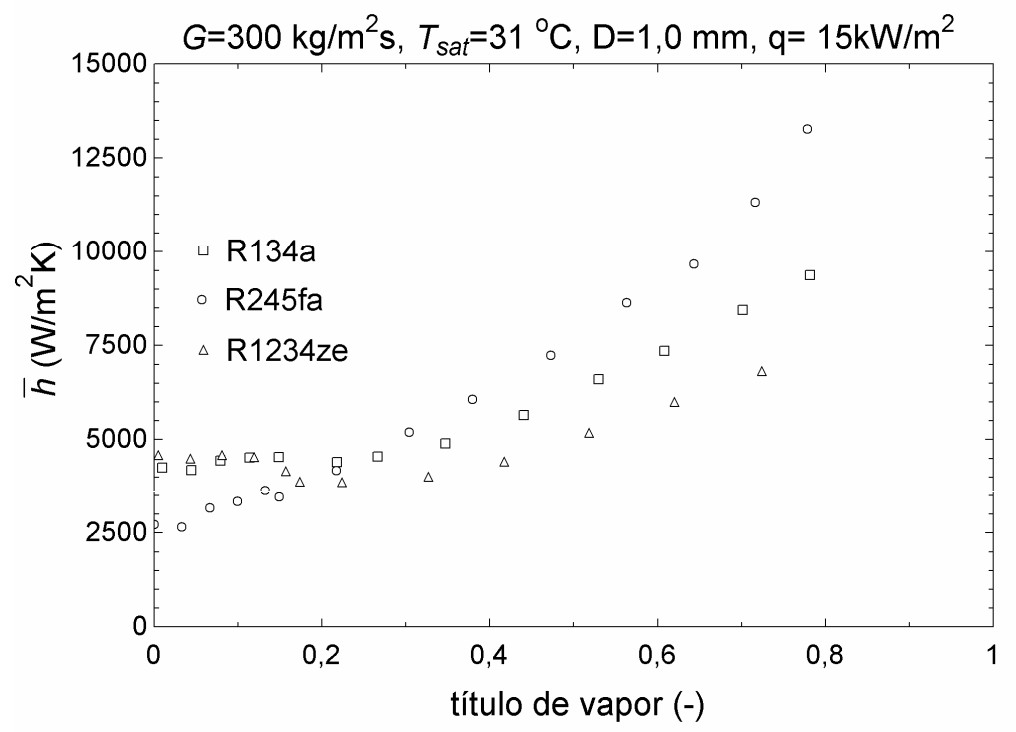

Figura 5.17 - Comparação do efeito do fluido no CTC para R134a, R245fa e R1234ze(E).

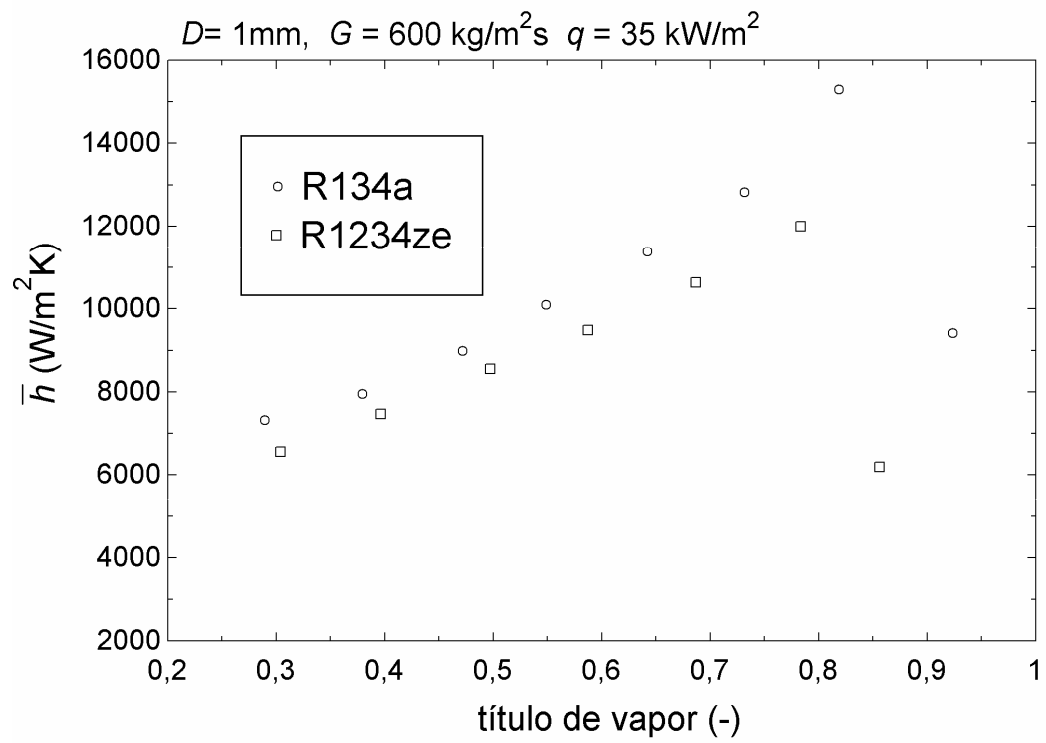

Figura 5.18 - Comparação do efeito do fluido no CTC para R134a e R1234ze(E) (TIBIRIÇÁ; RIBATSKI; THOME, 2011)

\subsubsection{EFEITO DA TEMPERATURA}

As Figura 5.19 e Figura 5.20 ilustram o efeito da temperatura de saturação no CTC para distintas condições experimentais. Observa-se que, em geral, o CTC aumenta com o incremento da temperatura de saturação. Esse comportamento é 
mais pronunciado em títulos de vapor e velocidades mássicas reduzidas e sua intensidade decresce com o incremento da velocidade mássica e do título de vapor. Esse comportamento está qualitativamente de acordo com aqueles observados durante a ebulição convectiva em macrocanais. Assim, mostra-se fazer sentido que métodos de previsão de coeficiente de transferência de calor em macrocanais sejam adotados para ebulição convectiva em microcanais e apresentem resultados satisfatórios para condições próximas às ensaiadas.

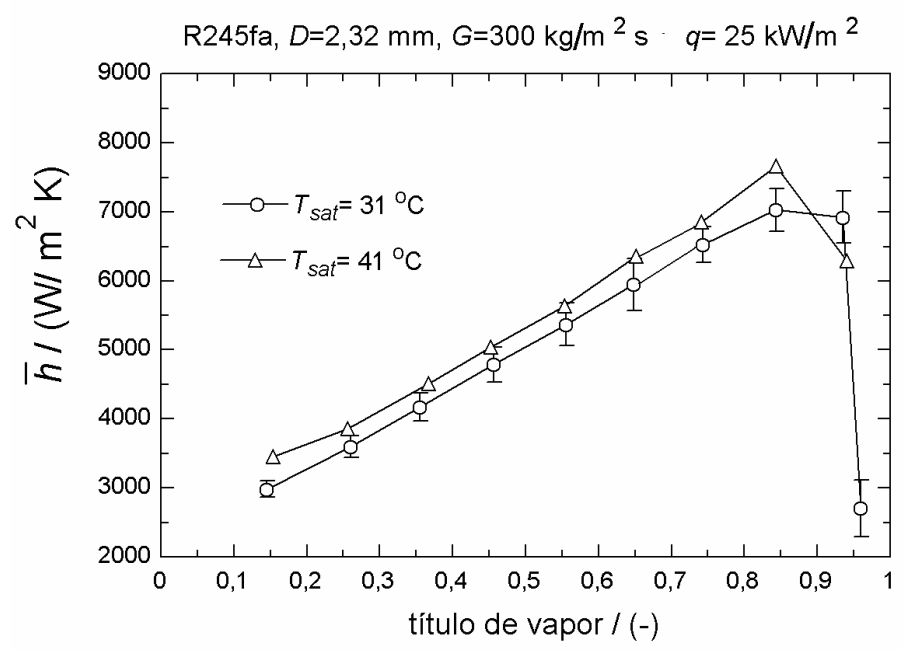

Figura 5.19 - llustração do efeito da temperatura de saturação no CTC. (R245fa, $\left.\mathrm{q}=25 \mathrm{~kW} / \mathrm{m}^{2}, \mathrm{G}=300 \mathrm{~kg} / \mathrm{m}^{2} \mathrm{~s}, D_{\mathrm{i}}=2,32 \mathrm{~mm}\right)$.

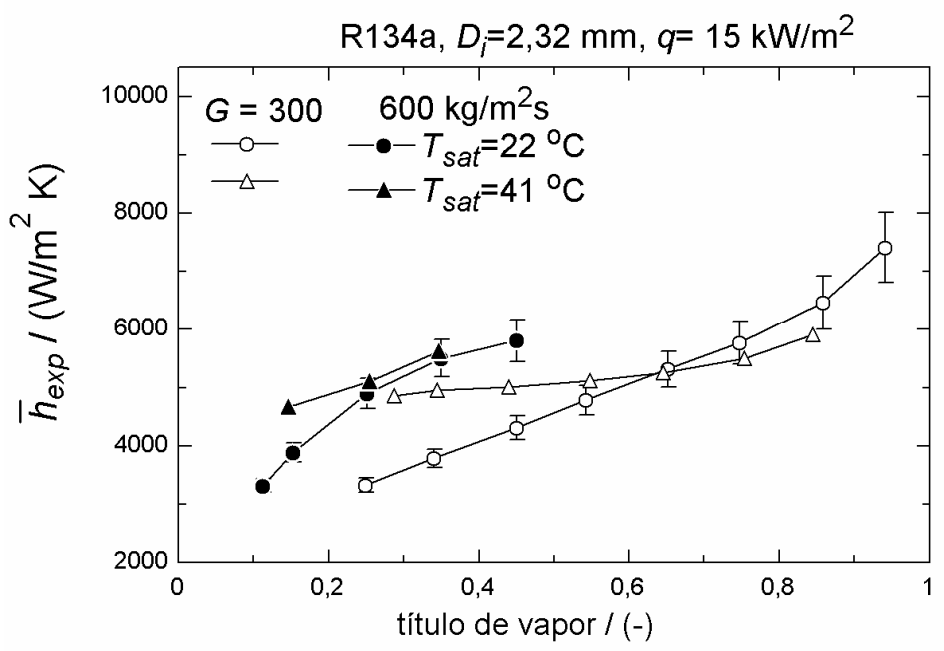

Figura 5.20 - llustração do efeito da temperatura de saturação no CTC para R134a, $D_{i}=1,00 \mathrm{~mm}, G=600 \mathrm{~kg} / \mathrm{m}^{2} \mathrm{~s}, q=55 \mathrm{~kW} / \mathrm{m}^{2}$. 


\subsubsection{EFEITO dO FLUXO DE CALOR}

De acordo com a Figura 5.21, exceto para alguns resultados na região de secagem de parede caracterizada por títulos de vapor próximo a 90\%, o CTC elevase com o aumento do fluxo de calor independentemente da faixa de velocidade mássica. Esse comportamento difere do observado em macrocanais, no qual o CTC eleva-se com o incremento do fluxo de calor apenas para velocidades mássicas e títulos de vapor reduzidos. Alguns autores indicam que este comportamento relaciona-se ao fato de a ebulição nucleada ser o mecanismo dominante na transferência de calor durante a ebulição convectiva em microcanais, independentemente do título de vapor e do padrão de escoamento estabelecido. Essa consideração vem da interpretação incorreta de que um processo de evaporação dependente do fluxo de calor necessariamente signifique que a ebulição nucleada é o mecanismo predominante. Thome, Dupont e Jacobi (2004), para escoamento pistonado, e Qu e Mudawar (2003), para escoamento anular, ilustraram que a evaporação do filme líquido pode também resultar num incremento do CTC com o incremento do fluxo de calor. A Figura 5.22 ilustra que este comportamento mantém-se para diâmetros distintos para o R134a. O fluido R1234ze(E) apresenta comportamento similar ao R134a.

A Figura 5.23 ilustra o efeito do fluxo de calor na ebulição convectiva do R245fa. Distintamente do R134a, para títulos de vapor elevados (associados ao escoamento anular), o CTC torna-se independente do fluxo de calor. Essa característica é observada para o diâmetro de 1,00mm e 2,20 mm, sendo que, neste último, efeito desprezível do fluxo de calor no CTC é verificado para títulos de vapor superiores. Para títulos de vapor reduzidos, associados a escoamentos em bolhas e intermitentes, o efeito do fluxo de calor mantém-se relevante também para o R245fa. 

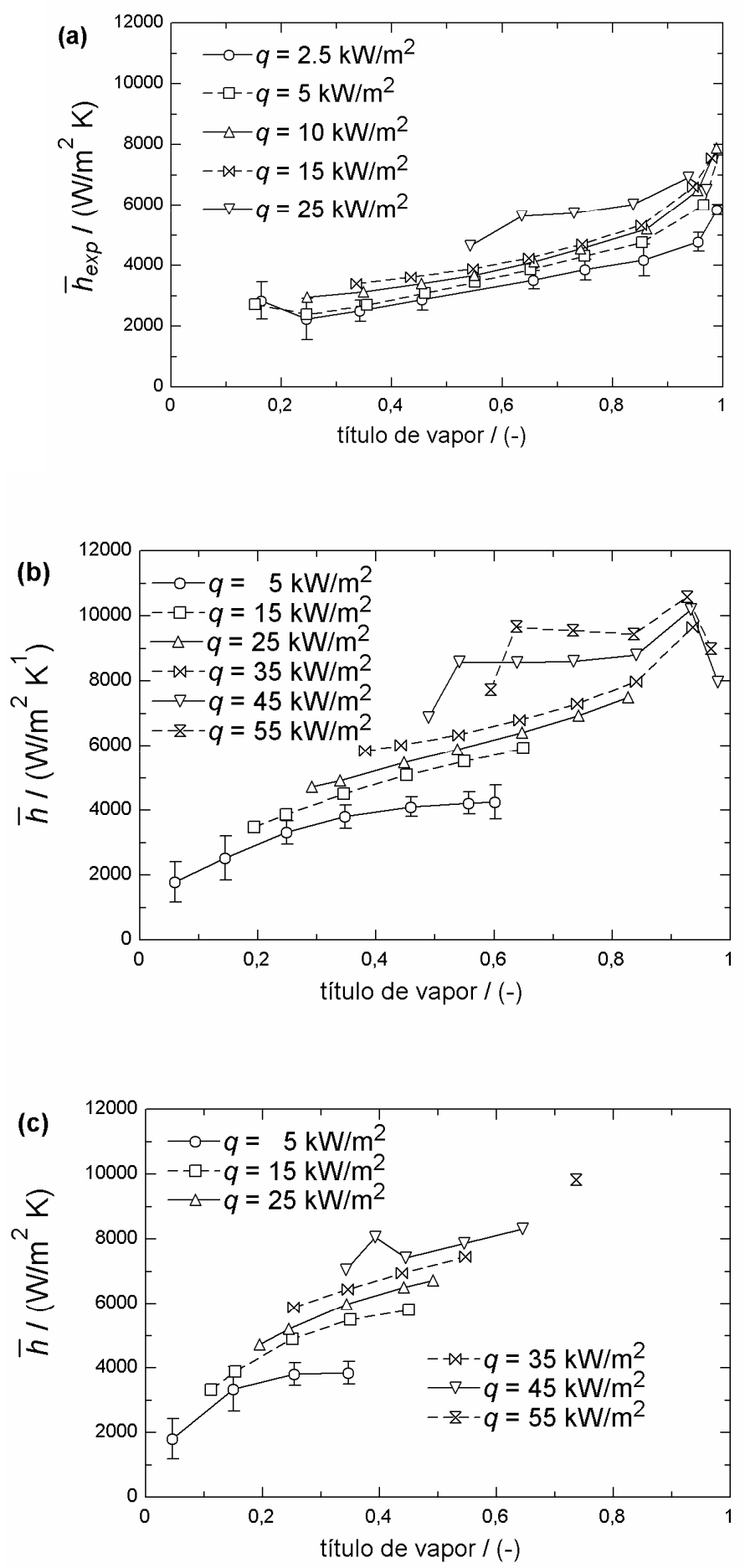

Figura 5.21 - llustração do efeito do fluxo de calor no CTC para (R134a, $D_{i}=2,32 \mathrm{~mm}$, $T_{\text {sat }}=22^{\circ} \mathrm{C}$ ). (a) $G=200 \mathrm{~kg} / \mathrm{m}^{2} \mathrm{~s}$; (b) $G=400 \mathrm{~kg} / \mathrm{m}^{2} \mathrm{~s}$; (c) $G=600 \mathrm{~kg} / \mathrm{m}^{2} \mathrm{~s}$. 

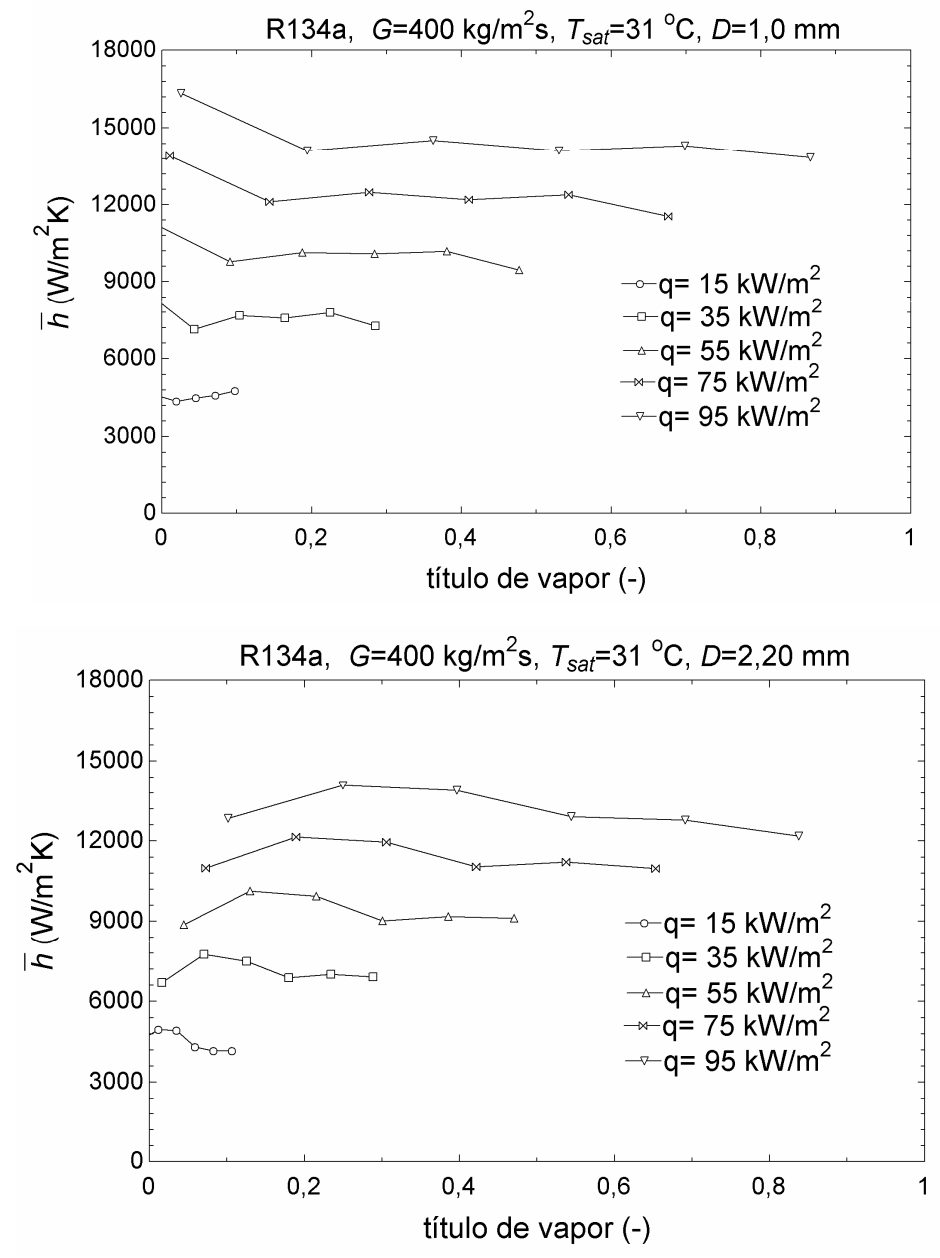

Figura 5.22 - Efeito do fluxo de calor no CTC para R134a.

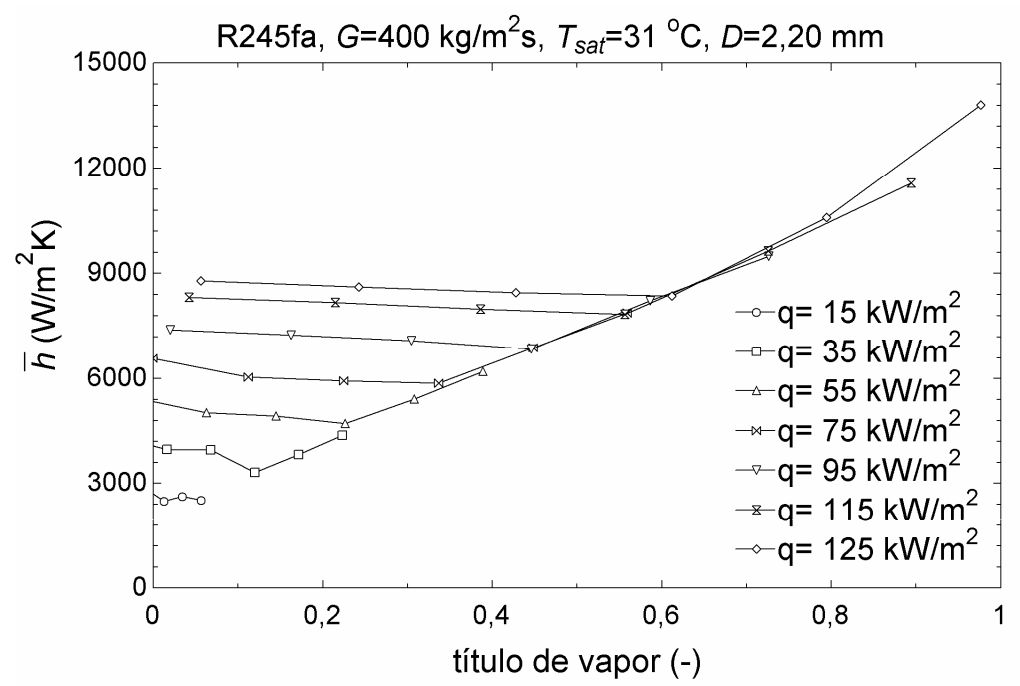

Figura 5.23 - Efeito do fluxo de calor no CTC para R245fa. 


\subsubsection{EFEITO DA GEOMETRIA}

As Figura 5.24 e Figura 5.25 ilustram os resultados do CTC para os perfis de canais achatados avaliados neste estudo, onde é possível avaliar o efeito da geometria no CTC. Esses perfis foram comparados com um canal circular de mesmo diâmetro equivalente que serviu de referência.

$\mathrm{Na}$ Figura 5.24a pode-se analisar o efeito da rotação no canal achatado no CTC. Na figura, o mesmo tubo achatado é comparado sobre rotações de $90^{\circ} \mathrm{em}$ torno do eixo axial, obtendo duas razões altura/largura $(H / W): 4$ e 1/4. Segundo a figura, para velocidades mássicas reduzidas, $G=100 \mathrm{~kg} / \mathrm{m}^{2} \mathrm{~s}$, o tubo com orientação da seção transversal horizontal $(H / W=1 / 4)$ não apresenta secagem de parede até altos títulos de vapor, pois o CTC continua se elevando; entretanto, o tubo com orientação vertical $(H / W=4)$ já demonstra sinais de secagem de parede devido a estratificação a partir do título de $60 \%$. Esse efeito torna-se desprezível ao elevar-se a velocidade mássica, como mostrado na Figura 5.24b.O tubo com orientação vertical, $(H / W)=4$, tem altura de $4 \mathrm{~mm}$, diâmetro no qual o escoamento estratificado se desenvolve para velocidade mássica de $100 \mathrm{~kg} / \mathrm{m}^{2} \mathrm{~s}$ com R134a.

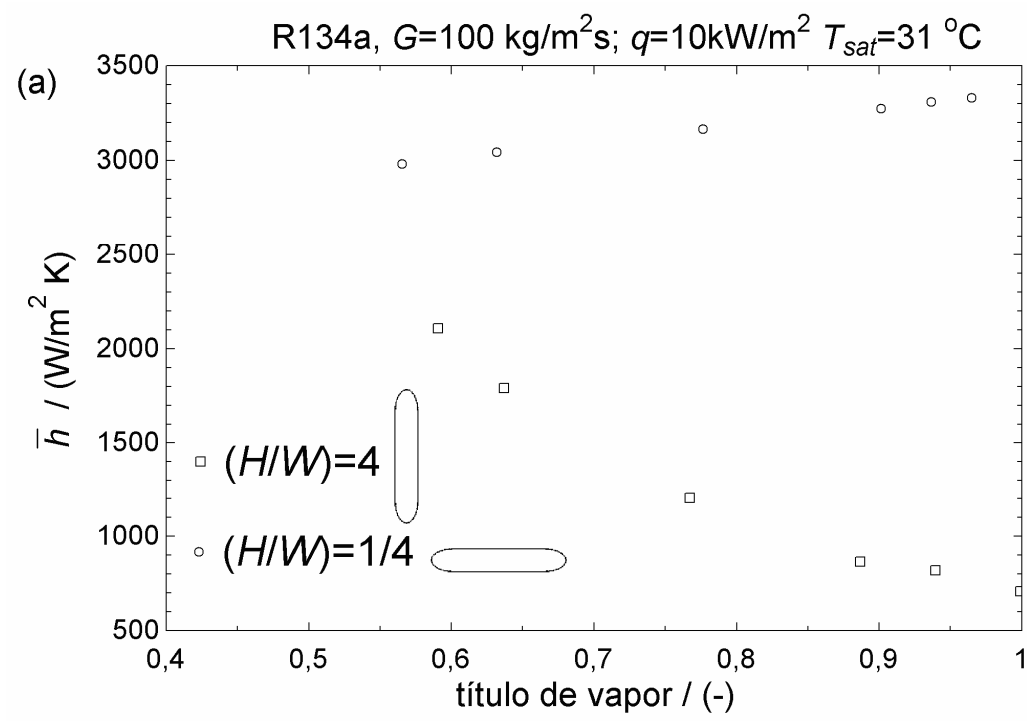




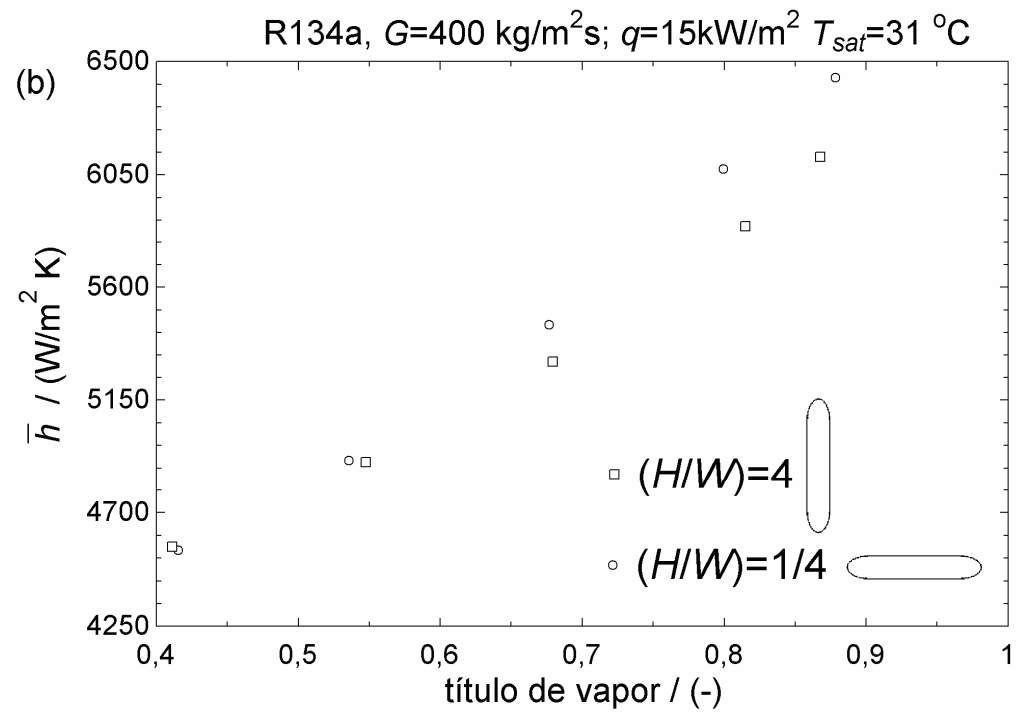

Figura 5.24 - Efeito da orientação da seção transversal do tubo achatado no CTC $\left(D_{e q}=2,20 \mathrm{~mm}\right)$

A Figura 5.25 ilustra uma comparação entre os resultados para tubos achatados e canal circular, considerando diâmetros equivalentes similares. Nota-se um efeito reduzido da geometria no CTC para a velocidade de $G=400 \mathrm{~kg} / \mathrm{m}^{2} \mathrm{~s}$. Assim, percebe-se que quando a magnitude dos efeitos gravitacionais tornam-se inferiores aos efeitos de inércia, a geometria tende a apresentar efeito desprezível no CTC.

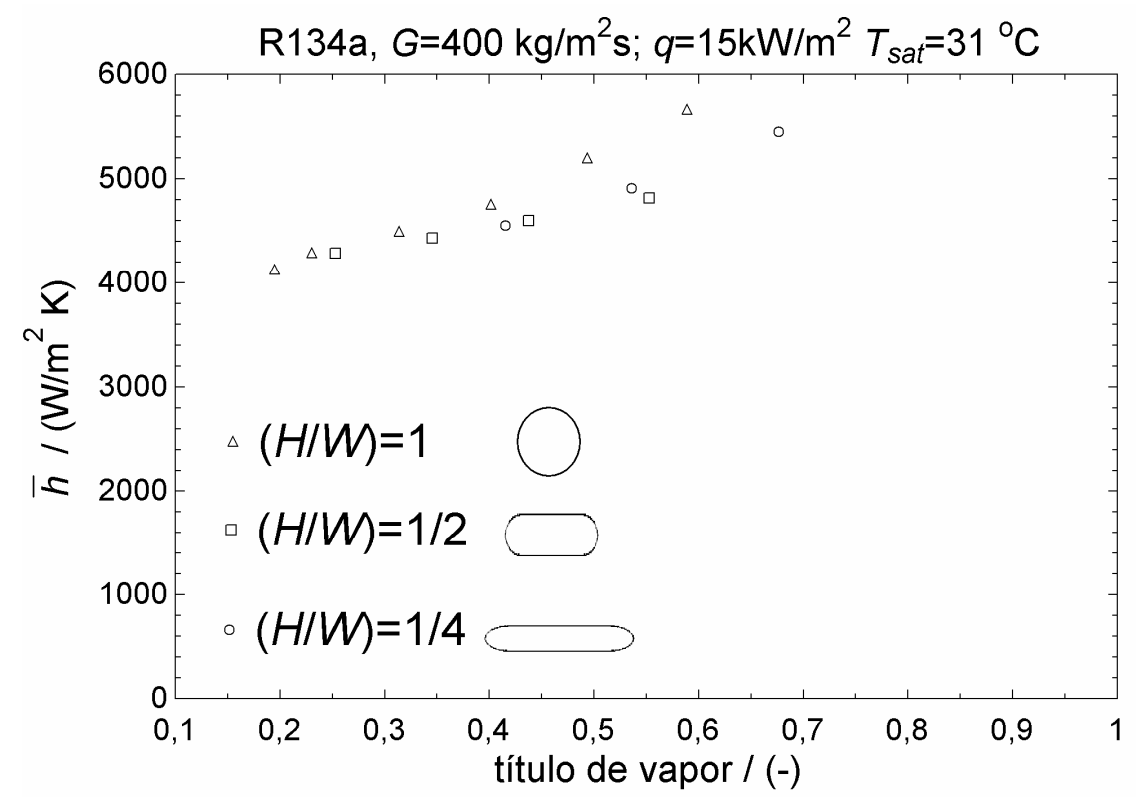

Figura 5.25 - Comparação entre CTC para tubos achatados e circular, para $D_{e q}=2,20 \mathrm{~mm}$. 


\subsubsection{AvaliaÇÃo dos mÉtodos de PREVISÃo do CTC}

Com o propósito de avaliar a capacidade dos métodos para determinação do coeficiente de transferência de calor, neste estudo foi realizada uma comparação entre os dados experimentais levantados e os métodos de previsão de transferência de calor em ebulição convectiva. Os métodos de previsão foram avaliados de acordo com dois critérios: fração de dados preditos dentro de uma faixa de erro de $\pm 30 \%, \lambda$, e o erro médio absoluto, $\varepsilon$.

A Tabela 5.3, para o tubo de 2,32mm de diâmetro, apresenta os resultados estatísticos das comparações envolvendo a totalidade deste banco de dados e também considerando os dados segregados de acordo com o padrão de escoamento. Escoamentos em bolhas não foram considerados já que foram observados somente para títulos de vapor de equilíbrio termodinâmico próximo a zero e, assim, a condição de ebulição convectiva saturada, foco deste trabalho, não é garantida devido às incertezas na estimativa do título de vapor. De acordo com a Tabela 5.3, o método de Saitoh, Daiguji e Hihara (2007) apresentou previsões superiores, no caso da comparação envolvendo a totalidade dos resultados experimentais. Esse resultado pode estar relacionado ao fato de as constantes empíricas utilizadas no método terem sido ajustadas baseadas somente em dados de R134a e para tubos de diâmetros internos variando de $0,5 \mathrm{~mm}$ a $11 \mathrm{~mm}$, coincidindo com as condições experimentais do presente trabalho. O método de Saitoh, Daiguji e Hihara (2007) apresentou resultados superiores também para o caso de escoamentos agitantes e anulares. $O$ método de Tran, Wambsganss e France (1996) apresentaram as menores incertezas para bolhas alongadas.

Um método para previsão do CTC não deve ser apenas estatisticamente acurado, mas também ser capaz de capturar as principais tendências experimentais. Levando esse fato em consideração, a Figura 5.26 ilustra a evolução do CTC com o título de vapor segundo diferentes métodos de previsão e os resultados levantados neste estudo. O pico de transferência de calor com baixos títulos de vapor, indicado no modelo de 3-Zonas de Thome, Dupont e Jacobi (2004), parece ocorrer apenas para as condições experimentais da Figura $5.26 \mathrm{~d}$, caracterizada por fluxos de calor e velocidade mássicas elevadas. O decréscimo do CTC com o incremento do título de vapor também ocorrem para as condições da Figura 5.26 a para $G=50 \mathrm{~kg} / \mathrm{m}^{2} \mathrm{~s}$. Saitoh, Daiguji e Hihara (2007) conseguiram prever razoavelmente o incremento do 
CTC com a elevação do título de vapor, como ilustrado na Figura 5.26b,c. A descontinuidade no CTC fornecido pelo método de Saitoh, Daiguji e Hihara (2007) está relacionada com a transição do escoamento turbulento para laminar, referente à fase líquida, dada pelo número de Reynolds líquido, $\operatorname{Re}_{l}=G \cdot(1-x) D / \mu$. Nesse método, o cálculo do parâmetro de Martinelli e do CTC da parcela convectiva têm correlações distintas, considerando fase líquida escoando em regime laminar ou turbulento. Comparações com o fluido R245fa apresentaram resultados similares.

Tabela 5.3 - Resultados estatísticos das comparações entre os valores fornecidos pelos métodos de previsão do CTC e os resultados experimentais de Tibiriçá e Ribatski (2010).

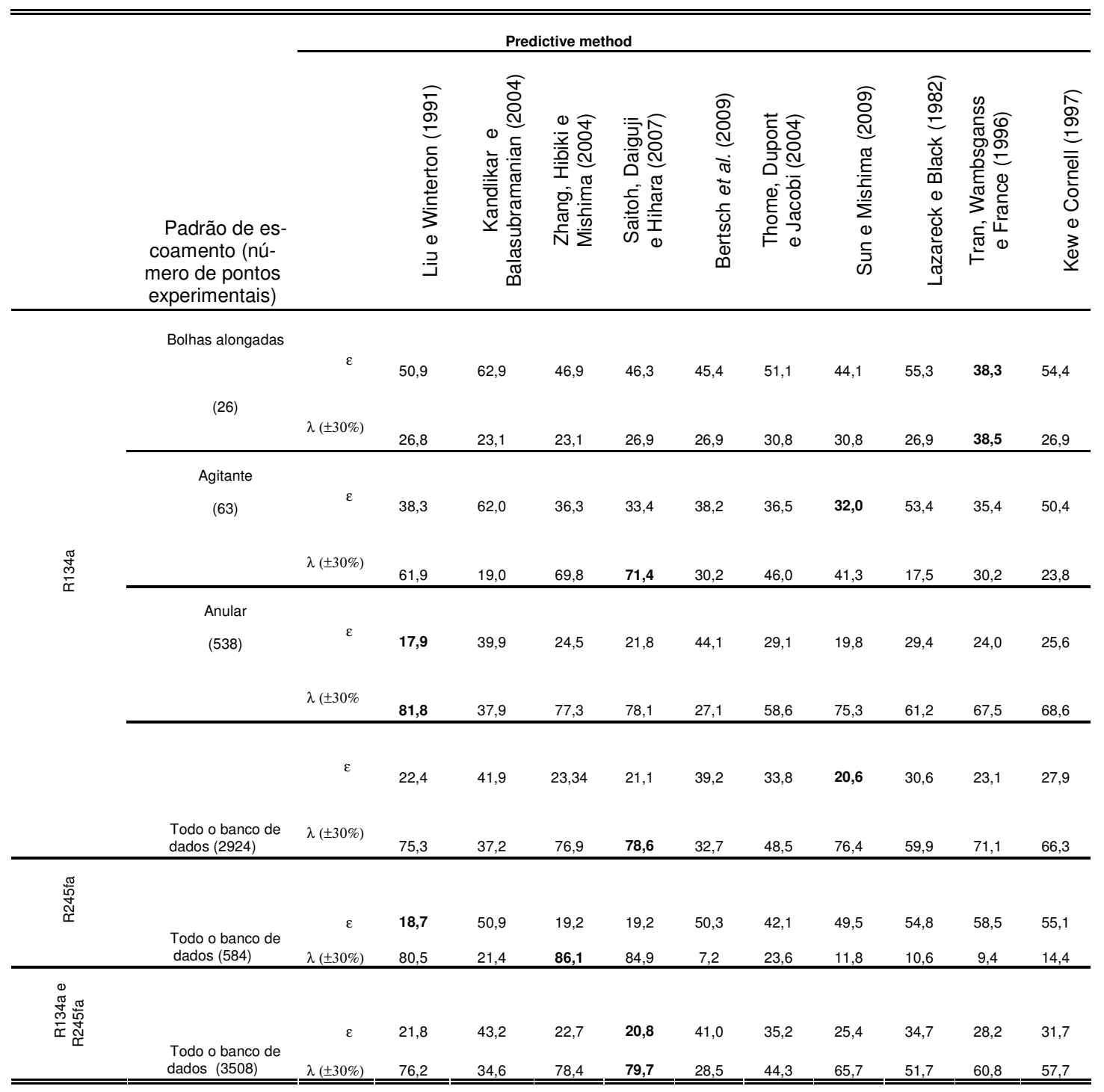



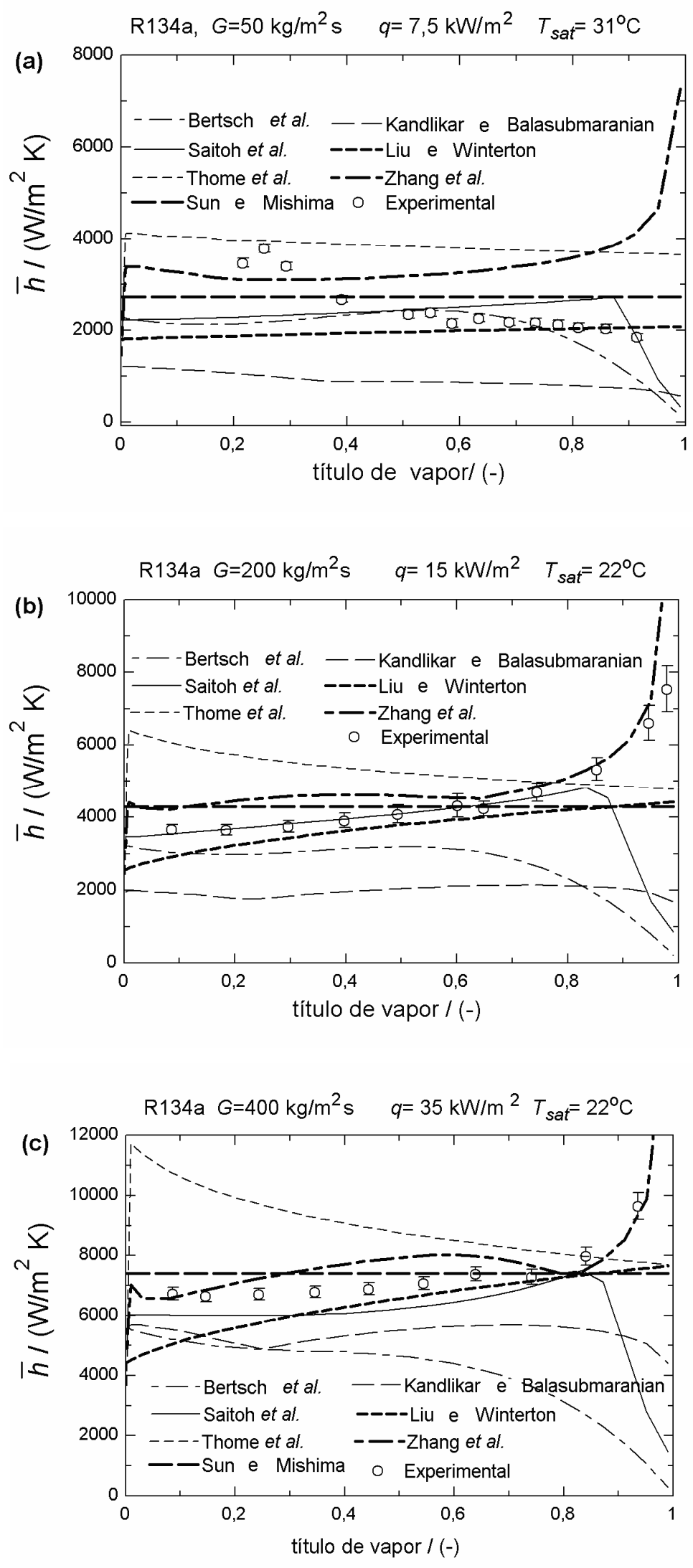


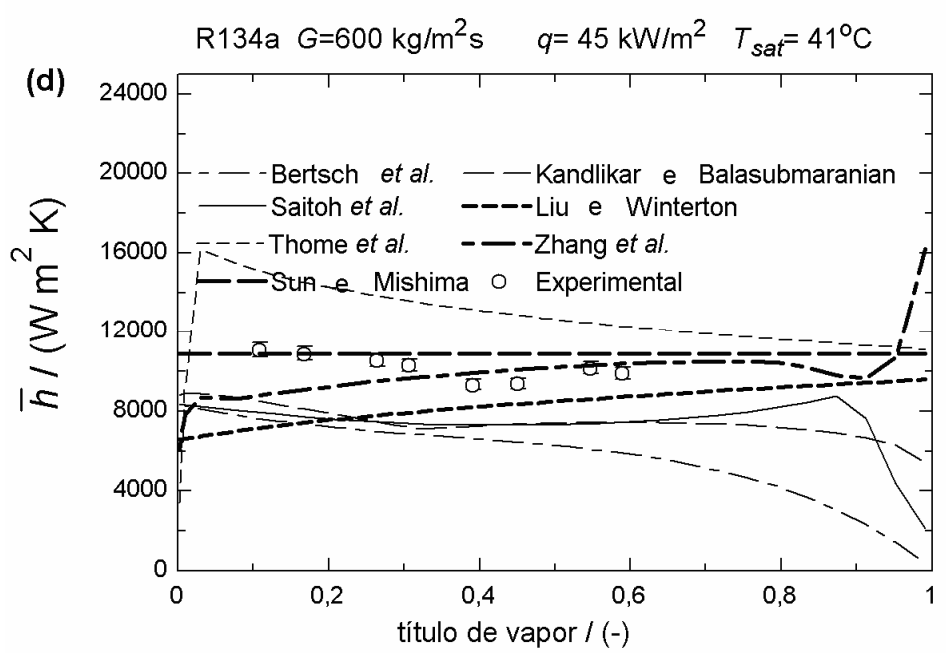

Figura 5.26 - Comparação da evolução do CTC com o título de vapor para os dados experimentais e métodos de previsão. (a) $\mathrm{G}=50 \mathrm{~kg} / \mathrm{m}^{2} \mathrm{~s} ; q=7,5 \mathrm{~kW} / \mathrm{m}^{2} ; \mathrm{T}_{\mathrm{sat}}=31^{\circ} \mathrm{C} ;$ (b) $\mathrm{G}=200 \mathrm{~kg} / \mathrm{m}^{2} \mathrm{~s} ; q=15 \mathrm{~kW} / \mathrm{m}^{2} ; \mathrm{T}_{\mathrm{sat}}=31^{\circ} \mathrm{C} ;$ (c) $\mathrm{G}=400 \mathrm{~kg} / \mathrm{m}^{2} \mathrm{~s} ; q=35 \mathrm{~kW} / \mathrm{m}^{2} ; \mathrm{T}_{\text {sat }}=22^{\circ} \mathrm{C}$; (d) $\mathrm{G}=600 \mathrm{~kg} / \mathrm{m}^{2} \mathrm{~s} ; \mathrm{q}=45 \mathrm{~kW} / \mathrm{m}^{2} ; \mathrm{T}_{\mathrm{sat}}=41^{\circ} \mathrm{C}$.

Posteriormente foram avaliadas as duas correlações com menores incertezas da Tabela 5.3, a de Saitoh, Daiguji e Hihara (2007) e a de Liu e Winterton (1991), para prever resultados experimentais do novo fluido $R 1234 z e(E)$ com tubos de 2,20mm e 1,00mm, como mostrado na Tabela 5.4. O modelo de três zonas também foi avaliado considerando somente dados para escoamento segundo bolhas alongadas. Os métodos de Liu e Winterton (1991) e de Saitoh, Daiguji e Hihara (2007) foram avaliados sem considerar os padrões de escoamento dos dados experimentais. Nesta análise, os métodos também foram avaliados considerando dois critérios: fração de dados preditos dentro de uma faixa de erro de $\pm 30 \%, \lambda$, e o erro médio absoluto, $\varepsilon$. Novamente, o método de Saitoh, Daiguji e Hihara (2007) mostrou-se superior, considerando todo o banco de dados.

Tabela 5.4 - Estatísticas de comparação do CTC entre correlações e dados experimentais para $\mathrm{R} 1234 z e(\mathrm{Y})$ para tubos circulares com $D=1,00 \mathrm{~mm}$ e $\mathrm{D}=2,20 \mathrm{~mm}$ (TIBIRIÇÁ; RIBATSKI; THOME, 2011)

\begin{tabular}{lccc}
\hline & \multicolumn{3}{c}{ Método de previsão de CTC } \\
\cline { 2 - 4 } & $\begin{array}{c}\text { Liu e Winterton } \\
(1991)\end{array}$ & $\begin{array}{c}\text { Saitoh, Daiguji } \\
\text { e Hihara (2007) }\end{array}$ & $\begin{array}{c}\text { Thome, Dupont e } \\
\text { Jacobi (2004) (so- } \\
\text { mente dados para } \\
\text { bolhas alongadas) }\end{array}$ \\
\hline № de pontos & 1398 & 1398 & 172 \\
experimentais & 22,8 & 19,4 & 15,9 \\
$\varepsilon(\%)$ & 71,4 & 79,8 & 93,6 \\
$\lambda( \pm 30 \%)$ & & &
\end{tabular}




\subsection{FLUXO CRÍTICO DE CALOR}

Os resultados apresentados para o FCC foram estimados utilizando-se o procedimento de regressão descrito no capítulo 4. Buscou-se realizar ensaios para uma faixa de condições ampla, limitada pelas restrições do aparato experimental.

\subsubsection{EFEITO DO DIÂMETRO}

Para se avaliar corretamente o efeito do diâmetro no $\mathrm{FCC}$, a relação $L_{\text {aqued }} D$ deve ser a mesma para todos os diâmetros avaliados, de forma a obter títulos de vapor na saída da região aquecida similares. Os demais parâmetros, mantidos constantes para uma investigação adequada dos efeitos do diâmetro, são: temperatura de saturação, velocidade mássica e grau de sub-resfriamento. A Figura 5.27 ilustra resultados de FCC para os diâmetros de $1,00 \mathrm{~mm}$ e $2,20 \mathrm{~mm}$. Para o tubo de $1,00 \mathrm{~mm}$, a relação $\left(L_{\text {aqued }} D\right)=180$ e para o tubo de $2,20 \mathrm{~mm}\left(L_{\text {aqued }} D\right)=164$. Apesar da diferença das relações $(L / D)$ ser da ordem de $10 \%$, elas são próximas o suficiente para serem comparadas, pois, de acordo com Katto e Ohno (1984), essa diferença resulta num acréscimo da ordem de $3 \%$ no FCC para o tubo com $(L / D)=164$. Assim, analisando-se a Figura 5.27 constata-se um efeito desprezível do diâmetro para as condições avaliadas, tornando-se perceptível apenas em vazões superiores, com o tubo de diâmetro inferior apresentando um FCC ligeiramente superior.

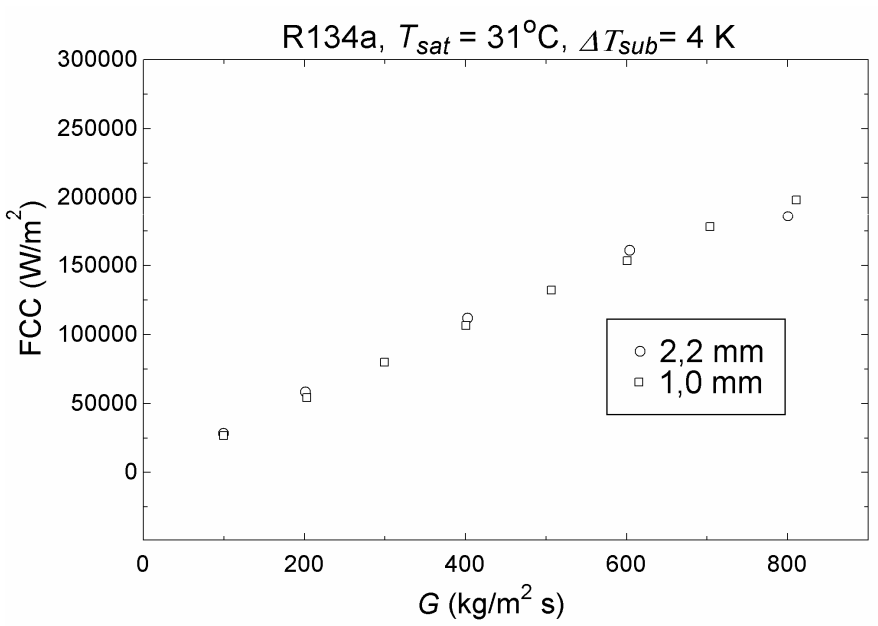

Figura 5.27 - Efeito do diâmetro para FCC com R134a com tubos de 1,00mm e 2,20mm. 


\subsubsection{EFEITO DO FLUIDO}

A Figura 5.28 ilustra uma comparação do FCC para os refrigerantes R134a e R245fa. Nela se observa que o FCC do R245fa é superior ao do R134a, considerando-se condições de operação similares. Esse resultado também foi observado por Ong e Thome (2011b) durante sua campanha experimental e é similar ao comportamento previsto pelas correlações avaliadas. A explicação principal para este resultado é o fato de o calor latente de evaporação do R245fa ser aproximadamente 10\% superior ao do R134a (ver Tabela 5.1) e o FCC ser diretamente proporcional ao calor latente de evaporação. O mesmo efeito é observado entre R134a e R1234ze(E), visto na Figura 5.29, devido ao fato de o calor latente de evaporação do R134a ser aproximadamente 7\% superior ao do R1234ze(E).

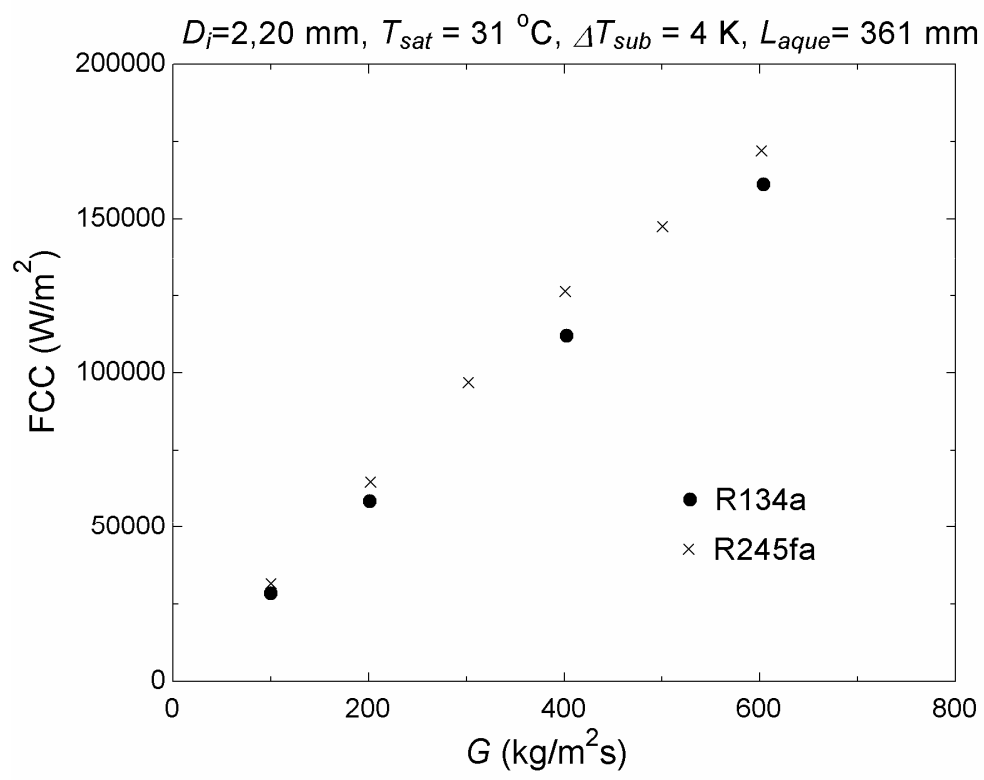

Figura 5.28 - Comparação entre o FCC do R134a e R245fa para tubo de 2,20mm. 


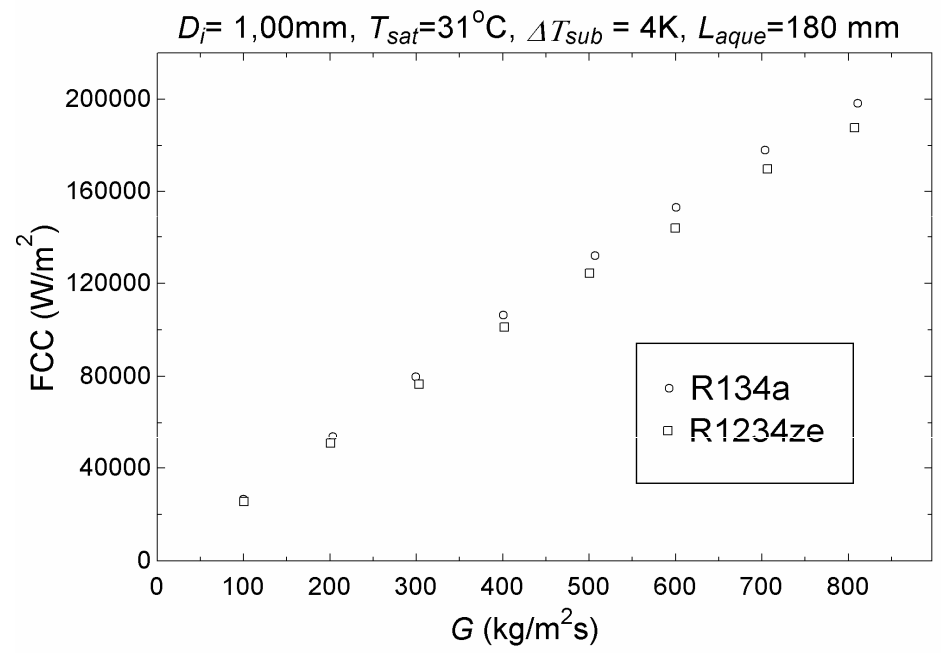

Figura 5.29 - Comparação entre o FCC do R134a e R1234ze(E) para tubo de 1,00mm.

\subsubsection{EFEITO dA TEMPERATURA}

A Figura 5.30 ilustra o efeito da temperatura do fluido no FCC para o R134a em um tubo de diâmetro igual a 2,20 mm. Nessa figura, para as velocidades mássicas superiores verifica-se que o FCC decresce com o incremento da temperatura de saturação. Esse comportamento é capturado pela maioria das correlações e está associado ao decréscimo do calor latente de vaporização com o incremento da temperatura.

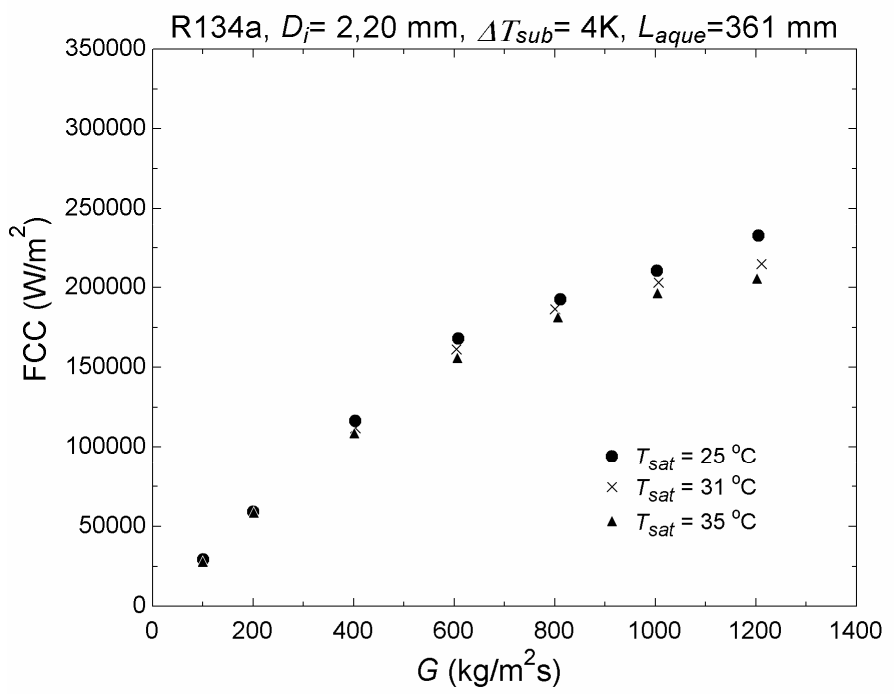

Figura 5.30 - Efeito da temperatura de saturação no FCC para R134a e $D_{i}=2,20 \mathrm{~mm}$. 


\subsubsection{EFEITO DO SUB-RESFRIAMENTO}

A redução do sub-resfriamento na entrada do canal tem um efeito similar ao da redução do comprimento aquecido. Para sub-resfriamentos elevados, a potência de aquecimento necessária para se atingir um título de vapor crítico similar se eleva, incrementando, portanto, o FCC. Entretanto, para os sub-resfriamentos utilizados neste estudo experimental, este efeito tende a ser reduzido. As Figura 5.31 e Figura 5.32 ilustram, respectivamente, os efeitos do sub-resfriamento para R245fa e R1234ze(E).

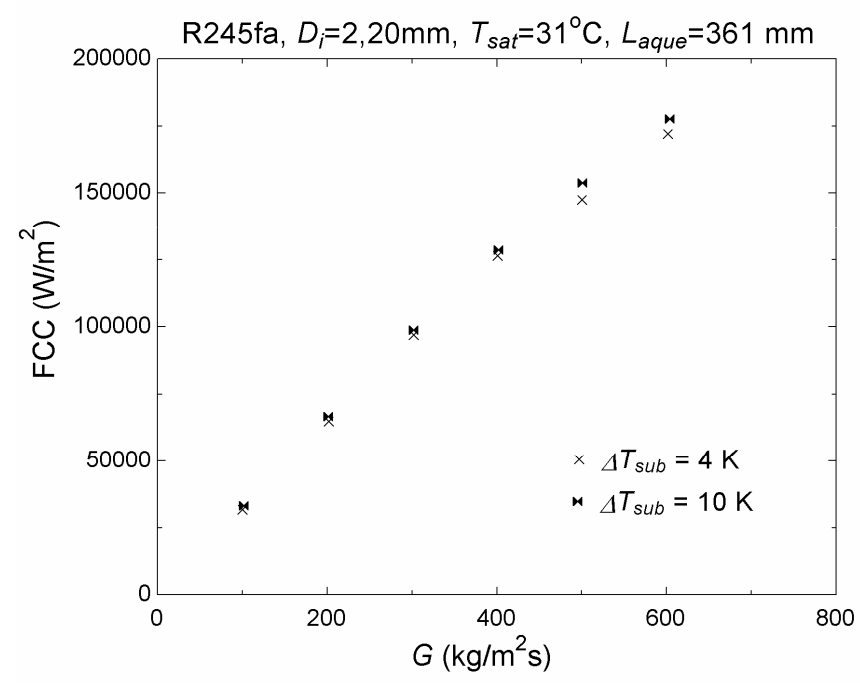

Figura 5.31 - Efeito do subresfriamento no FCC para o fluido R245fa em tubo de 2,20mm.

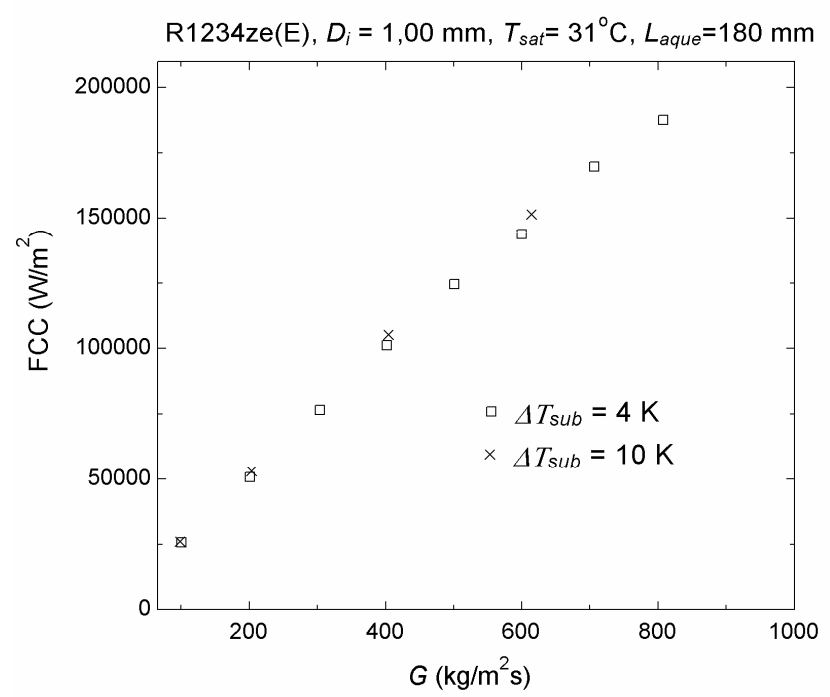

Figura 5.32 - Efeito do subresfriamento no FCC para o fluido R1234ze em tubo de 1,00mm. 


\subsubsection{EFEITO DA VELOCIDADE MÁSSICA}

Nas Figura 5.27 à Figura 5.33 ilustram-se o efeito da velocidade mássica no FCC. De acordo com essas figuras, o FCC se eleva com o incremento da velocidade mássica para os fluidos e faixa de vazões avaliadas, independentemente do grau de sub-resfriamento, da temperatura de saturação e do comprimento aquecido. Nota-se na Figura 5.33 que a inclinação da curva CHF vs $G$ altera-se a partir de $G=600 \mathrm{~kg} / \mathrm{m}^{2} \mathrm{~s}$. Isso indica uma mudança do mecanismo responsável pelo FCC, o qual inicialmente está relacionado à secagem da parede por deficiência de líquido. Para fluxos de calor elevados, relacionados a vazões superiores e comprimentos aquecidos reduzidos, ocorre a nucleação de bolhas junto à superfície na presença do filme líquido durante escoamento anular. Com o incremento da intensidade de nucleação e a possibilidade de secagem da parede em uma situação de excesso de líquido, alcança-se uma condição de escoamento anular invertido, isto é, o líquido escoa na região central e o vapor junto à superfície.

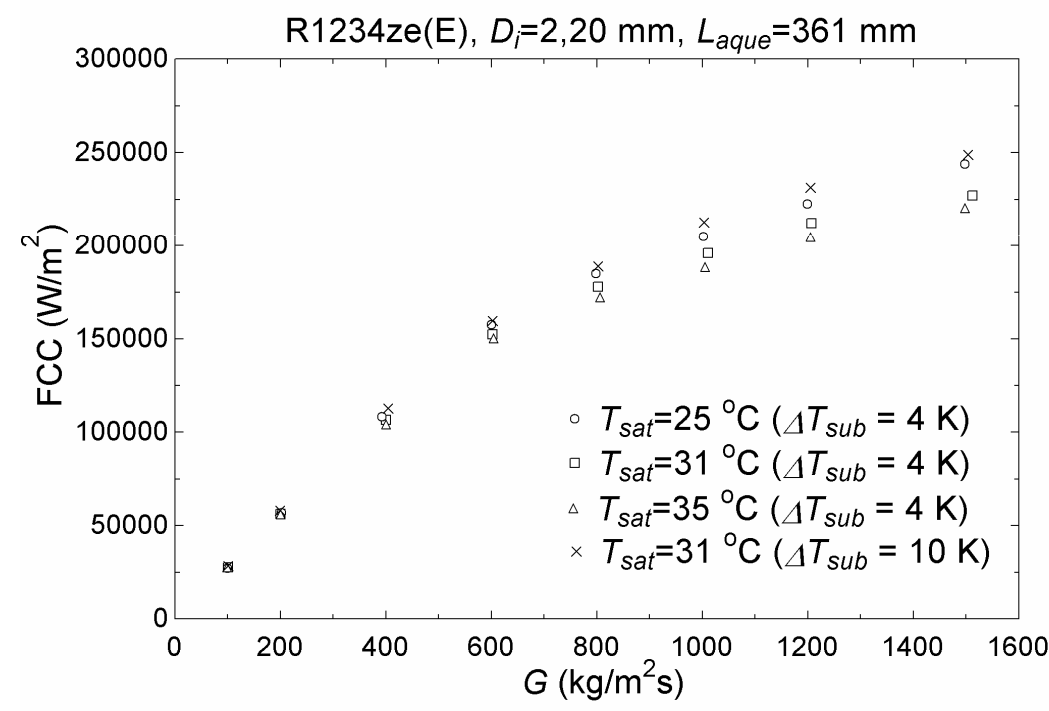

Figura 5.33 - Variação do FCC com a vazão para o R1234ze(E) em tubo de $D_{\digamma}=2,20 \mathrm{~mm}$.

\subsubsection{EFEITO DO COMPRIMENTO}

Mantendo-se o grau de sub-resfriamento e reduzindo-se o comprimento aquecido, verifica-se o incremento do FCC, conforme ilustrado na Figura 5.34. Isso decorre da redução da área de transferência de calor e, portanto, para se alcançar o 
mesmo título de vapor crítico, um fluxo de calor superior se faz necessário. Nessa análise se considera que os mecanismos de FCC se mantém os mesmos.

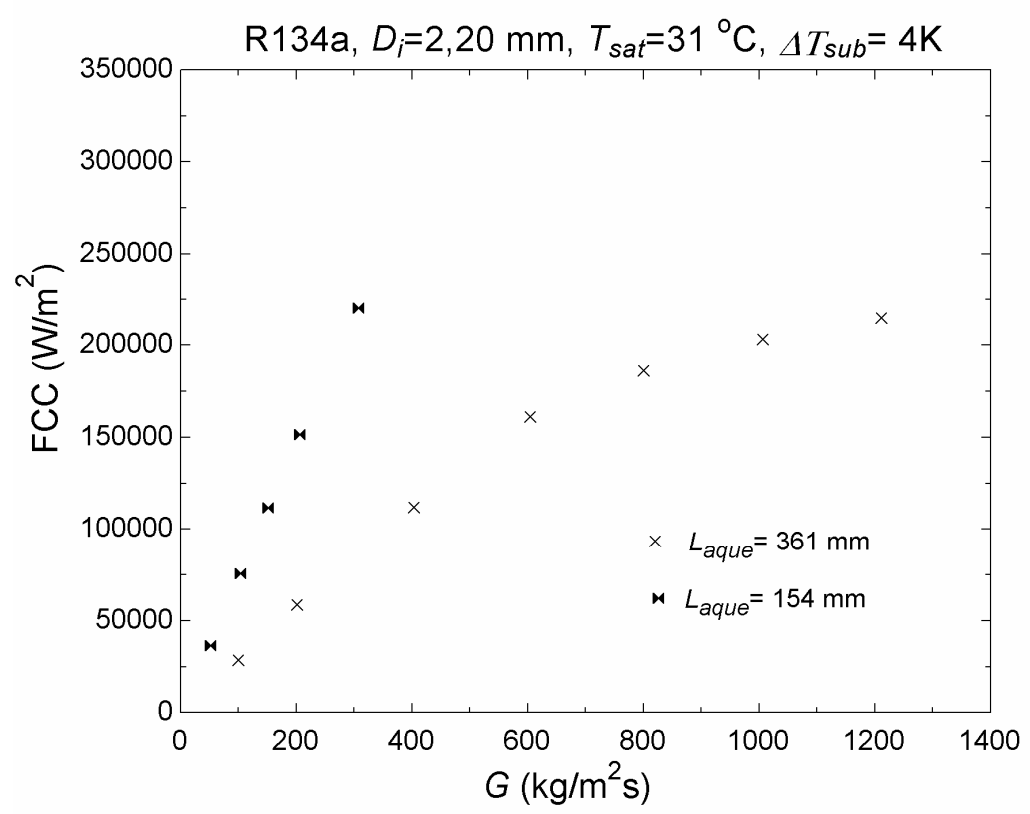

Figura 5.34 - Efeito do comprimento aquecido no FCC para R134a em tubo de $D_{i}=2,20 \mathrm{~mm}$.

\subsubsection{EFEITO dA GEOMETRIA}

O efeito da geometria foi avaliado comparando o FCC dos tubos achatados, descritos na seção 4, com os valores verificados para diâmetros equivalentes similares. Tais comparações, caso efetuadas fixando-se o comprimento aquecido, resultam em títulos de vapor distintos na saída da seção de testes para um mesmo fluxo de calor. Isto implica que os canais com maior grau de achatamento apresentam um FCC inferior, pois o título de vapor na saída da seção de testes é superior devido a uma maior área de transferência de calor. Assim, resultados foram obtidos considerando comprimentos aquecidos de tubo equivalentes, isto é, áreas de superfície interna similares, conforme equação (5-1).

$$
\begin{aligned}
& \pi \cdot D_{e q} \cdot L_{e q}=P_{\text {erim,aquec }} \cdot L \Rightarrow \\
& L_{e q}=\frac{P_{\text {erim,aquec }} \cdot L}{\pi \cdot D_{e q}}
\end{aligned}
$$


A Figura 5.35 apresenta os resultados para R245fa, da comparação de um canal circular e dois perfis achatados utilizados neste trabalho para $D_{e q}=2,20 \mathrm{~mm}$ e $L_{e q}=361 \mathrm{~mm}$. Segundo essa figura, para um mesmo $D_{e q}$ e $L_{e q}$, o efeito das geometrias avaliadas no FCC é desprezível.

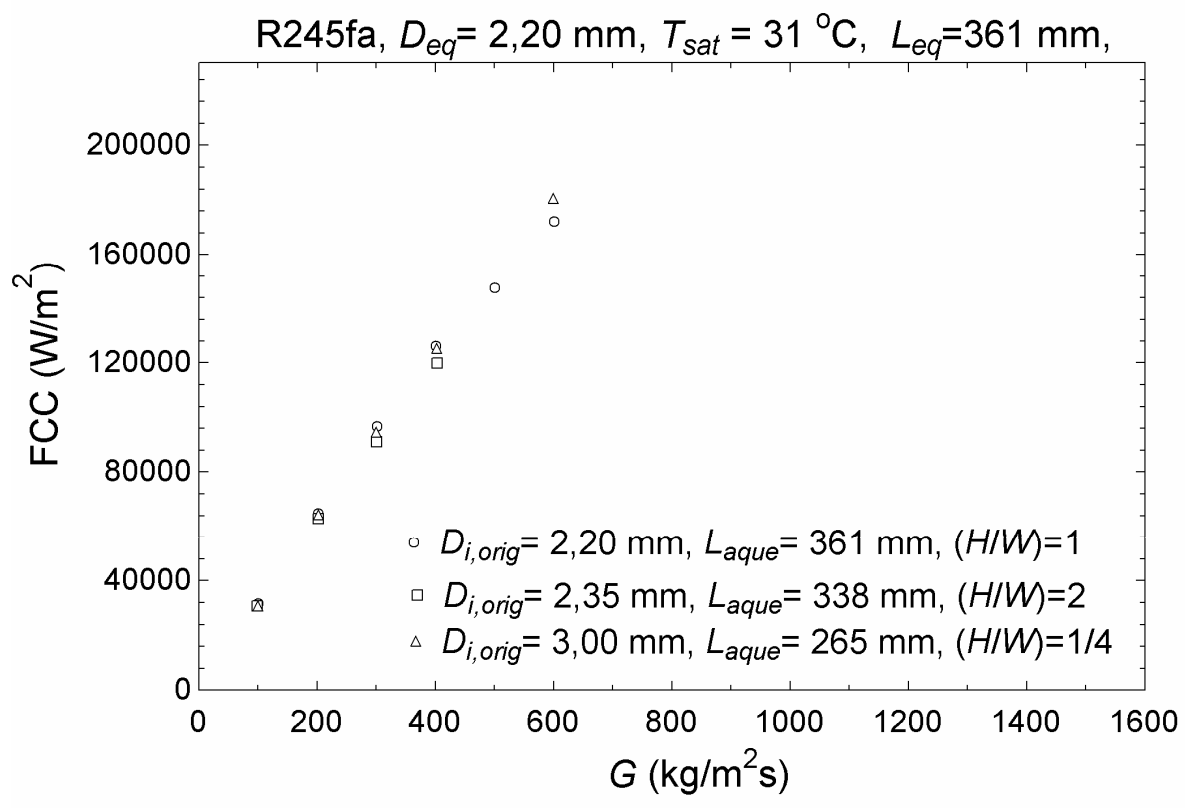

Figura 5.35 - Efeito da geometria no FCC para R245fa com $D_{e q}=2,20 \mathrm{~mm}$.

\subsubsection{AVALIAÇÃO dOS MÉTOdOS DE PREDIÇÃO}

Neste item, os métodos de previsão do FCC propostos por Katto e Ohno (1984), Shah (1987), Zhang et al. (2006) e Ong e Thome (2011b) são comparados aos resultados experimentais levantados neste estudo. Os métodos são avaliados de acordo com o erro médio absoluto e a parcela de dados com desvio em relação aos resultados experimentais inferior a $25 \%$. A Tabela 5.5 apresenta os resultados desta comparação considerando o tubo de 2,2mm. De maneira geral, o método de Katto e Ohno (1984) foi o que apresentou as melhores previsões dos resultados levantados neste estudo, seguido de Ong e Thome (2011b) e Zhang et al. (2006). Para ambos os fluidos, a Figura $\mathbf{5 . 3 6}$ mostra a dispersão dos dados experimentais em relação as correlações.

A Tabela 5.6 apresenta os resultados da comparação do novo fluido $R 1234 z e(E)$ contra estas correlações para canais circulares de 1,00mm e 2,20mm. 
Como ocorrido para o tubo de 2,20mm, a correlação de Katto e Ohno (1984) novamente apresentou os menores erros na previsão dos resultados experimentais.

Tabela 5.5 - Resultados das comparações para FCC entre métodos de previsão e resultados experimentais para $D_{i}=2,20 \mathrm{~mm}$, para R134a e R245fa.

\begin{tabular}{|c|c|c|c|c|c|c|}
\hline \multirow[b]{2}{*}{ Fluido } & \multirow[b]{2}{*}{ № de pontos } & & \multicolumn{4}{|c|}{ Método de previsão de FCC } \\
\hline & & & $\begin{array}{c}\text { Katto and } \\
\text { Ohno (1984) }\end{array}$ & Shah (1987) & $\begin{array}{c}\text { Zhang et al. } \\
(2006)\end{array}$ & $\begin{array}{c}\text { Ong e Thome } \\
(2011 \mathrm{~b})\end{array}$ \\
\hline \multirow[t]{2}{*}{ R134a } & 32 & $\varepsilon(\%)$ & 10,8 & 24,0 & 14,0 & 14,1 \\
\hline & & $\lambda( \pm 25 \%)$ & 90,6 & 46,9 & 90,6 & 96,9 \\
\hline \multirow[t]{2}{*}{$\mathrm{R} 245 \mathrm{fa}$} & 22 & $\varepsilon(\%)$ & 2,7 & 25,9 & 18,9 & 13,0 \\
\hline & & $\lambda( \pm 25 \%)$ & 100,0 & 27,3 & 100,0 & 81,8 \\
\hline \multirow{2}{*}{$\begin{array}{c}\text { Total } \\
\text { (R134a + } \\
\text { R245fa) }\end{array}$} & 54 & $\varepsilon(\%)$ & 7,5 & 24,8 & 16,0 & 13,6 \\
\hline & & $\lambda( \pm 25 \%)$ & 94,4 & 38,9 & 94,4 & 90,8 \\
\hline
\end{tabular}
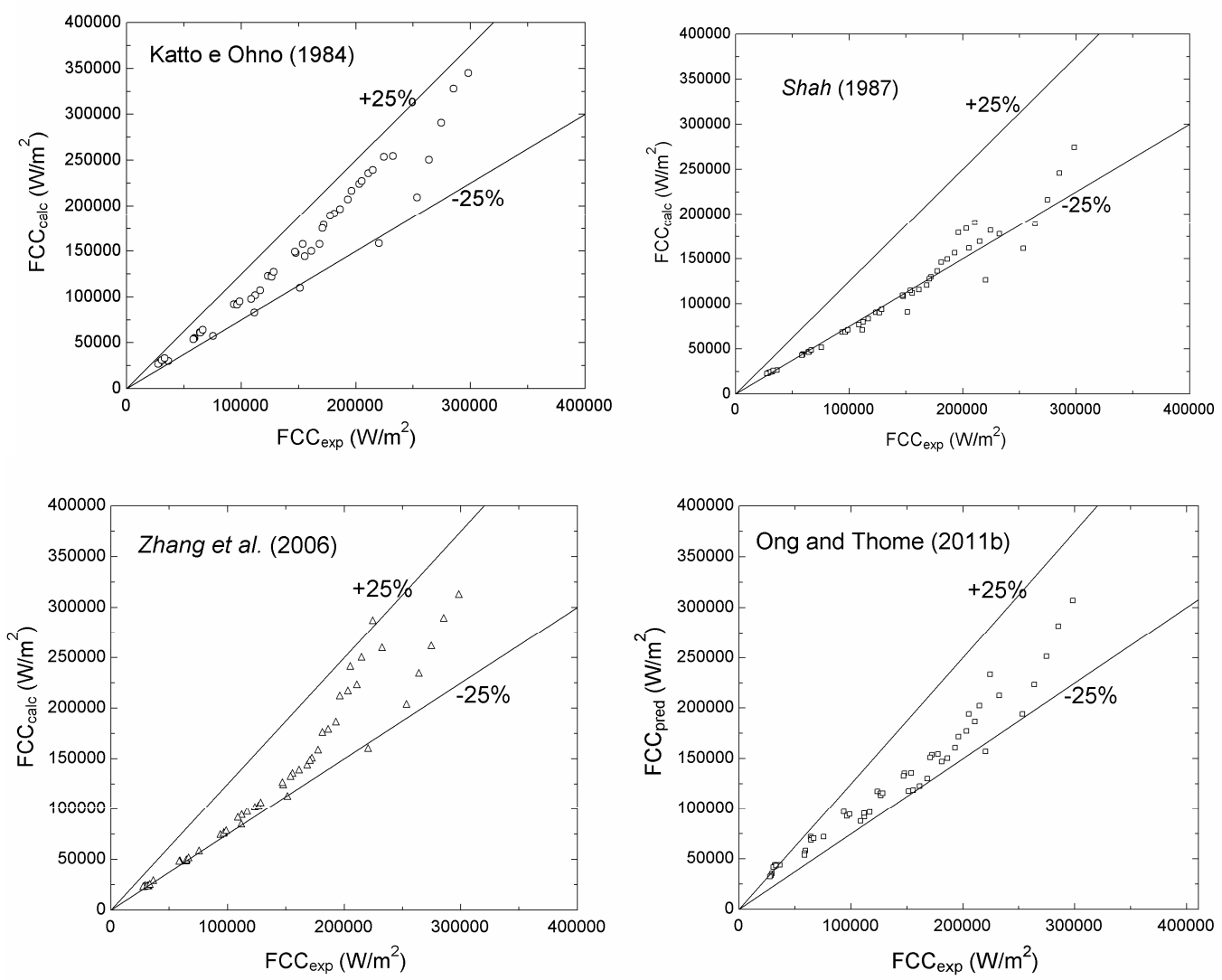

Figura 5.36 - Comparação entre correlações e dados experimentais para FCC. 
Tabela 5.6 - Estatísticas de comparação para FCC entre correlações e banco de dados de $1,00 \mathrm{~mm}$ e 2,20mm para R1234ze(E).

\begin{tabular}{|c|c|c|c|c|c|c|}
\hline \multirow[b]{2}{*}{ Tubo } & \multirow[b]{2}{*}{ № de pontos } & & \multicolumn{4}{|c|}{ Métodos de previsão de FCC } \\
\hline & & & $\begin{array}{c}\text { Katto e } \\
\text { Ohno (1984) }\end{array}$ & Shah (1987) & $\begin{array}{l}\text { Zhang et al. } \\
\qquad(2006)\end{array}$ & $\begin{array}{l}\text { Ong e } \\
\text { Thome } \\
\text { (2011b) }\end{array}$ \\
\hline \multirow[t]{3}{*}{$1,00 \mathrm{~mm}$} & 22 & $\varepsilon(\%)$ & 5,9 & 25,5 & 16,9 & 19,0 \\
\hline & & $\lambda( \pm 20 \%)$ & 100 & 13,6 & 95,5 & 45,5 \\
\hline & & $\lambda( \pm 30 \%)$ & 100 & 95,5 & 100,0 & 86,4 \\
\hline \multirow[t]{3}{*}{$2,20 \mathrm{~mm}$} & 32 & $\varepsilon(\%)$ & 6,5 & 32,7 & 13,1 & 16,0 \\
\hline & & $\lambda( \pm 20 \%)$ & 100 & 6,3 & 93,8 & 59,4 \\
\hline & & $\lambda( \pm 30 \%)$ & 100 & 46,9 & 100 & 100 \\
\hline Total & 54 & $\varepsilon(\%)$ & 6,3 & 29,7 & 14,6 & 17,2 \\
\hline \multirow{2}{*}{$(1,00$ e $2,20 \mathrm{~mm})$} & & $\lambda( \pm 20 \%)$ & 100 & 9,3 & 94,4 & 53,7 \\
\hline & & $\lambda( \pm 30 \%)$ & 100 & 66,7 & 100 & 94,5 \\
\hline
\end{tabular}

\subsection{Conclusões}

Foram obtidos novos resultados para transferência de calor em ebulição convectiva em microcanais com R134a, R245fa e R1234ze(E) em tubos circulares e tubos achatados com diâmetros equivalentes variando de $1,00 \mathrm{~mm}$ a $2,32 \mathrm{~mm}$. As conclusões levantadas a partir destes resultados são as seguintes:

- o padrão de escoamento estratificado é improvável de se desenvolver durante ebulição convectiva do R134a e R245fa para tubos com diâmetros iguais ou inferiores a 2,32mm;

- o fluido R245fa apresenta transição para escoamento anular a títulos de vapor inferiores aos observados para o R134a;

- o decréscimo do diâmetro tende a reduzir o título da transição intermitente-anular; o aumento da temperatura de saturação tende a elevar o título de transição intermitente-anular;

- o método de previsão de padrão de escoamento de Ong e Thome (2011a) e Felcar, Ribatski e Jabardo (2007) previram satisfatoriamente os dados experimentais independentes levantados neste doutorado, entretanto ambos os métodos podem ser aprimorados na previsão dos padrões de escoamento em condições de velocidades mássicas reduzidas;

- verificou-se o incremento do FCC saturado com a elevação da velocidade mássica e um incremento moderado do FCC com a elevação do grau de subresfriamento; conforme já indicado na literatura, o FCC decresce com o incremento da temperatura de saturação e do comprimento aquecido; 
- o R245fa apresenta FCC saturado superior ao R134a nas mesmas condições experimentais;

- comparações entre o banco de dados levantados neste estudo e correlações da literatura indicaram que o método de Katto e Ohno (1984) proporciona previsões satisfatórias com erro médio próximo a $7 \%$;

- o FCC para os tubos achatados avaliados foi próximo ao dos tubos circulares, desde que a comparação seja baseada no diâmetro e comprimento equivalentes;

- estratificação do escoamento foi observada e medidas de temperatura local revelaram seus efeitos na variação circunferencial do CTC ao longo do perímetro do tubo;

- de forma geral, foi observado que o CTC aumenta com o incremento do fluxo de calor, velocidade mássica e temperatura de saturação. Comportamentos distintos do CTC com a variação do título de vapor foram observados para o R134a para velocidade mássica inferiores a $200 \mathrm{~kg} / \mathrm{m}^{2} \mathrm{~s}$;

- para R245fa, o CTC fica independente do fluxo de calor para títulos de vapor elevados na região de escoamento anular;

- o efeito da geometria foi avaliado através do estudo de tubos achatados, revelando que para condições em que os efeitos de inércia são preponderantes sobre os efeitos gravitacionais (caso de vazões elevadas), a geometria tem pouco efeito sobre o CTC médio, desde que se comparem resultados com mesmo diâmetro equivalente;

- o método para CTC de Saitoh, Daiguji e Hihara (2007) comparado aos demais métodos avaliados e aos resultados experimentais, capturou adequadamente 0 fato do CTC incrementar com o aumento do título de vapor;

- o novo fluido refrigerante R1234ze(E), candidato a substituto do R134a com baixo potencial de aquecimento global, apresenta desempenho de transferência de calor durante a ebulição convectiva próximo ao do R134a. Resultados de CTC, FCC e mapas de padrões de escoamento foram similares aos do R134a. 


\section{DesenVolvimento de MODELOS}

Neste capítulo são apresentados modelos desenvolvidos neste trabalho com o intuito de contribuir para o avanço do estado da arte na área de ebulição convectiva em microcanais. Novos critérios relacionados à previsão da transição entre macro e microcanais são apresentados, juntamente com novos modelos e correlações simplificadas para previsão do CTC e FCC.

\subsection{TRANSIÇÃO ENTRE MACRO E MICROCANAIS}

Critérios para a distinção entre macro e microcanais receberam destaque nas duas últimas décadas, tornando-se uma discussão central em trabalhos envolvendo ebulição convectiva em canais de reduzido diâmetro. Diversos critérios foram desenvolvidos, como descritos no capítulo 2, a partir dos quais diâmetros de transição podem ser calculados. Entretanto, esses métodos apresentam grande divergência quando comparados entre si, pois cada um utiliza uma fundamentação diferente, negligenciando, em suas concepçõesos efeitos sobre o CTC e FCC. Nesse sentido, buscou-se identificar, na presente pesquisa, distinções entre macro e micro-escala que teriam efeitos diretos em aplicações de engenharia, ou seja, influenciassem diretamente o CTC, o FCC e a perda de pressão dos escoamentos bifásicos.

A partir dos experimentos realizados com tubos de diâmetros de $1,00 \mathrm{~mm}$ a 2,32mm e também da ampla revisão bibliográfica, identificaram-se as seguintes características típicas em escoamentos bifásicos em canais de reduzido diâmetro:

(1) inexistência de escoamento estratificado;

(2) tendência de simetria do filme líquido no escoamento anular ao longo do perímetro para canais horizontais.

A primeira característica refere-se a um critério objetivo, possível de ser modelado analiticamente. A ocorrência de escoamento estratificado tem implicações diretas no desempenho de um trocador, pois a transferência de calor pela fase gasosa em contato com a parede é inferior à do líquido, tornando o escoamento estratificado ineficiente. Dessa forma, este trabalho propõe como critério de transição macro/micro o diâmetro a partir do qual não ocorra escoamento estratificado. 
A segunda característica observada é a tendência, com a redução do diâmetro, do escoamento anular apresentar filme líquido simétrico ao longo do perímetro, o que, por consequência, torna o CTC uniforme. Filmes assimétricos ocorrem em escoamentos horizontais com diâmetros superiores e, assim, a secagem prematura da parede na parte superior do canal ocorre devido a efeitos de gravidade. Dessa forma, a simetria do filme também pode ser utilizada como um critério de transição macro/microcanal, apesar desta transição ocorrer de forma gradual, se comparada ao critério baseado na existência do escoamento estratificado.

\subsubsection{CRItÉrio de transição deVido ao escoamento estratificado}

Um primeiro modelo de condição de estratificação pode ser resolvido considerando-se um pistão de líquido saturado estático preenchendo um canal de diâmetro, $D$, e envolto em ambos os lados por vapor saturado, conforme ilustrado na Figura 6.1. Para que este pistão de líquido se mantenha estaticamente estável, uma condição mínima necessária é que a força devido à pressão estática na interface seja inferior à força devido à tensão superficial no contato entre a interface e a parede. Desprezando-se os efeitos inerciais e viscosos, hipóteses razoáveis, considerando-se que o escoamento estratificado só é observado para vazões reduzidas, a força de pressão, $F_{p}$, e a força devido à tensão superficial junto à parede, $F_{T S \text {, são }}$ obtidas de acordo com a exposição a seguir.
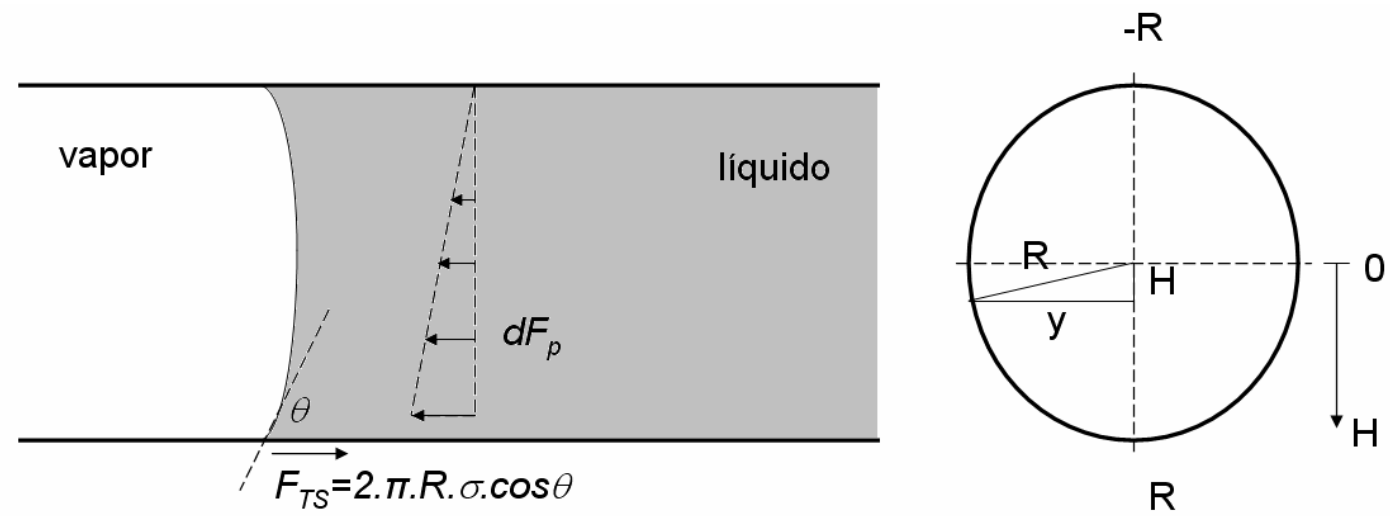

Figura 6.1 - Forças de pressão e de tensão superficial para modelagem da condição de estratificação.

Força de pressão estática na interface:

$$
\begin{gathered}
d F_{p}=\left(\rho_{l}-\rho_{v}\right) \cdot g \cdot(H+R) \cdot d A \\
d A=2 \cdot y \cdot d H
\end{gathered}
$$




$$
\begin{gathered}
y^{2}=R^{2}-H^{2} \\
d F_{p}=\left(\rho_{l}-\rho_{v}\right) \cdot g \cdot(H+R) \cdot 2 \cdot \sqrt{R^{2}-H^{2}} \cdot d H \\
F_{p}=\int_{-R}^{R}\left(\rho_{l}-\rho_{v}\right) \cdot g \cdot(H+R) \cdot 2 \cdot \sqrt{R^{2}-H^{2}} \cdot d H
\end{gathered}
$$

Força da tensão superficial na interface com a parede:

$$
F_{T S}=2 \cdot \pi \cdot R \cdot \sigma \cdot \cos \theta
$$

Igualando-se as forças, obtém-se:

$$
\begin{gathered}
F_{T S}=F_{p} \\
2 \cdot \pi \cdot R \cdot \sigma \cdot \cos \theta=\int_{-R}^{R}\left[\left(\rho_{l}-\rho_{v}\right) \cdot g \cdot(H+R) \cdot 2 \cdot \sqrt{R^{2}-H^{2}}\right] \cdot d H
\end{gathered}
$$

A solução da equação (6-1) fornece o valor do raio do tubo, $R$, para a transição na qual o regime estratificado deixa de existir.

Um segundo critério para avaliar o diâmetro em que ocorre escoamento estratificado foi desenvolvido. Neste, considera-se a altura capilar como critério para o líquido estratificar dentro do tubo. Se o diâmetro $D$ do tubo for maior que a altura capilar para um tubo de diâmetro $D$, o líquido tende a se estratificar. Novamente desprezando-se os efeitos de inércia e viscosos, hipóteses razoáveis para vazões reduzidas. A altura de uma coluna de líquido num tubo capilar na vertical, $H$, é dada pela equação (6-2).

$$
H=\frac{2 \cdot \sigma \cdot \cos \theta}{\rho \cdot g \cdot R}
$$

onde $R$, é o raio do tubo. Considerando dessa forma que o diâmetro de transição da estratificação é igual à altura capilar, obtém-se:

$$
D=\frac{2 \cdot \sigma \cdot \cos \theta}{\rho \cdot g \cdot \frac{D}{2}}
$$

Isolando-se $D$, obtém-se a equação (6-3).

$$
D=\sqrt{\frac{4 \cdot \sigma \cdot \cos \theta}{\left(\rho_{l}-\rho_{v}\right) \cdot g}}
$$

A Tabela 6.1 apresenta uma comparação dos diâmetros de estratificação calculados segundo as equações (6-1) e (6-3) e os critérios propostos na literatura e descritos no capítulo 2 (Revisão bibliográfica). O diâmetro $D_{E o}$ foi calculado utili- 
zando o número de Eotvos com critério de transição macro/microcanal com Eo=1, segundo Brauner e Moalem-Marom (1992). O diâmetro $D_{C o}$ foi calculado considerando o número de confinamento, assumindo critério de transição macro/micro de Co=0,5, conforme proposto por Kew e Cornwell (1997), e $D_{\text {Lap }}$ é o diâmetro dado pela constante de Laplace, segundo Triplet et al. (1999). Como apresentado na Tabela 6.1, para ângulos de contato reduzidos, os diâmetros de transição, segundo Kew e Cornwell (1997), $D_{C o}$, e a equação (6-3), $D_{\text {eq.(6.3) }}$ são similares. O diâmetro de

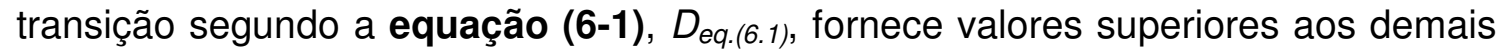

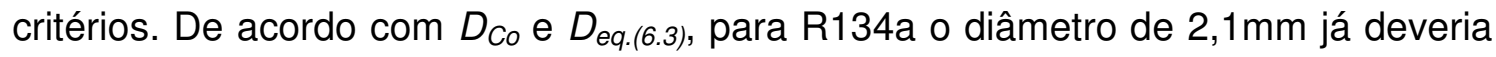
apresentar escoamento estratificado. Porém, durante os experimentos realizados em ebulição convectiva para R134a e R245fa não foi visualizada qualquer formação de escoamento estratificado para o diâmetro de $2,1 \mathrm{~mm}$, ainda que para velocidades mássicas próximas a zero, na qual o escoamento estratificado tem maior facilidade de se desenvolver, demonstrando que o critério devido à equação (6-1) é próximo do observado experimentalmente. Fator importante a ser considerado é a inclusão do ângulo de contato no cálculo da transição, parâmetro não considerado nos critérios de transição da literatura avaliados.

Tabela 6.1 - Diâmetros de transição para critérios da literatura e para os novos critérios de transição, baseados em estratificação (diâmetros em milímetros).

\begin{tabular}{cccccc}
\hline & $D_{\text {Lap }}$ & $D_{\text {Eo }}$ & $D_{\text {Co }}$ & $D_{\text {eq. }(6.1)}$ & $D_{\text {eq. }(6-3)}$ \\
\hline R134a $\left(31^{\circ} \mathrm{C}\right)$ & 0,81 & 5,1 & 1,6 & $2,2\left(\theta_{\text {cont }}=7^{\circ}\right)$ & 1,6 \\
\hline R245fa $\left(31^{\circ} \mathrm{C}\right)$ & 1,01 & 6,4 & 2,0 & $2,9\left(\theta_{\text {cont }}=7^{\circ}\right)$ & 2,0 \\
\hline Água-ar $\left.25^{\circ} \mathrm{C}\right)$ & 2,7 & 17,0 & 5,4 & $7,7\left(\theta_{\text {cont }}=7^{\circ}\right)$ & $5,4\left(\theta_{\text {cont }}=7^{\circ}\right)$ \\
& & & & $5,8\left(\theta_{\text {cont }}=55^{\circ}\right)$ & $4,1\left(\theta_{\text {cont }}=55^{\circ}\right)$ \\
& & & $5,5\left(\theta_{\text {cont }}=60^{\circ}\right)$ & \\
\hline Álcool-ar & 1,7 & 10,7 & 3,4 & $4,8\left(\theta_{\text {cont }}=7^{\circ}\right)$ & $3,4\left(\theta_{\text {cont }}=7^{\circ}\right)$ \\
$\left(25^{\circ} \mathrm{C}\right)$ & & & & $3,4\left(\theta_{\text {cont }}=60^{\circ}\right)$ & $2,4\left(\theta_{\text {cont }}=60^{\circ}\right)$ \\
\hline
\end{tabular}

Com o objetivo de verificar a validade dos critérios propostos, um experimento com ar-água foi elaborado. Conforme a Figura 6.2, o experimento consistiu numa placa de acrílico com furos de vários diâmetros contendo água e ar, de forma a permitir identificar o diâmetro em que ocorre estratificação. De acordo com essa figura, a estratificação, isto é, a presença de uma interface horizontal entre as fases líquido e vapor, ocorreu para diâmetros superiores a 5,6mm. O valor calculado pela 
equação (6-1) para um ângulo de contato de $60^{\circ}$ (valor medido para o par água/acrílico) foi de $5,5 \mathrm{~mm}$.

Apesar da relativa concordância entre os valores previstos pela equação (61) com os resultados experimentais, deve-se considerar que ela não considera efeitos inerciais, os quais tendem a modificar o diâmetro de transição.

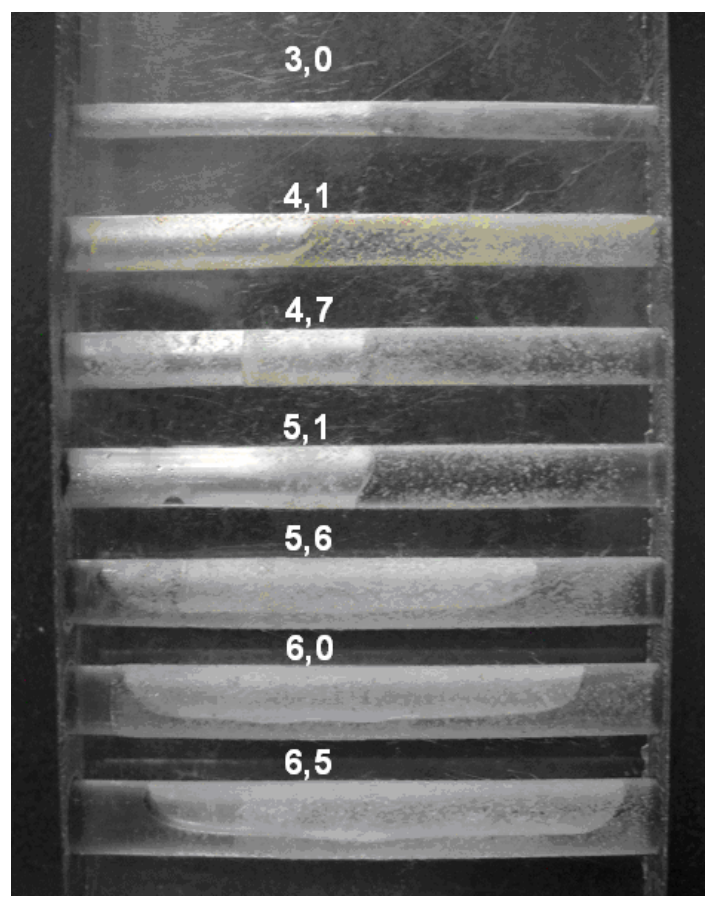

Figura 6.2 - Experimento elaborado para verificar o diâmetro em que ocorre estratificação de água e ar (diâmetros em milímetros).

\subsubsection{CRITÉRIO DE TRANSIÇÃO DEVIDO À SIMETRIA DO FILME LÍQUIDO}

Para escoamento anular horizontal, o grau de simetria do filme líquido ao longo do perímetro do tubo se eleva através da redução do diâmetro do canal ou incremento da velocidade superficial do vapor. Segundo Kandlikar (2010), diâmetros reduzidos implicam na preponderância das forças de tensão superficial sobre efeitos gravitacionais e o incremento da velocidade superficial do vapor na preponderância das forças de inércia sobre as gravitacionais. Considerando que a simetria do filme líquido é uma característica intrinsecamente relacionada ao desempenho termohidráulico do microcanal, optou-se por analisar um critério de transição macro-micro que considere tal aspecto. 
Kandlikar (2010) apresentou parâmetros que permitem comparar as grandezas das cinco principais forças presentes nos escoamentos em ebulição convectiva. Essas forças são devidas à inércia, tensão superficial, tensão de cisalhamento, gravidade e evaporação, e podem ser comparadas através dos parâmetros apresentados na Tabela 6.2.

Tabela 6.2 - Parâmetros de Kandlikar (2010) para avaliar a grandeza das forças em escoamentos bifásicos.

\begin{tabular}{ccccc}
\hline $\begin{array}{c}\text { Forças de } \\
\text { inércia }\end{array}$ & $\begin{array}{c}\text { Tensão } \\
\text { superficial }\end{array}$ & $\begin{array}{c}\text { Força de } \\
\text { cisalhamento }\end{array}$ & Gravidade & Evaporação \\
\hline$F_{i}=\frac{G^{2} \cdot D}{\rho_{l}}$ & $F_{\sigma}=\sigma$ & $F_{\tau}=\frac{\mu_{l} \cdot G}{\rho_{l}}$ & $F_{\text {grav }}=\left(\rho_{l}-\rho_{v}\right) \cdot g \cdot D^{2}$ & $F_{m}=\frac{\left(\frac{q}{h_{l v}}\right)^{2} \cdot D}{\rho_{l}}$ \\
\hline
\end{tabular}

Para essa análise, as forças identificadas por Kandlikar (2010) como necessárias para avaliação da simetria do filme são a gravitacional e a de tensão superficial. Assumindo-se que as forças gravitacionais se tornem desprezíveis quando o parâmetro $F_{\text {grav }}$ for da ordem de $5 \%$ de $F_{\sigma}$, obtém-se o seguinte critério de transição macro-microcanal:

$$
\begin{aligned}
\frac{F_{\text {grav }}}{F_{\sigma}} & <0,05=\frac{1}{20} \rightarrow \frac{\left(\rho_{l}-\rho_{v}\right) \cdot g \cdot D^{2}}{\sigma}<\frac{1}{20} \rightarrow \\
D & <\sqrt{\frac{\sigma}{20 \cdot\left(\rho_{l}-\rho_{v}\right) \cdot g}}
\end{aligned}
$$

Considerando que este critério também indica a preponderância de efeitos de tensão superficial, pode-se adotá-lo como critério para o estabelecimento de uma espessura de filme média uniforme ao longo do perímetro do tubo.

A Tabela 6.3 mostra valores do diâmetro de transição calculados pela equação (6-4) para R134a, R245fa e água. Observa-se que esse diâmetro é cerca de dez vezes menor que o diâmetro de estratificação calculado pela equação (6-1) considerando a mesma temperatura.

Com o propósito de avaliar a equação (6-4), buscou-se na literatura métodos que estimassem a espessura do filme líquido ao longo do perímetro do tubo no escoamento anular horizontal. Hulburt e Newell (2000) desenvolveram um método que 
possibilita estimar a espessura média do filme, $\delta_{m}$, e a espessura do filme na base do canal, $\delta_{0}$. Com essas medidas de espessuras de filme, definiram um parâmetro de simetria do filme líquido dado pela razão $\delta_{m} / \delta_{0}$, o qual é igual a unidade quando o filme é completamente simétrico. Considerando-se que escoamentos anulares horizontais têm um alto grau de simetria com valores de $\delta_{m} / \delta_{0}=0,95$, calculou-se, pelo método de Hulburt e Newell (2000), o diâmetro para obter esta simetria nas condições da Tabela 6.3. Para esse cálculo, é necessário adotar uma velocidade mássica determinada, pois esta é parâmetro de entrada do método. Adotou-se uma valor reduzido para velocidade mássica, $G=50 \mathrm{~kg} / \mathrm{m}^{2} \mathrm{~s}$, de forma que os efeitos de inércia fossem minimizados. Observa-se na Tabela 6.3 que os valores dados pela equação (6-4) e do modelo de Hulburt e Newell (2000) foram relativamente próximos, mas deve-se destacar que o modelo de Hulburt e Newell (2000) foi desenvolvido para aplicações em macrocanais.

Tabela 6.3 - Diâmetros para simetria do filme líquido dado pela equação (6-4), comparado com diâmetro para simetria dado pelo modelo de Hulburt e Newell (2000).

\begin{tabular}{ccc}
\hline & $D_{\text {eq.(6.4) }}$ & $\begin{array}{c}D_{\delta \mathrm{m} / \delta 0=0,95} \\
\left(\mathrm{G}=50 \mathrm{~kg} / \mathrm{m}^{2} \mathrm{~s}\right) \\
\text { Hulburt e Newell (2000) }\end{array}$ \\
\hline R134a $\left(31^{\circ} \mathrm{C}\right)$ & 0,18 & 0,20 \\
R245fa $\left(31^{\circ} \mathrm{C}\right)$ & 0,23 & 0,16 \\
Água $\left(25^{\circ} \mathrm{C}\right)$ & 0,61 & 0,75 \\
\hline
\end{tabular}

\subsection{Coeficiente de tRANSFerÊNCIA DE CALOR}

Os resultados experimentais e as comparações com modelos de CTC no capítulo 5 revelaram que os métodos disponíveis preveem o banco de dados com erros médios absolutos da ordem de $20 \%$ e não capturam adequadamente a tendência dos dados observados experimentalmente com a variação dos parâmetros de entrada. Isso demonstra a necessidade do desenvolvimento de novas correlações e modelos teóricos. Nesse sentido, as seguintes abordagens foram adotadas neste trabalho: (i) ajustar correlações da literatura segundo o presente banco de dados experimental, visando o uso imediato por projetistas; e, (ii) desenvolver um modelo 
com fundamentação teórica que permita explorar e identificar mecanismos físicos presentes durante a ebulição convectiva em microcanais quando comparados ao banco de dados levantados neste estudo. Foram ajustadas as correlações de Saitoh, Daiguji e Hihara (2007) e Liu e Winterton (1991), por apresentarem melhores desempenhos nas avaliações efetuadas ao longo deste trabalho. O banco de dados utilizado para ajustar estas novas correlações contêm 1970 pontos experimentais, para tubos circulares, horizontais, fluidos R134a, R245fa, diâmetros de 1,00mm, 2,20mm e 2,32mm, L/D entre 90 e 200, temperaturas de saturação de 22, 25, 31, 35 e $41^{\circ} \mathrm{C}$, para condições de títulos de vapor inferiores às da secagem da parede.

\subsubsection{NOVAS CORRELAÇÕES}

A correlação de Saitoh, Daiguji e Hihara (2007) trata-se de um método do tipo Chen, onde efeitos de ebulição nucleada e convectivos são ponderados de acordo com o título de vapor para a região anterior à secagem da parede, conforme descrito no capítulo 2. As quatro constantes empíricas do método de Saitoh, Daiguji e Hihara (2007) - a, l, m, $n$ - foram ajustadas com base no presente banco de dados. Na versão modificada da correlação de Saitoh, Daiguji e Hihara (2007), desprezou-se a transição laminar/turbulento no número de Martinelli e na parcela convectiva do CTC, estas relacionadas à descontinuidade no CTC com o incremento do título de vapor, mantendo-se os termos para escoamento turbulento. Tal hipótese considera que a agitação proporcionada pelo vapor no filme líquido mantém, ou até mesmo incrementa, os efeitos de intensificação relacionados à turbulência. A correlação modificada baseada em Saitoh, Daiguji e Hihara (2007) é dada por:

$$
\begin{aligned}
\operatorname{Re}_{l} & =G \cdot(1-x) \cdot \frac{D}{\mu_{l}} \\
G_{v} & =G \cdot x \\
W e_{v} & =\frac{D \cdot G_{v}{ }^{2}}{\rho_{v} \cdot \sigma}
\end{aligned}
$$




$$
\begin{aligned}
& X_{v}=\left(\frac{1-x}{x}\right)^{0,9}\left(\frac{\rho_{v}}{\rho_{l}}\right)^{0,5}\left(\frac{\mu_{l}}{\mu_{v}}\right)^{0,1} \\
& d_{b}=0,51\left(\frac{2 \sigma}{g\left(\rho_{l}-\rho_{v}\right)}\right)^{0,5} \\
& h_{p o o l}=207 \frac{k_{l}}{d_{b}}\left(\frac{q d_{b}}{k_{l} T}\right)^{0,745}\left(\frac{\rho_{v}}{\rho_{l}}\right)^{0,581} \operatorname{Pr}_{l}^{0,533} \\
& F=1+\frac{\left(\frac{1}{X_{v}}\right)^{l}}{\left(1+W e_{v}{ }^{m}\right)} \\
& \operatorname{Re}_{t p}=\operatorname{Re}_{l} F_{h}^{1,25} \\
& S=\frac{1}{1+a\left(\operatorname{Re}_{t p} \cdot 10^{-4}\right)^{n}} \\
& h_{t p}=F \cdot h_{l}+S \cdot h_{p o o l}
\end{aligned}
$$

onde os coeficientes ajustados têm o valor de:

$$
\begin{aligned}
& a=0,233 \\
& l=0,915 \\
& m=-55 \\
& n=1,14
\end{aligned}
$$

De forma análoga, novos coeficientes foram ajustados para a correlação de Liu e Winterton (1991), baseados no presente banco de dados. A correlação modificada, baseada em Liu e Winterton (1991), é dada por:

$$
\begin{aligned}
& \operatorname{Re}_{l}=\frac{G D}{\mu_{l}} \\
& F=\left(1+x \cdot \operatorname{Pr}_{l} \cdot\left(\frac{\rho_{l}}{\rho_{v}}-1\right)\right)^{0,32} \\
& S=\left(1-0,0391 \cdot F^{-22} \cdot \operatorname{Re}_{l}^{-25}\right)^{-1} \\
& F r=\frac{G^{2}}{\rho_{l}^{2} g D} \\
& e_{f}=1 \\
& e_{s}=1 \\
& \text { se } \quad(F r<0,05)\left\{\begin{array}{c}
\left.e_{f}=F r^{(0,1-2 F r}\right) \\
e_{s}=F r^{0,5}
\end{array}\right.
\end{aligned}
$$




$$
\begin{aligned}
& h_{l}=0,023 \cdot \frac{k_{l}}{D} \cdot \operatorname{Re}_{l}^{0,8} \cdot \operatorname{Pr}_{l}^{0,4} \\
& h_{\text {pool }}=55 \cdot \operatorname{Pr}^{0,12} \cdot q^{\frac{2}{3}} \cdot\left(-\log _{10}\left(p_{r}\right)\right)^{-0,55} \cdot M^{-0,5} \\
& h_{t p}=\sqrt{\left(F \cdot h_{l} \cdot e_{f}\right)^{2}+\left(S \cdot h_{p o o l} \cdot e_{s}\right)^{2}}
\end{aligned}
$$

\subsubsection{NOVO MODELO PARA ESCOAMENTO ANULAR}

Como observado no capítulo 5, o escoamento anular é o padrão que tende a ser predominante em aplicações envolvendo a evaporação no interior de tubos. A redução dos diâmetros e o incremento da velocidade mássica tornam este padrão ainda mais abrangente. Além disso, CTCs superiores são verificados para este padrão. Nesse sentido, a compreensão dos mecanismos de transferência de calor para o escoamento anular e a proposição de modelos mecanísticos têm sido objetivos de pesquisadores nesta área. Modelos para a transferência de calor durante a ebulição convectiva em micro-escala, como os de 3-zonas proposto por Thome, Dupont e Jacobi (2004), para o regime de bolhas alongadas, Qu e Mudawar (2003), para o escoamento anular, considera a condução através de um filme líquido como o principal mecanismo de transferência de calor. Considerando que o filme líquido se encontra no regime laminar e termicamente desenvolvido, o coeficiente de transferência de calor, $h$, pode ser estimado a partir da espessura do filme líquido, $\delta$, por meio da equação (6-7).

$$
h=\frac{k_{l}}{\delta}
$$

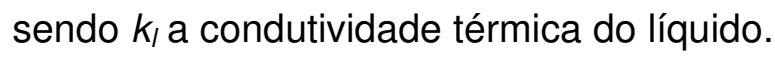

$\mathrm{Na}$ obtenção dessa equação, considera-se que a interface líquido-vapor se encontra à temperatura de saturação e o filme líquido superaquecido apresenta gradiente de temperatura constante. De forma geral, a equação (6-7) também é válida para filmes líquidos de reduzida espessura em condições de escoamento saturados, pois nestes, ainda que o escoamento encontre-se no regime turbulento, a espessura é tão diminuta que uma aproximação linear do perfil de temperatura torna-se razoável. A espessura do filme líquido pode ser estimada a partir do cálculo da fração de vazio. Diversas correlações para a determinação da fração de vazio 
estão disponíveis na literatura, sendo a maioria baseada no modelo de deslizamento de fases de Zuber e Findlay (1965). Com base na correlação do Rouhani e Axelsson (1970) para cálculo de fração de vazio e considerando o escoamento com fluido R134a a $31^{\circ} \mathrm{C}$, com $q=108 \mathrm{~kW} / \mathrm{m}^{2}, G=1435 \mathrm{~kg} / \mathrm{m}^{2} \mathrm{~s}, x=20 \%$, em um tubo de $500 \mu \mathrm{m}$ de diâmetro, obtém-se um CTC a partir da equação (6-7) igual a $2615 \mathrm{~W} / \mathrm{m}^{2} \mathrm{~K}$, valor próximo ao obtido através do cálculo de espessura segundo o método de Revellin e Thome (2007b), ilustrado na Figura 3.2, porém 10 vezes inferior ao valor experimental obtido por Consolini (2008). Diversas comparações realizadas pelo presente estudo, com diâmetros variando de $0,5 \mathrm{~mm}$ até $13 \mathrm{~mm}$ demonstraram que a utilização da equação equação (6-7) para cálculo do CTC em escoamentos anulares tende a subestimar o CTC por fatores de 2 a 10 vezes, permitindo especular uma espessura do filme líquido inferior à fornecida pelo método de cálculo de fração de vazio. Vale ressaltar que medidas de espessura de filmes líquidos para escoamento anular em microcanais circulares não são verificadas na literatura, conforme a extensa pesquisa bibliográfica elaborada por Tibiriçá, Do Nascimento e Ribatski (2010); assim, métodos para estimativas de fração de vazio em macrotubos não foram validados para microtubos.

Com o intuito de identificar razões para esta diferença, foram investigadas as imagens de escoamento em alta velocidade realizadas neste estudo e também as fornecidas na literatura. Uma das primeiras observações foi que o filme líquido dificilmente é liso. Verificou-se a presença de ondulações na interface, conforme ilustrado na Figura 6.3, obtida por Revellin (2005) para um tubo de $0,509 \mathrm{~mm}$. Essas ondulações estão relacionadas com diferenças de velocidades entre as fases líquida e vapor e a presença de instabilidades. Para diâmetros superiores, conforme ilustrado na Figura 6.4, obtida no presente estudo para um tubo de diâmetro igual a 2,32 mm, fenômeno similar ocorre, ao qual soma-se a tendência de o filme líquido na região inferior tornar-se mais espesso devido a efeitos de gravidade. 


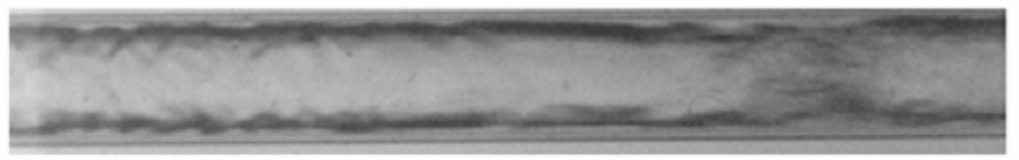

(A)

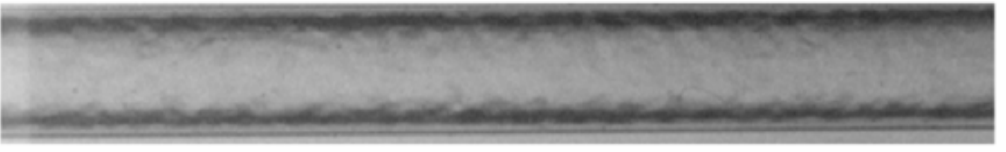

(B)

Figura 6.3 - Padrões de escoamento anular obtidos por Revellin (2005) para R134a, $\mathrm{D}=0,509 \mathrm{~mm}, \mathrm{G}=500 \mathrm{~kg} / \mathrm{m}^{2} \mathrm{~s}, T_{\text {sat }}=30^{\circ} \mathrm{C}$. (A) $\mathrm{x}=40 \%$, (B) $\mathrm{x}=82 \%$;

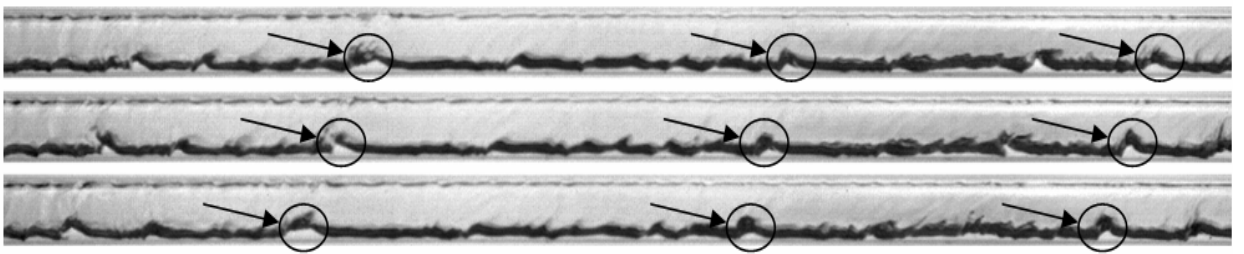

Figura 6.4 - Evolução das ondulações na superfície do filme líquido durante o escoamento anular do R134a, $D=2,32 \mathrm{~mm}, \mathrm{G}=50 \mathrm{~kg} / \mathrm{m}^{2} \mathrm{~s}, \mathrm{~T}_{\text {sat }}=31^{\circ} \mathrm{C}, \mathrm{x}=80 \%$. Intervalo entre imagens: $2 \mathrm{~ms}$.

No presente estudo, também foram observadas frentes de ondas intermitentes contendo gotículas caracterizadas por regiões escuras, como ilustrado na Figura 6.5 , movendo-se a velocidades aparentemente superiores às do escoamento bifásico. Tal fenômeno foi observado para os padrões de escoamento anular, secagem de parede e agitante. Através da análise de imagens do escoamento e da variação da temperatura e pressão do fluido durante a propagação da frente de onda, verificou-se que a passagem desta frente coincide com picos na temperatura e pressão local do fluido.

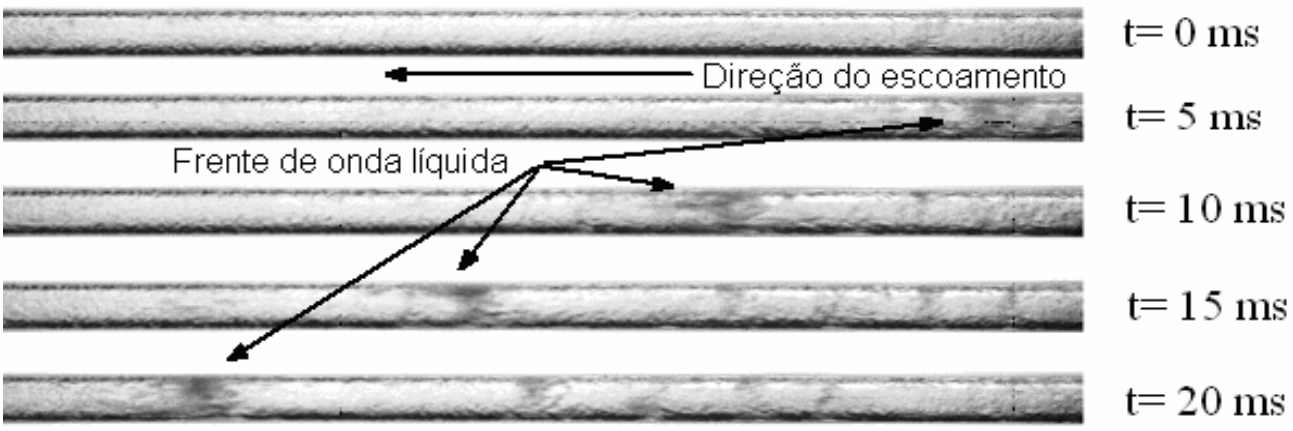

Figura 6.5 - Frente de onda durante a ebulição convectiva do R134a para $G=200 \mathrm{~kg} / \mathrm{m}^{2} \mathrm{~s}$; $q=15 \mathrm{~kW} / \mathrm{m}^{2}, \mathrm{~T}_{\text {sat }}=31^{\circ} \mathrm{C}, \mathrm{x}=75 \%$. 
Essas frentes de ondas incrementam a espessura local do filme líquido e promovem a formação de gotículas dispersas no vapor. Em condições de secagem de parede, pode-se especular que as gotículas dispersas na frente de onda agem de forma a molhar a superfície de troca de calor, postergando a secagem da parede. Essas oscilações parecem estar relacionadas às características da seção aquecida (pré-aquecedor e seção de testes).

Dessa forma, realizou-se uma avaliação de como essas modificações do perfil do filme líquido poderiam afetar o CTC médio na seção do tubo.

Inicialmente avaliou-se o efeito da assimetria do filme líquido em relação ao eixo central do tubo, conforme esquema ilustrado na Figura 6.6. Como se vê na figura, quando o centro da fase vapor é deslocado, o filme se torna mais espesso na base do canal, porém ressalta-se que este deslocamento não afeta a fração de vazio que se mantém. Considerando o mecanismo de transferência de calor como sendo a condução unidimensional através do filme, o CTC médio, $\bar{h}$, pode ser calculado como na equação (6-8).

$$
\bar{h}=\frac{\int_{0}^{\pi} \frac{k_{l}}{\delta} d \theta}{\pi}
$$

A espessura do filme, $\delta$, em função do ângulo $\theta$, pode ser determinada através da lei dos cossenos. A equação 6-13 foi aplicada a três condições ilustrativas dadas por:

(a) $\bar{h}\left(k_{l}=1, R=1, r=0,5, e=0\right)=2 \mathrm{~W} / \mathrm{m}^{2} K$, condição de simetria do filme líquido;

(b) $\bar{h}\left(k_{l}=1, R=1, r=0,5, e=0,45\right)=2,2 \mathrm{~W} / \mathrm{m}^{2} K$;

(c) $\bar{h}\left(k_{l}=1, R=1, r=0,5, e=0,49\right)=4 W / m^{2} K$.

Conforme ilustrado nos exemplos acima, verifica-se uma variação do CTC médio de até $100 \%$, dependendo do grau de simetria do filme. 


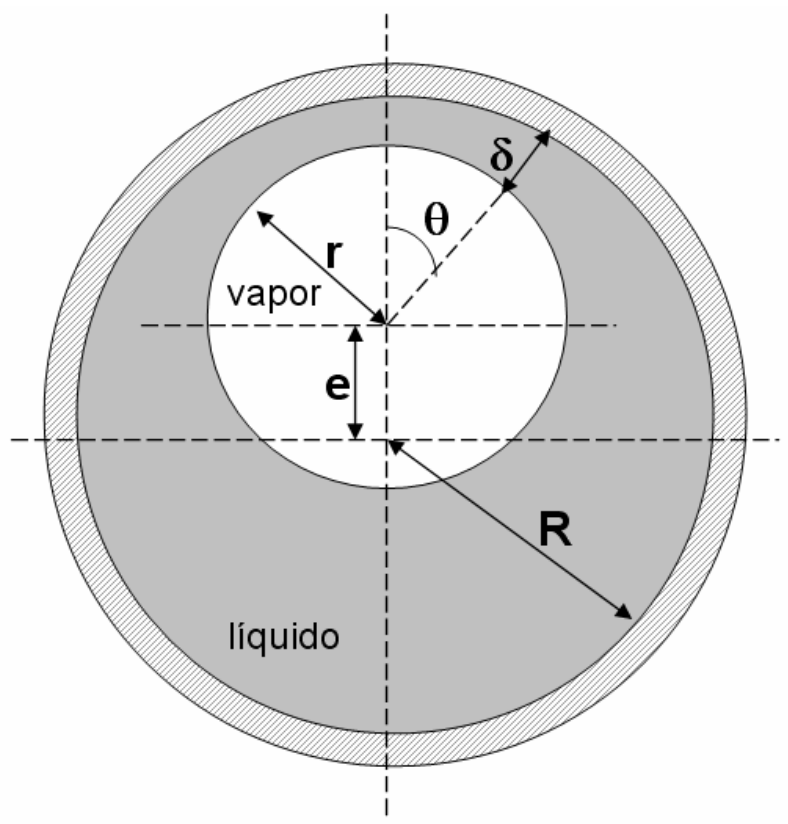

Figura 6.6 - llustração do modelo para avaliação do efeito da assimetria do núcleo de vapor no CTC médio.

Também foram avaliados, qualitativamente, efeitos das ondulações no filme líquido, a partir de condições de interface esquematicamente ilustradas na Figura 6.7. Considerando-se uma ondulação senoidal, com amplitude $\psi_{m}$, para filme líquido de reduzida espessura, e condução unidimensional, o CTC médio no tempo é dado por:

$$
\bar{h}=\frac{\int_{0}^{1 / f} \frac{k_{l}}{\delta} d t}{1 / f}
$$

onde $\delta=\bar{\delta} \cdot\left(1+\psi_{m} \cdot \operatorname{sen}(2 \cdot \pi \cdot f \cdot t)\right) \cdot$ e $f$ é a freqüência de oscilação.

A partir da definição do CTC médio pela equação (6-9), calculou-se seu valor para as seguintes condições:
(a) $\bar{h}\left(k_{l}=1 ; f=1 ; \bar{\delta}=1 ; \psi=0 ;\right)=1 \mathrm{~W} / \mathrm{m}^{2} \mathrm{~K}$, condição sem ondulação;
(b) $\bar{h}\left(k_{l}=1 ; f=1 ; \bar{\delta}=1 ; \psi=0,5 ;\right)=1,15 \mathrm{~W} / \mathrm{m}^{2} \mathrm{~K}$;
(c) $\bar{h}\left(k_{l}=1 ; f=6 ; \bar{\delta}=1 ; \psi=0,5\right)=1,15 \mathrm{~W} / \mathrm{m}^{2} \mathrm{~K}$;
(d) $\bar{h}\left(k_{l}=1 ; f=1 ; \bar{\delta}=1 ; \psi=0,99\right)=5 \mathrm{~W} / \mathrm{m}^{2} \mathrm{~K}$. 
Conforme resultados para as condições (b) e (c), verifica-se que a frequência da ondulação não afeta o $\bar{h}$, entretanto, ao se compararem as condições (a) e (d), nota-se uma elevada influência da amplitude no CTC médio. Tal comportamento indica que efeitos de ondulações da interface no CTC médio são relevantes.

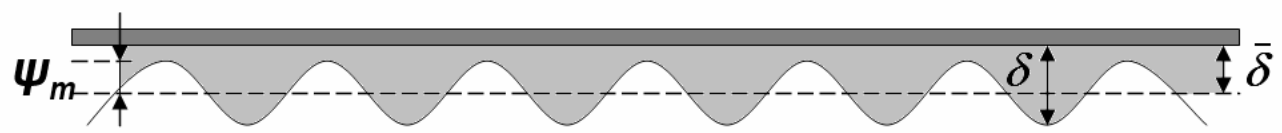

Figura 6.7 - llustração esquemática das ondulações na interface em torno da espessura média, $\bar{\delta}$.

Considerando-se esse aspecto, um novo modelo para escoamento anular é proposto, onde o efeito da ondulação da interface é incluído. No contexto de escoamento em microcanais, as seguintes hipóteses foram adotadas: considera-se que o filme líquido tem espessura reduzida, de forma que a relação $h=k / \delta$ seja válida, e também que exista simetria do filme líquido ao longo do perímetro do canal. Assim, o novo modelo é dado pela equação (6-10).

$$
\bar{h}=\frac{\int_{0}^{1 / f} \frac{k_{l}}{\bar{\delta} \cdot\left(1+\psi_{m} \cdot \operatorname{sen}(2 \cdot \pi \cdot f \cdot t)\right)} d t}{1 / f}
$$

A espessura média do filme, $\bar{\delta}$, é calculada através da equação (6-11) com fração de vazio, $\varepsilon$, segundo a correlação de Rouhani e Axelsson (1970) apresentada na equação (6-12).

$$
\bar{\delta}=\frac{D-D_{v}}{2}
$$

onde:

$$
\begin{aligned}
& D_{v}=\left(4 \frac{A_{v}}{\pi}\right)^{1 / 2} \\
& A_{v}=A \cdot \varepsilon \\
& A_{l}=A \cdot(1-\varepsilon) \\
& A=\pi \frac{D^{2}}{4}
\end{aligned}
$$

$\mathcal{E}$, é a correlação de Rouhani e Axelsson (1970), ou seja, 


$$
\varepsilon=\frac{j_{v}}{C_{0} \cdot\left(j_{l}+j_{v}\right)+v_{d r i f t}}
$$

sendo,

$$
\begin{aligned}
& v_{\text {drift }}=1,18\left(g \sigma \frac{\left(\rho_{l}-\rho_{v}\right)}{\rho_{l}^{2}}\right)^{0,25} \\
& C_{0}=1,12 \\
& j_{l}=\frac{(1-x) G}{\rho_{l}} \\
& j_{v}=\frac{x G}{\rho_{v}}
\end{aligned}
$$

Embora não se verifique na literatura um modelo ou correlação para a previsão da fração de vazio em canais de reduzido diâmetro, optou-se pela correlação de Rouhani e Axelsson (1970) por apresentar resultados satisfatórios para macrocanais. Correlações mais atuais, como a de Woldesemayat e Ghajar (2007), apresentam resultados similares para a fração de vazio.

A amplitude da oscilação, $\psi_{m}$, nesse modelo, depende da velocidade de deslizamento das fases, da gravidade, da tensão superficial, sendo também afetada por efeitos de instabilidades do escoamento. Os efeitos das instabilidades na interface do filme líquido são complexos, podendo ser dependentes do fluxo de calor devido a meta-estabilidade do escoamento e também devido a efeitos de coalescência de bolhas. No presente modelo, devido a sua complexidade, desprezaram-se os efeitos de instabilidade na espessura do filme e adotou-se a teoria de ondas em filme finos, descrita em Carey (1992), segundo a qual a amplitude da onda depende da razão de deslizamento das fases e da relação entre forças gravitacionais e tensão superficial, podendo esta ser escrita como uma função do número de Bond dado na equação (6-13).

$$
\text { Bond }=\frac{\left(\rho_{l}-\rho_{v}\right) \cdot g \cdot(D / 2)^{2}}{\sigma}
$$

Além disso, o número de ebulição foi introduzido como forma de capturar efeitos do fluxo de calor no CTC, conforme observado nos resultados experimentais. Quatro parâmetros foram ajustados a esta correlação, utilizando-se o banco de dados para tubos circulares levantado neste estudo. Mediante o procedimento adotado, obteve-se a equação (6-14) para o cálculo da amplitude média da onda da interface, $\psi_{m}$. 


$$
\psi_{m}=1,03 \cdot\left(\frac{q}{G \cdot i_{l v}}\right)^{0,0039} \cdot\left(\frac{u_{v}}{u_{l}}\right)^{-0,0064} \cdot\left(\frac{\left(\rho_{l}-\rho_{v}\right) \cdot g \cdot(D / 2)^{2}}{\sigma}\right)^{0,0091}
$$

onde:

$$
\begin{aligned}
& u_{v}=\frac{G \cdot x}{\rho_{v} \cdot \varepsilon} \\
& u_{l}=\frac{G \cdot(1-x)}{\rho_{l} \cdot(1-\varepsilon)}
\end{aligned}
$$

\subsubsection{TRANSFERÊNCIA DE CALOR NA REGIÃO DE PÓS-SECAGEM DA PAREDE}

A transferência de calor na região de pós-secagem de parede depende da determinação do título de vapor onde se inicia a secagem da parede. Fatores que antecipam a ocorrência da secagem de parede são: gotículas de líquido no núcleo de vapor, afinamento do filme líquido na parte superior do tubo devido a gravidade, alta rugosidade da parede e ângulo de contato. Fatores que podem promover atraso da secagem de parede são: frentes de onda carregando líquido proveniente de efeitos de instabilidade, vorticidade axial no escoamento levando líquido da parte inferior para a superior. A modelagem de todos estes fatores é extramente complexa e uma forma prática de se determinar o título de secagem é através de balanço de energia na condição de FCC saturado. Assumindo que o título de secagem independe do fluxo de calor, hipótese que pode ser considerada válida considerando que os mapas de escoamento também não dependem do fluxo de calor, pode-se calculá-lo fazendo-se o balanço de energia entre a entrada e a saída da seção de testes, nos termos da equação (6-15).

$$
Q=\dot{m} \cdot\left(h_{s}-h_{e}\right)
$$

sendo a entalpia da saída dada por meio da equação (6-16):

$$
i_{s a i}=x \cdot i_{l v, s a i}+i_{l, s a i}
$$

Expressando em termos de fluxo de calor e velocidade mássica tem-se:

$$
\begin{aligned}
& Q=q . A_{\text {aque }} \\
& m=G . A
\end{aligned}
$$


Substituindo as equações (6-16), (6-17) e (6-18) na equação (6-15) obtêm-se:

$$
\begin{aligned}
& \frac{Q}{\dot{m}}=\left(x \cdot i_{l v, s a i}+i_{l, s a i}-i_{\text {ent }}\right) \\
& \frac{q \cdot A_{\text {aque }}}{G \cdot A_{\mathrm{sec}}}-\left(i_{l, s} a i-i_{\text {ent }}\right)=x \cdot i_{l, s a i}
\end{aligned}
$$

Isolando-se o título de vapor:

$$
x=\frac{\frac{q \cdot A_{\text {aque }}}{G \cdot A_{\text {sec }}}-\left(i_{l_{\text {sai }}}-i_{\text {ent }}\right)}{i_{l v, s a i}}
$$

Para a condição de fluxo crítico, obtém-se o título de vapor correspondente igual a:

$$
x_{c r i t}=\frac{\frac{q_{c r i t} \cdot A_{\text {aque }}}{G \cdot A_{\text {sec }}}-\left(i_{l, s a i}-i_{\text {ent }}\right)}{i_{l v, s} a i}
$$

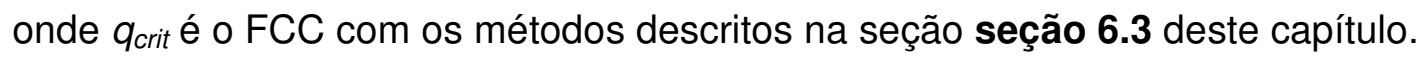

A partir do $x_{\text {crit, }}$ O CTC tende a se aproximar do CTC do vapor, o qual pode ser calculado, por exemplo, através da correlação de Gnielinski (1976) no caso de escoamento de transição e turbulento. Assim, adota-se entre $x=x_{\text {crit }}$ e $x=1$, o decréscimo do coeficiente de transferência de calor com seu valor local, dado conforme a equação (6-23):

$$
h_{\text {pos }}=h_{\text {crit }}-\left(h_{\text {crit }}-h_{\text {vap }}\right) \cdot \frac{\left(x-x_{\text {crit }}\right)}{\left(1-x_{\text {crit }}\right)}
$$

onde,

$$
\begin{aligned}
& h_{\text {crit }}=h\left(x=x_{\text {crit }}\right) \\
& h_{\text {vap }}=\frac{k_{v}}{D} \frac{(f / 8)\left(\operatorname{Re}_{D}-1000\right) \cdot \operatorname{Pr}}{1+12.7(f / 8)^{1 / 2}\left(\operatorname{Pr}^{2 / 3}-1\right)}, \text { sendo } f=\left(0,790 \ln \operatorname{Re}_{D}-1,64\right)^{-2}
\end{aligned}
$$

\subsubsection{COMPARAÇÕES}

Com o intuito de avaliar os resultados proporcionados pelos modelos e as correlações para previsão do CTC, uma comparação foi efetuada entre todos eles e o mesmo banco de dados. A Tabela 6.4 contém os resultados desta comparação 
em termos do erro médio absoluto, $\varepsilon$, e a parcela de dados com erro inferior a $20 \%$, $\lambda$.

As três últimas colunas da Tabela 6.4 apresentam os parâmetros estatísticos, considerando os desvios em relação aos dados experimentais para as correlações modificadas no presente estudo e o modelo proposto. As quatro primeiras colunas apresentam parâmetros de comparações similares para as correlações originais, o modelo de Cioncolini (2001) para escoamento anular. Também é apresentado o CTC, dado pela razão entre $k / \delta$ com a fração de vazio calculado segundo Rouhani e Axelsson (1970) desprezando efeitos de ondulação na interface. Conforme apresentado nesta tabela, o novo modelo para escoamento anular, considerando ondulações na interface, proporciona previsões superiores aos do cálculo apenas por intermédio da razão $k / \delta$.

Pelo modelo proposto, observa-se que os valores de $\psi_{m}$, fornecido pela equação (6-14), variam em torno do valor de 0,98 , indicando que as ondulações possuem amplitudes próximas da espessura média do filme líquido. O modelo de Cioncolini e Thome (2011), que também utiliza o conceito de espessura de filme no escoamento anular, teve desempenho próximo do novo modelo, porém, neste, a amplitude independe do fluxo de calor, comportamento observado neste estudo apenas para o R245fa durante escoamento anular com elevados títulos de vapor.

Conforme indicado no capítulo 5, a correlação de Saitoh, Daiguji e Hihara (2007) apresentou novamente o melhor desempenho entre as correlações avaliadas e a modificação desta correlação implicou numa melhora de $11,2 \%$ para $8,8 \%$ de erro médio absoluto. A correlação de Saitoh, Daiguji e Hihara (2007) modificada apresenta vantagens de eliminar a descontinuidade do CTC verificada em sua versão original, relacionada à transição entre o regime laminar e turbulento, utilizada no cálculo do parâmetro de Martinelli, e também ampliar o banco de dados para o qual sua proposição foi baseada (a correlação original somente utilizou dados para o fluido R134a). Essas descontinuidades, além de não serem observadas nos dados experimentais, dificultam a convergência de programas de simulação numérica.

A correlação modificada de Liu e Winterton (1991) também apresentou meIhoras na previsão do banco de dados levantados neste estudo, quando comparada com a sua versão original. 
Tabela 6.4 - Comparação entre as correlações originais, modificadas, e o novo modelo para escoamento anular versus dados experimentais deste estudo.

\begin{tabular}{lccccccc}
\hline & $\begin{array}{c}\text { Saitoh, Dai- } \\
\text { guji e Hihara. } \\
(2007)\end{array}$ & $\begin{array}{c}\text { Liu e } \\
\text { Winterton }\end{array}$ & $\begin{array}{c}\text { Modelo } k_{l} / \delta \\
\text { sem ondulações } \\
\text { de interface }\end{array}$ & $\begin{array}{c}\text { Cioncolini } \\
\text { e Thome } \\
(2011)\end{array}$ & $\begin{array}{c}\text { Modificação de } \\
\text { Saitoh, Daiguji e } \\
\text { Hihara (2007) }\end{array}$ & $\begin{array}{c}\text { Modificação de } \\
(1991)\end{array}$ & $\begin{array}{c}\text { Novo modelo } \\
\text { para escoamento } \\
\text { anular }\end{array}$ \\
\hline$\varepsilon$ & 11,2 & 16,5 & 82,6 & 21,6 & 8,8 & 12,1 & 23,4 \\
$\lambda( \pm 20 \%)$ & 87,6 & 66,2 & 0,0 & 56,7 & 94,3 & 82,3 & 57,0 \\
\hline
\end{tabular}

A Figura 6.8 apresenta uma comparação direta dos novos modelos versus dados experimentais para R134a no tubo de 2,32mm. A Figura 6.9 apresenta a mesma comparação com os modelos da literatura.

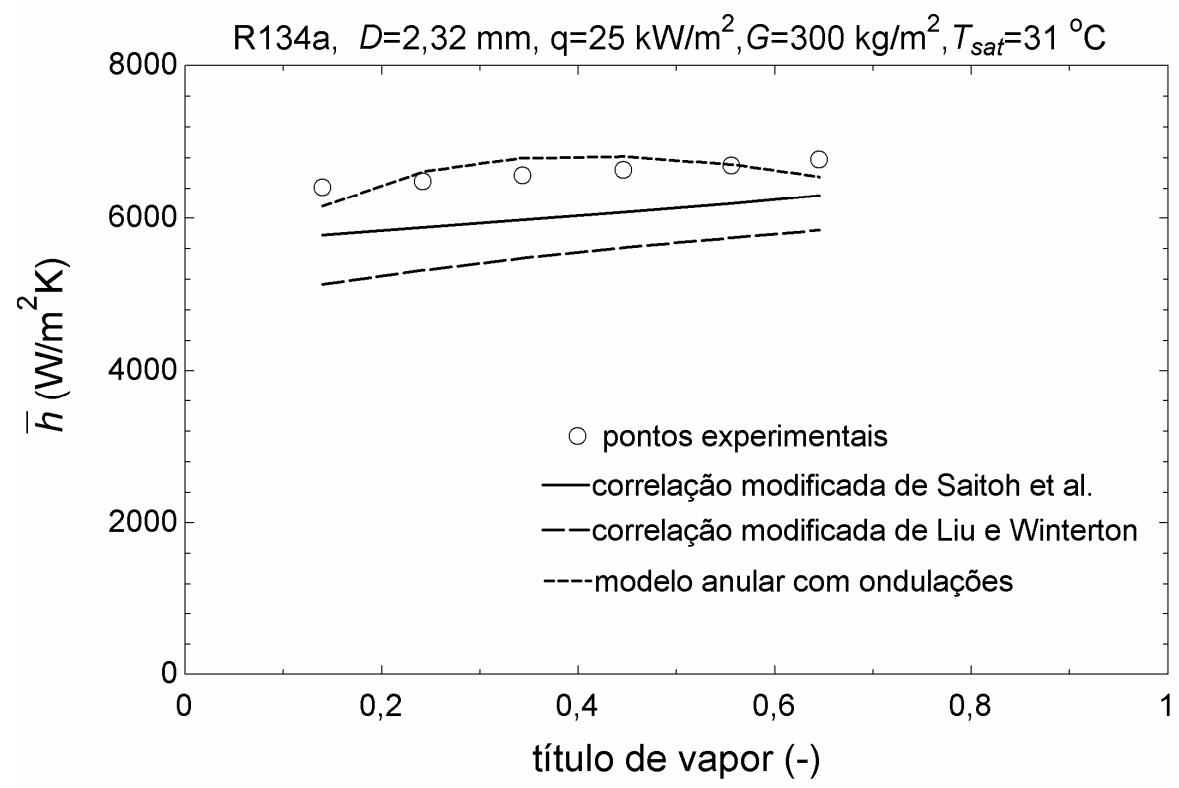

Figura 6.8 - Comparação dos novos modelos de CTC com dados experimentais.

A Figura 6.10 mostra o cálculo de CTC utilizando a condição de póssecagem da parede apresentada na equação (6-23). Para o cálculo do $x_{\text {crit, }}$ foi utilizada a correlação de FCC modificada de Katto e Ohno (1984). O CTC na região de pré-secagem foi calculado utilizando-se a correlação modificada de Saitoh, Daiguji e Hihara (2007), apresentada na equação (6-5). 


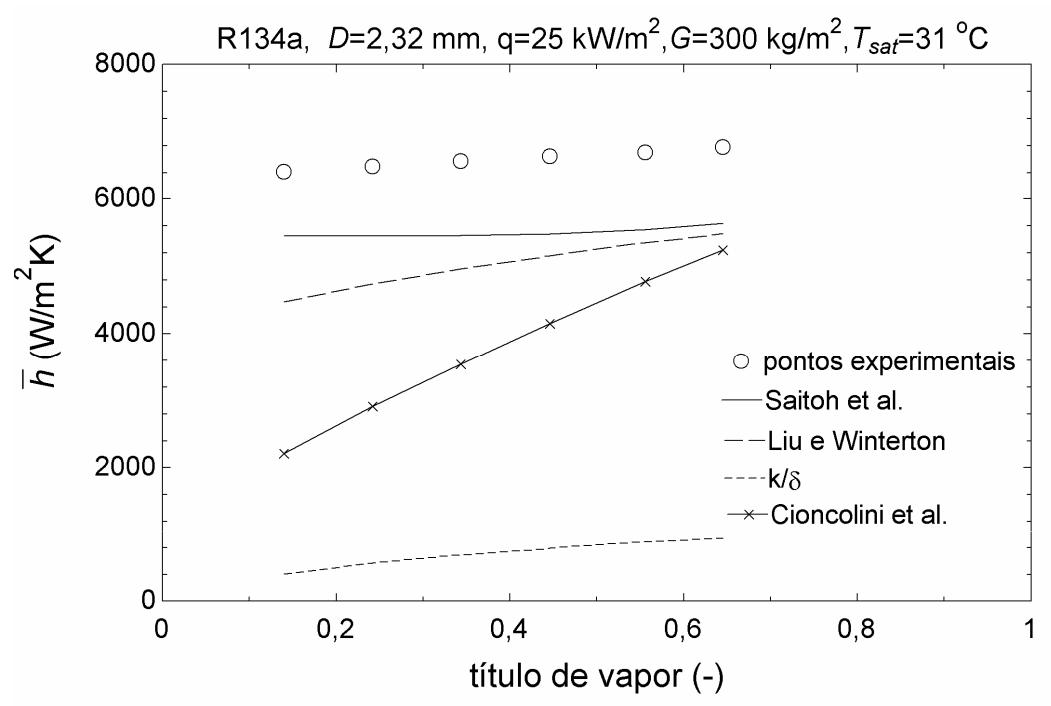

Figura 6.9 - Comparação de correlações da literatura para CTC com dados experimentais.

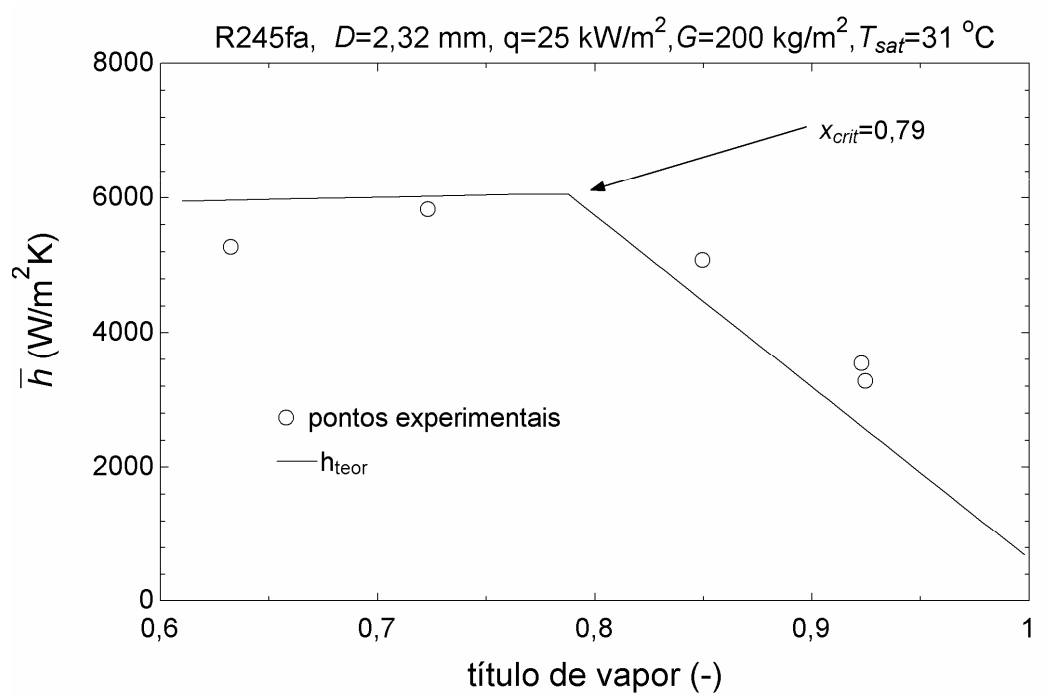

Figura 6.10 - Modelo de pós-secagem da parede, pela equação (6-23).

\subsection{FLUXO CRÍTICO DE CALOR}

Os resultados experimentais e as comparações com modelos de FCC indicaram não haver diferenças significativas entre FCC para macro e microcanais, já que métodos desenvolvidos para macro-escala previram satisfatoriamente os resultados levantados neste estudo. As correlações de Katto e Ohno (1984), Zhang et al. (2006) e Ong e Thome (2011b), por apresentarem desempenhos superiores nas 
avaliações efetuadas no Capítulo 5 (Resultados experimentais), foram selecionadas para serem ajustadas de acordo com o presente banco de dados. O banco de dados contêm 150 pontos experimentais, para tubos circulares horizontais, com fluidos R134a, R1234ze, R245fa, diâmetros de 2,20mm e 1,10mm, relações comprimento/diâmetro (L/D) entre 90 e 180, temperaturas de saturação de 25,31 e $35^{\circ} \mathrm{C}$ e subresfriamentos de 4 e $10 \mathrm{~K}$.

\subsubsection{DESENVOLVIMENTO DE CORRELAÇÕES PARA FCC}

O método de Katto e Ohno (1984) foi o que apresentou desvios inferiores quando comparado ao presente banco de dados, conforme ilustrado no Capítulo 5. O desempenho superior deste método se deve principalmente à definição de quatro regimes de FCC, cada um com uma correlação específica. Comparando o método com o presente banco de dados, verifica-se que os resultados levantados enquadram-se em apenas dois regimes, ambos relacionados a condições de secagem de parede, sendo o primeiro para vazões reduzidas e o segundo para vazões elevadas. Dessa forma, somente as correlações relacionadas a estes regimes foram otimizadas a partir do banco de dados, também segregado segundo estes regimes, devendo as demais equações seguirem o método original de Katto e Ohno (1984). O método proposto é dado pelas equações (6-24) e (6-25).

$$
\begin{aligned}
& q_{c o 1}=G \cdot i_{f g} \cdot C \cdot\left(\frac{\sigma \cdot \rho_{l}}{G^{2} \cdot L}\right)^{0,0298} \cdot \frac{1}{L / D} \\
& q_{c o 2}=G \cdot i_{f g} \cdot 0,06213 \cdot\left(\frac{\rho_{v}}{\rho_{l}}\right)^{0,085} \cdot\left(\frac{\sigma \cdot \rho_{l}}{G^{2} \cdot L}\right)^{0,31348} \cdot \frac{1}{1+0,0031 \cdot L / D}
\end{aligned}
$$

onde $C$ é dado por:

$$
\begin{aligned}
& C=0,25 \text { para } \frac{L}{D}<50 \\
& C=0,25+0,00076\left(\frac{L}{D}-50\right) \text { para } 50<\frac{L}{D}<150 \\
& C=0,32576 \text { para } \frac{L}{D}>150
\end{aligned}
$$


A correlação de Zhang et al. (2006) também foi ajustada aos dados experimentais levantados neste estudo, resultando na correlação expressa por meio da equação (6-26). A correlação original utilizou somente dados de água para o ajuste dos coeficientes, enquanto a proposta neste estudo se baseia em 3 fluidos refrigerantes.

$$
q_{c r i t}=G \cdot i_{f g} \cdot 0,02843 \cdot\left(\frac{G^{2} D}{\sigma \cdot \rho_{l}}+0,0119 \cdot\left(\frac{\mathrm{L}}{\mathrm{D}}\right)^{2,138} \cdot\left(\frac{\rho_{\mathrm{v}}}{\rho_{\mathrm{f}}}\right)^{0.529}\right)^{-0.295}\left(\frac{\mathrm{L}}{\mathrm{D}}\right)^{-0,311} \cdot\left(2.05 \cdot\left(\frac{\rho_{\mathrm{v}}}{\rho_{\mathrm{f}}}\right)^{0.17}-\mathrm{x}_{\mathrm{in}}\right)
$$

A correlação de Ong e Thome (2011b) também foi ajustada aos dados experimentais resultando na seguinte equação (6-27).

$$
q_{\text {crit }}=G \cdot i_{f_{\mathrm{g}}} \cdot 0,1782\left(\frac{\mu_{1}}{\mu_{\mathrm{v}}}\right)^{-0,0815}\left(\frac{\rho_{\mathrm{v}}}{\rho_{\mathrm{f}}}\right)^{-0.00627}\left(\frac{G^{2} L}{\sigma \cdot \rho_{l}}\right)^{-0,143}\left(\frac{\mathrm{L}}{\mathrm{D}}\right)^{-0,045}\left(\frac{\mathrm{D}}{\left(\frac{2 \cdot \sigma}{\mathrm{g}\left(\rho_{1}-\rho_{\mathrm{v}}\right)}\right)^{0,5}}\right)^{-0,0065}
$$

\subsubsection{COMPARAÇÕES}

A Figura 6.11 apresenta uma comparação entre dados experimentais e os métodos de previsão segundo Katto e Ohno (1984), Zhang et al. (2006) e Ong e Thome (2011b). Segundo os resultados experimentais, ocorrem duas tendências de FCC: uma a vazões inferiores a $600 \mathrm{~kg} / \mathrm{m}^{2} \mathrm{~s}$, onde o $\mathrm{FCC}$ varia linearmente com a velocidade mássica, e outra a partir de $800 \mathrm{~kg} / \mathrm{m}^{2} \mathrm{~s}$, onde o efeito da velocidade mássica no FCC decresce, parecendo tender a um valor máximo a partir do qual o efeito da vazão é desprezível. A baixas vazões, os modelos apresentam concordâncias satisfatórias com os dados experimentais. Entretanto, à medida que a vazão se eleva, divergências elevadas são observadas. O modelo de Katto e Ohno (1984) foi o único a capturar a alteração da tendência do FCC em vazões superiores, entretanto superestima os resultados experimentais.

A Figura 6.12 compara os mesmos dados experimentais com as versões otimizadas dos métodos. A correlação modificada de Ong e Thome (2011b) praticamente não teve seu desempenho alterado, mesmo considerando vazões reduzidas. Os resultados fornecidos pela correlação modificada de Zhang et al. (2006) aproximaram-se dos experimentais em relação à versão anterior, entretanto não foi captu- 
rada a alteração na inclinação da curva com incremento da vazão. A correlação modificada de Katto e Ohno (1984) foi a que melhor se ajustou aos dados, corroborando a existência de distintos regimes para o FCC.

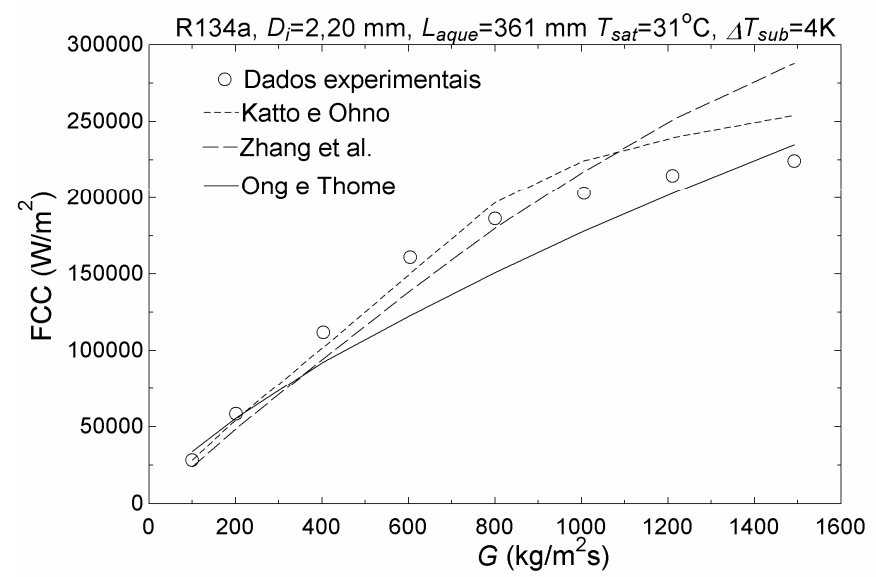

Figura 6.11 - Comparação entre valores de FCC e correlações originais da literatura selecionadas para otimização com o banco de dados.

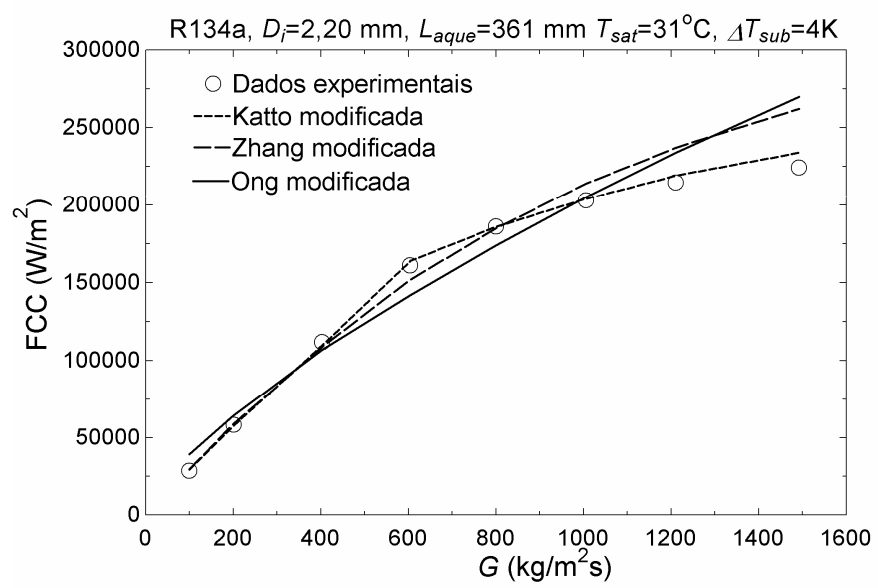

Figura 6.12 - Comparação entre valores de FCC e as correlações propostas, com base no banco de dados levantado.

A Tabela 6.5 ilustra os resultados estatísticos dos métodos originais e modificados com o banco de dados levantado. Na tabela, são apresentados o erro médio absoluto, $\varepsilon$, e a parcela de dados com desvio inferior a $5 \%, \lambda$. De modo geral, as correlações modificadas de Katto e Ohno (1984) e Zhang et al. (2006) apresentaram ótima concordância, com erro médio absoluto de 3\% e aproximadamente $80 \%$ dos dados com erro inferior a 5\%. A Figura 6.13 apresenta a comparação do banco de dados utilizados no ajuste e os métodos de previsão modificados neste estudo. 
Tabela 6.5 - Comparação do banco de dados de FCC com os métodos de previsão originais e suas modificações.

\begin{tabular}{lcccccc}
\hline & $\begin{array}{c}\text { Katto e } \\
\text { Ohno } \\
(1984)\end{array}$ & $\begin{array}{c}\text { Zhang et } \\
\text { al. }(2006)\end{array}$ & $\begin{array}{c}\text { Ong e } \\
\text { Thome } \\
(2011 \mathrm{~b})\end{array}$ & $\begin{array}{c}\text { Katto e } \\
\text { Ohno }(1984) \\
\text { modificada }\end{array}$ & $\begin{array}{c}\text { Zhang et al. } \\
(2006) \\
\text { modificada }\end{array}$ & $\begin{array}{c}\text { Ong e Thome } \\
(2011 \mathrm{~b}) \\
\text { modificada }\end{array}$ \\
\hline$\varepsilon$ & 6,3 & 16,3 & 15,2 & 3,1 & 3,5 & 14,9 \\
$\lambda( \pm 5 \%)$ & 38 & 6,7 & 17,3 & 84,6 & 78,0 & 26,7 \\
\hline
\end{tabular}
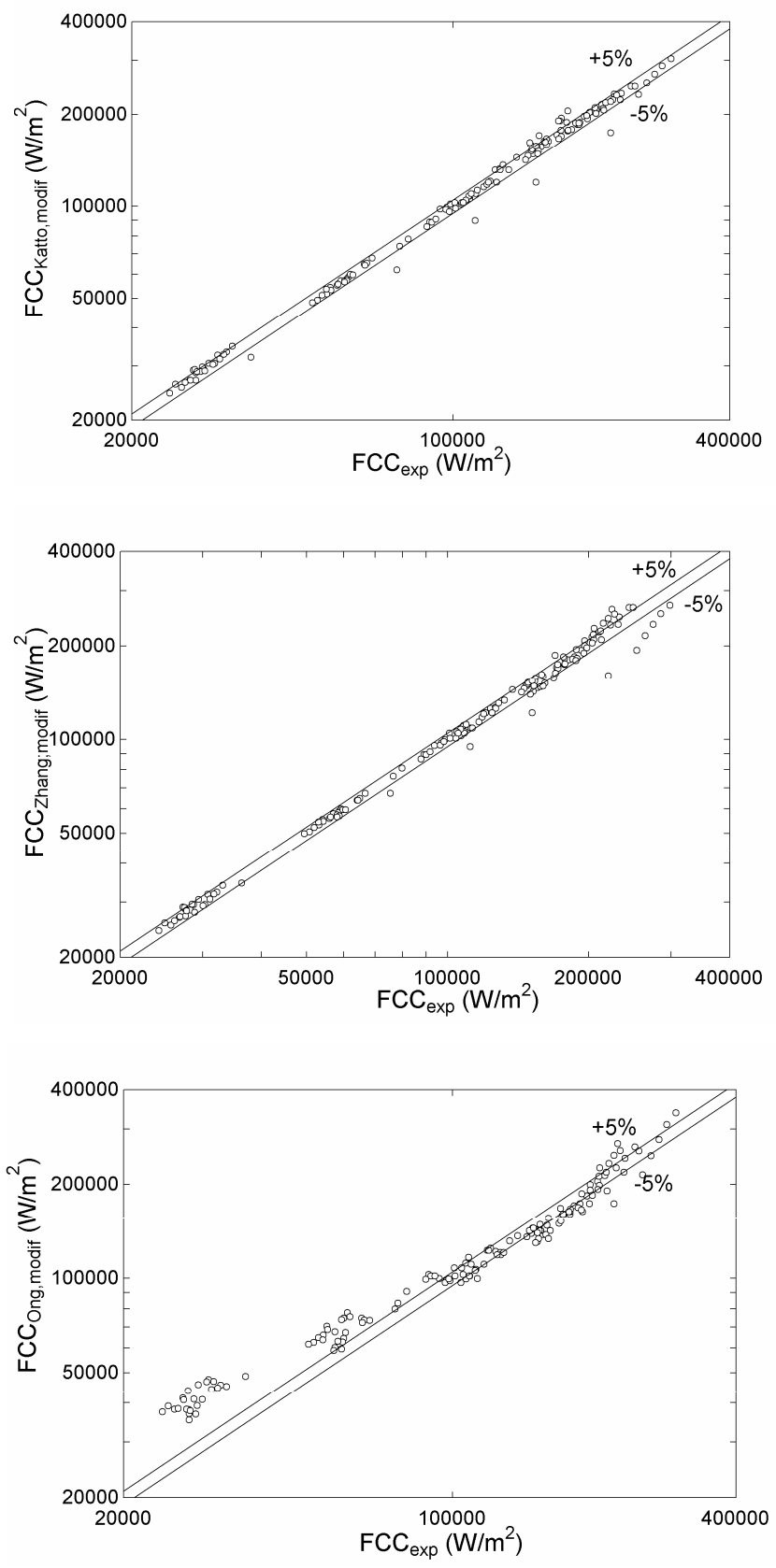

Figura 6.13 - Comparações entre as correlações modificadas e o banco de dados experimental. (a) Modificação de Katto e Ohno (1984); (b) Modificação de Zhang et al. (2006); (c) Modificação de Ong e Thome (2011b). 
Conforme anteriormente indicado no item de CTC na região de secagem, o modelo modificado de Katto e Ohno (1984) aplica-se para a previsão do título de secagem da parede.

A nova correlação, derivada do modelo de Katto e Ohno (1984), será utilizada para o cálculo do título de secagem de parede, apresentado no próximo item.

\subsubsection{APLICAÇÃo EM TUBOS NÃO CIRCULARES}

Os resultados de FCC para tubos achatados revelaram que o FCC não foi afetado consideravelmente pela forma do tubo. Também foi observado que duas condições devem ser respeitadas para se aplicar corretamente as correlações de FCC em tubos não circulares. Essas condições são:

(1) utilizar o diâmetro equivalente, ao invés do diâmetro hidráulico. O diâmetro equivalente, definido no Capítulo 4, é dado equação (6-28).

$$
D_{e q}=\sqrt{\frac{4 \cdot A_{\text {seção }}}{\pi}}
$$

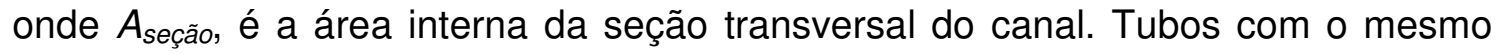
$D_{\text {eq, }}$ para uma vazão fixa, têm a mesma área interna e velocidades médias iguais, tornando, assim, as condições hidrodinâmicas mais similares;

(2) a outra condição a ser respeitada, é utilizar o comprimento equivalente do tubo, $L_{e q}$, ao invés do comprimento real. O comprimento equivalente, definido no Capítulo 4, determina o comprimento que o tubo deve ter para ter a mesma troca de calor de um tubo circular aquecido uniformemente. Assim, em ebulição convectiva, tubos de mesmo comprimento equivalente teriam o mesmo título de saída, para o mesmo fluxo de calor e a mesma condição de entrada.

$$
\begin{aligned}
& \pi \cdot D_{e q} \cdot L_{e q}=P_{\text {erim,aquec }} \cdot L \\
& L_{e q}=\frac{P_{\text {erim,aquec }} \cdot L}{\pi \cdot D_{e q}}
\end{aligned}
$$


onde $P_{\text {erim,aquec }}$ é o perímetro aquecido na seção transversal do tubo.

Aplicando essas definições e comparando o banco de dados de FCC para tubos achatados, descrito no capítulo 4 , com as correlações originais e suas versões modificadas, obtêm-se os resultados estatísticos listados na Tabela 6.6.

Tabela 6.6 - Comparação do banco de dados de FCC de tubos achatados, contra as novas correlações e as correlações da literatura. Banco de dados com 74 pontos experimentais.

\begin{tabular}{lcccc}
\hline & $\begin{array}{c}\text { Katto e Ohno } \\
(1984)\end{array}$ & $\begin{array}{c}\text { Zhang et al. } \\
(2006)\end{array}$ & $\begin{array}{c}\text { Katto } \\
\text { modificada }\end{array}$ & $\begin{array}{c}\text { Zhang } \\
\text { modificada }\end{array}$ \\
\hline$\varepsilon$ & 9,0 & 15,3 & 4,8 & 6,4 \\
$\lambda( \pm 10 \%)$ & 63,5 & 22,9 & 89,1 & 81,1 \\
\hline
\end{tabular}

As Figura 6.14 e Figura 6.15 ilustram a comparação das correlações contra os dados experimentais para tubos achatados baseados no diâmetro e comprimento equivalentes.
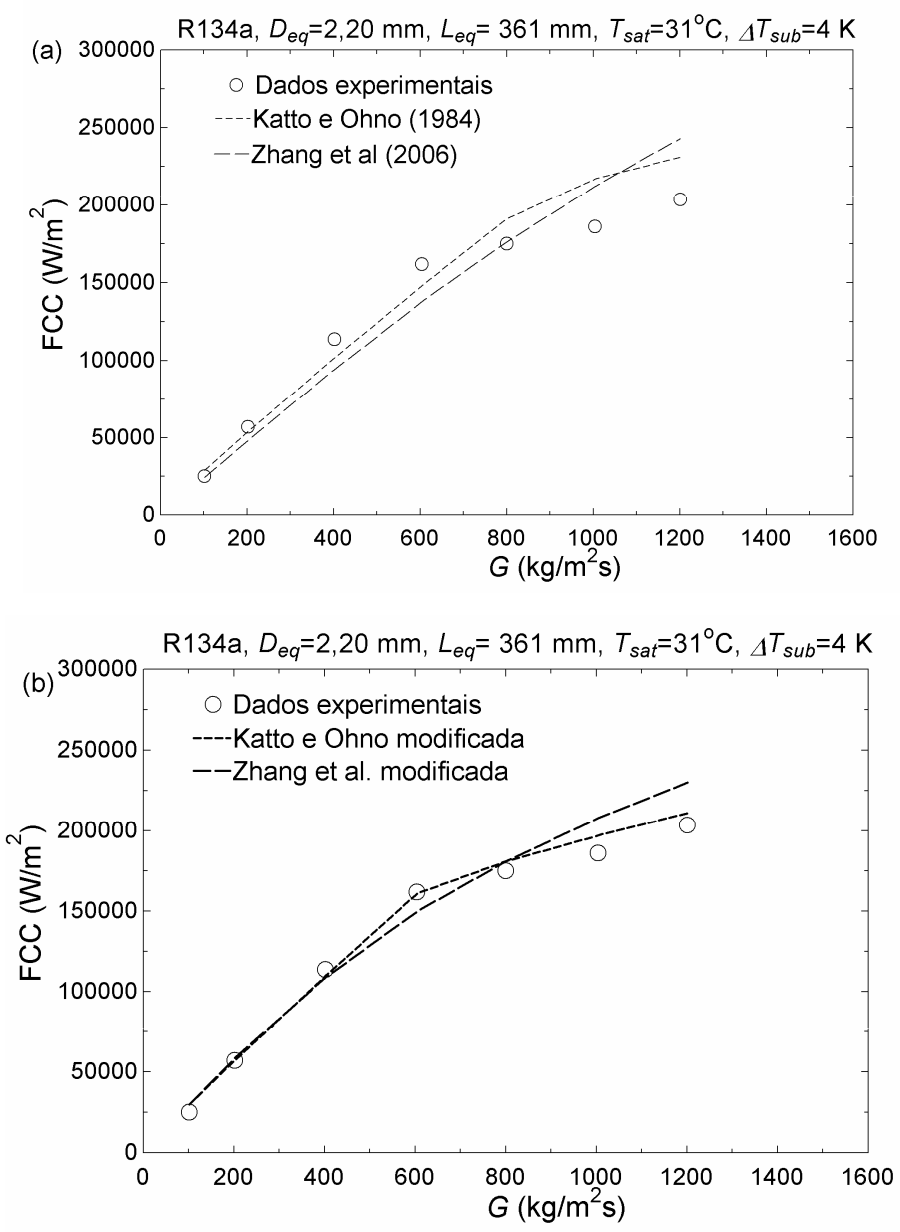

Figura 6.14 - Comparação dos dados experimentais para canais não circulares e correlações de FCC. (a) modelos originais; (b) modelos reajustados. 

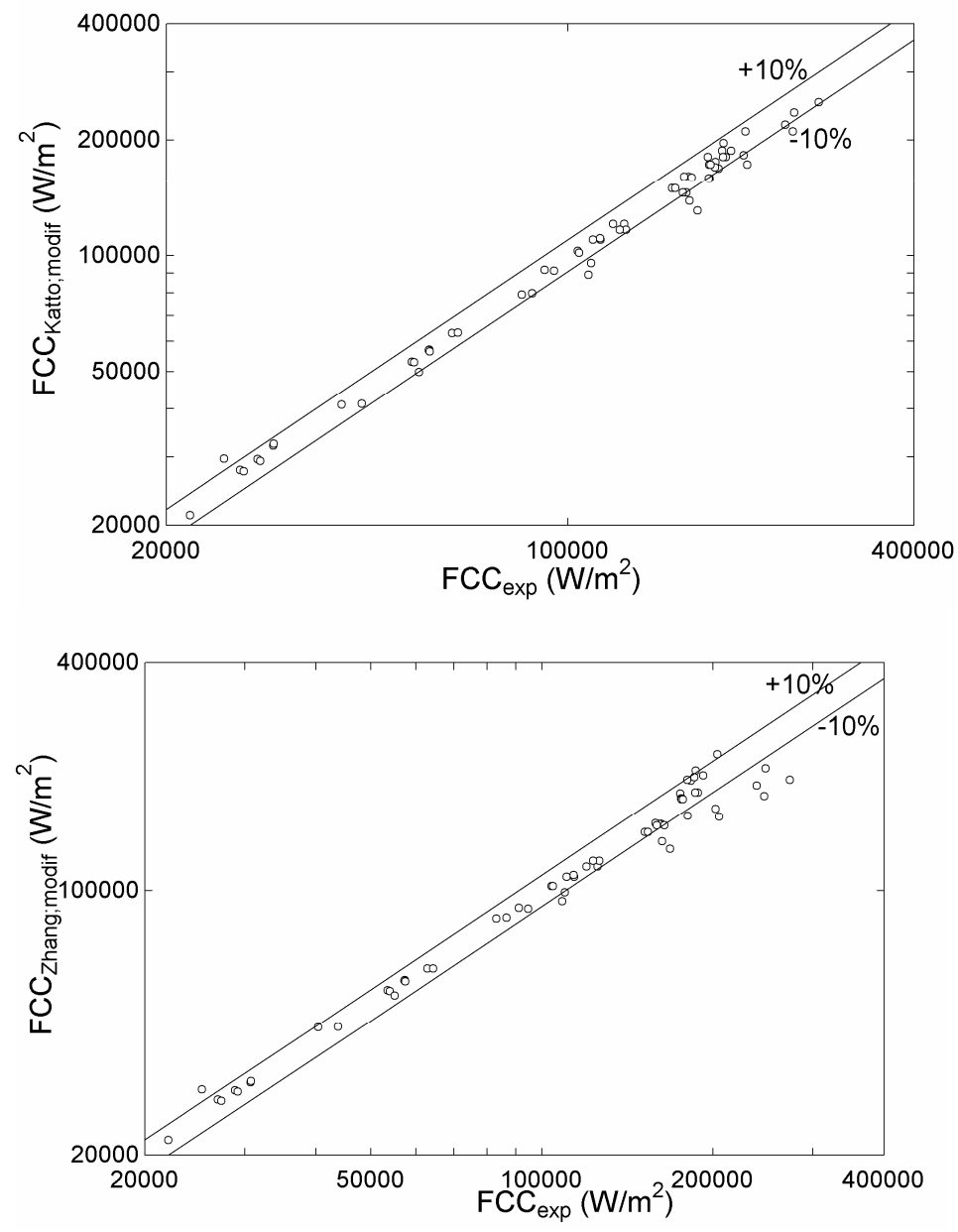

Figura 6.15 - Comparação dos dados experimentais de FCC para canais não circulares versus correlações modificadas.

Como observado nessas figuras, a utilização do diâmetro equivalente e do comprimento equivalente possibilitou a previsão adequada do FCC para geometrias não circulares utilizando-se métodos de previsão para tubos circulares. Essa metodologia, desenvolvida na presente pesquisa, não foi observada em outros estudos da revisão bibliográfica. 


\section{CONCLUSÕES}

Este trabalho envolveu um estudo da transferência de calor e fluxo crítico de calor durante a ebulição convectiva no interior de canais de diâmetros reduzidos. Também investigou uma possível transição entre comportamentos para micro e macro-escala. Uma ampla revisão bibliográfica foi realizada e novos experimentos foram conduzidos em bancadas experimentais construídas para essa finalidade. Foram levantados resultados para tubos circulares de $1,00 \mathrm{~mm}$ a 2,32mm de diâmetro e tubos achatados com diâmetro equivalente de 2,20mm para os fluidos R134a, R245fa e R1234ze(E). Tendo sido os objetivos alcançados, podem ser apresentadas as seguintes conclusões:

\section{Conclusões "Capítulo 5 - Resultados experimentais"}

- O fluido R245fa apresenta transição para escoamento anular em títulos de vapor mais baixos que o R134a.

- O decréscimo do diâmetro tende a reduzir o título da transição intermitente/anular. O aumento da temperatura de saturação tende a aumentar o título de transição intermitente/anular.

- O método de previsão de padrão de escoamento de Ong e Thome (2011a) e Felcar, Ribatski e Jabardo (2007) previram relativamente bem os dados experimentais independentes obtidos neste doutorado, podendo, ambos os métodos, serem aprimorados na previsão dos padrões de escoamento a baixas velocidades mássicas.

- Estratificação do escoamento foi visualizada e medidas de temperatura local revelaram seus efeitos na variação circunferencial do CTC ao longo do perímetro do tubo.

- De forma geral, foi observado que o CTC aumenta com o incremento do fluxo de calor, a velocidade mássica e a temperatura de saturação. Comportamentos distintos do CTC, com variação do título de vapor, foram determinados para uma velocidade mássica abaixo e acima de $200 \mathrm{~kg} / \mathrm{m}^{2} \mathrm{~s}$ para $\mathrm{R} 134 \mathrm{a}$.

- Para R245fa, o CTC fica independente do fluxo de calor para títulos de vapor elevados na região de escoamento anular. 
- O efeito da geometria foi avaliado através do estudo de tubos achatados, revelando que para condições em que o efeito gravitacional é pequeno, caso de altas vazões, a geometria tem pouco efeito sobre o CTC médio, desde que se mantenha o mesmo diâmetro equivalente, $D_{e}$.

- O método para CTC de Saitoh, Daiguji e Hihara (2007) forneceu resultados com erros médios absoluto inferiores aos demais métodos de previsão de coeficiente de transferência de calor e capturou adequadamente o fato de o CTC ser incrementado com o aumento do título de vapor.

- O novo fluido refrigerante R1234ze(E), candidato a substituto do R134a com baixo potencial de aquecimento global, apresenta desempenho de transferência de calor próximo ao do R134a. Resultados de CTC, FCC e mapas de padrões de escoamento foram similares aos do R134a.

- O FCC saturado aumenta com o incremento da velocidade mássica e mais moderadamente com o grau de sub-resfriamento. Ele decresce com o incremento da temperatura de saturação e do comprimento aquecido.

- O fluido R245fa tem FCC saturado maior que o do R134a em condições experimentais similares.

- Comparações entre o banco de dados e correlações selecionadas da literatura revelaram uma melhor concordância com Katto e Ohno (1984), com erro médio próximo de $7 \%$.

- O FCC para tubos achatados avaliados tem valores próximos ao dos tubos circulares, desde que se considere o diâmetro equivalente, $D_{\text {eq }}$, e o comprimento equivalente, $L_{e q}$, na comparação.

\section{Conclusões Capítulo 6 - Desenvolvimento de modelos}

- Duas características marcantes foram observadas em escoamentos em microescala, que os distinguem dos escoamentos considerados macro-escala: (i) a inexistência de escoamento estratificado; (ii) a tendência de simetria do filme líquido no escoamento anular ao longo do perímetro em canais horizontais.

- Critérios de transição macro/microcanais foram desenvolvidos em cima dessas características, permitindo calcular o diâmetro em que a o escoamento estratificado deixa de existir e o diâmetro no qual o escoamento anular tem simetria. 
- Duas novas correlações para CTC foram ajustadas ao presente banco de dados. A que obteve melhor desempenho com erro médio de $8,8 \%$ foi a correlação baseada em Saitoh, Daiguji e Hihra (2007).

- Foram investigados fatores que afetam o CTC médio ao longo do perímetro do tubo. A investigação mostrou que mesmo se mantendo a fração de vazio constante no escoamento anular, ondulações na interface líquido/vapor do escoamento anular geram consideráveis modificações do CTC médio. Efeito similar também foi identificado para o afinamento do filme líquido no topo do escoamento anular devido à força gravitacional.

- Um novo modelo para escoamento anular em microcanais foi desenvolvido considerando o efeito das ondulações na interface. Comparações com dados experimentais mostraram que o novo modelo previu o banco de dados com erro médio absoluto de $23 \%$.

- Três novas correlações para FCC foram ajustadas ao presente banco de dados experimentais. A nova correlação, baseada na correlação de Katto e Ohno (1984), foi a que apresentou melhor desempenho, conseguindo prever o banco de dados com erro médio absoluto de 3,1\%.

- As correlações de FCC podem ser aplicadas com baixo erro a tubos não circulares desde que se utilize o diâmetro equivalente, $D_{e q}$, e o comprimento equivalente, $L_{e q}$, dos tubos não circulares nas correlações originais para tubos circulares.

\subsection{LINHAS DE PESQUISAS A SEREM CONTINUADAS}

A experiência obtida com a montagem das bancadas experimentais, com os experimentos realizados, com a implementação de modelos e correlações da literatura, e o desenvolvimento de novos modelos permitiram identificar novas frentes de pesquisa que poderão contribuir para o avanço do estado da arte na área de ebulição convectiva. Entre alguns temas importantes a serem considerados em novos projetos de pesquisa podem-se citar:

- Estudo da simetria de escoamento em filmes com câmera de alta velocidade e comparação com modelos disponíveis na literatura. Até então, os modelos dispo- 
níveis foram desenvolvidos para macrocanais onde efeitos de tensão superficial tem sido desprezados.

- Medição da espessura do filme utilizando-se a técnica de Laser focus displacement, técnica avaliada em Tibiriçá, Do Nascimento e Ribatski (2010), que se mostra promissora para ser utilizada em pesquisas sobre escoamentos bifásicos em micro-escala.

- Medição das ondulações na interface com a técnica de Laser focus displacement e correta caracterização da amplitude das ondas.

- Estudo de instabilidades em sistemas bifásicos de micro-escala.

- Desenvolvimento de modelos de CTC utilizando modelos transientes que incluam os diversos tipos de instabilidades presentes nos escoamentos bifásicos.

- Aprimoramento das correlações para CTC, FCC e mapas de padrão de escoamento utilizando o banco de dados já disponível.

- Experimentos detalhados envolvendo o estudo da ocorrência do escoamento estratificado em condições sem e com escoamento.

- Experimentos investigando o título de secagem da parede e sua dependência com do fluxo de calor, com comprimento aquecido e com a temperatura de saturação.

- Estudos da frequência de formação de bolhas e de coalescência de bolhas, avaliando o efeito da velocidade mássica e do fluxo de calor. A energia liberada durante a coalescência de bolhas pode estar relacionada com algumas instabilidades observadas em escoamentos bifásicos.

- Estudos avaliando o efeito da rugosidade do tubo no CTC e FCC.

- Realizar novos experimentos para avaliar o efeito do comprimento no CTC, relacionando com a modificação da espessura do filme líquido.

- Experimentos de microPIV em micro-escala no padrão anular para avaliar turbulência no filme líquido.

- Realização de experimentos com canais abaixo de $200 \mu \mathrm{m}$ e avaliação da simetria do filme líquido no escoamento anular.

- Demonstração experimental de que para diâmetros muito reduzidos, o escoamento anular ocorre praticamente sobre toda a faixa de títulos de vapor. 
- Investigação de a partir de qual diâmetro reduzido as ondulações na interface são desprezíveis durante o escoamento anular, pois é esperado que a tensão superficial amorteça essas ondulações tornando o filme liso.

- Análises isoladas da transferência de calor na condução através de filme líquido e na condução transiente na frente do pistão.

- Montagem de experimentos com visualização de todo o processo de ebulição convectiva de evaporação utilizando seções transparentes, de forma a investigar com câmera de alta velocidade todo o desenvolvimento do processo de ebulição convectiva em microcanais, relacionado a instabilidades devido à coalescência de bolhas. 


\section{REFERÊNCIAS BIBLIOGRÁFICAS}

ABERNETHY, R.B.; THOMPSON, J.W. (1973). Handbook uncertainty in gas turbine measurements. Tennessee (U.S.A.): Arnold Engineering Development Center, Arnold Air Force Station.

AGOSTINI, B.; BONTEMPS, A. (2005). Vertical flow boiling of refrigerant R134a in small channels. Int. J. Heat Fluid Flow, v. 26, p. 296-306.

AGOSTINI, B.; THOME, J.R.; FABBRI, M.; CALMI, D.; KLOTER, U.; MICHEL, B. (2007). High heat flux flow boiling in silicon multi-microchannels: Part III- saturated critical heat flux of R236fa and two-phase pressure drops. Int. J. Heat Mass Transfer, v. 51, n. 21-22, p. 5426-5442.

ARCANJO, A.A.; TIBIRIÇÁ, C.B.; RIBATSKI, G. (2010). Evaluation of flow patterns and elongated bubble characteristics during the flow boiling of halocarbon refrigerants in a micro-scale channel. Exp. Thermal and Fluid Science, v. 34, p. 766-775.

BAKER, O. (1954). Simultaneous flow of oil and gas. Oil Gas Journal, v. 53, p. 185190.

BANG, K.H.; CHOO, W.H. (2004). Flow boiling in minichannels of copper, brass, and aluminum round tubes. In: International Conference on Microchannels and Minichannels, $2^{\text {nd }}, 2004$, Rochester (U.S.A.). Proceedings... Rochester: 2004, p. 559-564.

BAO, Z.Y.; FLETCHER, D.F.; HAYNES, B.S. (2000). Flow boiling heat transfer of Freon 11 and HCFC123 in narrow passages. Int. J. Heat Mass Transfer, v. 43, p. 3347-3358.

BARBIERI, P.E.L.; JABARDO, J.M.S.; BANDARRA FILHO, P. (2008). Flow patterns in convective boiling of refrigerant $r-134 a$ in smooth tubes of several diameters. In: European Thermal-Sciences Conference, $5^{\text {th }}, 2008$, The Netherlands. Proceedings... The Nederlands: 2008.

BARBOSA, J. R.; HEWITT, G. F.; KÖNIG, G.; RICHARDSON, S. M. (2002). Liquid entrainment, droplet concentration and pressure gradient at the onset of annular flow in a vertical pipe. Int. J. of Multiphase Flow, v. 28, n. 6, p. 943-961.

BARNEA, D.; LUNINSKI, Y.; TAYTEL, Y. (1983). Flow pattern in horizontal and vertical two phase flow in small diameter pipes. Can. J. Chem. Eng., v. 61, p. 617-620.

BEJAN, A. (1995). Convection heat transfer. $2^{\text {nd }}$ ed. New York: John Wiley \& Sons. $623 p$.

BERGLES, A.E.; ROHSENOW, W.M. (1964). The determination forced-convection surface boiling heat transfer. J. Heat Transfer, v. 86, p. 365-272. 
BERTSCH, S.S.; GROLL, E.A.; GARIMELLA, S.V. (2009). A composite heat transfer correlation for saturated flow boiling in small channels. Int. J. of Heat and Mass Transfer, v. 52, n. 7-8, p. 2110-2118.

BOWERS, M.; MUDAWAR, I. (1994). High flux boiling in low flow rate, low pressure drop mini-channel and micro-channel heat sinks. Int. J. Heat Mass Transfer, v. 37, p. 321-332.

BRAUNER, N.; MOALEM-MARON, D. (1992). Identification of the range of small diameter conduits regarding two-phase flow pattern transitions. Int. Commun. Heat Mass Transfer, v. 19, p. 29-39.

CABRAL, F. P.; RIBATSKI, G. (2010). Theoretical modeling heat transfer coefficient of nanofluids flow boiling inside a horizontal channel. In: Brazilian Congress of Thermal Sciences and Engineering, $13^{\text {th }}, 2010$, Uberlândia, Brasil.

CAREY, V. P. (1992). Liquid-vapor phase-change phenomena. New York: Hemisphere Publishing. 645 p.

CELATA, G.P.; KATTO, Y.; MARIANI, A. (1999). Prediction of the critical heat flux in water subcooled flow boiling using a new mechanistic approach. Int. J. of Heat and Mass Transfer, v. 42, p. 1457-1466.

CELATA, G.P.; CUMO, M.; MARCONI, V.; MCPHAIL, S.J.; ZUMMO, G. (2006). Microtube liquid single-phase heat transfer in laminar flow. Int. J. of Heat and Mass Transfer, v. 49, p. 3538-3546.

CELATA, G.P.; CUMO, M.; GERVASI, M.; ZUMMO, G. (2007). Flow pattern analysis of flow boiling in microgravity. Multiphase Science and Technology, v. 19, p.183210.

CELATA, G. P. (2008). Single- and two-phase flow heat transfer in micropipes. In: European Thermal-Science Conference, $5^{\text {th }}, 2008$, The Netherlands. Proceedings... The Nederlands: 2008.

CIONCOLINI, A.; THOME, J.R. (2011). Algebraic turbulence modeling in adiabatic and evaporating annular two-phase flow. Journal of Heat and Fluid Flow. (no prelo).

CHEN, J.C. (1966). Correlation for boiling heat transfer to saturated fluids in convective flow. I\&EC Process Des. Dev., v. 5 (3), p. 322-329.

CHENG, L.; RIBATSKI, G.; THOME, J.R. (2007). Two-phase flow patterns and flow pattern maps: fundamentals and applications. Applied Mechanics Reviews, v. 61, p. 050802-1.

CHENG, L.; RIBATSKI, G.; QUIBEN, J.; THOME, J.R. (2008). New prediction methods for $\mathrm{CO} 2$ evaporation inside tubes: Part I - A two-phase flow pattern map and a flow pattern based phenomenological model for two-phase flow frictional pressure drops. Int. J. of Heat and Mass Transfer, v. 51, p. 111-124. 
CHURCHILL, S.W.; CHU, H.H.S. (1975). Correlating equations for laminar and turbulent free convection from a horizontal cylinder. Int. J. of Heat and Mass Transfer, v. 18, n. 9 , p. $1049-1053$.

COLLIER; J.; THOME, J.R. (1994). Convective boiling and condensation. $3^{\text {rd }}$ ed. Oxford: Clarendo Press, 595p.

CONSOLINI, L. (2008). Convective boiling heat transfer in a single micro-channel. Tese de doutorado. EPFL, Suíça.

CONSOLINI, L.; RIBATSKI, G.; ZHANG, W.; XU, J.; THOME, J.R. (2007). Heat transfer in confined force-flow boiling. Heat Transfer Engineering, v. 28, n. 9.

COOPER, M.G. (1984). Heat flow rates in saturated nucleate pool boiling - A wide range examination using reduced properties. Adv. Heat Transfer, v.16, p. 157-238.

DAVIS, E.J.; ANDERSON, G.H. (1966). The incipience of nucleated boiling in forced convection flow. AIChE Journal, v. 12, n. 4, p. 774-780.

DEMIRAY, F.; KIM, J. (2004). Microscale heat transfer measurements during pool boiling of FC-72: effect of subcooling. Int. J. of Heat and Mass Transfer, v. 47, p. 3257-3268.

DIAZ, M.; SCHMIDT, J. (2007). Experimental investigation of transient boiling heat transfer in microchannels. Int. J Heat Fluid Flow, v. 28, p. 95-102.

DITTUS, F.W.; BOELTER, L.M.K. (1930). Heat transfer in automobile radiators of the tubular type. Publications in engineering, University of California, v. 2, p. 443461.

DUPONT, V.; THOME, J.R.; JACOBI, A.M. (2004). Heat transfer model for evaporation in microchannels. Part II: comparison with the database. International Journal of Heat and Mass Transfer, v. 47, p. 3387-3401.

EES. (2009). Engineering equation solver. F-chart software. V.8.3.

FELCAR, H.O.M.; RIBATSKI, G.; JABARDO, J.M.S. (2007). A gas-liquid flow pattern predictive method for macro and mini-scale round channels. In: UK Heat Transfer Conference, $10^{\text {th }}$, Edinburgh, Scotland, UK. Proceedings... Edinburgh: 2007.

FOSTER, H. K.; ZUBER, N. (1955). Bubble dynamics and boiling heat transfer. AlChe Journal, v. 1, p. 531-535.

GNIELINSKI, V. (1976). New equations for heat and mass transfer in turbulent pipe and channel from. Int. Chem. Eng., v. 16, p. 359-368.

HALL, D.; MUDAWAR, I. (2000). Critical heat flux (CHF) for water flow in tubes - II Subcooled CHF correlations. Int. J. Heat Mass Transfer, v. 43, p. 2605-2640.

HETSRONI, G.; MOSYAK, A.; POGREBNYAK, E.; SEGAL, Z. (2005). Explosive boiling of water in parallel micro-channels. Int. J. Multiphase Flow, v. 31, p. 371-392. 
HULBURT, E.; NEWELL, T. (2000). Prediction of the circumferential film thickness distribution in horizontal annular gas-liquid flow. J. of Fluids Engineering, v. 122, p. 396-402.

KAKAC, S.; BON, B. (2008). A Review of two-phase flow dynamic instabilities in tube boiling systems. Int J Heat Mass Transfer, v. 51, p. 399-433.

KANDLIKAR, S.G. (1991). A model for predicting the two-phase flow boiling heat transfer coefficient in augmented tube and compact heat exchanger geometries. $\mathbf{J}$. Heat Transfer, v. 113, p. 966-972.

KANDLIKAR, S. G. (2002). Fundamental issues related to flow boiling in minichannels and microchannels. Experimental Thermal and Fluid Science, v.26, pp. 389407.

KANDLIKAR, S.G.; GRANDE, W.J. (2003). Evolution of microchannel flow passages - Thermohydraulic performance and fabrication technology. Heat Transfer Engineering, v. 24, p. 3-17.

KANDLIKAR, S.G.; BALASUBRAMANIAN, P. (2004). An extension of the flow boiling correlation to transition, laminar, and deep laminar flows in minichannels and microchannels. Heat Transfer Engineering, v. 25, p. 86-93.

KANDLIKAR, S.G. (2005) High flux heat removal with microchannels - A roadmap of challenges and opportunities. Heat Transfer Engineering, v. 26, p.5-14.

KANDLIKAR, S.G.; GARIMELA, S.; LI, D.; COLIN, S.; KING, M.R.I. (2005). Heat Transfer and fluid flow in minichannels and microchannels. London (UK): Elsevier. $450 \mathrm{p}$.

KANDLIKAR, S.G. (2010) Scale effects on flow boiling in microchannels: a fundamental perspective. International Journal of Thermal Sciences, v. 49, n. 7, p. 1073-1085.

KARAYIANNIS, T.G.; MAHMOUD , M.M.; KENNING , D.B.R. (2011) A study of discrepancies in flow boiling results in small to micro diameter metallic tubes. Experimental Thermal and Fluid Science. (em publicação)

KATTO, Y.; OHNO, H. (1984). An improved version of the generalized correlation of critical heat flux for the forced convective boiling in uniformly heated vertical tubes.

Int. J. Heat Mass Transfer, v. 27, p. 648-1648.

KATTO, Y.; YOKOYA, S. (1982). CHF of forced convection boiling in uniformly heated vertical tubes: Experimental study of HP-regime by the use of refrigerant 12 . Int. Journal of Multiplhase Flow, v. 8, p. 165-181.

KATTO, Y.; YOKOYA, S. (1984). Critical heat flux of liquid helium (I) in forced convective boiling. Int. Journal of Multiphase Flow, v. 10, p. 401-413. 
KEW, P.A.; CORNWELL, K. (1997). Correlations for the prediction of boiling heat transfer in small-diameter channels, Applied Thermal Engineering, v. 17, p. 705715.

KIM, N.H.; SIM, Y.S.; MIN, C.K. (2004). Convective boiling of R22 in a flat extruded aluminum multi-port tube, in: Proceedings of 2nd International Conference on Microchannels and Minichannels, Rochester, USA, pp. 507-514.

KOSAR, A.; PELES, Y. (2007). Critical Heat Flux of R-123 in Silicon-based microchannels. Transactions of ASME, v. 29, p. 844-851.

LAZAREK, G.M.; BLACK, S.H. (1982), Evaporative heat transfer, pressure drop and critical heat flux in a small vertical tube with R-113. Int. J. Heat Mass Transfer, v. 25 , p. $945-960$.

LEE, C.H.; MUDAWAR, I. (1988). A mechanistic critical heat flux model for subcooled flow boiling based on local bulk flow conditions. Int. J. Mult. Flow, 14, 711728.

LEE, J.; MUDAWAR, I. (2009). Critical heat flux for subcooled flow boiling in microchannel heat sinks. Int. J. of Heat and Mass Transfer, v. 52, n. 13-14, p. 3341-3352

LIN, S.; KEW, P.A.; CORNWELL, K. (2001). Two-phase heat transfer to a refrigerant in a $1 \mathrm{~mm}$ diameter tube. Int. J. Refrigeration 24 (2001) 51-56.

LIU, Z.; WINTERTON, R.H.S.A. (1991). General correlation for saturated and subcooled flow boiling in tubes and annuli, based on a nucleate pool boiling equation. Int. J. of Heat and Mass Transfer, v. 34, p. 2759-2766.

LOWDERMILK, W.; LANZO, C.; SIEGEL, L. (1958). Investigation of boiling burnout and flow stability for water flowing in tubes. NACA. TN 4382.

MEHENDAL, S.S.; JACOBI, A.M.; SHAH, R.K. (2000). Fluid flow and heat transfer at micro- and meso-scales with applications to heat exchangers design. Appl. Mech. Rev., v. 53, p. 175-193.

MOFFAT, R.J. (1988). Describing the uncertainties in experimental results. Exp. Thermal Fluid Science, v. 1, p. 3-17.

MOGHADDAM, S.; KIGER, K. (2009). Physical mechanisms of heat transfer during single bubble nucleate boiling of FC-72 under saturation conditions - I. Experimental investigation. Int. J. of Heat and Mass Transfer, Vol. 52, pp. 1284-1294.

MUDAWAR, I.; BOWERS, M. (1999), Ultra-high critical heat flux (CHF) for subcooled water flow boiling - I CHF data and parametric effects for small diameter tubes, Int. J. Heat Mass Transfer, v. 42, p.1405-1428.

MYERS, J.G.; YERRAMILLI, V.K.; HUSSEY, S.W.; YEE, G.F.; KIM, J. (2005). Time and space resolved wall temperature and heat flux measurements during nucleate boiling with constant heat flux boundary conditions. Int. J. of Heat and Mass Transfer, v. 48, p. 2429-2442. 
ONG, C.L. (2010). Macro-to-microchannel transition in two-phase flow and evaporation. Tese de doutorado. EPFL, Suíça.

ONG, C.L.; THOME, J.R. (2011a) Macro-to-microchannel transition in two-phase flow: Part 1 - Two-phase flow patterns and film thickness measurements. Exp. Thermal and Fluid Science, v. 35, n. 1, p. 37-47.

ONG, C.L.; THOME, J.R. (2011b) Macro-to-microchannel transition in two-phase flow: Part 2 - Flow boiling heat transfer and critical heat flux. Exp. Thermal and Fluid Science, v. 35, n. 6, p. 873-886.

OWHAIB, W.; PALM, B. (2003). Flow boiling heat transfer in a vertical circular microchannel tube. In: Proceedings of Eurotherm Seminar No. 72, Valencia, Spain.

PAMITRAN, A.S.; CHOI, K.I. (2003). Effect on boiling heat transfer of horizontal smooth microchannel for R410A and R407C. In: Proceedings of 21st IIR International Congress of Refrigeration, Washington DC, USA.

PETUKHOV, B.S. (1970). In T.F. Irvine and J.P. Hartnett, Eds. Advances in Heat Transfer, v. 6, Academic Press, New York.

PIORO, I.L.; GROENEVELD, D.C.; LEUNG, L.K.H.; DOERFFER, S.S.; CHENG, S.C.; ANTOSHKO, Y.U.V.; GUO, Y.; VASIC, A. (2002). Comparison of CHF measurements in horizontal and vertical tubes cooled with R-134a. Int. J. Heat Mass Transfer, v. 45, p. 4435-4450.

QI, S.; ZHANG, P.; WANG, R.Z.; XU, L. (2007). Flow boiling of liquid nitrogen in micro-tubes: Part II - Heat transfer characteristics and critical heat flux. Int. J. of Heat and Mass Transfer, v. 50, p. 5017-5030.

QU, W.; MUDAWAR, I. (2003). Flow boiling heat transfer in two-phase microchannel heat sinks-II. Annular two phase flow model. Int. J. of Heat and Mass Transfer, v. 46, p. 2773-2784.

QU, W.; MUDAWAR, I. (2004). Measurements and correlation of critical heat flux in two-phase micro-channel heat sinks. Int. J. Heat Mass Transfer, v. 47, p. 20452059.

REFPROP (2008). NIST reference fluid thermodynamic and transport properties database. V.7.

REVELLIN, R. (2005). Experimental two-phase fluid flow in microchannels. Tese de doutorado. EPFL, Suíça.

REVELLIN, R.; THOME, J.R. (2007a). A new type of diabatic flow pattern map for boiling heat transfer in microchannels. Micromech. Microeng. v. 17, p. 788-796.

REVELLIN, R.; THOME, J.R. (2007b). A theoretical model for the prediction of the critical heat flux, Int. J. Heat Mass Transfer, v.51, p. 1216-1225. 
RIBATSKI, G.; WOJTAN, L.; THOME, J.R. (2006). An analysis of experimental data and prediction methods for two-phase frictional pressure drop and flow boiling heat transfer in micro-scale channels. Exp. Thermal Fluid Sc, v. 31, p.1-19.

RIBATSKI, G.; ZHANG, W.; CONSOLINI; L.; XU, J.; THOME, J.R. (2007). On the prediction of heat transfer in micro-scale flow boiling. Heat Transfer Engineering. $v$. 28, p 842-851.

ROUHANI, S.Z.; AXELSSON, E. (1970). Calculation of void volume fraction in the subcooled and quality boiling regions. Int. J. of Heat and Mass Transfer, v. 13, n. 2, p. 383-393.

SAITOH, S.; DAIGUJI, H.; E, HIHARA. (2007). Correlation for boiling heat transfer of $\mathrm{R}-134 \mathrm{a}$ in horizontal tubes including effect of tube diameter. Int. J. Heat and Mass Transfer, v. 50, p 5215-5225.

SARMA, P.K.; SRINIVAS, V.; SHARMA, K.V.; DHARMA RAO, V.; CELATA, G.P. (2006). A correlation to evaluate critical heat flux in small diameter tubes under subcooled conditions of the coolant. Int. J. Heat Mass Transfer, v. 49, p. 42-51.

SCHWEIZER, N.; FREYSTEIN, M.; STEPHAN, P. (2010). High resolution measurement of wall temperature distribution during forced convective boiling in a single minichannel. Proceedings of the ASME 3rd Joint US-European Fluids Engineering Summer Meeting and 8th International Conference on Nanochannels, Microchannels, and Minichannels FEDSM-ICNMM, Montreal, Canada.

SHAH, M. (1987). Improved general correlation for critical heat flux during upflow in uniformly heated vertical tubes. Heat and Fluid Flow, v. 8, p. 326-335.

SOBIERSKA, E.; KULENOVIC, R.; MERTZ, R.; GROLL, M. (2006). Experimental results of flow boiling of water in a vertical microchannel. Exp. Thermal and Fluid Science, v. 31, p. 111-119.

STEPHAN, K.; ABDELSALAM, M. (1980). Heat-transfer correlations for natural convection boiling. Int. J. Heat Mass Transfer, v. 23, p. 73-87.

SUMITH, B.M.; KAMINAGA, F.; MATSUMURA, K. (2003). Saturated flow boiling of water in a vertical small diameter tube. Exp. Thermal Fluid Science, v. 27, p. 789801.

SUN, L.; MISHIMA, K. (2009). An evaluation of prediction methods for saturated flow 666 boiling heat transfer in mini-channels. Int. J. Heat Mass Transfer, v. 52, p. 5323-5329.

TAITEL, Y.; DUKLER, A.E. (1976). A model for predicting regime transitions in horizontal and near horizontal gas-liquid flow. AIChE Journal, v. 22, p. 47-55.

TAPIA, D. F. S. (2011). Estudo teórico-experimental dos padrões de escoamento durante a evaporação convectiva no interior de canais com diâmetro reduzido. Tese (Mestrado) - Escola de Engenharia de São Carlos, Universidade de São Paulo, São Carlos. 
THOME, J.R.; DUPONT, V.; JACOBI, A.M. (2004). Heat transfer model for evaporation in microchannels, Part I: presentation of the model. Int. J. of Heat and Mass Transfer, v. 47, p. 3375-3385.

TIBIRIÇÁ, C.B.; FELCAR, H.O.M.; RIBATSKI, G. (2008). An analysis of experimental data and prediction methods for critical heat fluxes in micro-scale channels. In: 5th European Thermal-Sciences Conference, Eindhoven.

TIBIRIÇÁ, C.B.; RIBATSKI, G. (2008). Análise de dados experimentais e métodos para previsão do coeficiente de transferência de calor em micro-canais. In: Proceedings of EBECEM, 1st Brazilian Meeting on Boiling, Condensation and Multiphase Flow, Florianópolis, Brazil, paper MF-103, 2008.

TIBIRIÇÁ; C.B.; RIBATSKI, G . (2010). Flow boiling heat transfer of R134a and R245fa in a 2.3mm tube. Int. J. of Heat and Mass Transfer, v. 53, p. 2459-2468.

TIBIRIÇÁ, C.B.; DO NASCIMENTO, F.J.; RIBATSKI, G. (2010). Film thickness measurement techniques applied to micro-scale two-phase flow systems. Experimental Thermal and Fluid Science, v. 34, p. 463-473.

TIBIRIÇÁ, C.B.; SZCZUKIEWICZ; S.; RIBATSKI, G.; THOME, J.R . (2010). Critical heat flux of R134a and R245fa in a $2.2 \mathrm{~mm}$ circular tube. In: 13th Brazilian Congress of Thermal Sciences and Engineering, Uberlândia. (Submetido ao HTE).

TIBIRIÇÁ, C.B.; RIBATSKI, G. (2011). Two-phase frictional pressure drop and flow boiling heat transfer for R245fa in a $2.32 \mathrm{~mm}$ tube. Heat Transfer Engineering, v. 32, n. 13-14, p. 1139-1149.

TIBIRIÇÁ, C.B.; DINIZ DA SILVA, J.; RIBATSKI, G. (2011). Experimental investigation of flow boiling pressure drop of R134A in a microscale horizontal smooth tube (2011). J. of Thermal Science and Engineering Applications, v. 3, p. 011006.

TIBIRIÇÁ, C.B.; RIBATSKI, G.; THOME, J.R. (2011). Flow boiling characteristics for R1234ze in 1.0 and $2.2 \mathrm{~mm}$ circular channels. The ASME/JSME $8^{\text {th }}$ Thermal Engineering Conference, Honolulu, Havai, EUA (Submetido ao ASME Journal Of Heat Transfer)

TRAN, T.N.; WAMBSGANSS, M.W.; FRANCE, D.M. (1996). Small circular- and rectangular-channel boiling with two refrigerants. Int. J. Multiphase Flow, v. 22, v. 485498.

TRIPLETT, K.A.; GHIAASIAAN, S.M.; ABDEL-KHALIK, S.I.; SADOWSKI, D.L. (1999). Gas-liquid two-phase flow in microchannels. Part I: Two-phase flow patterns. Int. J. Multiphase Flow, v. 25, p. 377-394.

VANDERVORT, C.; BERGLES, A.; JENSEN, K. (1994). An experimental study of critical heat flux in very high heat flux subcooled boiling. Int. J. Heat Mass Transfer, v. 37, p. 161-173.

WAMBSGANSS, M.W.; FRANCE, D.M.; JENDRZEJCZYK, J.A.; TRAN, T.N. (1993). Boiling heat transfer in a small-diameter tube. J. Heat Transfer, v. 115, p. 963-972. 
WOJTAN, L.; URSENBACHER, T.; THOME, J. (2005). Investigation of flow boiling in horizontal tubes: Part I - A new diabatic two-phase flow pattern map. Int J. Heat

Mass Transfer, v. 48, p. 2955-2969.

WOJTAN, L.; REVELLIN, R.; THOME, J.R. (2006). Investigation of saturated critical heat flux in a single, uniformly heated microchannel. Exp. Thermal Fluid Sc., v. 30, p. 765-774.

WOLDESEMAYAT, M.A.; GHAJAR, A.J. (2007). Comparison of void fraction correlations for different flow patterns in horizontal and upward inclined pipes. Int. J. Multiphase Flow, v. 33, p. 347-370.

YAN, Y.Y.; LIN, T.F. (1998). Evaporation heat transfer and pressure drop of refrigerant R-134a in a small pipe. Int. J. Heat Mass Transfer, v. 41, p. 4183-4194.

YANG, Y.; FUJITA, Y. (2004). Flow boiling heat transfer and flow pattern in rectangular channel of mini-gap. In: Proceedings of 2nd International Conference on Microchannels and Minichannels, Rochester, USA, p. 573-580.

YUN, R.; KIM, Y. (2003). Critical quality prediction for saturated flow boiling of $\mathrm{CO}_{2}$ in horizontal small diameter tubes. Int. J. Heat Mass Transfer, v. 46, p. 2527-2535.

YUN, R.; HEO, J.; KIM, Y.; CHUNG, J.T. (2004). Convective boiling heat transfer characteristics of R410A in microchannels. In: Proceedings of 10th International Refrigeration and Air Conditioning Conference, Purdue, West Lafayette, USA.

ZHANG, W.; HIBIKI, T.; MISHIMA, K.; MI, Y. (2006). Correlation of critical heat flux for flow boiling of water in mini-channels. Int. J. Heat Mass Transfer, v. 49, p. 10581072.

ZHANG, W.; HIBIKI, T.; MISHIMA, K. (2004). Correlation for flow boiling heat transfer in mini-channels. Int. J. Heat Mass Transfer, v. 47, p. 5749-5763.

ZUBER, N.; FINDLAY, J.A. (1965). Average volumetric concentration in two-phase flow systems. ASME J. Heat Transfer, v. 87, p. 435-468. 


\section{APÊNDICE A - CALIBRAÇÃO DAS MEDIDAS DE TEMPERATURA}

A medição de temperatura com acuracidade é essencial para estimar corretamente o coeficiente de transferência de calor, balanço de energia e o título de vapor. Para reduzir os erros de medida de temperatura, o conjunto termopares e seus canais de aquisição foram calibrados num banho termostático HAAKE C35, Figura A.0.1. As temperaturas medidas pelos termopares mergulhados no banho foram comparadas as temperaturas medidas por um termômetro de precisão de mercúrio com resolução de $0,1^{\circ} \mathrm{C}$ e erro $0,05^{\circ} \mathrm{C}$ (v. figura 10$)$.

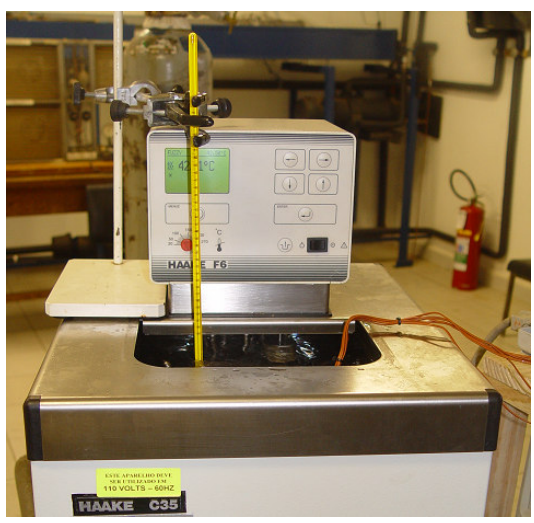

Figura A.0.1 - Banho termostático utilizado para calibrar os canais de termopares

As medidas de temperatura foram calibradas numa faixa de $5^{\circ} \mathrm{C}$ a $57,5^{\circ} \mathrm{C}$ com incrementos de $7,5^{\circ} \mathrm{C}$. Para calibração e dedução de incertezas adotou-se procedimento descrito por Abernethy e Thompson (1973). Este procedimento consta de:

1. levantamento de $\mathrm{N}$ curvas de subida (com incremento de temperatura) e descida (decremento de temperatura) de calibração, onde temperaturas conhecidas são aplicadas e os valores fornecidos pelo sistema de aquisição são armazenados;

2. ajuste de uma curva aos dados de cada calibração;

3. cálculo da incerteza do processo de calibração;

4. ajuste de uma curva utilizando os dados de todas as curvas de calibração para fornecer a temperatura real em função da temperatura medida pelo canal. 


\section{A.1. Levantamento de $\mathbf{N}$ curvas de calibração}

Foram levantadas cinco curvas de calibração para todos os 16 canais de aquisição de temperatura. Adotou-se levantar cinco curvas de calibração para reduzir a incerteza da medida. A Tabela A.0.1 apresenta a curva da primeira calibração para os canais de número 2 a 20 (canais 1, 3, 4 e 18 não foram utilizados). Todos os termopares foram imersos no banho termostático contendo água, dentro de um tubo de ensaio também preenchido com água, para garantir temperatura homogênea entre os termopares e isolamento elétrico do banho termostático. Entre cada incremento ou decréscimo da temperatura foi aguardado as medidas entrarem em regime permanente antes dos dados serem salvos. A calibração foi conduzida com temperatura da sala aproximadamente estável em torno de $22^{\circ} \mathrm{C}$.

Tabela A.0.1 - Valores indicados pelos canais de temperatura para obtenção da primeira curva de calibração.

\begin{tabular}{|c|c|c|c|c|c|c|c|c|c|c|c|c|c|c|c|c|c|}
\hline $\mathrm{T}_{\text {objetivo }}$ & $T_{\text {real }}$ & 2 & 5 & 6 & 7 & 8 & 9 & 10 & 11 & 12 & 13 & 14 & 15 & 16 & 17 & 19 & 20 \\
\hline 5 & 4.93 & 5.98 & 6.77 & 6.66 & 6.38 & 6.61 & 6.47 & 6.60 & 6.85 & 6.62 & 5.90 & 6.11 & 6.16 & 6.30 & 6.08 & 6.46 & 6.62 \\
\hline 12.5 & 12.5 & 13.83 & 14.24 & 14.13 & 13.85 & 14.10 & 13.95 & 14.08 & 14.32 & 14.10 & 13.39 & 13.60 & 13.65 & 13.77 & 13.55 & 13.93 & 14.09 \\
\hline 20 & 19.92 & 21.67 & 21.76 & 21.63 & 21.36 & 21.61 & 21.47 & 21.60 & 21.81 & 21.61 & 20.91 & 21.11 & 21.14 & 21.29 & 21.07 & 21.43 & 21.59 \\
\hline 27.5 & 27.4 & 29.53 & 29.26 & 29.13 & 28.86 & 29.11 & 28.98 & 29.11 & 29.31 & 29.14 & 28.42 & 28.61 & 28.65 & 28.81 & 28.57 & 28.92 & 29.06 \\
\hline 35 & 34.94 & 37.32 & 36.73 & 36.54 & 36.32 & 36.59 & 36.46 & 36.58 & 36.77 & 36.59 & 35.90 & 36.10 & 36.13 & 36.25 & 36.06 & 36.38 & 36.53 \\
\hline 42.5 & 42.4 & 45.11 & 44.17 & 43.91 & 43.78 & 44.02 & 43.91 & 43.99 & 44.23 & 44.05 & 43.39 & 43.56 & 43.55 & 43.60 & 43.35 & 43.78 & 43.99 \\
\hline 50 & 49.9 & 52.93 & 51.65 & 51.22 & 51.23 & 51.49 & 51.40 & 51.51 & 51.73 & 51.54 & 50.88 & 51.07 & 51.02 & 51.09 & 50.92 & 51.27 & 51.48 \\
\hline 57.5 & 57.35 & 60.70 & 59.02 & 58.58 & 58.52 & 58.85 & 58.77 & 58.93 & 59.16 & 58.93 & 58.16 & 58.48 & 58.41 & 58.57 & 58.34 & 58.69 & 58.90 \\
\hline 50 & 49.9 & 52.93 & 51.62 & 51.55 & 51.30 & 51.60 & 51.46 & 51.55 & 51.76 & 51.57 & 50.93 & 51.04 & 51.12 & 51.26 & 50.93 & 51.36 & 51.38 \\
\hline 42.5 & 42.45 & 45.11 & 44.19 & 43.88 & 43.79 & 44.06 & 43.94 & 44.05 & 44.27 & 44.06 & 43.42 & 43.60 & 43.60 & 43.66 & 43.46 & 43.83 & 44.04 \\
\hline 35 & 34.95 & 37.33 & 36.80 & 36.68 & 36.37 & 36.65 & 36.50 & 36.64 & 36.82 & 36.69 & 35.99 & 36.12 & 36.18 & 36.37 & 36.11 & 36.48 & 36.55 \\
\hline 27.5 & 27.4 & 29.53 & 29.31 & 29.20 & 28.91 & 29.12 & 28.98 & 29.15 & 29.33 & 29.19 & 28.46 & 28.61 & 28.66 & 28.86 & 28.63 & 28.97 & 29.05 \\
\hline 20 & 19.9 & 21.72 & 21.94 & 21.84 & 21.53 & 21.67 & 21.51 & 21.74 & 21.89 & 21.82 & 21.07 & 21.15 & 21.22 & 21.50 & 21.30 & 21.61 & 21.63 \\
\hline 12.5 & 12.5 & 13.84 & 14.26 & 14.14 & 13.86 & 14.11 & 13.97 & 14.09 & 14.33 & 14.11 & 13.40 & 13.61 & 13.66 & 13.78 & 13.58 & 13.93 & 14.09 \\
\hline 5 & 4.96 & 6.01 & 6.78 & 6.66 & 6.38 & 6.61 & 6.46 & 6.59 & 6.84 & 6.62 & 5.89 & 6.10 & 6.15 & 6.28 & 6.08 & 6.44 & 6.61 \\
\hline
\end{tabular}

\section{A.2. Ajuste de uma curva aos dados de cada calibração}

Após a obtenção das curvas de calibração, funções foram ajustadas aos dados de calibração de cada canal. Adotaram-se funções lineares e estas foram ajustadas pelo método dos mínimos quadrados independentemente para cada canal. A função linear utilizada tem o formato:

$$
T_{m}=T_{\text {real }} \cdot m+b
$$

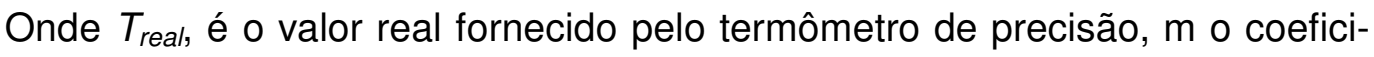
ente angular de ajuste da curva, b o coeficiente linear e $T_{m}$ é a temperatura medida pelo canal. $\mathrm{m}$ e b são calculados pelo método dos mínios quadrados. A Tabela A.0.2 apresenta os coeficientes, $m$ e b, das curvas ajustadas para cada canal e o valor de $T_{m}$ para as temperaturas $T_{\text {objetivos, que são as temperaturas desejadas na }}$ calibração. 
Tabela A.0.2 - Valores dos coeficientes da equação de ajuste, $m$ e b, para cada canal e os valores fornecidos por essa equação para as temperatura $T_{\text {objetivo. }}$.

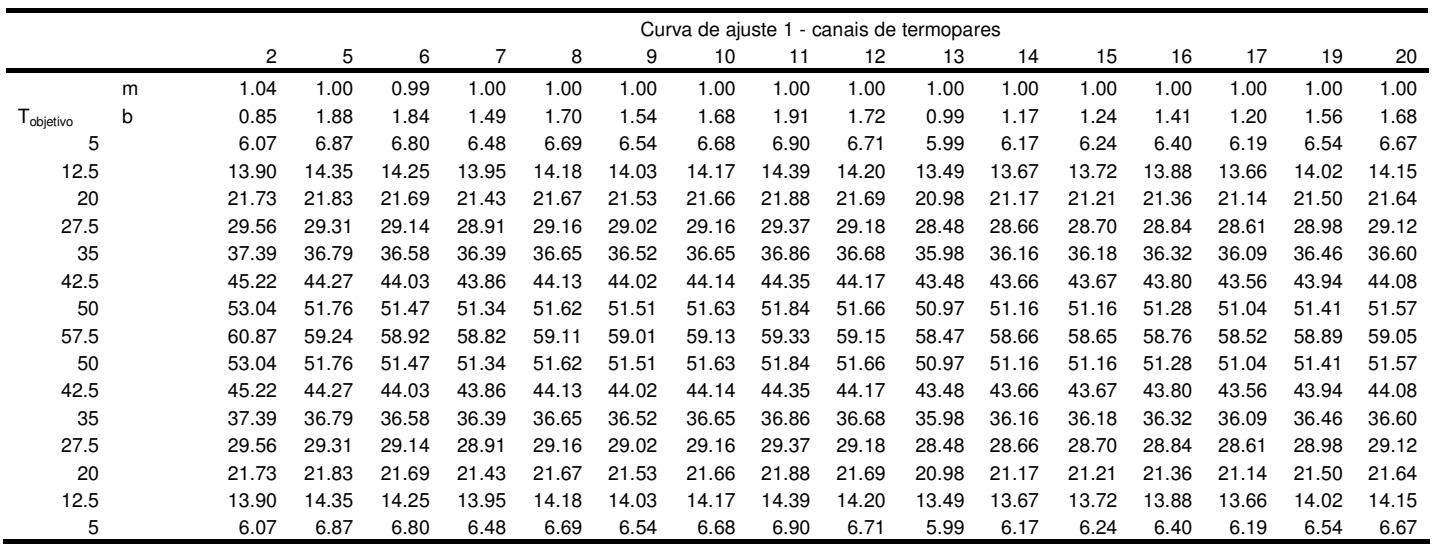

\section{A.3. Cálculo da incerteza do processo de calibração}

A incerteza da calibração, $U$, é calculada usando o método padrão mais amplamente adotado e recomendado pela NBS (National Bureau of Standards - atual NIST). Ele consta da soma do erro sistemático mais um múltiplo do erro de precisão.

$$
U= \pm\left(B_{1}+t_{95} \cdot S_{1}\right)
$$

sendo: $B_{1}=$ erro sistemático do instrumento de calibração

$S_{1}=$ índice de precisão da calibração

$t_{95}=95$ percentil da distribuição t-Student com $d f$ graus de liberdade

$$
\begin{array}{lr}
S_{1}= \pm \sqrt{\sum_{i} s_{i}^{2}} & s_{i}= \pm \sqrt{\sum_{j=1}^{N} \frac{\left(Y_{j}-\bar{Y}\right)^{2}}{N-1}} \\
d f=\frac{\left(\sum_{i} s_{i}^{2}\right)^{2}}{\sum_{i} \frac{s_{i}^{4}}{d f_{i}}} & d f_{i}=N-1
\end{array}
$$

sendo: $s_{i}=$ índice de precisão para cada temperatura $i=T_{\text {objetivo }}$ aplicada.

$N=$ número de calibrações realizadas

$\bar{Y}=$ valor médios de todos os $Y_{j}$ para um temperatura $T_{\text {objetivo }}$

$Y_{j}=$ valores calculados dos ajustes de curvas, eq. A1 para cada calibração $j$, $1<j<N$ e para uma $T_{\text {objetivo, }}$.

A Tabela A.0.3 mostra os resultados dos cálculos de $s_{i}$ dos termopares 2 a 20, para cada $\mathrm{T}_{\text {objetivo. }}$ 
Tabela A.0.3 - Índice de precisão, $s_{i}$, de cada canal para cada $T_{\text {objetivo. }}$.

\begin{tabular}{|c|c|c|c|c|c|c|c|c|c|c|c|c|c|c|c|c|}
\hline \multirow[b]{2}{*}{$T_{\text {objetivo }}$} & \multicolumn{16}{|c|}{$\mathrm{S}_{\mathrm{i}}$ - canais de aquisição } \\
\hline & 2 & 5 & 6 & 7 & 8 & 9 & 10 & 11 & 12 & 13 & 14 & 15 & 16 & 17 & 19 & 20 \\
\hline 5 & 0.007 & 0.011 & 0.020 & 0.010 & 0.010 & 0.009 & 0.010 & 0.007 & 0.009 & 0.012 & 0.009 & 0.009 & 0.012 & 0.010 & 0.011 & 0.008 \\
\hline 12.5 & 0.008 & 0.010 & 0.013 & 0.008 & 0.008 & 0.008 & 0.009 & 0.007 & 0.009 & 0.009 & 0.008 & 0.007 & 0.010 & 0.009 & 0.010 & 0.007 \\
\hline 20 & 0.008 & 0.010 & 0.009 & 0.008 & 0.008 & 0.008 & 0.009 & 0.008 & 0.010 & 0.008 & 0.007 & 0.007 & 0.009 & 0.008 & 0.009 & 0.008 \\
\hline 27.5 & 0.010 & 0.011 & 0.011 & 0.012 & 0.010 & 0.009 & 0.010 & 0.009 & 0.012 & 0.008 & 0.007 & 0.009 & 0.009 & 0.009 & 0.010 & 0.009 \\
\hline 35 & 0.011 & 0.012 & 0.017 & 0.016 & 0.013 & 0.011 & 0.012 & 0.010 & 0.014 & 0.010 & 0.008 & 0.011 & 0.010 & 0.010 & 0.011 & 0.011 \\
\hline 42.5 & 0.012 & 0.015 & 0.025 & 0.021 & 0.017 & 0.013 & 0.014 & 0.012 & 0.016 & 0.013 & 0.009 & 0.013 & 0.013 & 0.012 & 0.013 & 0.013 \\
\hline 50 & 0.013 & 0.017 & 0.033 & 0.026 & 0.021 & 0.015 & 0.016 & 0.013 & 0.019 & 0.017 & 0.010 & 0.016 & 0.015 & 0.015 & 0.015 & 0.015 \\
\hline 57.5 & 0.015 & 0.020 & 0.040 & 0.031 & 0.024 & 0.017 & 0.019 & 0.015 & 0.021 & 0.020 & 0.012 & 0.019 & 0.018 & 0.017 & 0.018 & 0.018 \\
\hline
\end{tabular}

A partir dos cálculos de $s_{i}$, o grau de liberdade, $d f$, e o índice de precisão, $S_{i}$, foram calculados, adotando $N=5$. Dispondo do grau de liberdade, $d f$, $t_{95}$ foi calculado utilizando a função INVT() do Microsoft Excel. A Tabela A.0.4 apresenta o resultado desses cálculos e a incerteza da calibração $U$, adotando o erro sistemático, $B_{1}=0,05^{\circ} \mathrm{C}$, igual ao erro do termômetro de calibração.

Tabela A.0.4 - Índice de precisão de calibração, $\mathrm{S}_{i}$, graus de liberdade, df, erro sistemático, B, percentil t-Student, $t_{95}$ e incerteza experimental de cada canal, U.

\begin{tabular}{|c|c|c|c|c|c|c|c|c|c|c|c|c|c|c|c|c|}
\hline & \multicolumn{16}{|c|}{ Canais de termopares } \\
\hline & 2 & 5 & 6 & 7 & 8 & 9 & 10 & 11 & 12 & 13 & 14 & 15 & 16 & 17 & 19 & 20 \\
\hline $\mathrm{Si}$ & 0,031 & 0,039 & 0,066 & 0,052 & 0,043 & 0,033 & 0,036 & 0,030 & 0,041 & 0,036 & 0,025 & 0,035 & 0,035 & 0,033 & 0,035 & 0,033 \\
\hline df & 25,76 & 24,40 & 17,15 & 17,56 & 19,59 & 24,07 & 24,86 & 24,66 & 23,04 & 22,11 & 28,27 & 20,96 & 24,81 & 24,20 & 25,81 & 22,22 \\
\hline B & 0,05 & 0,05 & 0,05 & 0,05 & 0,05 & 0,05 & 0,05 & 0,05 & 0,05 & 0,05 & 0,05 & 0,05 & 0,05 & 0,05 & 0,05 & 0,05 \\
\hline t95 & 2,06 & 2,06 & 2,11 & 2,11 & 2,09 & 2,06 & 2,06 & 2,06 & 2,07 & 2,07 & 2,05 & 2,09 & 2,06 & 2,06 & 2,06 & 2,07 \\
\hline $\mathbf{U}$ & 0,11 & 0,13 & 0,19 & 0,16 & 0,14 & 0,12 & 0,12 & 0,11 & 0,13 & 0,13 & 0,10 & 0,12 & 0,12 & 0,12 & 0,12 & 0,12 \\
\hline
\end{tabular}

Como se pode ver na tabela, exceto pelos canais 6 e 7, todos os outros obtiveram erros inferiores a $0,15^{\circ} \mathrm{C}$.

\section{A.4. Ajuste da função final de calibração}

Por fim, para obter a curva de ajuste para cada canal fez-se a regressão linear com os dados de todas as 5 calibrações, obtendo-se uma nova função que relaciona a temperatura real, $T_{\text {real, }}$ com a temperatura medida pelo canal, $T_{m}$.

$$
T_{m}=T_{\text {real }} \cdot m+b
$$

Isolando-se $T_{\text {real, obtém-se: }}$

$$
T_{\text {real }}=\frac{1}{m} \cdot T_{m}-\frac{b}{m}
$$

Assim, para corrigir o canal multiplicou-se o valor medido pelo canal de aquisição, $T_{m}$, pelo coeficiente $1 / \mathrm{m}$, subtraindo b/m. A Tabela A.0.5 mostra os valores de $m$ e $b$ para cada canal. 
Tabela A.0.5 - Valores de correção dos canais de temperatura.

\begin{tabular}{|c|c|c|c|c|c|c|c|c|c|c|c|c|c|c|c|c|}
\hline & \multicolumn{16}{|c|}{ Canais de termopares } \\
\hline & 2 & 5 & 6 & 7 & 8 & 9 & 10 & 11 & 12 & 13 & 14 & 15 & 16 & 17 & 19 & 20 \\
\hline $\mathrm{m}$ & 1,044 & 0,999 & 0,996 & 0,998 & 1,000 & 1,001 & 1,000 & 0,999 & 0,999 & 1,001 & 1,001 & 1,000 & 0,999 & 0,998 & 0,998 & 0,999 \\
\hline b & 0,846 & 1,838 & 1,757 & 1,457 & 1,665 & 1,514 & 1,654 & 1,893 & 1,692 & 0,947 & 1,141 & 1,212 & 1,363 & 1,167 & 1,517 & 1,656 \\
\hline $1 / \mathrm{m}$ & 0,958 & 1,001 & 1,004 & 1,002 & 1,000 & 0,999 & 1,000 & 1,001 & 1,001 & 0,999 & 0,999 & 1,000 & 1,001 & 1,002 & 1,002 & 1,001 \\
\hline$(-b / m)$ & $-0,810$ & $-1,841$ & 1,764 & 1,459 & 1,665 & 1,513 & 1,653 & 1,894 & 1,693 & 0,946 & 1,140 & 1,212 & 1,364 & 1,170 & 1,519 & 1,658 \\
\hline
\end{tabular}

É importante considerar que a calibração foi verificada ao longo de semanas para aferir a capacidade do sistema de aquisição manter a calibração. Antes da calibração final, percebeu-se que a calibração não era mantida pelo sistema da National Instruments, chegando a variações de $0,5^{\circ} \mathrm{C}$. A investigação deste problema indicou que o bloco terminal utilizado (SCXI-1303) não conseguia manter as juntas frias dos termopares a uma temperatura uniforme e igual a do sensor de compensação de junta fria, e assim, a variação da temperatura ambiente estaria afetando a calibração. Para contornar este problema, a calibração dos termopares foi refeita, mas agora com a temperatura da sala mantida próxima a $22^{\circ} \mathrm{C}$ através do sistema de condicionamento de ar. Desta forma, adotou-se como procedimento de operação da bancada manter a sala a uma temperatura próxima a $22^{\circ} \mathrm{C}$, para manter a incerteza de calibração constante. Outro detalhe a ser considerado, é manter o sistema de aquisição ligado, pois os chassis levam cerca de 40min para entrarem em equilíbrio térmico com o ambiente, efeitos relacionados com a dissipação térmica de seus componentes eletrônicos.

Avaliações contínuas foram feitas na medida de temperatura dos termopares, depois da instalação deles na bancada experimental, através de escoamentos monofásicos com velocidades mássicas elevadas na seção de testes e aplicando-se potência somente no pré-aquecedor de forma a manter uma temperatura uniforme em toda seção de testes. A faixa de temperatura para estes testes foi superior a $22^{\circ} \mathrm{C}$ de forma a simular condições de temperatura similares às dos ensaios bifásicos. Nesses testes, verificou-se uma excelente concordância das temperaturas fornecidas pelos termopares, sempre com diferença dentro de uma margem de $0,15^{\circ} \mathrm{C}$ entre eles. Assim, mesmo com uma incerteza ligeiramente superior a $0,15^{\circ} \mathrm{C}$ para os termopares 6 e 7, adotou-se uma incerteza de $0,15^{\circ} \mathrm{C}$ para todas as medidas de temperatura nesses canais de aquisição com termopares, incerteza restrita à faixa de temperatura de $22^{\circ} \mathrm{C}$ a $55^{\circ} \mathrm{C}$. 


\section{APÊNDICE B - TABELAS DE RESULTADOS EXPERIMENTAIS}

Tabela B.0.1 - Resultados para coeficiente de transferência de calor médio, $\bar{h}$, para canais circulares.

Tabela B.0.2 - Resultados para fluxo crítico de calor para canais circulares.

Tabela B.0.1- Resultados para coeficiente de transferência de calor médio, $\bar{h}$, para canais circulares.

\begin{tabular}{ccccccc}
\hline Fluido & $G$ & $q$ & $x$ & $D$ & $T_{\text {sat }}$ & $\bar{h}$ \\
& $\left(\mathrm{~kg} / \mathrm{m}^{2} \mathrm{~s}\right)$ & $\left(\mathrm{W} / \mathrm{m}^{2}\right)$ & $(-)$ & $(\mathrm{m})$ & $\left({ }^{\circ} \mathrm{C}\right)$ & $\left(\mathrm{W} / \mathrm{m}^{2} \mathrm{~K}\right)$ \\
\hline
\end{tabular}


Tabela B.0.2 - Resultados para fluxo crítico de calor para canais circulares.

\begin{tabular}{ccccccc}
\hline Fluido & $G$ & $L_{\text {aque }}$ & $x_{\text {ent }}$ & $D_{i}$ & $T_{\text {sat }}$ & FCC \\
& $\left(\mathrm{kg} / \mathrm{m}^{2} \mathrm{~s}\right)$ & $(\mathrm{m})$ & $(-)$ & $(\mathrm{m})$ & $\left({ }^{\circ} \mathrm{C}\right)$ & $\left(\mathrm{W} / \mathrm{m}^{2}\right)$ \\
\hline
\end{tabular}




\section{APÊNDICE C - CRONOGRAMA DOS TRABALHOS REALIZADOS}

Este doutorado foi realizado de setembro de 2007 a julho de 2011, de acordo com as etapas apresentadas no quadro abaixo.

Quadro de atividades realizadas neste doutorado.

\begin{tabular}{|c|c|c|c|c|c|c|c|c|c|}
\hline & & $\begin{array}{l}1^{\circ} \mathrm{sem} . \\
\text { Anol }\end{array}$ & $\begin{array}{l}2^{\circ} \text { sem } \\
\text { Ano I }\end{array}$ & $\begin{array}{l}1^{\circ} \text { sem } \\
\text { Ano II }\end{array}$ & $\begin{array}{l}2^{\circ} \text { sem } \\
\text { Ano II }\end{array}$ & $\begin{array}{l}1^{\circ} \mathrm{sem} \\
\text { Ano III }\end{array}$ & $\begin{array}{l}2^{\circ} \text { sem } \\
\text { Ano III }\end{array}$ & $\begin{array}{l}1^{\circ} \text { sem } \\
\text { Ano IV }\end{array}$ & $\begin{array}{l}2^{0} \text { sem } \\
\text { Ano IV }\end{array}$ \\
\hline Disciplinas de pós-graduação & & & & & & & & & \\
\hline Levantamento bibliográfico & & & & & & & & & \\
\hline $\begin{array}{l}\text { Desenvolvimento de programas } \\
\text { e tratamento de dados }\end{array}$ & aquisição & & & & & & & & \\
\hline $\begin{array}{l}\text { Lançamento e ajuste da bancad } \\
\text { iniciais para o escoamento mor } \\
\text { R134a }\end{array}$ & $\begin{array}{l}\text { om ensaios } \\
\text { sico de }\end{array}$ & & & & & & & & \\
\hline Realização do exame de qualifi & & & & & & & & & \\
\hline $\begin{array}{l}\text { Levantamento experimental } \\
\text { para escoamento bifásico em }\end{array}$ & $2,3 \mathrm{~mm}$ & & & & & & & & \\
\hline $\begin{array}{l}\text { seções circulares (R134a, } \\
\text { R245fa) }\end{array}$ & $1,1 \mathrm{~mm}$ & & & & & & & & \\
\hline $\begin{array}{l}\text { Levantamento experimental } \\
\text { para escoamento bifásico em }\end{array}$ & $2,2 \mathrm{~mm}$ & & & & & & & & \\
\hline $\begin{array}{l}\text { seções circulares (R134a, } \\
\text { R245fa, R1234ze) }\end{array}$ & $1,0 \mathrm{~mm}$ & & & & & & & & \\
\hline & $\begin{array}{r}\text { Canal } \\
(\mathrm{H} / \mathrm{W})=4\end{array}$ & & & & & & & & \\
\hline $\begin{array}{l}\text { Levantamento experimental } \\
\text { para escoamento bifásico em }\end{array}$ & $\begin{array}{c}\text { Canal } \\
(\mathrm{H} / \mathrm{W})= \\
1 / 4\end{array}$ & & & & & & & & \\
\hline $\begin{array}{l}\text { seções não-circulares (R134a, } \\
\text { R245fa) }\end{array}$ & $\begin{array}{r}\text { Canal } \\
(H / W)=2\end{array}$ & & & & & & & & \\
\hline & $\begin{array}{c}\mathrm{Ca}- \\
\mathrm{nal}(\mathrm{H} / \mathrm{W}) \\
=1 / 2\end{array}$ & & & & & & & & \\
\hline Análises dos resultados experir & & & & & & & & & \\
\hline Elaboração do modelo teórico $p$ & & & & & & & & & \\
\hline Elaboração do modelo teórico & o qcrit & & & & & & & & \\
\hline $\begin{array}{l}\text { Proposição de critério para a tra } \\
\text { macro e microcanais baseado }\end{array}$ & $\begin{array}{l}\text { ẽa entre } \\
\text { e qcrit }\end{array}$ & & & & & & & & \\
\hline Redação e defesa da tese & & & & & & & & & \\
\hline
\end{tabular}

Período relativo ao doutorado realizado no Brasil (USP-São Carlos)

Período relativo a estágio de doutorado no exterior (EPFL-Lausanne) 


\section{CURRICULUM VITAE}

\section{Informações pessoais}

Nome: Cristiano Bigonha Tibiriçá

Local e ano de nascimento: Juiz de Fora, MG, Brasil, 1981.

\section{Formação}

Doutorando em Engenharia Mecânica. Área: térmica e fluídica. Universidade de São Paulo, São Carlos, SP, Brasil. 2008-2011.

Doutorado sanduíche no Laboratory of Heat and Mass Transfer, LTCM/EPFL, Lausanne, Suíça. 2009-2010.

Mestrado em Engenharia Mecânica. Área: controle, dinâmica de sistemas. Universidade de São Paulo, São Carlos-SP. 2005-2007.

Graduação em Engenharia Mecânica, com ênfase em mecatrônica, aeronáutica e computação. Universidade de São Paulo, São Carlos, SP, Brasil.1999-2004.

Estágio na Smar Equipamentos Industriais. Sertãozinho-SP. 2000-2002

\section{Publicações}

Tibiriçá, C.B.; Ribatski, G.; Thome, J.R. Flow boiling characteristics for R1234ze in 1.0 and $2.2 \mathrm{~mm}$ circular channels. Journal Of Heat Transfer- ASME, 2011 (aceito para publicação).

Tibiriçá, C.B.; Szczukiewicz, S.; Ribatski, G.; Thome, J.R. Critical heat flux of R134a and R245fa in a $2.2 \mathrm{~mm}$ circular tube. Heat Transfer Engineering, 2011 (em revisão).

Tibiriçá, C.B.; Ribatski, G. Two-phase frictional pressure drop and flow boiling heat transfer for R245fa in a 2.3mm tube. Heat Transfer Engineering, v. 32, n. 13-14, p. 1139-1149, 2011.

Tibiriçá, C.B.; Silva, J.D.; Ribatski, G. Experimental investigation of flow boiling pressure drop of R134a in a microscale horizontal smooth tube, Thermal Science and Engineering Applications-ASME, v. 3, p. 011006-011014, 2011.

Tibiriçá; C.B.; Ribatski, G. Flow boiling heat transfer of R134a and R245fa in a 2.3mm tube. International Journal of Heat and Mass Transfer, v. 53, p. 24592468, 2010.

Arcanjo, A.A.; Tibiriçá, C.B.; Ribatski, G. Evaluation of flow patterns and elongated bubble characteristics during the flow boiling of halocarbon refrigerants in a microscale channel. Experimental Thermal and Fluid Science, v. 34, p. 766-775, 2010. 
Tibiriçá, C.B.; Nascimento, F.J.; Ribatski, G. Film thickness measurement techniques applied to micro-scale two-phase flow systems. Experimental Thermal and Fluid Science, v. 34, p. 463-473, 2010.

Tibiriçá, C.B.; Ribatski, G. An experimental study on micro-scale flow boiling heat transfer of R134a. International Journal of Microscale and Nanoscale Thermal and Fluid Transport Phenomena, v. 1, n. 1, p. 37-38, 2010.

Tibiriçá, C.B.; Szczukiewicz, S.; Ribatski, G.; Thome, J.R. Critical heat flux of R134a and R245fa in a $2.2 \mathrm{~mm}$ circular tube. In: 13th Brazilian Congress of Thermal Sciences and Engineering, 2010, Uberlândia.

Tibiriçá, C.B.; Ribatski, G.; Thome, J.R. Flow boiling characteristics for R1234ze in 1.0 and $2.2 \mathrm{~mm}$ circular channels. In: ASME/JSME 8th Thermal Engineering Conference, 2011, Honolulu.

Araújo, D.C.; Nascimento, F.J.; Arcanjo, A.A.; Tibiriçá, C.B.; Ribatski, G. Neural networks approach for prediction of gas-liquid two-phase flow pattern during convective evaporation in microscale channels. In: 7th International Conference on Heat Transfer, Fluid Mechanics and Thermodynamics, Antalya, 2010.

Tibiriçá, C.B.; Ribatski, G. Experimental investigation of flow boiling pressure drop of R134a in a micro-scale horizontal smooth tube. In: 14th International Heat Transfer Conference (IHTC), Washington D.C., 2010.

Tibiriçá, C.B. ; Ribatski, G. An experimental study on micro-scale flow boiling heat transfer. In: International Conference on Boiling Heat Transfer, 2009, Florianópolis. International Conference on Boiling Heat Transfer, 2009.

Tibiriçá, C.B.; Ribatski, G. An experimental study on micro-scale flow boiling heat transfer of R245fa. In: 2nd Micro and Nano Flows conference, Uxbridge. 2nd Micro and Nano Flows Conference, 2009.

Arcanjo, A.A.; Freitas, J.O.; Tibiriçá, C.B.; Ribatski, G. Two-phase flow characteristics during flow boiling of halocarbon refrigerants in micro-scale channels. In: $\mathrm{ECI}$ International Conference on Boiling Heat Transfer, Florianópolis, 2009.

Ribatski, G.; Tibiriçá, C.B. Flow boiling heat transfer and two-phase flow behavior in micro-scale channels. In: Fourth International Topical Team Workshop on TwoPhase Systems for Ground and Space Applications, Novosibirsk, Russia, 2009.

Tibiriçá, C.B.; Felcar, H.O.M.; Ribatski, G. An analysis of experimental data and prediction methods for critical heat fluxes in micro-scale channels. In: 5th European Thermal-Sciences Conference,Eindhoven. 5th European Thermal-Sciences Conference, 2008.

Tibiriçá, C.B.; Ribatski, G. Análise de dados experimentais e métodos para predição do coeficiente de transferência de calor em micro-canais. In: EBECEM, Florianópolis, 2008. 